Data de Depósito:

Assinatura:

\title{
Movimento de malhas e remalhamento de malhas superficiais
}

\author{
Igor Prata Soares
}

Orientador: Prof. Dr. José Alberto Cuminato

Tese apresentada ao Instituto de Ciências Matemáticas e de Computação - ICMC-USP, como parte dos requisitos para obtenção do título de Doutor em Ciências - Ciências de Computação e Matemática Computacional. 

Movimento de malhas e remalhamento de malhas superficiais

Igor Prata Soares 

$\grave{A}$ Cynthia e aos meus pais 


\section{Agradecimentos}

É em momentos como este que eu gostaria de ser poeta. Conseguir traduzir em texto miúdo o tamanho dessa gigantesca bolha inflante de agradecimentos. Mas como não sou, tenho a difícil tarefa de contentar-me em escrever apenas o simples obrigado. Mas saibam vocês, alvos do meu agradecimento, que essa palavrinha com seis letras espremidas entre dois ós diz muito mais que um sonoro e reconhecido obrigado.

O primeiro obrigado vai para a pessoa que mais contribuiu comigo enquanto navegava nessas ondas tão violentas, esse mar em ressaca, essa coisa estranha. Agradeço a você, Deus, porque me fez ver um horizonte muito além daquela linha curva que nossos pobres olhos conseguem enxergar. Porque me fez ter porto, antes mesmo de alcançá-lo.

Digo obrigado também a você Cynthia, minha amada esposa, com quem tenho aprendido muito, mas não coisas pequenas como as apresentadas nesta tese, mas coisas maiores, coisas de vida. Você, em palavras e silêncios, afetos e atenções, me nutri, e só eu sei o quanto. Esta é uma tese sua também.

Aos meus quatro pais, digo mil e vinte e quatro obrigados. Vocês são inspiração para mim, tenho em vocês exemplo.

Aos meus amigos e grandes amigos vão muitos obrigados. Quem sou eu sem os amigos? Nada. Tudo, conversas, escaladas, discussões, churrasco, computadores, pizza, problemas, gargalhadas, incentivo, neve, planos, acampamentos, museus, projeto, emprego, vivência, $\mathrm{C}++$, entrevista, viagem, surpresas, tudo que vivemos juntos merecem aplausos. Um obrigado especial a vocês, Marcello, Renan, Billy, Tiago, Antônio, João Paulo, Cássio, Mário, Fernando, Everton que contribuíram diretamente neste suado doutorado.

Tenho por vocês Fairfax Presbyterian Church e Truro a gratidão de quem precisou desesperadamente de ajuda e recebeu. Jamais poderei recompensá-los.

Agradeço a vocês, professores e funcionários do ICMC, pela competência e suporte. Em especial ao trio Poti, Castelo e Gustavo e ao Dr. Löhner pela atenção.

Agradeço ao CNPq e à Capes pelo suporte financeiro. 


\section{Resumo}

Malhas dinâmicas são comumente utilizadas em problemas de simulação sobre dominios cuja geometria varia com o tempo. Sempre que o domínio onde a malha está definida é alterado, as molas são acionadas movimentando os vértices para que estes se conformem com a nova descrição do domínio. Os tipos de molas mais utilizadas são: as longitudinais, as torcionais e as semi-torcionais. Nesta tese uma nova mola é proposta, a mola altura, que além de evitar sobreposição de elementos, é conceitualmente simples e fácel de ser implementada. Outra contribuição desse trabalho é o mecanismo de vértices ativos, que permite economia de processamento durante a resolução da malha dinâmica. Quando a fronteira do domínio sofre grandes alterações, o processo dinâmico pode não ter êxito na correção da malha. Para contornar esse problema, a fronteira deve ser alterada aos poucos. Uma nova estratégia para realizar grandes deformações em pequenos passos é introduzida nesta tese. Em algumas aplicações, o movimento da fronteira da malha pode comprometer células da própria fronteira. A correção da fronteira e um processo delicado, já que em muitos casos ele implica em alterar a descrição do domínio. Um novo método para efetuar a correção da fronteira é apresentado neste trabalho. Ele é baseado em malhas dinâmicas e utiliza um novo conceito de molas, as molas conservativas. Todas as contribuições citadas acima tiveram aplicação prática na industria aeronáutica, sendo utilizadas na implementação de uma metodologia inovadora para acoplar um simulador de escoamento de fluidos tridimensional com uma ferramenta de projeto inverso de aerofólios que roda em um contexto bidimensional.

O outro assunto abordado e o remalhamento de triangulações superficiais. Foi proposto um novo método, chamado ANTS (Anisotropic Triangulations on Surfaces) que produz triangulações anisotrópicas de qualidade sobre superfícies descrevendo objetos com geometria complexa. O método ANTS é caracterizado por efetuar o remalhamento diretamente na triangulação inicial, isto é, ele não faz uso de qualquer tipo de parametrização, seja global ou local. O processo de remalhamento é feito por meio de quatro operadores: inserção, remoção e movimento de vértices e alternância de arestas. Os operadores de inserção e remoção de vértices possibilitam controlar a densidade de vértices no domínio, permitindo que nós sejam 
inseridos em regiões com densidade baixa ou eliminados onde a densidade é alta. A qualidade dos triângulos é controlada por meio dos operadores de movimento de vértices e de alternância (flipping) de arestas. O operador de movimento é utilizado no núcleo do processo de remalhamento. Para evitar que o remalhamento danifique a forma original da superfície, as quinas e os córneres são detectados no inicio do processo e preservados durante o remalhamento. A densidade de vértices sobre o domínio é controlada por uma função de espalhamento. Tal função pode ser passada como entrada para o ANTS ou calculada pelo próprio método. $\mathrm{O}$ ANTS foi aplicado com êxito em diversos exemplos gerando malhas de boa qualidade. 


\section{Abstract}

This thesis intends to make a contribution on the field of dynamic meshes. Dynamic meshes are commonly used in the simulation of problems on domains whose geometry varies in time. Virtual springs are placed in the mesh to rearrange its vertices whenever the domain is changed. The most commonly used types of springs are: longitudinal, torsional and semi-torsional. In this thesis a new type of spring is introduced, the height spring, that is conceptually simple but produces good results. Another contribution of this thesis is the active vertices mechanism, that can improve the CPU processing time of the dynamic mesh. When the mesh domain undergoes large deformations, the proposed dynamic mesh algorithm may fail in correcting the mesh. A solution to this problem is perform large deformations in smal steps. A new strategy for this purpose is presented. Sometimes the motion of the mesh boundary can damage cells on the boundary itself. This is a trick problem to solve since the correction of boundary might change the domain geometry. A new method to correct the boundary cells is also presented in this study. The method is based on the dynamic mesh concept and uses a new type of spring, the conservative spring. All the mentioned contributions had been applied in the aeronautics industry. The techniques developed here has been used to implement an innovative methodology to couple a three-dimensional fluid dynamic solver with a two-dimensional inverse design tool for airfoils.

This thesis also deals with remeshing. It is presented the ANTS, a practical method for remeshing anisotropic triangulations on surfaces of complex geometry. The method is capable of performing refinement and coarsening during the same process using the well-known remeshing operators: vertex motion, vertex deletion (by collapsing edges), vertex insertion, and edge flipping. An interesting feature is that vertex motion is used in the core of the process instead of in a post-processing smoothing step. The ANTS uses the input mesh as the geometrical description and works directly on the surface mesh without using any other auxiliary structure (besides the input mesh itself) to preserve the geometrical shape. Moreover, neither global nor local parameterization are applied. Sharp edges and points are identified at the beginning and kept during the process in order to preserve ridges and details. The method 
viii

has been successfully applied to several examples producing high quality meshes. 


\section{Sumário}

1 Introdução 1

2 Conceitos básicos $\quad 11$

2.1 Definições preliminares . . . . . . . . . . . . . . . . . . . 11

2.2 Notações . . . . . . . . . . . . . . . . . . . . . . . . . 16

2.3 Anisotropia . . . . . . . . . . . . . . . . . . . 16

2.4 Medidas no espaço anisotrópico . . . . . . . . . . . . . . . . . . . . 17

2.4 .1 Cálculo de distâncias . . . . . . . . . . . . . . . . . . . . 17

2.4 .2 Cálculo de ângulos . . . . . . . . . . . . . . . . . . . 18

2.5 Representação gráfica de um tensor métrico . . . . . . . . . . . . . . 19

2.6 Função de espaçamento definida por meio de uma malha . . . . . . . . . . . 20

2.7 O tensor métrico e a matriz hessiana . . . . . . . . . . . . . . . . 21

2.7 .1 Tensores de transformação . . . . . . . . . . . . . . . . 23

2.7 .2 O tensor de deformação relativa . . . . . . . . . . . . . . 24

3 Malhas Dinâmicas $\quad 27$

3.1 O funcionamento das malhas dinâmicas . . . . . . . . . . . . . . . . 29

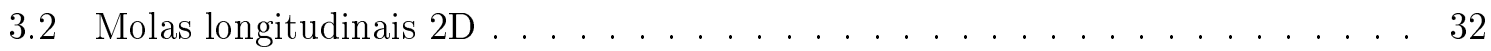

3.3 Molas para tratar triângulos inválidos . . . . . . . . . . . . . 35

3.3 .1 Molas torcionais . . . . . . . . . . . . . . . . 36

3.3 .2 Molas semi-torcionais . . . . . . . . . . . . . . . . 38

3.3 .3 Molas altura . . . . . . . . . . . . . . . . . . . . . 39

3.4 Comparação entre molas . . . . . . . . . . . . . . . . . . . . 42

4 A execução da malha dinâmica $\quad 45$

4.1 Os vértices ativos . . . . . . . . . . . . . . . . . . . 45

4.2 Grandes deformações em pequenas etapas . . . . . . . . . . . . . . 48 
5 Malha dinâmica tridimensional $\quad 55$

5.1 Molas longitudinais $3 \mathrm{D} \ldots \ldots \ldots \ldots \ldots \ldots \ldots \ldots$

5.2 Molas torcionais em tetraedros . . . . . . . . . . . . . . . 56

5.3 Molas semi-torcionais em Tetraedros . . . . . . . . . . . . . . . . 59

5.4 Molas altura em tetraedros . . . . . . . . . . . . . . . . 60

5.5 Comparação entre molas . . . . . . . . . . . . . . . . . . . 62

6 O movimento da fronteira da malha $\quad 65$

6.1 Molas conservativas . . . . . . . . . . . . . . . . . 67

6.1.1 Configuração da malha dinâmica com molas conservativas . . . . . . . . 68

6.2 Remodelagem automática da geometria de um avião . . . . . . . . . . . 70

6.2 .1 Tratamento da asa . . . . . . . . . . . . . . . . . 73

6.2 .2 Tratamento do bordo-de-fuga . . . . . . . . . . . . . . 74

6.2 .3 Tratamento da ponta-de-asa . . . . . . . . . . . . . . 76

6.2 .4 Tratamento da Fuselagem . . . . . . . . . . . . . . . 76

6.2 .5 O movimento da malha volumétrica $\ldots \ldots \ldots$. . . . . . . . 77

$\begin{array}{lll}7 & \text { Remalhamento de triangulações superficiais } & 81\end{array}$

$\begin{array}{lll}8 & \text { As estruturas de controle geométrico } & 95\end{array}$

9 A função de espalhamento $\quad 101$

9.1 Construção de uma função de espaçamento . . . . . . . . . . . . . . . . . . 102

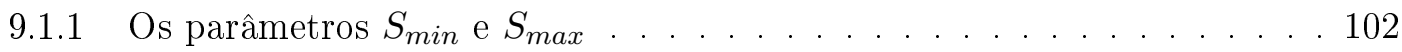

9.1.2 Estimativa de tensores métricos nos vértices de uma malha . . . . . . 103

9.1 .3 O conjunto de vértices $V_{v} \ldots \ldots \ldots \ldots \ldots \ldots \ldots$

9.2 Ajuste da função de espaçamento . . . . . . . . . . . . . . . . 108

9.2 .1 Suavização de funções de espaçamento . . . . . . . . . . . . . . 111

10 O processo de remalhamento $\quad 119$

10.1 Gerenciamento dos vértices iterados . . . . . . . . . . . . . . . . 122

10.2 Critério para preservar a forma geométrica da superfície . . . . . . . . . . . 123

10.3 Operações de remalhamento . . . . . . . . . . . . . . . . . . 124

10.3 .1 Flipping de arestas . . . . . . . . . . . . . . 126

10.3.2 Movimento de vértices . . . . . . . . . . . . . . . . . 127

10.3.3 Inserção de vértices . . . . . . . . . . . . . . . . . . . . . . . 129

10.3 .4 Remoção de vértices . . . . . . . . . . . . . . . . . . . . 132 
10.4 A parada do algoritmo . . . . . . . . . . . . . . . 136

11 Resultados do remalhamento $\quad 139$

11.1 Exemplo 1: Ossos do pé . . . . . . . . . . . . . . . . . . . . 140

11.2 Exemplo 2: Vasos sanguíneos . . . . . . . . . . . . . . . . . . 145

11.3 Exemplo 3: Melhoramento de malhas geradas a partir de imagens . . . . . . . 149

11.4 Outros exemplos . . . . . . . . . . . . . . . . . . . . . 154

12 Conclusão $\quad 159$

12.1 Conclusões sobre movimento de malhas . . . . . . . . . . . . . . 159

12.2 Conclusões sobre remalhamento de malhas superficiais . . . . . . . . . 163 



\section{Lista de Figuras}

1.1 Exemplos de diferentes malhas geradas para um mesmo domínio [14] . . . . . . 3

1.2 Exemplo de malha triangular estruturada (a) e não-estruturada (b). . . . . . . 4

1.3 Malha não-estruturada com densidade de pontos variante sobre o domínio [97]. 4

2.1 Exemplo do fecho convexo de um conjunto de pontos no plano. . . . . . . . . 12

2.2 Faces de uma célula. . . . . . . . . . . . . . . . . . . . . . . . . 13

2.3 Ligação entre células. . . . . . . . . . . . . . . . . . . . . . . . . 13

2.4 Exemplo de componentes. . . . . . . . . . . . . . . . . . . . . . 14

2.5 Estrela e link de vértices. . . . . . . . . . . . . . . . . 15

2.6 Representação da anisotropia por curvas de nível. . . . . . . . . . . . . . . . . . 19

2.7 Representação por elipsóide 2D . . . . . . . . . . . . . . . 20

2.8 Exemplo de malha de fundo para definir a anisotropia sobre o domínio (a) e uma possível malha anisotrópica para o domínio (b) [14] . . . . . . . . . . 21

2.9 Aproximação por uma função linear por partes $g$ de uma função original $f$ [52]. 22

2.10 Fator de encolhimento de uma aresta. . . . . . . . . . . . . . 24

2.11 Tensores de deformação e tensores de deformação relativa [53] . . . . . . . . . . . 24

3.1 Movimento de uma malha bidimensional por malha dinâmica. . . . . . . . . 27

3.2 Força produzida segundo a lei de Hook pelo deslocamento de uma partícula. . . 30

3.3 Sistema de duas partículas conectadas por uma mola longitudinal. . . . . . . 30

3.4 Sistema de molas. . . . . . . . . . . . . . . . . . . . . . . . 31

3.5 Diferença entre desacoplamento e acoplamento de coordenadas em molas longitudinais. . . . . . . . . . . . . . . . . . . . . . . . 33

3.6 Diferença entre utilizar e não utilizar o acoplamento de coordenadas em molas longitudinais. . . . . . . . . . . . . . . . . . . . . . 34

3.7 Diferença entre utilizar e não utilizar o acoplamento de coordenadas em molas longitudinais. . . . . . . . . . . . . . . . . . . . . . . 35 
3.8 As molas longitudinais não impedem o surgimento de célula inválida. . . . . . . 35

3.9 Ilustração de uma mola torcional. . . . . . . . . . . . . . . . . . . . . . . 36

3.10 Mola semi-torcional proposta por Blom [10] . . . . . . . . . . . . . . . . 38

3.11 As molas torcionais em $v_{k}$ e $v_{l}$ são agregadas à mola longitudinal na aresta $e_{i j} . \quad 39$

3.12 Ilustração de uma mola altura. . . . . . . . . . . . . . . . . . . . 40

3.13 Comparação entre a mola altura e o método Ball-vertex de Bottasso et al. [17]. 41

3.14 Isolinhas das métricas utilizadas para a qualidade de triângulos. . . . . . . . . . 43

3.15 Comparação entre molas bidimensionais. . . . . . . . . . . . . . . . . . 44

4.1 A estratégia de vértices ativos. . . . . . . . . . . . . . 50

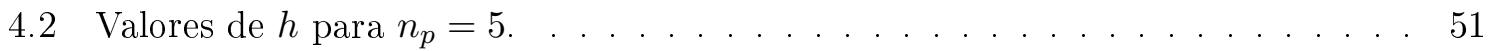

4.3 Grandes deformações em pequenos passos. . . . . . . . . . . . . . . . . 54

5.1 Mola longitudinal 3D com acoplamento de coordenadas. . . . . . . . . . 56

5.2 Inseção de um triângulo fictício dentro de um tetraedro. . . . . . . . . . . . 57

5.3 Controle do volume do tetraedro. . . . . . . . . . . . . . . . . . 58

5.4 Equipando o tetraedro com molas torcionais. . . . . . . . . . . . . . . 58

5.5 Configuração de quatro triângulos por tetraedro. . . . . . . . . . . . . . 59

5.6 Configuração de doze triângulos por tetraedro. . . . . . . . . . . . . . . 59

5.7 Mola semi-torcional diedral para controlar um dos ângulos diedral de um tetraedro. 60

5.8 Exemplo de altura 3D em tetraedro. . . . . . . . . . . . . . . 61

5.9 Deslocamento do bordo esférico interior da malha volumétrica. . . . . . . . 63

5.10 Comparação entre molas 3D. . . . . . . . . . . . . . . . . 64

6.1 Deslocamento parcial da fronteira em um domínio retangular 2D . . . . . 66

6.2 Deslocamento parcial da fronteira em um domínio curvo 2D . . . . . . . 66

6.3 Molas conservativas agindo sobre um curva. . . . . . . . . . . . . 68

6.4 Efeitos do parâmetro $\alpha_{c}$ em malhas dinâmicas com molas conservativas. . . . . 70

6.5 Integração entre projeto inverso (2D) e simulador de escoamento de fluidos (3D). 72

6.6 O modelo de avião composto por quatro grupos: $G_{F}, G_{A s a}, G_{B F}$ e $G_{P A} \ldots \ldots 72$

6.7 Os conjuntos perfis-velhos e perfis-novos tratados nesta seção. . . . . . . . . . 73

6.8 Problemas causados no modelo devido ao movimento da asa. . . . . . . . . . 74

6.9 Esquema de compartilhamento da fronteira do bordo-de-fuga com as outras componentes do avião. . . . . . . . . . . . . . . . . . . 74

6.10 Detalhes dos problemas causados na componente bordo-de-fuga devido ao movimento da asa. . . . . . . . . . . . . . . . . . . . . . . . 75 
6.11 Correção da componente bordo-de-fuga. . . . . . . . . . . . . . . 75

6.12 Correção da componente ponta-de-asa. . . . . . . . . . . . . . 76

6.13 Correção da componente fuselagem. . . . . . . . . . . . . . . . . 77

6.14 Qualidade dos elementos da malha original e da malha final. . . . . . . . . . 79

7.1 Classes de métodos para geração de malhas. . . . . . . . . . . . . . . 88

8.1 Características geométricas em um cubo. . . . . . . . . . . . 96

8.2 Ilustração graus-de-quina de vertices. . . . . . . . . . . . . . . . . 97

8.3 Efeito do processo simplificador de linhas-de-controle. . . . . . . . . . . 99

9.1 O sistema de coordenadas local $\Im\left(v, \vec{\chi}_{v}, \vec{\gamma}_{v}, \vec{n}_{v}\right)$ definido a partir do vértice $v$ para o cálculo da quádrica. . . . . . . . . . . . . . . . . . . . . 104

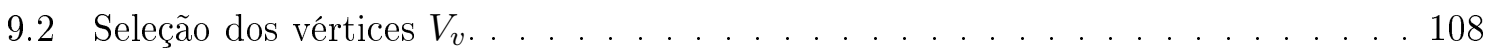

9.3 Efeito do parâmetro $n_{e}$ para os valores 6,12 e $24 \ldots \ldots \ldots$. . . . . . 109

9.4 Construção de uma função de espaçamento sobre a superfície de um toro. . . . 110

9.5 Comparação entre métodos de suavização de funções de espaçamento. . . . . . 118

10.1 Diagrama de estados da rotulação dos vértices. . . . . . . . . . . . . . . 123

10.2 Entidades envolvidas no cálculo da métrica $Q_{G} \ldots \ldots \ldots$. . . . . . . 124

10.3 Efeitos da métrica $Q_{G}$ no processo de remalhamento. . . . . . . . . 125

10.4 Flipping de uma aresta. . . . . . . . . . . . . . . . 126

10.5 Movendo um vértice pertencente a uma superfície-de-controle. . . . . . . . . 127

10.6 Movendo um vértice pertencente a uma linha-de-controle. . . . . . . . . . 128

10.7 Exemplifição do problema no critério simplificado dado pela Restrição 10.6. . 131

10.8 Procedimento complementar para a inserção de vértices. . . . . . . . . . . . . 131

10.9 Caso limite para o procedimento complementar para inserção de vértices. . . . . 132

10.10Remalhamento da triangulação original (a) sem utilizar (b) e utilizando (c) o procedimento complementar de inserção . . . . . . . . . . . . . . . . . . 133

10.11Remoção do vértice $v_{i}$ seguida de retriangulação. . . . . . . . . . . . 133

10.12Remoção do vértice $v_{i}$ pela colapsação da aresta $e_{i j} \ldots \ldots$. . . . . . . . 134

10.13Colapsação de qualquer aresta tracejada resulta em elementos inválidos. . . . . 134

10.14Condição para remoção de um vértice em uma linha-de-controle. . . . . . . . 134

10.15Condição para remoção de um vértice em uma ponta-de-controle. . . . . . . . 135

10.16Remoção de vértices em superfícies-de-controle. . . . . . . . . . . . 136 
11.1 Malha original (à esquerda) e remalhamento isotrópico uniforme (à direita) dos ossos do pé. . . . . . . . . . . . . . . . . . . . . . . . . 142

11.2 Histograma dos comprimentos de arestas da malha isotrópica uniforme dos ossos do pé. . . . . . . . . . . . . . . . . . . . . . . . . 143

11.3 Ossos do pé após a suavização da forma (à esquerda) e após o remalhamento anisotrópico (à direita) . . . . . . . . . . . . . . . . . . . . . . . 144

11.4 Histograma dos comprimentos de arestas da malha anisotrópica dos ossos do pé. 145

11.5 Remalhamento anisotrópico dos vasos sangüíneos. . . . . . . . . . . . . . . . . 146

11.6 Detalhes das malhas dos vasos sangüíneos. . . . . . . . . . . . . . . . . . . 147

11.7 Histograma dos comprimentos de arestas da malha anisotrópica dos vasos sangüíneos. . . . . . . . . . . . . . . . . . . . . . . . 148

11.8 Crânio original (à esquerda) e após tratamento de suavização de forma e remalhamento isotrópico uniforme (à direita) . . . . . . . . . . . . . . 150

11.9 Histograma dos comprimentos de arestas da malha isotrópica uniforme do crânio.151

11.10Remalhamento anisotrópico do crânio suavizado. . . . . . . . . . . . . . 152

11.11Histograma dos comprimentos de arestas da malha anisotrópica do crânio. . . . 152

11.12Remalhamento isotrópico do crânio suavizado. . . . . . . . . . . . . . . 154

11.13Histograma dos comprimentos de arestas da malha isotrópica do crânio. . . . . 155

11.14Remalhamento de uma formiga. . . . . . . . . . . . . . . . 156

11.15Remalhamento de uma vaca. . . . . . . . . . . . . . . . . 157

11.16Remalhamento de um ônibus espacial. . . . . . . . . . . . . . . . . 158 


\section{Lista de Tabelas}

6.1 Medições de qualidade dos elementos da malha volumétrica. . . . . . . . . 78

11.1 Informações sobre o remalhamento isotrópico uniforme dos ossos do pé. . . . . 141

11.2 Medições de ângulos da malha isotrópica uniforme para os ossos do pé. . . . . . 141

11.3 Informações sobre o remalhamento anisotrópico dos ossos do pé. . . . . . . . . 143

11.4 Medições de ângulos da malha anisotrópica para os ossos do pé. . . . . . . . . 143

11.5 Medições de ângulos para o exemplo dos vasos sangüíneos. . . . . . . . . . . 145

11.6 Informações sobre o remalhamento dos vasos sangüíneos. . . . . . . . . . . . . 148

11.7 Medições de ângulos da malha isotrópica uniforme do crânio. . . . . . . . . . . 151

11.8 Informações sobre o remalhamento isotrópica uniforme do crânio. . . . . . . . . 151

11.9 Medições de ângulos na malha anisotrópica do crânio. . . . . . . . . . . . 153

11.10Informações sobre o remalhamento anisotrópico do crânio. . . . . . . . . . . 153

11.11Medições de ângulos da malha isotrópica do crânio. . . . . . . . . . . . 155

11.12Informações sobre o remalhamento isotrópico do crânio. . . . . . . . . . 155 



\section{Capítulo 1}

\section{Introdução}

Um passo essencial em simulação numérica é a construção de uma discretização apropriada do domínio onde se deseja executar a simulação. Este é precisamente o problema tratado pela geração de malhas. A geração de malhas é um bom exemplo de atividade interdisciplinar, sendo que seu desenvolvimento se dá mediante avanços em geometria computacional e combinatorial, estrutura de dados, análise numérica e aplicações científicas.

A geração de malhas é um componente chave em simulações computacionais de fenômenos físicos ou de engenharia, que são freqüentemente modelados por equações diferenciais parciais (EDP). Nem sempre é possível resolver tais equações analiticamente, como por exemplo quando as condições de contorno são complicadas ou quando os domínios são irregulares. Nestes casos é necessário trabalhar com aproximações. Os métodos numéricos mais comumente usados para aproximar EDPs são: diferenças finitas, elementos finitos (ou MEF - finite elements method) e volumes finitos. Eles são usados para modelar os mais variados fenômenos, tais como: deformação mecânica, transferência de calor, dinâmica dos fluidos, propagação de ondas eletromagnéticas e mecânica quântica.

Uma simulação numérica normalmente utiliza os seguintes passos básicos:

1. Modelagem Matemática: define o domínio contínuo $\Omega$ e as equações diferenciais parciais sobre $\Omega$ que modelam o problema.

2. Modelagem Geométrica: aproxima o domínio contínuo $\Omega$ por uma representação discreta.

3. Geração de Malha: decompõe o interior do domínio em elementos por meio de uma malha.

4. Aproximação Numérica: refere-se à construção de um sistema de equações lineares ou não-lineares sobre a malha para representar as EDPs governantes. 
5. Solução Numérica: resolve o sistema de equações e estima o erro na solução.

6. Processo Adaptativo: se necesário, refina e/ou engrossa a malha e repete os passos 5 e 6 sobre a malha refinada.

Para discretizar um domínio, não é suficiente escolher um conjunto qualquer de pontos para serem os nós, o domínio deve ser particionado em pequenas partes de formato simples. No caso do FEM, por exemplo, estas partes são chamadas elementos e são triângulos ou quadriláteros (em duas dimensões), ou ainda tetraedros, prismas, pirâmides e hexaedros (em três dimensões). O FEM emprega um nó em cada vértice dos elementos, estes nós são compartilhados por vários elementos. A coleção dos nós e elementos é chamada de malha. Como os elementos possuem formatos simples, é possível aproximar o comportamento da EDP em cada elemento. Acumulando estes efeitos sobre todos os elementos, deriva-se um sistema de equações cuja solução aproxima um conjunto de quantidades físicas (temperatura, por exemplo) em cada nó do domínio.

A precisão da solução depende intimamente da qualidade da malha. Uma malha é considerada de boa qualidade se ela for constituída por elementos adequados em termos de formato e tamanho. A Figura 1.1 apresenta quatro malhas diferentes para um mesmo domínio, sendo que cada uma delas se adequada a um tipo diferente de problema.

As malhas são geralmente categorizadas em estruturadas e não-estruturadas. As malhas estruturadas apresentam uma estrutura topológica uniforme, o que não acontece nas malhas não-estruturadas. Nas malhas estruturadas, os índices dos vizinhos de um nó podem ser obtidos por uma função simples. As malhas não-estruturadas são representadas por estruturas de dados mais elaboradas e os índices dos vizinhos são obtidos por meio de consultas a estas estruturas de dados. A Figura 1.2 apresenta dois exemplos de malhas triangulares, uma estruturada e outra não-estruturada. Um tipo particularmente simples de malha estruturada é a malha cartesiana regular, onde os elementos são quadriláteros ou hexaedros idênticos.

As malhas estruturadas são mais fáceis de serem geradas e manipuladas, requerem estruturas de dados simples e reduzem a dificuldade de programação. No entanto, o uso de malhas estruturadas regulares limitam a aplicabilidade dos métodos numéricos a problemas com domínios de geometria simples e com soluções dadas por funções suaves. Por outro lado, para problemas envolvendo domínios complicados onde as soluções variam rapidamente sobre o domínio, é necessário usar uma malha não-estruturada. Essas malhas possibilitam variar facilmente a topologia e o espaçamento em diferentes regiões do domínio. Por exemplo, considere a modelagem de terromotos, é necessário uma discretização mais fina e densa no centro do tremor, pois não se deve desperdiçar pontos em regiões de pouca atividade. Porém, para 


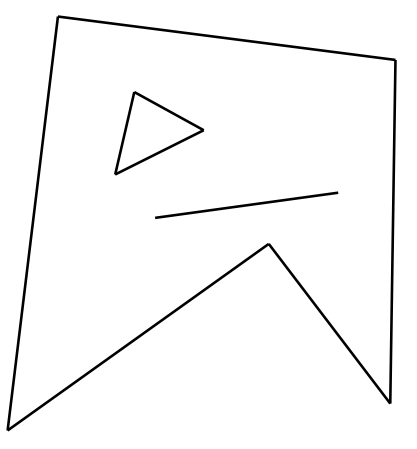

(a) Geometria do domínio

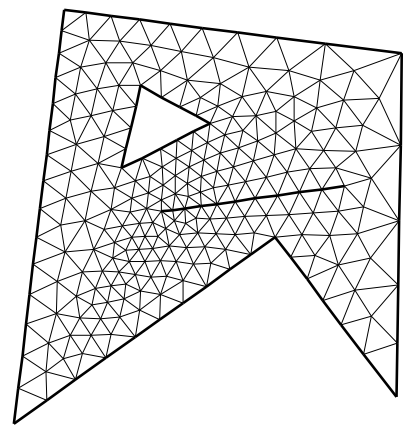

(c) Malha refinada.

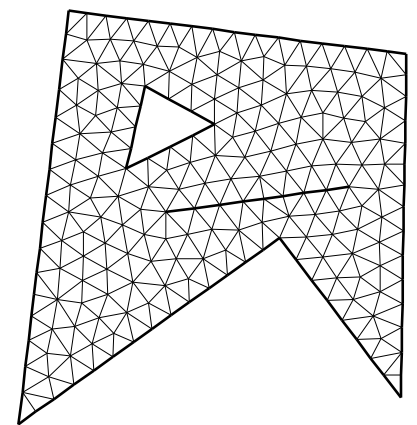

(b) Malha uniforme.

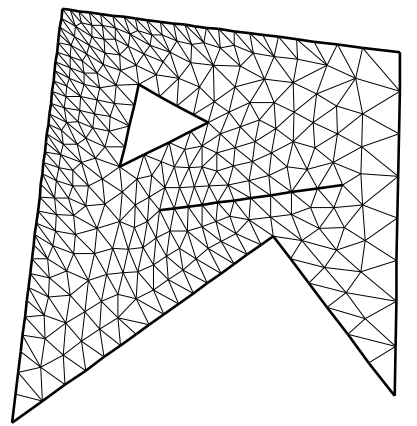

(d) Malha anisotrópica.

Figura 1.1: Exemplos de diferentes malhas geradas para um mesmo domínio [14].

esse tipo de malha a construção do método numérico se torna mais difícil e a implementação dos algoritmos mais trabalhosa.

Um gerador de malhas deve controlar tanto quanto possível os tamanhos dos elementos na malha. Idealmente, esse controle inclui a habilidade de variar entre pequenos e grandes elementos em diferentes regiões do domínio. A razão disso é que o tamanho do elemento tem dois efeitos numa simulação. Uma região com elementos pequenos oferece mais precisão do que uma com elementos grandes, porém o tempo requerido para resolver um problema é proporcional ao número de elementos. Assim, escolher o tamanho dos elementos consiste em ponderar entre desempenho e precisão. Além disso, o tamanho de elemento requerido para se obter uma dada precisão depende do comportamento do fenômeno físico modelado e o tamanho pode ainda variar entre diferentes regiões do domínio do problema (ver Figura 1.3). Por exemplo, em simulação de dinâmica dos fluidos, elementos pequenos devem ser dispostos nas regiões de turbulência e elementos maiores podem ser utilizados nas áreas de relativa quietude. Em três dimensões, o volume de um elemento ideal em regiões distintas da malha pode diferir na razão de um para um milhão. Se uma malha for construída por elementos de tamanho uniforme, estes devem ser pequenos o suficiente para garantir a precisão desejada 


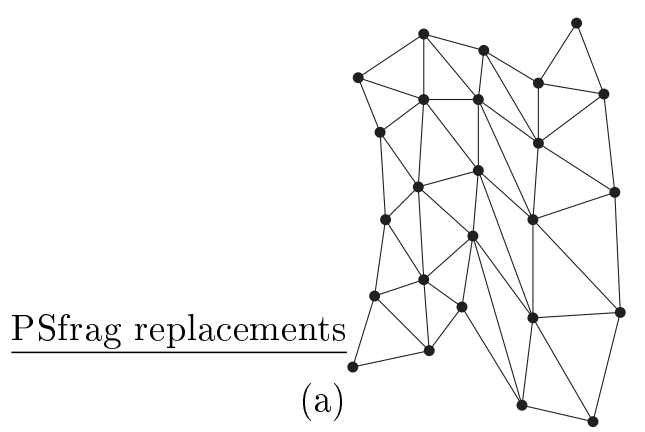

(b) $\quad \mathrm{A}$

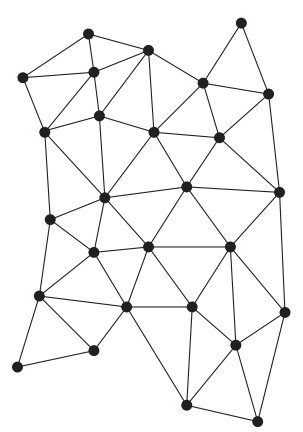

$\mathrm{B}$

Figura 1.2: Exemplo de malha triangular estruturada (a) e não-estruturada (b).

na parte do domínio mais relevante, podendo, portanto, demandar uma quantidade excessiva de computação. Um gerador de malhas deve, portanto, possibilitar variações no tamanho dos elementos sobre o domínio.

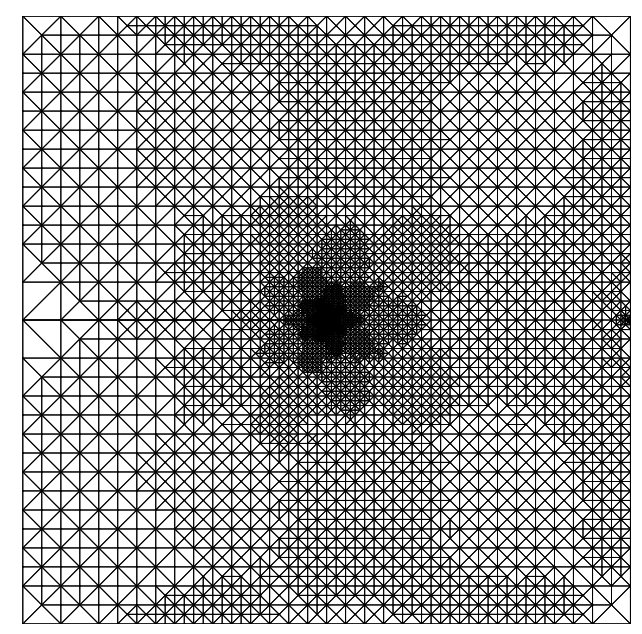

Figura 1.3: Malha não-estruturada com densidade de pontos variante sobre o domínio [97].

Refinamento e simplificação de malhas são processos utilizados para ajustar a densidade de nós da malha, e, conseqüentemente, os tamanhos dos elementos. O papel do refinamento é aumentar a densidade de nós e não é um procedimento simples de ser realizado. O processo de simplificação, por sua vez, trata da eliminação de nós e é um procedimento consideravelmente mais complicado que o de refinamento. Por isso os geradores de malhas normalmente se propõem a gerar uma malha tão grossa quanto possível e então oferecem uma opção para refinar regiões onde se deseja maior precisão numérica. Esta foi a estratégia empregada na geração da malha da Figura 1.3.

Não apenas o tamanho dos elementos influencia na qualidade da malha, mas também a forma. Sendo assim, outro objetivo dos geradores de malha é produzir elementos com formatos 
adequados para o propósito da malha. Essa é uma tarefa consideravelmente difícil e poucos geradores são capazes de produzir malhas atendendo determinados critérios de qualidade relativos ao formato dos elementos $[27,70,81,78]$. De uma maneira geral, os geradores procuram criar elementos tão próximos quanto possível dos eqüiláteros. Elementos com ângulos próximos de $180^{\circ}$ podem causar erros inaceitáveis de discretização. Por princípio, a solução discreta deve aproximar a solução exata da EDP quando o tamanho dos elementos tender a zero. Entretanto, no caso de FEM, Babuska [8] mostra que se os ângulos aproximarem-se de $180^{\circ}$ à medida que diminuem, a convergência para a solução exata não ocorre. Portanto, elementos com ângulos grandes devem ser evitados.

Um outro problema causado por ângulos grandes são os erros nas derivadas da solução, os quais sobresaem como artefatos de interpolação sobre a malha. Esse problema pode afetar qualquer aplicação que faça uso de malhas para interpolação.

Segundo [20], ângulos pequenos também podem causar problemas, por tornarem mal condicionados os sistemas acoplados de equações numéricas produzidos pelo método numérico. Se o sistema é mal condicionado e for solucionado por métodos diretos, os erros de arredondamento degradam a precisão da solução; já nos métodos iterativos, a convergência torna-se lenta.

Sabe-se, portanto, que o tamanho e o formato dos elementos devem ser controlados para garantir uma determinada precisão na solução. Mas como determinar quais regiões do domínio devem ser mais densas e quais devem ser menos densas? A resposta para esta pergunta reside nas condições numéricas do domínio do problema.

O domínio do problema é descrito pela sua geometria, possivelmente criada em algum sistema CAD, e também pelas condições numéricas sobre o domínio. As condições numéricas do problema afetam a precisão da solução, uma vez que estão diretamente relacionadas com os erros de discretização. Elas definem a densidade de espaçamento local desejada nas diversas regiões do domínio. A densidade, por sua vez, é geralmente obtida a partir de uma análise de erro a priori ou a posteriori baseada na simulação numérica inicial.

Um exemplo de indicador de densidade de pontos comumente utilizado é o gradiente da solução. Para um problema cuja solução tem variação lenta, é possível utilizar uma malha uniforme, isto é, com elementos de aproximadamente o mesmo tamanho. Para problemas com soluções que apresentam variações rápidas, pode ser necessário usar malhas mais refinadas em algumas regiões e menos refinadas em outras.

As condições numéricas definem uma função de espaçamento, denotada por $h(x)$, para cada ponto $x$ do domínio. O valor de $h(x)$ determina qual a distância que um vértice em $x$ deve estar dos outros vértices na malha, ou seja, o tamanho esperado das arestas. O valor de 
$h(x)$ depende dos autovalores da matriz hessiana, denotada por $H(x)$, da solução $u$ da EDP governante. O espaçamento $h(x)$, depende da raiz quadrada do maior autovalor em módulo de $H(x)$.

Em simulações numéricas adaptativas pode-se, por exemplo, começar com uma malha mais grossa e uniforme para o passo inicial. Os autovalores da matriz hessiana são estimados para um determinado conjunto de pontos no domínio baseado na aproximação numérica obtida na malha inicial. Os autovalores são então usados para determinar o espaçamento da nova malha.

Um outro fator que pode influenciar na solução produzida por um método numérico é a anisotropia. Quando o problema apresenta um comportamento fortemente anisotrópico os elementos da malha podem ser finos e orientados de acordo com a anisotropia. A Figura 1.1(d) mostra uma malha anisotrópica. Por exemplo, na análise de um vôo supersônico em mecânica dos fluidos, os elementos devem estar esticados e orientados ao longo da camada de choque. Malhas anisotrópicas são utilizadas em vários problemas de mecânica de fluidos computacional $[69,21,2]$ e os resultados mostram que estas malhas oferecem um bom compromisso entre precisão numérica e número de elementos da malha.

A matriz hessiana $H(x)$ da solução estabelece uma métrica riemanniana que determina o espaçamento local. Considerando um ponto $x$ do domínio, o elemento ideal para possibilitar um erro de aproximação uniforme em todas as direções é um elipsóide cujos eixos são dados pelos autovetores $\vec{\nu}_{1}, \ldots, \vec{\nu}_{d}$ e cujos raios ao longo de $\vec{\nu}_{i}$ são proporcionais a $1 / \sqrt{\left|\xi_{i}\right|}$, onde $\xi_{i}$ é o autovalor associado a $\vec{\nu}_{i}[80]$.

Como mencionado anteriormente, na geração de malhas isotrópicas o espaçamento $h(x)$ requerido para oferecer precisão em um ponto $x$ do domínio depende da raiz quadrada do maior autovalor de $H(x)$ no ponto $x$. Entretanto, em aplicações anisotrópicas o maior autovalor em módulo pode diferir consideravelmente dos demais. Nesse caso, uma malha isotrópica poderá conter muito mais elementos que o necessário; já as malhas anisotrópicas são mais adequadas, pois o uso de elementos finos pode satisfazer às necessidades de precisão em diferentes direções, desde que os elementos estejam corretamente posicionados e direcionados no domínio.

A transformação de uma malha em outra malha mais adequada para o passo seguinte de simulação é conhecido como remalhamento (remeshing). Dependendo da configuração da função de espaçamento $h(x)$ a malha produzida pode ser isotrópica ou anisotrópica. Note que a discussão até o momento considerou um domínio fixo. Porém, existem aplicações onde a geometria do domínio varia com o tempo. São os problemas conhecidos como moving boundary problems, ou seja, problemas com fronteira móvel. Tais problemas são encontrados em diversas aplicações científicas e de engenharia, incluindo: simulação da circulação sangüínea, oscilações de aerofólio, análise de corpos em movimento, otimização de formas, além dos problemas em 
mecânica de fluidos computacional com superfície livre. Durante a simulação dessas aplicações, o objeto em estudo sofre alterações em seu formato, modificando assim o domínio sobre o qual a malha está definida. Uma mudança contínua no domínio requer modificações consecutivas na malha a fim de garantir que esta permaneça conforme com a descrição geométrica do domínio. Dessa forma, sempre que o domínio for alterado, é necessário ajustar a malha para a nova geometria do espaço.

De modo geral, têm-se três alternativas para tratar a malha em aplicações com domínio variante: (1) gerar uma nova, (2) alterar a malha original e (3) malhas dinâmicas. A primeira opção consiste em gerar uma nova malha sempre que o domínio for alterado. O custo computacional dessa opção é geralmente proibitivo, principalmente em três dimensões, pois as malhas são comumente grandes e a alteração no domínio ocorre em pequenas etapas, o que requer a geração de várias malhas durante o processo. Além disso, o processo de geração de malha é difícil de ser automatizado, pois a intervenção do usuário é quase sempre requerida para configurar os parâmetros do gerador a fim produzir malhas de boa qualidade.

A seguinda opção, remalhamento, modifica a malha por meio de operações como inserção, remoção e movimento de vértices e alternância (flipping) de arestas. Geralmente as alterações da malha ocorrem apenas onde o domínio foi modificado, podendo deixar intacta grande parte da malha original. Apesar de oferecer bons resultados, o remalhamento não é simples de ser implementado computacionalmente. A tarefa se torna ainda mais complexa em malhas volumétricas, em especial quando estas são compostas por elementos outros que não tetraedros. Note que o remalhamento neste caso tem um propósito diferente do discutido anteriormente onde a intenção era alterar os elementos de uma malha existente para que obedecessem uma determinada função de espaçamento $h(x)$ (isotrópica ou anisotrópica) definida sobre um domínio fixo. Neste caso, o remalhamento tem por objetivo principal corrigir as distorções na malha causadas pelo movimento da fronteira do domínio, sendo que a função de espaçamento $h(x)$ pode ou não estar envolvida.

A terceira opção, conhecida na literatura como malha dinâmica [36, 18, 73, 46, 89], consiste em manter inalterada a conectividade da malha original e realizar o ajuste à nova configuração do domínio por meio de movimentação de vértices. A malha dinâmica é obtida pela distribuição de molas virtuais sobre a malha a ser movimentada. Sempre que o domínio sofrer alteração, as molas são acionadas movimentando os vértices para que estes se conformem com a nova descrição do domínio. Se comparada com as outras opções, as malhas dinâmicas oferecem as seguintes vantagens: elas são relativamente fáceis de serem implementadas, mesmo em malhas volumétricas; geralmente requerem menos tempo para modificar a malha para a próxima etapa da aplicação; e não requerem a intervenção do usuário, o que torna a aplicação mais fácil de 
ser automatizada. No entanto, as malhas dinâmicas possuem uma limitação intrínseca. Como a conectividade da malha não é alterada, quando o domínio sofre grandes deformações a malha resultante pode não oferecer boas condições para o próximo passo da aplicação. Quando isso ocorre, a geração de uma nova malha ou o remalhamento é aplicado.

Neste trabalho de doutorado são exploradas abordagens para tratamento de malhas por meio de malhas dinâmicas e de remalhamento. Nos dois casos, a intenção é produzir malhas para fins de simulação numérica.

A motivação inicial para o estudo de malhas dinâmicas neste trabalho está relacionada com a necessidade de movimentar malhas volumétricas em aplicações de dinâmica de fluidos computacional na indústria aeronáutica. Uma das contribuições desta tese é um estudo comparativo entre variadas configurações de molas e a proposta de um novo tipo de mola, chamada mola altura, que oferece vantagens sobre as molas longitudinais, torcionais e semi-torcionais, que são as mais comumente utilizadas.

Outra motivação para estudar malhas dinâmicas está relacionada com a carência de uma estratégia baseada em malhas dinâmicas para acoplar de forma automática um simulador de escoamento de fluidos tridimensional com uma ferramenta auxiliar bidimensional para projeto inverso de aerofólios. Esta também é uma das contribuições desta tese. Esse acoplamento se dá no seguinte contexto. Após realizar uma simulação numérica inicial na malha volumétrica em volta do avião, são aplicados planos de corte perpendiculares à asa. As interseções desses planos com a asa definem um conjunto de curvas denominadas perfis. O papel da ferramenta auxiliar de projeto inverso é modificar a geometria desses perfis. O grande desafio surge no momento de modificar o modelo tridimensional do avião com base apenas nas informações geométricas fornecidas pelo conjunto de perfis. Em face desse desafio, esta tese introduz uma estratégia inovadora para movimentar malhas superficiais. Tal estratégia é baseada em um novo tipo de mola introduzida neste trabalho que é conhecida como mola conservativa. Estas molas são capazes de movimentar malhas superficiais sem prejudicar a forma geométrica geral da superfície de entrada e sem precisar para isso fazer uso de projeção de pontos.

Como mencionado anteriormente, esta tese também introduz uma nova técnica de remalhamento. A técnica recebe o nome de ANTS (Anisotropic Triangulations on Surfaces) e tem por objetivo produzir triangulações anisotrópicas de qualidade sobre superfícies descrevendo objetos com geometria complexa. A motivação para tratar de tal assunto surgiu da limitação natural das malhas dinâmicas, que não são capazes de produzir malhas de boa qualidade quando o domínio sofre certas alterações geométricas, em geral deformações relativamente grandes. Como mencionado anteriormente, em tais cenários o remalhamento é uma alternativa interessante, pois ela pode manter inalteradas certas regiões da malha original, o que 
promove economia de processamento.

O ANTS é caracterizado por efetuar o remalhamento diretamente na triangulação inicial, isto é, ele não faz uso de qualquer tipo de parametrização, seja global ou local. O processo de remalhamento se dá por meio de quatro operadores. Os operadores de inserção e remoção de vértices possibilitam controlar a densidade de vértices no domínio, permitindo que vértices sejam inseridos em regiões com densidade baixa e que vértices sejam eliminados onde a densidade é alta. A qualidade dos triângulos é controlada por meio dos operadores de movimento de vértices e de alternância (flipping) de arestas. Motivado pela flexibilidade das malhas dinâmicas e pelo trabalho de Bossen e Heckbert [15], o operador de movimento é utilizado no núcleo do processo de remalhamento e não em um passo de pós processamento, como acontece em vários métodos.

Para evitar que o remalhamento danifique a forma original da superfície, as quinas e os córneres são detectados no início do processo e preservados durante o remalhamento. Os vértices detectados como córneres não são nem movidos nem eliminados. Nas arestas detectadas como quina, o operador de flipping não é aplicado.

A densidade de vértices sobre o domínio é controlada por uma função de espaçamento. Tal função pode ser passada como entrada para o ANTS ou calculada pelo próprio método. Como mencionado anteriormente, as vezes a função de espaçamento pode ser provida mediante a análise dos estimadores de erro a posteriori, os quais são calculados a partir de uma simulação numérica executada previamente no mesmo domínio, possivelmente na própria triangulação de entrada. Em outros casos, o ANTS pode estimar uma função de espaçamento anisotrópica ou isotrópica (dependendo da necessidade do usuário) em função das principais curvaturas da malha de entrada.

Os capítulos dessa tese estão estruturados na seguinte ordem. O próximo capítulo trata dos conceitos básicos úteis para o entendimento do restante do texto. Embora as técnicas de malhas dinâmicas e de remalhamento estejam de uma certa maneira relacionadas, pois ambas têm o propósito de modificar malhas já existentes, elas diferem consideravelmente em suas metodologias. O assunto malha dinâmica está abordado nos capítulos 3,4 e 5 ao passo que os capítulos $6,7,8,9$ e 10 tratam de remalhamento. Já o capítulo 11 apresenta conclusões e sugestões para trabalhos futuros referentes aos dois assuntos. 


\section{Capítulo 2}

\section{Conceitos básicos}

Este capítulo apresenta definições e conceitos fundamentais para o entendimento dos próximos capítulos.

\subsection{Definições preliminares}

As definições apresentadas a seguir estão principalmente baseadas em [33, 64, 35, 42].

Definição 1 (Espaço Euclidiano) $O$ Espaço Euclidiano de dimensão n é o espaço $\mathbb{R}^{n}$ dotado da métrica euclidiana usual, isto é, dado dois pontos $p=\left(p_{1}, \ldots, p_{n}\right), q=\left(q_{1}, \ldots, q_{n}\right) \in \mathbb{R}^{n}$, a distância entre $p$ e q é dada por:

$$
\|p-q\|=\sqrt{\left(p_{1}-q_{1}\right)^{2}+\left(p_{2}-q_{2}\right)^{2} \ldots+\left(p_{n}-q_{n}\right)^{2}}
$$

Definição 2 (Esfera) Um esfera de dimensão $n-1$, denotada por $S^{n-1}$, é definida como o conjunto dos pontos $x \in \mathbb{R}^{n}$ satisfazendo $\|x\|=1$.

Definição 3 (Disco) Um disco de dimensão n, denotado por $D^{n}$, é definido como o conjunto dos pontos $x \in \mathbb{R}^{n}$ satisfazendo $\|x\| \leq 1$.

Definição 4 (Homeomorfismo) Um homeomorfismo de um conjunto $A$ em um conjunto $B$ é uma aplicação $f: A \rightarrow B$ continua inversivel com inversa contínua. Dizemos que dois conjuntos $A$ e $B$ são homeomorfos se existe homeomorfismo de $A$ em $B$.

Definição 5 (Fecho Convexo) Dado um conjunto de pontos $P \subset \mathbb{R}^{n}$, o conjunto de todas as combinações lineares convexas, dado pela equação 2.2, exprime a definição de fecho convexo (figura 2.1). 


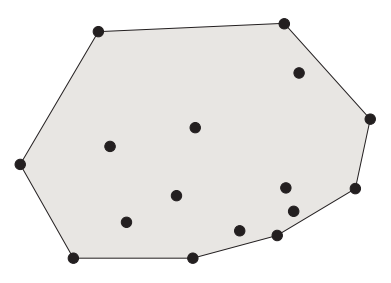

Figura 2.1: Exemplo do fecho convexo de um conjunto de pontos no plano.

$$
\operatorname{conv}(P)=\sum_{i=1}^{n} \lambda_{i} p_{i}
$$

em que $\sum_{i=1}^{n} \lambda_{i}=1, \lambda_{i} \geq 0, \lambda_{i} \in \mathbb{R}, p_{i} \in P$.

O fecho convexo $\operatorname{conv}(P)$ pode ser visto como o menor polígono convexo que contenha os pontos de $P$.

Definição 6 (Vetores em posição geral) Se $v_{0}, v_{1}, \ldots, v_{p}$ são vetores em $\mathbb{R}^{m}$, dizemos que esses $p+1$ vetores estão em posição geral, quando os vetores $\left(v_{1}-v_{0}\right),\left(v_{2}-v_{0}\right), \ldots,\left(v_{p}-v_{0}\right)$ são linearmente independentes.

Diz-se que o vetor $y$ é linearmente dependente de $v_{0}, v_{1}, \ldots, v_{p}$ se existir $\lambda_{0}, \lambda_{1}, \ldots, \lambda_{p}$ tal que $y=\sum_{i=0}^{p} \lambda_{i} v_{i}$.

Definição 7 (Célula convexa afim) É fecho convexo de um conjunto finito de pontos $p_{0}$, $p_{1}, \ldots, p_{n}$. Dizemos então que ela é gerada por $p_{0}, p_{1}, \ldots, p_{n}$.

Definição 8 (Subcélula) Uma subcélula convexa afim $\tau$ de um célula convexa afim $\sigma$, denotada por $\tau \prec \sigma$, é uma célula convexa afim $\tau$ contida no bordo de $\sigma$. denotada por $\tau \in \sigma$, se e somente se:

Um vértice de uma célula é uma subcélula com um só ponto. A célula $\sigma$ é considerada subcélula dela mesma.

Definição 9 (Dimensão de uma célula) Diz-se que uma célula convexa afim gerada por $p_{0}, \ldots, p_{m}$ tem dimensão $n$, denotado por $n$-célula, se ela contém $n+1$ vetores em posição geral dentre $p_{0}, \ldots, p_{m}$ e nâa mais do que isso.

Note que as subcélulas de uma 2-célula são: as suas arestas (1-subcélulas), e os seus vértices (0-subcélulas). A Figura 2.2 exemplifica as subcélulas de uma 2-célula retangular. 


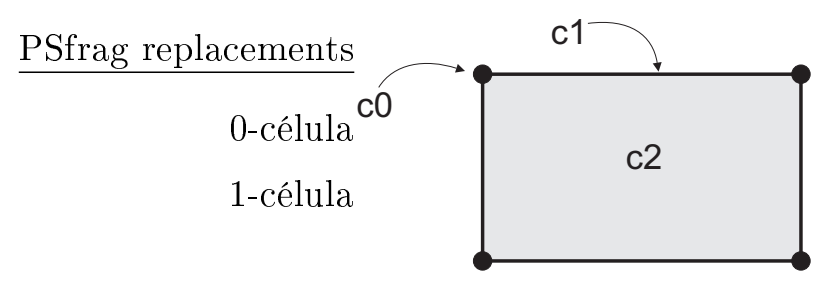

Figura 2.2: Faces de uma célula.

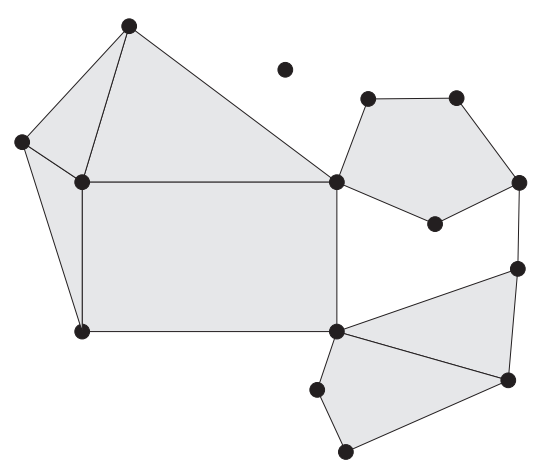

(a) Células propriamente ligadas

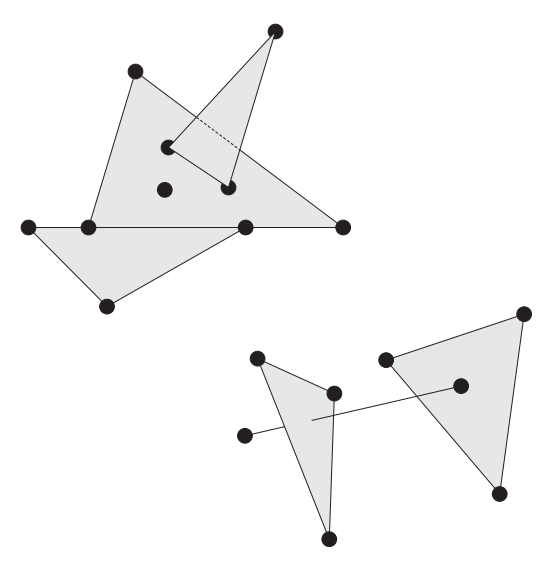

(b) Células impropriamente ligadas

Figura 2.3: Ligação entre células.

Definição 10 (Simplexo) Quando uma célula convexa afim possui dimensão n e é gerada por $n+1$ vetores em posição geral, ela é chamada de simplexo.

Definição 11 (Células propriamente ligadas) Duas células $\sigma^{m}$ e $\sigma^{n}$ são propriamente ligadas se alguma das seguintes condições forem satisfeitas:

- $\sigma^{m} \cap \sigma^{n}=\emptyset$, ou

- $\sigma^{m} \cap \sigma^{n}=\tau \operatorname{com} \tau \prec \sigma^{m}$ e $\tau \prec \sigma^{n}$.

A Figura 2.3 mostra exemplos de células propriamente e impropriamente ligadas.

Definição 12 (Complexo celular) Um complexo celular $n$-dimensional $K$ é uma coleção finita de células $i$-dimensionais $(i=0, \ldots, n)$ em $\mathbb{R}^{m}$ sob as seguintes condições:

1. Se $\sigma \in K$ e $\tau \in \sigma$ então $\tau \in K$.

2. Se $\sigma$ e $\rho \in K$ então $\sigma$ e $\rho$ são propriamente ligadas.

Definição 13 (Adjacência de subcélulas) Duas $k$-células $\sigma$ e $\rho$ de um complexo celular $K$ são adjacentes quando $\sigma \cap \rho \neq \emptyset$. 


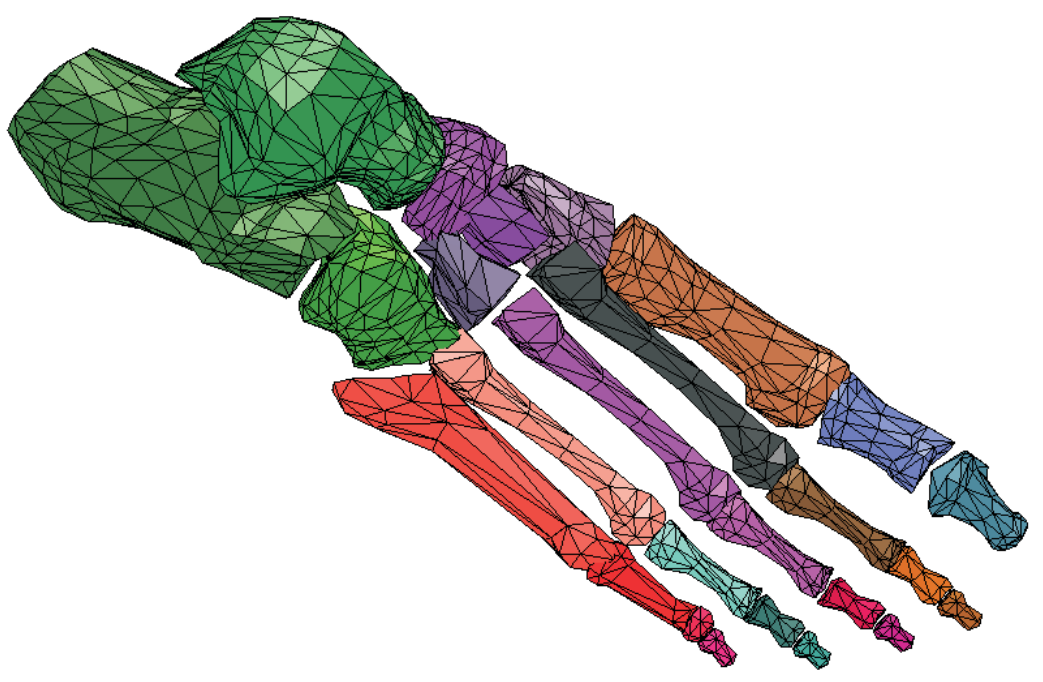

Figura 2.4: Exemplo de componentes.

Definição 14 (Incidência) Seja $K$ um complexo celular. Se $\tau \in K$ e $\rho \in K$ e $\tau$ é subcélula de $\rho$, diz-se que $\rho$ é incidente a $\tau$.

Definição 15 (Subcomplexo (ou grupo)) Se uma coleção de células $L \subset K$ é um complexo celular, então é chamado de um subcomplexo (ou grupo) de $K$.

Definição 16 (Complexo conectado) Um complexo $K$ é conectado se não pode ser representado como a união de dois subcomplexos disjuntos não vazios $L$ e $M$ sem células em comum.

Definição 17 (Componente) Uma componente de um complexo celular $K$ é um subcomplexo conectado que não está contido em um subcomplexo conectado maior em $\mathrm{K}$.

A Figura 2.4 ilustra um complexo celular composto por 26 componetes (uma para cada osso).

Definição 18 (Estrela) A estrela de uma célula convexa afim $\sigma \in K$ é um subcomplexo de $K$ composto pela união das células e subcélulas incidentes a $\sigma$ e é denotada por $\star_{\sigma}$.

Definição 19 (Link) O elo de uma célula convexa afim $\sigma$ que é denotado por 赵 $\sigma$ é o subcomplexo do bordo de $\star_{\sigma}$ que não contém $\sigma$.

A Figura 2.5 destaca a estrela (células destacadas em cinza) e o link (arestas em negrito) de dois vértices, indicados por $a$ e $b$, de um complexo celular bidimensional.

Definição 20 (Variedade combinatória) Um complexo celular n-dimensional $M,|M| \subset$ $\mathbb{R}^{m}$, é uma variedade combinatória de dimensão $n$ com bordo se o link de toda célula convexa afim $\sigma$ de $M$ for homeomorfo a $S^{n-1}$ ou a $D^{n-1}$. 


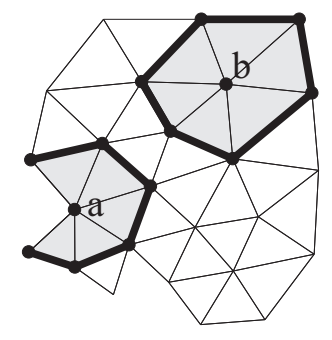

Figura 2.5: Estrela e link de vértices.

Definição 21 (Bordo de uma variedade combinatória) O bordo de uma variedade combinatória $M$ de dimensão $n$ é definido como o conjunto de todas as células cujo link é homeomorfo a $D^{n-1}$.

O bordo de uma variedade combinatória de dimensão $n$ é uma variedade combinatória de dimensão $(n-1)$ sem bordo. O bordo de uma superfície combinatória é um conjunto (possivelmente vazio) de curvas, onde cada uma é formada por um conjunto finito de arestas e vértices de bordo que formam uma curva simples fechada chamada de curvas de bordo. Uma aresta de uma superfície combinatória é dita do bordo se ela for incidente a uma única face, caso contrário a aresta é definida como do interior. Um vértice é de bordo se ele for incidente a uma aresta de bordo, caso contrário, o vértice é do interior.

Definição 22 (Variedade combinatória orientável) Uma variedade combinatória de dimensão n é orientável quando é possível escolher uma orientação coerente em suas n-células, isto é duas $n$-células adjacentes induzem orientaçôes opostas em suas $(n-1)$-células comuns.

Portanto, uma superfície combinatória orientável é aquela em que é possível orientar cada uma de suas faces de tal forma que uma aresta em faces adjacentes possui orientação oposta, isto é, uma aresta do interior incidente aos vértices $v_{a}$ e $v_{b}$ e às faces $f_{1}$ e $f_{2}$, possui duas orientações, uma de $v_{a}$ a $v_{b}$ na face $f_{1}$, e outra de $v_{2}$ a $v_{1}$ na face $f_{2}$. Quando a aresta é de bordo, ela possui uma orientação que é coerente com a orientação da face incidente a ela. Dá-se o nome de aresta orientada ou semi-aresta, à cada uma das orientações das arestas.

No restante deste texto, o termo curva referir-se-á a uma variedade combinatória de dimensão 1 orientada com ou sem bordo. O termo superfície referir-se-á a uma variedade combinatória de dimensão 2 orientada com ou sem bordo.

As malhas bidimensionais tratadas neste texto são variedades combinatórias de dimensão 2 orientada com ou sem bordo.

As malhas tridimensionais tratadas neste texto são variedades combinatórias de dimensão 3 orientada com bordo. 


\subsection{Notações}

No restante desta tese será utilizada a seguinte notação:

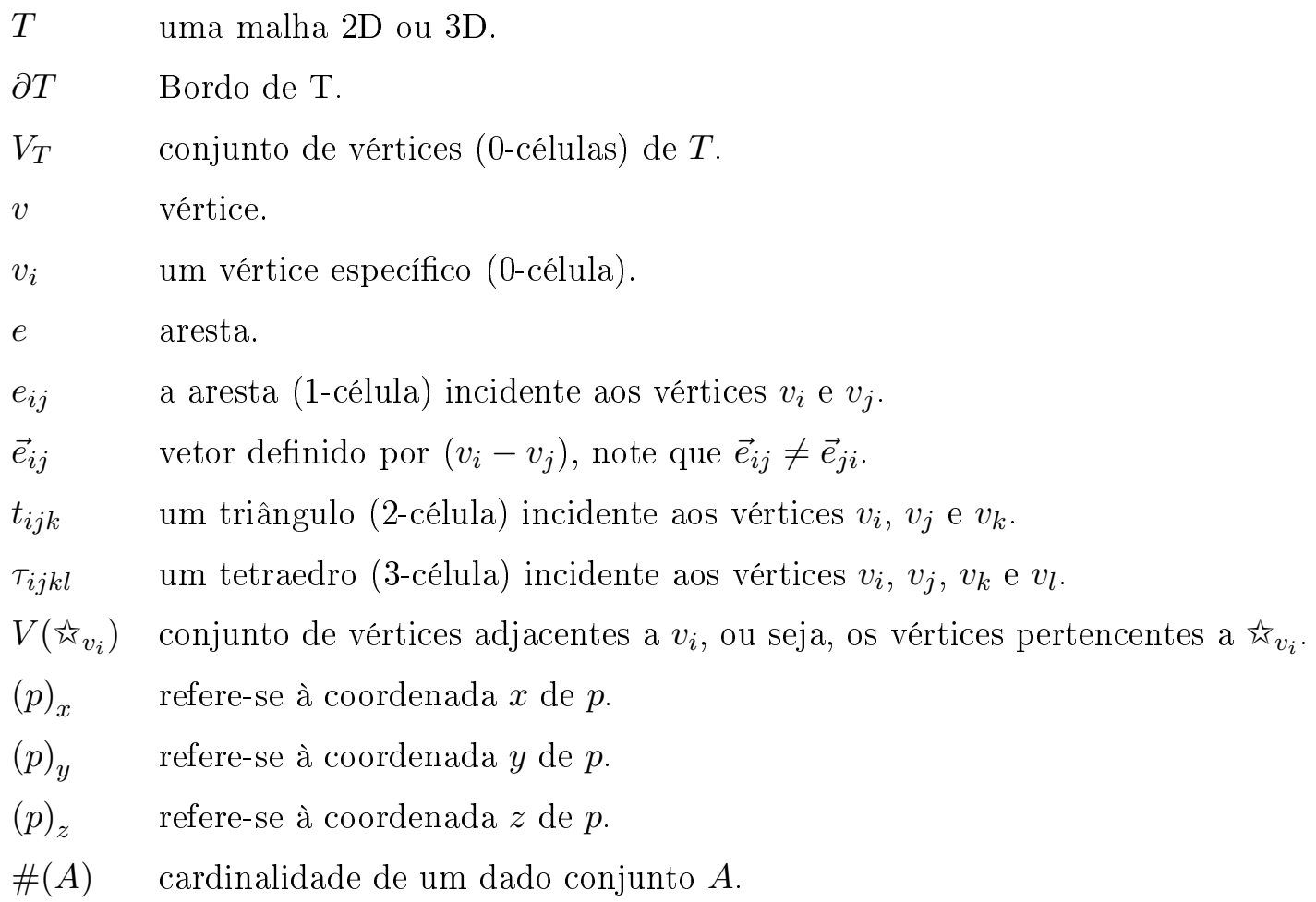

\subsection{Anisotropia}

Diferentemente da geometria euclidiana, onde a definição de distâncias é isotrópica e consideravelmente simples, a geometria riemanniana descreve espaços curvos. A anisotropia de distâncias, necessária para gerar malhas com triângulos esticados, é definida na geometria riemanniana por um tensor métrico $M$. Este tensor quantifica o "estiramento" desejado para os triângulos da malha.

Seja $\Omega$ o domínio de uma malha superficial em $R^{3}$. Qualquer função $H$ associando a cada ponto $w \in \Omega$ um tensor métrico positivo definido, denotado por $M_{w}$ define uma função de espaçamento. A notação $M_{w}$ será utilizada para denotar o tensor métrico $M$ associado ao ponto $w \in \Omega$, isto é, $H(w)=M_{w}$. O tensor métrico provém da geometria riemanniana e define anisotropia determinando como comprimentos e ângulos devem ser medidos.

O tensor métrico tridimensional $M$ é uma matriz $3 \times 3$ simétrica definida positiva. Sejam $\xi_{i}$ e $\vec{\nu}_{i}, i=1,2,3$, respectivamente, os autovalores (reais e positivos) e autovetores (unitários e ortogonais entre si) associados de $M$. Será utilizada a notação $\xi_{\min }$ e $\xi_{\max }$ para designar o menor e o maior autovalor de um tensor métrico $M$, e $\vec{\nu}_{\min }$ e $\vec{\nu}_{\max }$ seus respectivos autovetores 
unitários associados.

Em muitas situações, os autovalores e os autovetores de um tensor métrico são conhecidos, nestes casos, um tensor tridimensional pode ser construído da seguinte forma:

$$
\begin{aligned}
M & =\left[\begin{array}{lll}
\vec{\nu}_{1} & \vec{\nu}_{2} & \vec{\nu}_{3}
\end{array}\right]\left[\begin{array}{ccc}
\xi_{1} & 0 & 0 \\
0 & \xi_{2} & 0 \\
0 & 0 & \xi_{3}
\end{array}\right]\left[\begin{array}{ccc}
\vec{\nu}_{1} & \vec{\nu}_{2} & \vec{\nu}_{3}
\end{array}\right]^{t} \\
& =\xi_{1} \vec{\nu}_{1} \vec{\nu}_{1}^{t}+\xi_{2} \vec{\nu}_{2} \vec{\nu}_{2}^{t}+\xi_{3} \vec{\nu}_{3} \vec{\nu}_{3}^{t},
\end{aligned}
$$

onde $\vec{\nu}$ é uma matriz coluna e $\vec{\nu}^{t}$ é uma matriz quadrada $3 \times 3$.

Considere o seguinte exemplo para ilustrar como um tensor métrico influencia no formato de um triângulo. Seja um domínio bidimensional com anisotropia constante definida pelo seguinte tensor métrico bidimensional $M=\left[\begin{array}{ll}4 & 0 \\ 0 & 1\end{array}\right]$. Neste espaço, um triângulo com vértices $(1,1)$, $(3 / 2,1)$ e $(5 / 4, \sqrt{3} / 2)$ é eqüilátero. Pois, segundo a métrica, todas as arestas medem uma unidade.

Na geometria riemanniana, as operações geométricas básicas são redefinidas. Sejam dois vertores $\vec{a}$ e $\vec{b}$. O produto interno de $\vec{a}$ e $\vec{b}$ é dado por:

$$
\vec{a}^{t} \odot \vec{b}=\vec{a}^{t} M \vec{b}
$$

e o produto vetorial de $\vec{a}$ e $\vec{b}$ é dado por:

$$
\vec{a} \otimes \vec{b}=\sqrt{\operatorname{det}(M)}(\vec{a} \times \vec{b})
$$

onde $\operatorname{det}($.$) é o determinante de uma matriz e (.×.) é o produto vetorial no espaço euclidiano.$

\subsection{Medidas no espaço anisotrópico}

As medidas de distâncias, ângulos e áreas no espaço anisotrópico são realizadas de forma particular, como apresentadas nessa seção.

\subsubsection{Cálculo de distâncias}

Na geometria riemanniana, o comprimento $\ell$ de uma curva paramétrica $S(t)$ entre os pontos $x_{i}$ e $x_{j}$ segundo a métrica $M$, onde $t \in[0,1], S(0)=x_{i}$ e $S(1)=x_{j}$ é definida como:

$$
\ell(S)=\int_{0}^{1} \sqrt{\frac{d S^{t}}{d t} M_{S(t)} \frac{d S}{d t}} d t
$$


A distância entre dois pontos é dada pela menor curva paramétrica $S$, a qual é conhecida como curva geodésica. Observe que computar esta curva para uma métrica arbitrária não é trivial. Porém, uma aproximação pode ser feita computando-se o comprimento ao longo de uma curva mais simples, sem garantir que ela seja o menor caminho. Assim, a aproximação pode ser obtida pela integração ao longo do segmento de reta $S(t)=x_{i}+t\left(x_{j}-x_{i}\right)$. Considerando que a métrica $M$ varia linearmente entre quaisquer pontos $x_{i}$ e $x_{j}$ do domínio, então a distância entre os pontos pode ser definida por :

$$
\begin{aligned}
d_{i j} & =\int_{0}^{1} \sqrt{\left(\vec{r}_{i j}\right)^{t}\left[M_{i}+t\left(M_{j}-M_{i}\right)\right]\left(\vec{r}_{i j}\right)} d t \\
& =\int_{0}^{1} \sqrt{\left(d_{i j}^{i}\right)^{2}+t\left[\left(d_{i j}^{j}\right)^{2}-\left(d_{i j}^{i}\right)^{2}\right]} d t
\end{aligned}
$$

onde $\overrightarrow{r_{i j}}$ é o vetor saindo de $x_{i}$ para $x_{j}$, e

$$
d_{i j}^{k}=\sqrt{\left(\vec{r}_{i j}\right)^{t} M_{k}\left(\vec{r}_{i j}\right)}
$$

é a distância de $x_{i}$ a $x_{j}$ segundo a métrica $M_{k}$ definida em um ponto $k$ do domínio. Com mudanças apropriadas de variáveis, a Equação (2.7) pode ser reescrita como:

$$
d_{i j}=\frac{2}{3} \frac{\left(d_{i j}^{i}\right)^{2}+d_{i j}^{i} d_{i j}^{j}+\left(d_{i j}^{j}\right)^{2}}{d_{i j}^{i}+d_{i j}^{j}} .
$$

Assumindo que os pontos $x_{i}$ e $x_{j}$ estejam próximos uns dos outros e que a métrica varie pouco entre eles, aproximações mais grosseiras são possíveis. Por exemplo, a simples média aritmética das distâncias quando medidas segundo $x_{i}$ e $x_{j}$, isto é,

$$
d_{i j} \approx \frac{d_{i j}^{i}+d_{i j}^{j}}{2}
$$

ou a média aritimética das métricas, tal que

$$
d_{i j} \approx \sqrt{\left(\vec{r}_{i j}\right)^{t}\left(\frac{M_{i}+M_{j}}{2}\right)\left(\vec{r}_{i j}\right)} .
$$

\subsubsection{Cálculo de ângulos}

O ângulo $\theta_{a b c}^{k}$ entre os segmentos de reta $\overline{a b}$ e $\overline{b c}$ medido de acordo com a métrica $M_{k}$ é calculado da seguinte forma:

$$
\theta_{a b c}^{k}=\arccos \frac{(a-b)^{t} M_{k}(c-b)}{d_{a b}^{k} d_{c b}^{k}}
$$




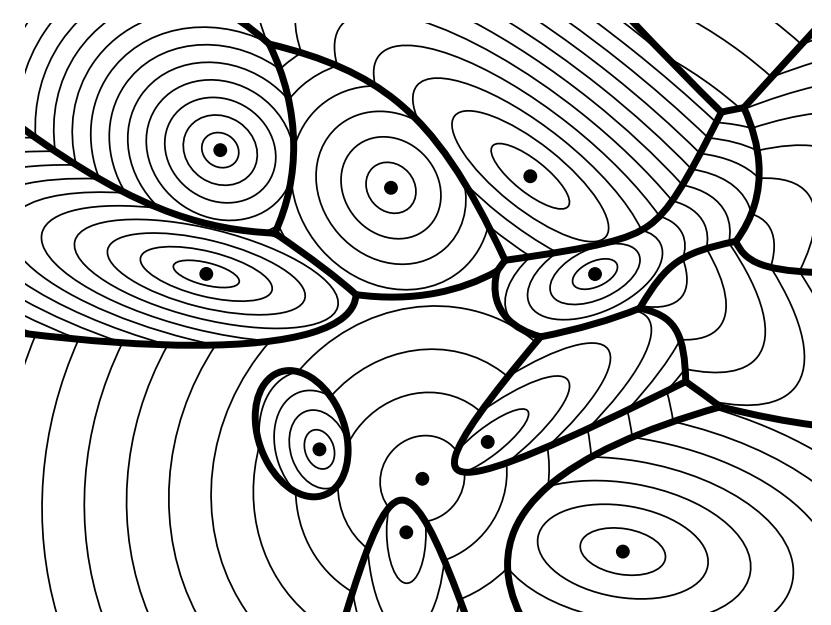

Figura 2.6: Representação da anisotropia por curvas de nível.

\subsection{Representação gráfica de um tensor métrico}

Uma das formas de representar a anisotropia em um ponto $w \in \Omega$ é descrevendo algumas curvas de nível da função $h(x)=x^{t} M_{w} x, x \in \Omega$. Note que uma curva de nível é formada por todos os pontos do domínio cuja distância de $w$ é igual a uma constante fixa, quando a distância é medida no espaço anisotrópico. A Figura 2.6 apresenta um exemplo em que a visualização por curvas de nível é empregada para visualizar uma aproximação do diagrama de Voronoi anisotrópico. As linhas de eqüidistância entre dois pontos estão em negrito.

Muito embora as curvas de nível ofereçam informações valiosas para analisar o comportamento da anisotropia, elas podem ser confusas em domínios tridimensionais. Uma alternativa é apresentar apenas uma curva de nível, mais especificamente, aquela cujos pontos distem de uma unidade do centro, isto é,

$$
\vec{r}_{w x}^{t} M_{w} \vec{r}_{w x}=1
$$

onde $\vec{r}_{w x}$ é o vetor de $w$ a $p$ (veja Equação (2.8)). A Figura 2.7 apresenta um exemplo da representação por elipsóide em um domínio 2D (a extensão para o caso 3D é imediata). Os raios do elipsóide podem ser calculados de acordo com autovalores de $M$ pela expressão

$$
r_{i}=1 / \sqrt{\xi_{i}}
$$

onde $r_{i}$ é o raio na direção do autovetor $\vec{\nu}_{i}$. Portanto, o menor raio do elipsóide está associado com o maior autovalor do tensor métrico.

Em malhas normalizadas, isto é, malhas em que todas as arestas têm comprimento unitário, a representação por elipsóide é apropriada. Pois, como todos os pontos sobre o elipsóide distam 


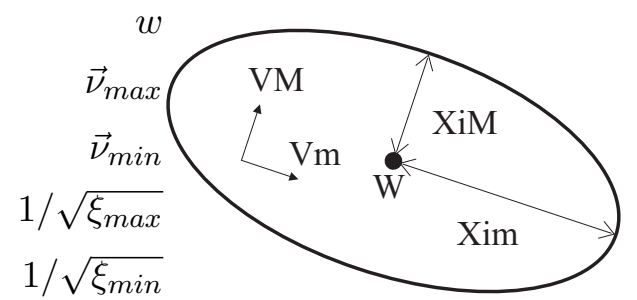

Figura 2.7: Representação por elipsóide 2D.

de uma unidade do centro, é possível estimar visualmente como vértices adjacentes devem estar separados uns dos outros.

Em malhas normalizadas, é importante determinar, no espaço euclidiano, qual deve ser o comprimento ideal de uma aresta em uma dada direção $\vec{d}$ segundo a anisotropia de um ponto $p \in \Omega, M_{p}$, tal valor é dado por:

$$
S_{p}(\vec{d})=\frac{1}{\sqrt{\vec{d}^{t} M_{p} \vec{d}}}
$$

\subsection{Função de espaçamento definida por meio de uma malha}

Como visto nas seções acima, são os tensores métricos que definem quais são os formatos e orientações dos elementos sobre um domínio. Embora seja possível associar tensores métricos a cada ponto do domínio explicitamente por meio de um conjunto de funções, esta não é a forma mais comumente utilizada. O que geralmente se faz é atribuir diretamente tensores a apenas alguns pontos do domínio e então fazer uso de interpolação para determiná-los para os demais pontos. Uma malha de fundo é utilizada para esse fim. Um tensor métrico é definido para cada vértice da malha de fundo, veja a Figura 2.8. Os tensores métricos para os outros pontos do domínio podem ser computados via interpolação linear. Por exemplo, considerando um triângulo $t_{a b c}$ da malha de fundo e um ponto $p \in t_{a b c}$, se $M_{a}, M_{b}$ e $M_{c}$ são os tensores métricos nos vértices de $t_{a b c}$, então o tensor métrico em $p$ pode ser interpolado pela seguinte equação:

$$
M_{p}=\frac{w^{a p} \cdot M_{a}+w^{b p} \cdot M_{b}+w^{c p} \cdot M_{c}}{w^{a p}+w^{b p}+w^{c p}}
$$

onde

$$
\begin{aligned}
w^{a p} & =\|(p-b) \times(c-b)\| \\
w^{b p} & =\|(p-c) \times(a-c)\| \\
w^{c p} & =\|(p-a) \times(b-a)\|
\end{aligned}
$$


Em alguns casos, as coordenadas baricêntricas de um ponto são conhecidas, e, neste caso, elas podem ser utilizadas para a interpolação. Assim, a Equação (2.16) pode ser simplificada para:

$$
M_{p}=\sum_{j=1}^{k} \lambda_{j} M_{j}
$$

onde $k=3 ; \sum_{j=1}^{k} \lambda_{j}=1$ e $\lambda_{j}$ é a coordenada baricêntrica de $p$ em $t_{123}$ associada ao vértice $v_{j}$ e $M_{j}$ é o tensor métrico associado ao vértice $v_{j}$ de $t_{123}$. Note que se $k=2$, a Equação $(2.17)$ interpola valores sobre retas.

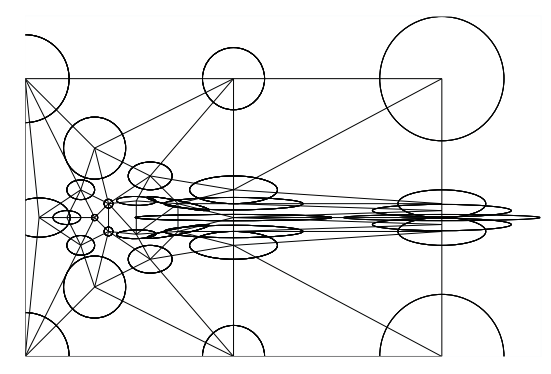

(a)

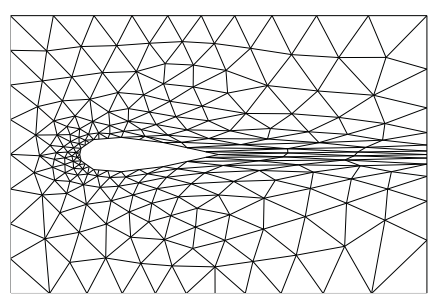

(b)

Figura 2.8: Exemplo de malha de fundo para definir a anisotropia sobre o domínio (a) e uma possível malha anisotrópica para o domínio (b) [14].

\subsection{O tensor métrico e a matriz hessiana}

Quando uma malha é usada para fazer uma interpolação linear por partes de uma determinada função, a precisão de tal aproximação depende do tamanho e formato dos elementos. Shewchuk [80] apresenta uma maneira de controlar a influência da geometria dos elementos na precisão da malha estimando-se limitantes para os erros na aproximação e medidas de qualidade dos elementos. Considere o exemplo apresentado na Figura 2.9, onde uma malha triangular define uma função linear por partes $g(x)$ que procura aproximar alguma função $f(x)$ que é uma descrição suave da superfície. Em muitas aplicações, a malha é utilizada como um suporte para se obter valores mediante interpolação. Por exemplo, é comum se ter valores conhecidos apenas nos vértices da malha e inferir valores nos outros pontos do domínio via interpolação. Observe que rasterização (rendering) de imagens é uma aplicação desse tipo, onde coordenadas, vetores normais, dentre outras entidades, são interpolados a fim de gerar uma imagem. Portanto, se 


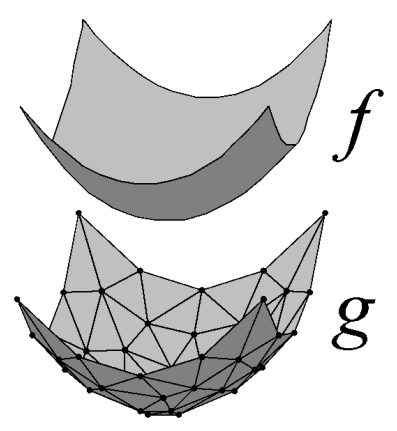

Figura 2.9: Aproximação por uma função linear por partes $g$ de uma função original $f$ [52].

a malha for utilizada para interpolação, um bom critério para se julgar a adequação da malha é verificar a diferença entre a função interpolada e a função original.

Seja $T$ uma malha triangular, $f(p)$ uma função escalar contínua definida sobre a malha. Seja gp uma aproximação linear por partes de $f(p)$, onde $g(v)=f(v)$ para cada vértice $v \in T$ e $g(p)$ é linear sobre cada elemento de $T$. O tensor métrico $M$ geralmente expressa os efeitos do formato do elemento no erro de interpolação. Portanto, $M_{p}$ está relacionada com a matriz hessiana de $f$ no ponto $p \in \Omega$, podendo inclusive ser a própria hessiana.

Seja $H_{p}$ a matriz hessiana de $f$ no ponto $p \in \Omega$. Suponha que $f$ satisfaz, de alguma forma, a seguinte restrição, para qualquer ponto $p \in \Omega$ e qualquer vetor direção $\vec{d}$ :

$$
\left|\vec{d}^{t} H_{p} \vec{d}\right| \leq \vec{d}^{t} M_{p} \vec{d}
$$

A inequação acima implica que a curvatura de $f$ no ponto $p$ ao longo da direção $\overrightarrow{\nu_{i}}$ não excede $\xi_{i}$. Mais especificamente, para qualquer vetor unitário $\vec{d}$, tem-se que:

$$
\vec{d}^{t} M_{p} \vec{d} \leq \xi_{\text {max }}
$$

assim, a curvatura máxima de $f$ no ponto $p \in \Omega$ é $\xi_{\max }$. Observe que se todos os autovalores $\xi_{i}$ forem iguais a 1 , então $M_{p}$ é o tensor identidade e o espaço é euclidiano.

Considere um ponto $p \in \Omega$. Como verificado na Equação (2.3), o tensor métrico $M_{p}$ pode ser construído a partir de um conjunto de autovalores e autovetores. O que significa que, se for possível estimar a matriz hessiana $H_{p}$, é possível gerar $M_{p}$ extraindo os autovalores (em módulo) e autovetores de $H_{p}$. Como afirmado anteriormente, diferente da hessiana, o tensor métrico $M_{p}$ deve ser uma matriz positiva definida, portanto, seus autovalores devem ser positivos $\left(\xi_{i}>0\right)$. Portanto, os autovalores de $f$, em módulo, servem como limitantes superiores para a magnitude das curvaturas de $f$ no ponto $p$ tomadas ao longo das direções definidas pelos autovetores. 


\subsubsection{Tensores de transformação}

Seja $E$ o tensor de transformação que faz o mapeamento de um ponto $p$ no espaço físico (o domínio onde a função $f$ está definida) em outro ponto $\widehat{p}$ no espaço isotrópico (onde se espera triângulos eqüiláteros). O tensor $E$ é dado por [80]:

$$
E=\sqrt{\left(\frac{1}{\xi_{\max }}\right) M}
$$

No caso bidimensional, o tensor de transformação $E$ fica:

$$
E=\left[\begin{array}{ll}
\vec{\nu}_{1} & \vec{\nu}_{2}
\end{array}\right]\left[\begin{array}{cc}
\sqrt{\xi_{1} / \xi_{\max }} & 0 \\
0 & \sqrt{\xi_{2} / \xi_{\max }}
\end{array}\right]\left[\begin{array}{ll}
\vec{\nu}_{1} & \vec{\nu}_{2}
\end{array}\right]^{t}
$$

Como $\overrightarrow{\nu_{1}}$ e $\overrightarrow{\nu_{2}}$ são vetores unitários ortogonais entre si, tem-se:

$$
E^{2}=\frac{1}{\xi_{\max }} M
$$

Portando $\widehat{p}=E$ E.p é a imagem no espaço isotrópico de um ponto $p$ qualquer no espaço físico. A notação $\widehat{t}$ refere-se à imagem no espaço isotrópico de um triângulo anisotrópico $t$.

\section{A constante de condicionamento de $M$}

Seja $\psi$ a constante de condicionamento do tensor métrico $M$ dada por [80]:

$$
\psi=\xi_{\max } / \xi_{\min }
$$

Algumas afirmações podem ser feitas com relação ao fator de encolhimento de uma aresta de um triângulo $t$ quando este é transformado em $\widehat{t}$ pela aplicação de $E$. O valor do fator de encolhimento pode ser de (Figura 2.10):

- no máximo $\sqrt{\psi}$, quando a aresta for paralela a $\vec{\nu}_{\min }$;

- no mínimo 1 , quando a aresta for paralela a $\vec{\nu}_{\max }$.

Se não for necessário preservar a curvatura máxima da função $f$ no espaço isotrópico, então o tensor de transformação $E$ pode ser simplificado. No caso bidimensional, o tensor métrico simplificado $F$ é definido por:

$$
F=\sqrt{M}
$$

No caso bidimensional, o tensor de transformação $F$ fica: 


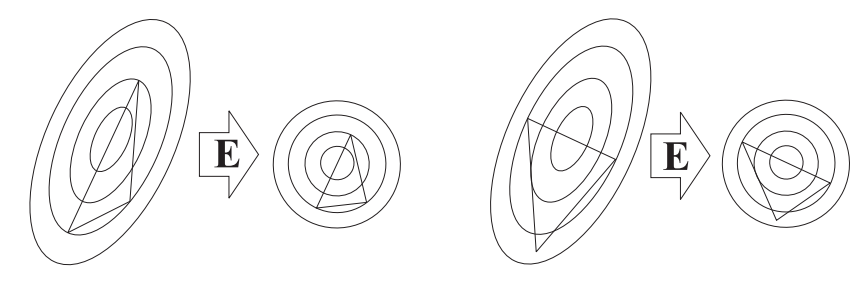

Figura 2.10: Fator de encolhimento de uma aresta.

$$
F=\left[\begin{array}{ll}
\overrightarrow{\nu_{1}} & \overrightarrow{\nu_{2}}
\end{array}\right]\left[\begin{array}{cc}
\sqrt{\xi_{1}} & 0 \\
0 & \sqrt{\xi_{2}}
\end{array}\right]\left[\begin{array}{ll}
\overrightarrow{\nu_{1}} & \overrightarrow{\nu_{2}}
\end{array}\right]^{t} .
$$

Como $\overrightarrow{v_{i}}$ são vetores unitários ortogonais entre si, tem-se que

$$
F^{2}=M
$$

Da mesma forma como $M_{p}$ representa o tensor métrico $M$ definido no ponto $p \in \Omega, E_{p}$ e $F_{p}$ designarão tensores de transformação referentes à métrica $M$ definida no ponto $p \in \Omega$.

\subsubsection{O tensor de deformação relativa}

Seja um ponto $p \in \Omega$. Se o tensor de transformação $F_{p}$ for aplicado, diz-se que o espaço é visto segundo a ótica do ponto $p$. O tensor de deformação relativa $F_{q} F_{p}^{-1}$ transforma o espaço a partir da ótica de $p$ para a ótica de $q$ [53], ou seja, faz com que o espaço passe a ser visto segundo a ótica do ponto $q$. A Figura 2.11 ilustra o relacionamento entre os tensores de deformação relativa $F_{q} F_{p}^{-1}$ e $F_{p} F_{q}^{-1}$ e os tensores de transformação $F_{q}$ e $F_{p}$.

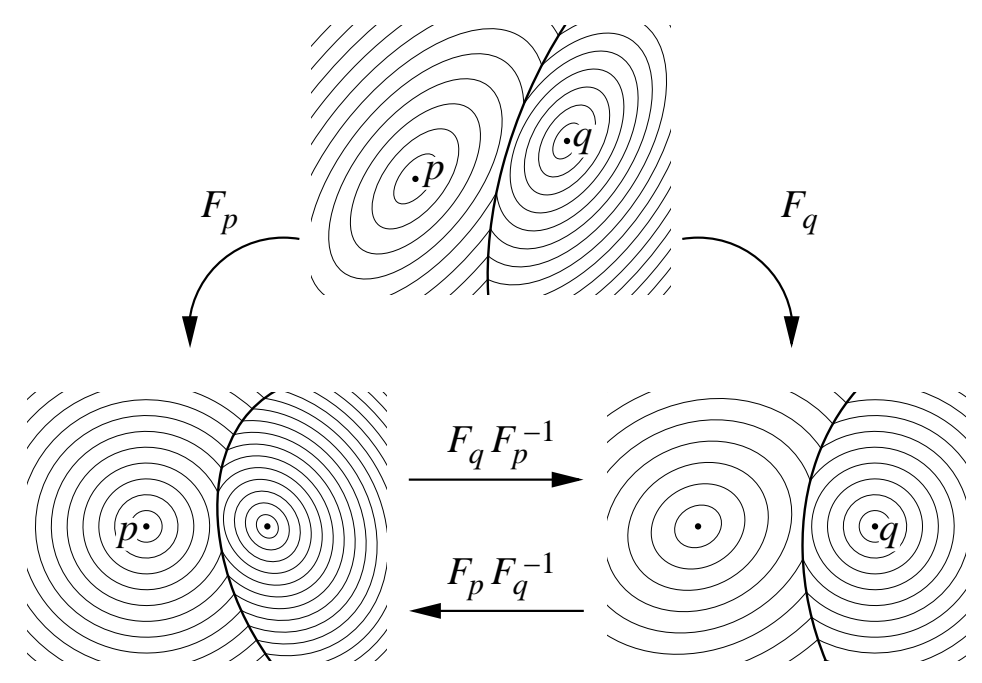

Figura 2.11: Tensores de deformação e tensores de deformação relativa [53]. 
As definições, conceitos e notações apresentadas neste capítulo serão utilizadas no restante desta tese. 


\section{Capítulo 3}

\section{Malhas Dinâmicas}

Malhas dinâmicas são comumente utilizadas em problemas de simulação sobre domínios cuja geometria varia com o tempo. Uma das formas mais comuns de implementar malhas dinâmicas é via distribuição de molas virtuais sobre os elementos da malha a ser reaproveitada. Sempre que o domínio onde a malha está definida é alterado, as molas são acionadas movimentando os vértices para que se conformem com a nova descrição do domínio. A Figura 3.1 ilustra o processo de movimento de malha para o caso bidimensional. A malha original (Figura 3.1(a)) tem suas fronteiras internas movimentadas (Figura 3.1(b)); note a presença de células sobrepostas. Após a aplicação do processo de malha dinâmica, os nós são movimentados para que a malha se conforme com a nova descrição do domínio (Figura 3.1(c)).

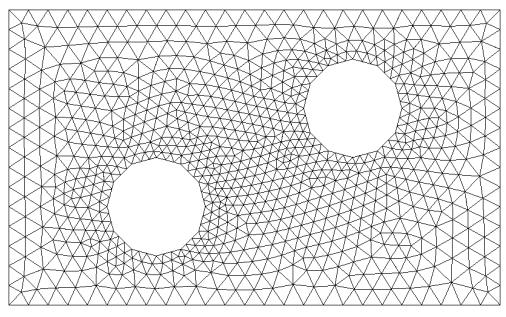

(a) Malha original

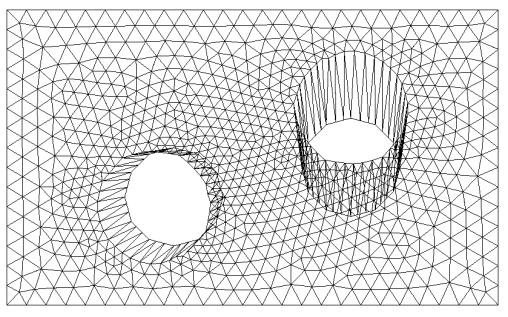

(b) Deformação no bordo

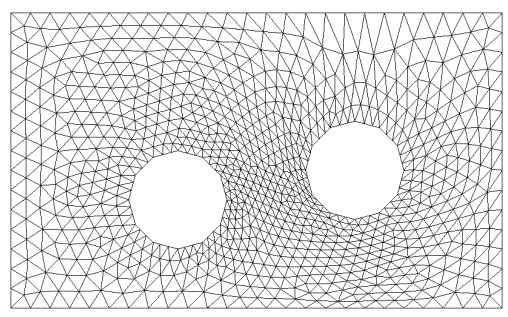

(c) Malha final movimentada

Figura 3.1: Movimento de uma malha bidimensional por malha dinâmica. 
A primeira proposta de malha dinâmica, e também a mais simples de ser implementada, é a composta por molas longitudinais. Por esse motivo, este tipo de mola será utilizado para descrever o funcionamento de malhas dinâmicas em geral, que será apresentado na subseção a seguir. Existem, porém, outros esquemas de molas mais eficazes como as torcionais, semitorcionais e altura, tais molas serão consideradas posteriormente.

Assumindo que as forças atuantes em um vértice tenham sido computadas de acordo com algum esquema de mola, é necessário formular alguma equação de movimento que possa reger o comportamento dinâmico dos vértices. Pela segunda lei de Newton tem-se que

$$
M \ddot{\Delta}=F
$$

onde $\Delta$ é o vetor deslocamento dos vértices da malha, $\dot{\Delta}$ é o vetor velocidade, $\ddot{\Delta}$ é o vetor aceleração, $M$ é a massa associada aos vértices e $F$ são as forças atuando nos vértices. Este modelo pode ser estendido para o tão conhecido caso massa-mola-amortecimento, onde a força $F$ é computada a partir das seguintes forças que agem nos vértices:

- $F_{K}$ : força entre-vértices. É análoga a uma mola e age entre vértices adjacentes.

- $F_{D}$ : força de amortecimento. É contrária ao movimento e contribui para a convergência do sistema.

Cada vértice $v_{i}$ possui três variáveis de estado, vetor deslocamento $\vec{\delta}_{i}$, vetor velocidade $\dot{\vec{\delta}}_{i}$, e vetor aceleração $\ddot{\vec{\delta}}_{i}$, e dois atributos, massa $m_{i}$ e coeficiente de amortecimento $d_{i}$. Uma das possíveis formas de simplificar o sistema é assumir que todos os vértices possuem a mesma massa e o mesmo coeficiente de amortecimento.

A força de amortecimento, $F_{D}$, contribui para a convergência dos vértices para uma configuração estável. Essa força é contrária ao movimento, proporcional à velocidade do vértice e é definida como:

$$
F_{D}=-D \dot{\Delta}
$$

onde $D$ é uma matriz contendo os coeficientes de amortecimento.

A força entre vértices é contrária ao deslocamento e proporcional ao coeficiente de resistividade, denotado por $K$, e é dada por

$$
F_{K}=-K \Delta \text {. }
$$

A força total $F$ agindo nos vértices é então dada por: 


$$
\begin{aligned}
F & =F_{K}+F_{D} \\
& =-K \Delta-D \dot{\Delta} .
\end{aligned}
$$

A equação final do sistema pode ser obtida substituindo a Equação (3.4) na Equação (3.1). Obtém-se, portanto, o seguinte sistema de equações diferenciais ordinárias de segunda ordem:

$$
M \ddot{\Delta}+D \dot{\Delta}+K \Delta=0
$$

Uma equação diferencial de primeira ordem também pode ser utilizada para formular o problema, como pode ser visto em [14, 106]. Embora esta simplificação ofereça mais chances da solução estacionar em um mínimo local, a formulação é mais estável numericamente. O movimento dos vértices passa a ser expresso pela seguinte equação:

$$
D \dot{\Delta}+K \Delta=0
$$

O problema pode ser simplificado ainda mais em um sistema conhecido como quase-estático [10, 36, 31], dado por

$$
F_{K}=K \Delta=0
$$

A formulação quase-estática é a mais amplamente utilizada em malhas dinâmicas e será a utilizada neste trabalho.

O sistema de equações (3.7) pode ser criado de várias maneiras. No restante deste capítulo são apresentas diferentes formas de se calcular as forças elásticas envolvidas considerando diferentes tipos de molas.

\subsection{O funcionamento das malhas dinâmicas}

Seja $\vec{f}$ uma componente da matriz $F_{K}$ da Equação (3.3). A força, $\vec{f}$, realizada por uma mola longitudinal é contrária ao deslocamento e é regida pela lei de Hook:

$$
\vec{f}=-\kappa \vec{\delta}
$$

onde $\kappa$ é o coeficiente de resistividade da mola e $\vec{\delta}$ representa a deformação na mola. A Figura 3.2 ilustra tal configuração. 


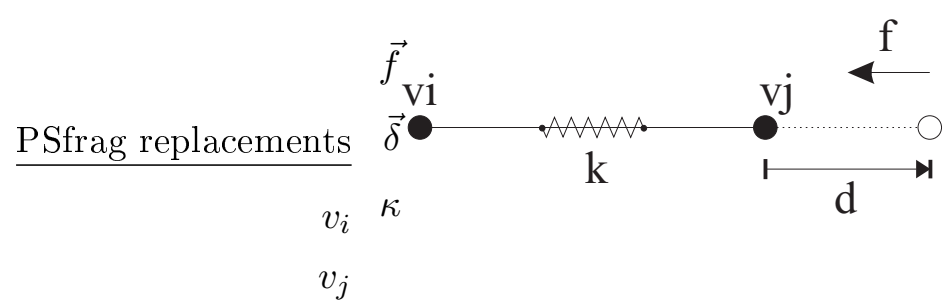

Figura 3.2: Força prod $\overrightarrow{f_{l}^{i}} \vec{i}$ ida segundo a lei de Hook pelo deslocamento de uma partícula.

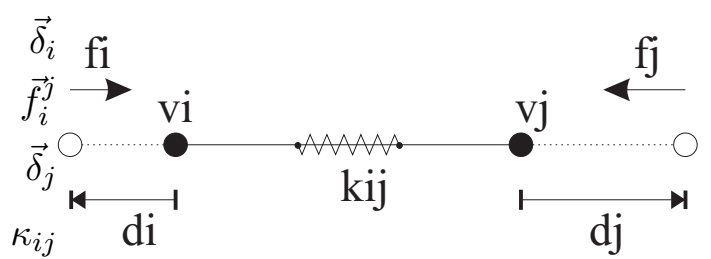

Figura 3.3: Sistema de duas partículas conectadas por uma mola longitudinal.

Batina em [9] foi possivelmente o primeiro pesquisador a utilizar a lei de Hook diretamente para implementar malhas dinâmicas. Ele propôs um método que manipula a malha como um sistema de molas fictícias onde cada aresta é vista como uma mola.

Para facilitar o entendimento de como a força pode ser calculada em um sistema de partículas, considere primeiramente um caso bem simples onde uma mola conecta duas partículas $v_{i}$ e $v_{j}$ que se movem, como ilustrado na Figura 3.3. A força em $v_{i}$ causada pelo deslocamento de $v_{j}$, denotada por $\vec{f}_{i}^{j}$, possui mesma direção e sentido do deslocamento $\vec{\delta}_{j}$, ou seja,

$$
\vec{f}_{i}^{j}=\kappa_{i j} \vec{\delta}_{j}
$$

Por outro lado, a força em $v_{i}$ causada pelo deslocamento do próprio vértice $v_{i}$, denotada por $\vec{f}_{i}^{i}$, possui mesma direção mas sentido contrário ao seu deslocamento $\vec{\delta}_{i}$, ou seja,

$$
\vec{f}_{i}^{\imath}=-\kappa_{i j} \vec{\delta}_{i}
$$

Portanto, a força resultante em $v_{i}$, denotada por $\vec{f}_{i}$, é dada por

$$
\overrightarrow{f_{i}}=\vec{f}_{i}^{j}+\vec{f}_{i}^{\imath}=\kappa_{i j}\left(\vec{\delta}_{j}-\vec{\delta}_{i}\right) .
$$

Considerando que a força resultante em um vértice é calculada apenas para as molas que incidem sobre ele, a própria conectividade da malha determina a influência entre vértices. Sendo assim, a força resultante exercida no vértice $v_{i}$ pode ser calculada por:

$$
\overrightarrow{f_{i}}=\sum_{v_{j} \in V\left(\vec{\sim}_{v_{i}}\right)} \kappa_{i j}\left(\vec{\delta}_{j}-\vec{\delta}_{i}\right) .
$$




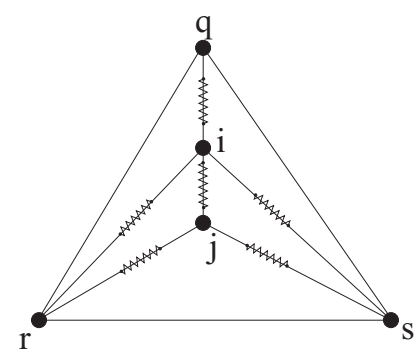

Figura 3.4: Sistema de molas.

onde $V\left(\widehat{\aleph}_{v_{i}}\right.$ ) é o conjunto de vértices adjacentes ao vértice $v_{i}$ (veja Capítulo 2). Um sistema de equações pode então ser montado considerando a força em cada nó da malha.

Suponha que $n$ seja o número de vértices do interior da malha e $m$ o número de vértices no bordo. O sistema de equações pode ser expresso matricialmente por (veja Equação (3.3))

$$
K \Delta=-F,
$$

onde $K$ é a matriz $(n \times n+m)$ dos coeficientes das molas, $\Delta$ é uma matriz $(n+m \times 1)$ com os vetores deslocamento dos vértices e $F$ é uma matriz $(n \times 1)$ com a força resultante em cada vértice.

Como o objetivo da malha dinâmica é encontrar uma disposição para os vértices do interior da malha, tal que a força resultante seja nula em cada um deles, o sistema tem os deslocamentos como incógnitas e as forças resultantes como vetores nulos. Sendo assim, todas as entradas da matriz $F$ da Equação (3.13) são vetores nulos.

Apenas para simplificar a escrita, considere que os $n$ vértices do interior da malha estejam agrupados da primeira coluna à $n$-ésima coluna de $K$. Dessa forma a Equação (3.13) pode ser expressa por

$$
\left[\begin{array}{c:c}
K_{I(n \times n)} & K_{B(n \times m)}
\end{array}\right] \cdot\left[\begin{array}{c}
\Delta_{I(n \times 1)} \\
\hdashline \Delta_{B(m \times 1)}
\end{array}\right]=\mathbf{0},
$$

onde a submatriz $K_{I}$ refere-se aos vértices do interior, a submatriz $K_{B}$ refere-se aos vértices do bordo, a submatriz $\Delta_{I}$ é composta pelos deslocamentos dos vértices do interior e a submatriz $\Delta_{B}$ é composta pelos deslocamentos dos vértices do bordo.

Para exemplificar as matrizes, considere a malha simples apresentada na Figura 3.4. A representação matricial do sistema para esse caso particular é dada por 


$$
\left[\begin{array}{cc:ccc}
-\sum_{v_{w} \in V\left(\varkappa_{w_{i}}\right)} \kappa_{i w} & \kappa_{i j} & \kappa_{i q} & \kappa_{i r} & \kappa_{i s} \\
\kappa_{i j} & -\sum_{v_{w} \in V\left(\varkappa_{j}\right)} \kappa_{j w} & 0 & \kappa_{j r} & \kappa_{j s}
\end{array}\right] \cdot\left[\begin{array}{c}
\vec{\delta}_{i} \\
\vec{\delta}_{j} \\
\hdashline \vec{\delta}_{q} \\
\vec{\delta}_{r} \\
\vec{\delta}_{s}
\end{array}\right]=\left[\begin{array}{c}
\overrightarrow{0} \\
\overrightarrow{0}
\end{array}\right]
$$

onde $w$ refere-se aos índices dos vértices obtidos de acordo com a conectividade da malha. As delimitações nas matrizes são para explicitar as submatrizes $K_{I}, K_{B}, \Delta_{I}$ e $\Delta_{B}$ conforme a Equação (3.14).

Observe que na Figura 3.4 não existem molas nas arestas do bordo. A razão para isso é que seus vértices possuem deslocamentos predefinidos que permanecem estáticos durante a solução da malha dinâmica. Portanto, as incógnitas são apenas duas neste exemplo, os deslocamentos dos dois vértices do interior $v_{i}$ e $v_{j}$. Sendo assim, as informações referentes aos vértices de bordo podem ser passadas para o lado direito da igualdade. O sistema (3.15) pode então ser reescrito da seguinte forma:

$$
\left[\begin{array}{cc}
-\sum_{v_{w} \in V\left(\varkappa_{v_{i}}\right)} \kappa_{i w} & \kappa_{i j} \\
\kappa_{j i} & -\sum_{v_{w} \in V\left(\text { 出 }_{j}\right)} \kappa_{j w}
\end{array}\right] \cdot\left[\begin{array}{c}
\vec{\delta}_{i} \\
\vec{\delta}_{j}
\end{array}\right]=\left[\begin{array}{c}
-\kappa_{i q} \vec{\delta}_{q}-\kappa_{i r} \vec{\delta}_{r}-\kappa_{i s} \vec{\delta}_{s} \\
-\kappa_{j r} \vec{\delta}_{r}-\kappa_{j s} \vec{\delta}_{s}
\end{array}\right]
$$

A matriz do lado esquerdo da igualdade é quadrada e simétrica, pois $\kappa_{i j}=\kappa_{j i}$. Além disso, ela é esparsa quando gerada a partir de malhas maiores.

A Equação (3.16) escrita em termos das submatrizes $K_{I}, K_{B}, \Delta_{I}$ e $\Delta_{B}$ é dada por

$$
K_{I} \cdot \Delta_{I}=-K_{B} \cdot \Delta_{B}
$$

No próximo capítulo serão apresentadas considerações sobre como o sistema da Equação (3.17) pode ser resolvido. Nas próximas seções são descritos alguns tipos de molas que podem ser usadas para compor o sistema.

\subsection{Molas longitudinais 2D}

Como mencionado anteriormente, as molas longitudinais foram propostas por Batina [9]. O autor propôs que os coeficientes de rigidez das molas sejam valores inversamente proporcionais ao comprimento de suas respectivas arestas. Assim, para uma aresta conectando os vértices $v_{i}$ e $v_{j}$, o coeficiente de rigidez da mola, denotado por $\kappa_{i j}$, é dado por: 


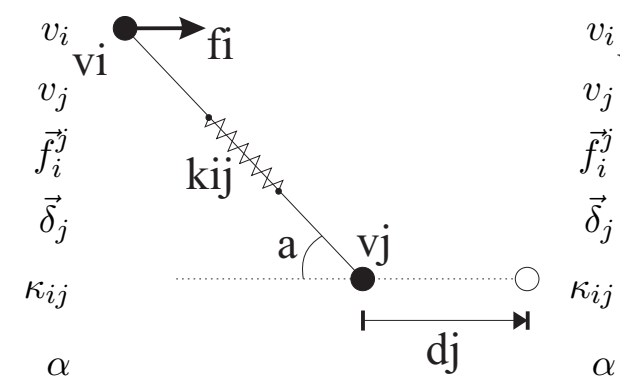

(a) Desacoplado

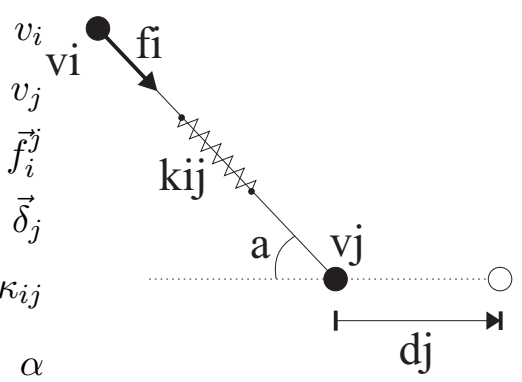

(b) Acoplado

Figura 3.5: Diferença entre desacoplamento e acoplamento de coordenadas em molas longitudinais.

$$
\kappa_{i j}=\frac{a}{\left(l_{i j}\right)^{b}}
$$

onde $l_{i j}$ é o comprimento da aresta ligando $v_{i}$ a $v_{j}$ e $a$ e $b$ são constantes (geralmente iguais a $1)$.

Considere que o domínio da malha está contido no plano $x y$. As notações ()$_{x}$ e ()$_{y}$ serão utilizadas para referir a uma coordenada específica. Por exemplo, $\left(\vec{\delta}_{i}\right)_{x}$ refere-se à coordenada $x$ do vetor deslocamento $\vec{\delta}_{i}$. A formulação de molas longitudinais descrita na Seção 3.1 trata cada componente da força separadamente, ou seja

$$
\begin{aligned}
& \left(\overrightarrow{f_{i}}\right)_{x}=\sum_{v_{j} \in V\left(\aleph_{i} v_{i}\right)} \kappa_{i j}\left[\left(\vec{\delta}_{j}\right)_{x}-\left(\vec{\delta}_{i}\right)_{x}\right] \\
& \left(\overrightarrow{f_{i}}\right)_{y}=\sum_{v_{j} \in V\left(\vec{\aleph}_{i}\right)} \kappa_{i j}\left[\left(\vec{\delta}_{j}\right)_{y}-\left(\vec{\delta}_{i}\right)_{y}\right] .
\end{aligned}
$$

Note que uma coordenada não interfere no cálculo da outra. Isso pode ser percebido na Figura 3.5 (a) onde o deslocamento horizontal em $v_{j}$ produz um deslocamento também horizontal em $v_{i}$

Essa formulação, no entanto, não simula o comportamento de uma rede de molas real, pois não há interação entre as coordenadas $x$ e $y$. Na Figura 3.5(b) é mostrado um exemplo em que o acoplamento é considerado e o deslocamento horizontal no vértice $v_{j}$ produz um deslocamento em ambas as direções no vértice $v_{i}$. Este acoplamento entre as duas direções pode ser feito da seguinte forma: 


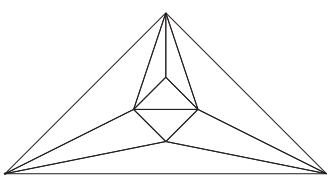

(a) Original

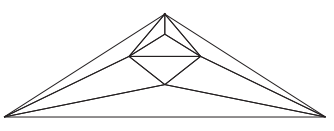

(c) Acoplado

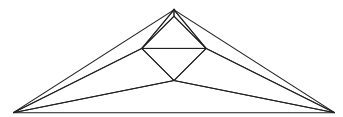

(b) Deslocamento

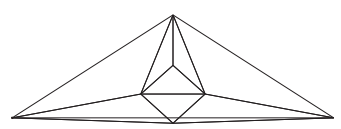

(d) Desacoplado

Figura 3.6: Diferença entre utilizar e não utilizar o acoplamento de coordenadas em molas longitudinais.

$$
\begin{aligned}
& \left(\vec{f}_{i}\right)_{x}=\sum_{v_{j} \in V\left(\Downarrow_{i} v_{i}\right)} \kappa_{i j}\left[\left(\vec{\delta}_{j}-\vec{\delta}_{i}\right)_{x} \cos \alpha+\left(\vec{\delta}_{j}-\vec{\delta}_{i}\right)_{y} \operatorname{sen} \alpha\right] \cos \alpha \\
& \left(\vec{f}_{i}\right)_{y}=\sum_{v_{j} \in V\left(\Downarrow_{\varkappa} v_{i}\right)} \kappa_{i j}\left[\left(\vec{\delta}_{j}-\vec{\delta}_{i}\right)_{x} \operatorname{sen} \alpha+\left(\vec{\delta}_{j}-\vec{\delta}_{i}\right)_{y} \operatorname{sen} \alpha\right] \cos \alpha
\end{aligned}
$$

A diferença entre usar ou não o acoplamento pode ser conferida visualmente na Figura 3.6. A malha original é apresentada na Figura 3.6(a). Apenas o vértice do topo foi deslocado verticalmente para baixo (veja a Figura 3.6(b)). As Figuras 3.6(c) e 3.6(d) apresentam, respectivamente, os resultados após aplicar o movimento desacoplado e acoplado.

Muito embora o acoplamento produza um comportamento mais próximo do real, ele não é aconselhável em configurações envolvendo grandes deformações. Nesses casos, as molas não são capazes de resolver sobreposição de células. Este problema pode ser visto na Figura 3.7. A malha original é apresentada na Figura 3.7(a). Apenas o bordo interior foi deslocado horizontalmente para a direita, como apresentado na Figura 3.7(b). Note que o deslocamento é o suficiente para causar sobreposição de células (regiões em destaque nas Figuras 3.7(b) e 3.7(c)). As Figuras 3.7(c) e 3.7(d) apresentam os resultados após aplicar o movimento com molas longitudinais com e sem acoplamento de coordenadas, respectivamente.

Para várias aplicações, as molas longitudinais produzem bons resultados, desde que o deslocamento inicial tenha uma amplitude relativamente pequena. Quando isso não acontece, é comum o surgimento de elementos inválidos causados pelo cruzamento de vértices sobre arestas. Fato que é causado porque a tensão da mola longitudinal previne que dois vértices adjacentes se colidam, porém não impede que um vértice cruze uma de suas arestas opostas, 


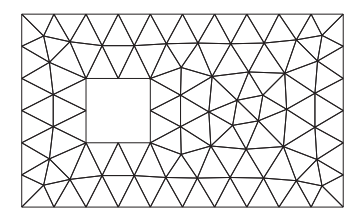

(a) Original

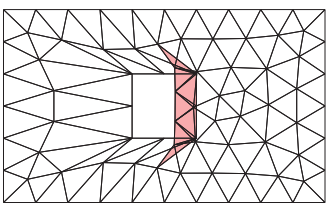

(c) Acoplado

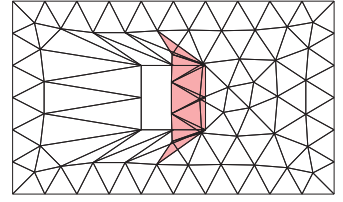

(b) Deslocamento

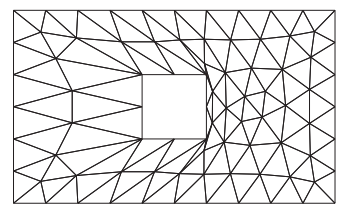

(d) Desacoplado

Figura 3.7: Diferença entre utilizar e não utilizar o acoplamento de coordenadas em molas longitudinais.

causando sobreposição de células. A sobreposição de células é caracterizada pela presença de células inválidas. A Figura 3.8 ilustra um caso em que o movimento de um vértice causa o surgimento de uma célula inválida (em destaque). Alguns métodos foram propostos para contornar esse problema, como será descrito nas próximas seções.

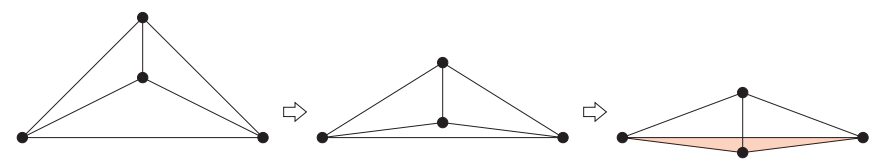

Figura 3.8: As molas longitudinais não impedem o surgimento de célula inválida.

\subsection{Molas para tratar triângulos inválidos}

A principal deficiência da mola longitudinal se deve ao fato da mesma não considerar em sua formulação as áreas dos elementos envolvidos. Assim, um triângulo pode estar próximo de apresentar área nula (ou mesmo razão de aspecto ruim) e este evento não ser notado pelas molas longitudinais. Nesta seção serão apresentadas algumas abordagens que levam em consideração as áreas dos elementos em suas formulações a fim de propiciar malhas de melhor qualidade após o movimento, podendo até mesmo impedir o surgimento de elementos inválidos em muitos casos. 


\subsubsection{Molas torcionais}

Diferentemente das molas longitudinais, que controlam comprimentos, as molas torcionais controlam ângulos. O emprego dessas molas em malhas dinâmicas foi proposto por Farhat et al. [36]. As molas torcionais e longitudinais se complementam para compor o sistema, ou seja, os dois tipos de molas agem em conjunto.

Considere o triângulo $t_{i j k}$ cujos vértices são designados por $v_{i}, v_{j}$ e $v_{k}$. Seja $\theta_{i}^{i j k}$ o ângulo entre as arestas $e_{i j}$ e $e_{i k}$. Seja $A\left(t_{i j k}\right)$ a área do triângulo $t_{i j k}$. O coeficiente da mola torcional no vértice $v_{i}$ do triângulo $t_{i j k}$ é dado por:

$$
C_{i}^{i j k}=\frac{1}{1+\cos \left(\theta_{i}^{i j k}\right)} \frac{1}{1-\cos \left(\theta_{i}^{i j k}\right)}=\frac{1}{\operatorname{sen}\left(\theta_{i}^{i j k}\right)^{2}}=\frac{\left(e_{i j}\right)^{2}\left(e_{i k}\right)^{2}}{4 A\left(t_{i j k}\right)^{2}}
$$

conforme ilustrado na Figura 3.9. Observe que o coeficiente tende a infinito quando o ângulo

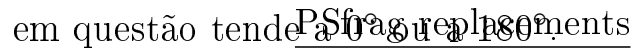

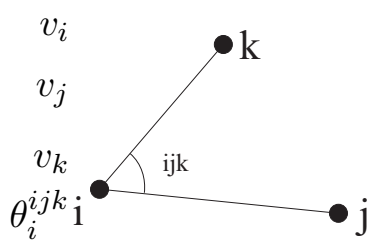

Figura 3.9: Ilustração de uma mola torcional.

Para montar o sistema de molas, é necessário anexar uma mola torcional para cada ângulo interno de cada triângulo da malha. Portanto, em cada vértice da malha é atribuida uma mola torcional para cada triângulo incidente.

Tendo em vista que as molas torcionais são apenas complementares, é necessário compor um sistema formado tanto por molas longitudinais quanto torcionais. No entanto, esta não é uma tarefa simples, pois as forças são calculadas seguindo formulações distintas em cada tipo de mola. No caso das torcionais, deslocamentos geram momentos. Os autores então aplicaram transformações nas forças torcionais para compor o sistema.

Considere um triângulo $t_{i j k}$. Os torques gerados nos vértices do triângulo (assumindo que cada ângulo interno possui uma mola torcional) são dados por:

$$
\mathbf{M}^{i j k}=\mathbf{C}^{i j k} \Delta \theta^{i j k}
$$

onde 


$$
\begin{aligned}
\mathbf{M}^{i j k} & =\left[M_{i} M_{j} M_{k}\right]^{t} ; \\
\mathbf{C}^{i j k} & =\left[\begin{array}{ccc}
C_{i}^{i j k} & 0 & 0 \\
0 & C_{j}^{i j k} & 0 \\
0 & 0 & C_{k}^{i j k}
\end{array}\right] \\
\Delta \theta^{i j k} & =\mathbf{R}^{i j k} \Delta^{i j k}
\end{aligned}
$$

sendo que $M_{w}, w=i, j, k$, é o torque no vértice $v_{w}, \Delta^{i j k}$ contém os vetores deslocamentos em cada vértice do triângulo e $\mathbf{R}^{i j k}$ é uma matriz de rotação. Vale dizer que no desenvolvimento para se chegar à matriz $\mathbf{R}$ os autores assumem pequenos deslocamentos e rotações, o que sugere que o método deve ser utilizado apenas em aplicações onde o domínio sofre pequenas deformações. Os momentos são então expressos por:

$$
\mathbf{M}^{i j k}=\left[\mathbf{C}^{i j k} \mathbf{R}^{i j k}\right] \Delta^{i j k}
$$

Os torques devem ser convertidos em forças torcionais equivalentes nos vértices, dadas por:

$$
\mathbf{F}_{\text {torção }}^{i j k}=\left[\begin{array}{c}
\left(\mathbf{F}_{i}\right)_{x} \\
\left(\mathbf{F}_{i}\right)_{y} \\
\left(\mathbf{F}_{j}\right)_{x} \\
\left(\mathbf{F}_{j}\right)_{y} \\
\left(\mathbf{F}_{k}\right)_{x} \\
\left(\mathbf{F}_{k}\right)_{y}
\end{array}\right] .
$$

Aplicando-se uma transformação linear da forma

$$
\mathbf{F}_{\text {torção }}^{i j k}=\mathbf{T}^{i j k} \mathbf{M}^{i j k}
$$

e assumindo que o trabalho realizado por $\mathbf{F}_{\text {torção }}^{i j k}$ e por $\mathbf{M}^{i j k}$ são equivalentes, isto é

$$
\begin{aligned}
\left(\mathbf{F}_{\text {torção }}^{i j k}\right)^{t} \Delta^{i j k} & =\left(\mathbf{M}^{i j k}\right)^{t} \Delta \theta^{i j k} \\
\left(\mathbf{M}^{i j k}\right)^{t}\left(\mathbf{T}^{i j k}\right)^{t} \Delta^{i j k} & =\left(\mathbf{M}^{i j k}\right)^{t} \mathbf{R}^{i j k} \Delta^{i j k}
\end{aligned}
$$

tem-se que $\mathbf{T}^{i j k}=\left(\mathbf{R}^{i j k}\right)^{t}$. Finalmente, as forças torcionais nos vértices do triângulo $t_{i j k}$ podem ser expressas por:

$$
\mathbf{F}_{\text {torção }}^{i j k}=\left[\left(\mathbf{R}^{i j k}\right)^{t} \mathbf{C}^{i j k} \mathbf{R}^{i j k}\right] \Delta^{i j k}=\mathbf{K}_{\text {torção }}^{i j k} \Delta^{i j k} \text {. }
$$




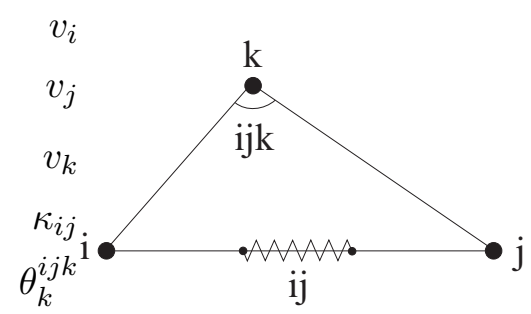

Figura 3.10: Mola semi-torcional proposta por Blom [10].

É possível extrair da Equação (3.30) a força torcional aplicada apenas no vértice $v_{i}$ da seguinte forma:

$$
\mathbf{F}_{\text {torção }}^{i}=\left[\mathbf{B}_{i}^{i j k} \mathbf{K}_{\text {torção }}^{i j k}\right] \Delta^{i j k}
$$

onde $\mathbf{B}_{i}^{i j k}$ é um operador para extrair a subcomponente associada com o vértice $v_{i}$.

A força total no vértice $v_{i}$ é dada pela soma de todas as forças longitudinais e torcionais que agem no vértice, ou seja

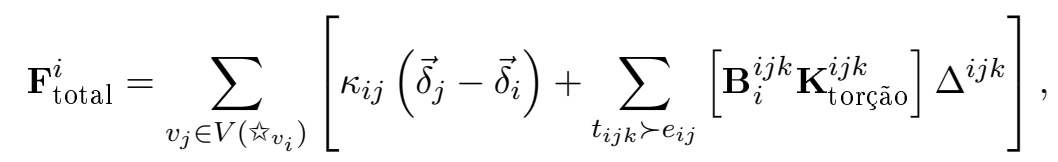

onde $\kappa_{i j}$ (ver Equação (3.18)) é o coeficiente de resistividade da mola longitudinal entre os vértices $v_{i}$ e $v_{j}$. A expressão $t_{i j k} \succ e_{i j}$ refere-se a todos os triângulos que incidem em uma dada aresta $e_{i j}$, no caso de uma triangulação bidimensional, tem-se geralmente dois triângulos.

\subsubsection{Molas semi-torcionais}

Blom [10], motivado pelo trabalho de Farhat et al. [36] descrito na seção anterior, propôs uma abordagem simplificada para agregar a informação dos ângulos num sistema composto por molas longitudinais. Ele denominou essa mola simplificada como semi-torcional. A idéia por trás das molas semi-torcionais é fazer com que os ângulos influenciem os coeficientes das molas longitudinais, sendo assim, o sistema contém, na realidade, apenas molas longitudinais. Para isso, Blom dividiu o coeficiente de resistividade da mola longitudinal pelo valor do ângulo oposto. Considere a Figura 3.10. O coeficiente da mola longitudinal na aresta $e_{i j}$ é dividido pelo valor do ângulo interno do triângulo $t_{i j k}$ em $v_{k}\left(\theta_{k}^{i j k}\right)$. O coeficiente de resistividade da mola semi-torcional de Blom, denominado $\kappa^{\text {Blom }}$, é dado por:

$$
\kappa_{i j}^{B l o m}=\frac{\kappa_{i j}}{\theta_{k}^{i j k}}
$$


Note que $\kappa^{\text {Blom }}$ quase não é alterado quando o triângulo em questão é eqüilátero, pois $\theta_{i}^{i j k}=\theta_{j}^{i j k}=\theta_{k}^{i j k}$. Quanto mais agudo for o ângulo, mais firme se torna a mola. Porém, quanto mais obtuso for o ângulo, menos rígida fica a mola, o que claramente não é desejado. Além disso, o autor não esclarece como calcular $\kappa^{\text {Blom }}$ de arestas internas, pois existem dois ângulos opostos simultaneamente.

Uma melhoria nas molas semi-torcionais foi introduzida por Zeng e Ethier [111]. A idéia básica consiste em adicionar diretamente o coeficiente de uma mola torcional ao coeficiente da mola longitudinal oposta. Assim, o coeficiente de rigidez longitudinal total $\kappa_{i j}^{\text {total }}$ da mola ligando os vértices $v_{i}$ e $v_{j}$ é dado por (veja a Figura 3.11):

$$
\kappa_{i j}^{\text {total }}=\kappa_{i j}+C_{k}^{i j k}+C_{l}^{i j l}
$$

onde $C$ é o coeficiente de rigidez da mola torcional apresentado na Equação (3.21).

No restante deste texto, o termo mola semi-torcional refere-se à proposta de Zeng e Ethier [111].

As molas semi-torcionais possuem algumas vantagens sobre as molas torcionais de Farhat et al. [36]. Elas são mais fáceis de serem implementadas computacionalmente. Segundo [112], são necessárias 72 adições e 117 multiplicações por elemento para se calcular o coeficiente de rigidez das molas torcionais, enquanto que apenas 18 adições e 20 multiplicações são necessárias para as molas sempiptarcionais Além disso, a formulação das molas semi-torcionais não assumem pequenos deslocamentos e ânguloss, o que sugere que as mesmas podem ser aplicadas para grandes deformações. Em contrapartida, sabe-se que o enrigecimento de molas longitudinais não é suficiente para evitar o surgimento de elementos inválidos em todos os casos.

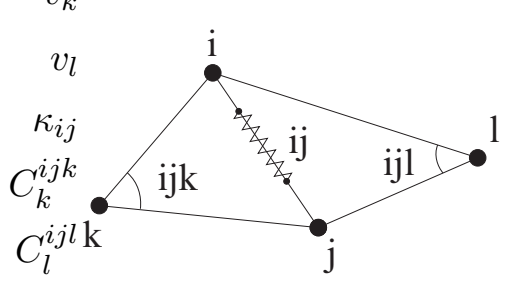

Figura 3.11: As molas torcionais em $v_{k}$ e $v_{l}$ são agregadas à mola longitudinal na aresta $e_{i j}$.

\subsubsection{Molas altura}

Neste trabalho de doutorado também foi desenvolvida uma mola para evitar elementos inválidos, são as molas altura. Ao invés de controlar as áreas dos triângulos por meio de ângulos, como o fazem as molas torcionais e semi-torcionais, o controle é feito verificando-se as alturas 


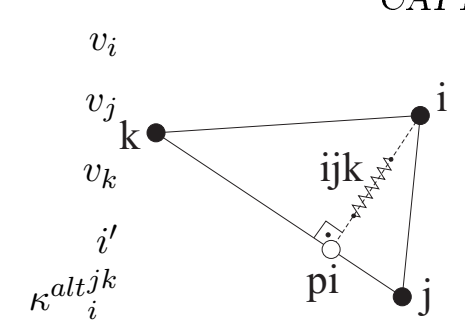

Figura 3.12: Ilustração de uma mola altura.

dos triângulos. A mola altura é na verdade uma mola longitudinal ligando um vértice à sua projeção na aresta oposta. A Figura 3.12 ilustra uma mola altura posicionada para evitar que o vértice $v_{i}$ cruze a aresta oposta $e_{j k}$. Cada triângulo é equipado com três molas altura, uma para cada vértice.

A força gerada em um vértice $v_{i}$ por uma mola altura ligando $v_{i}$ à sua projeção $i^{\prime}$ na reta definida por $v_{j}$ e $v_{k}$, conforme ilustrado na Figura 3.12, é dada por

$$
\vec{f}_{i}^{j k}=\kappa_{i}^{a l t j k}\left(\vec{\delta}_{i^{\prime}}-\vec{\delta}_{i}\right)
$$

onde $\vec{\delta}_{i^{\prime}}$ é calculado como sendo a interpolação linear dos vetores deslocamentos $\vec{\delta}_{j}$ e $\vec{\delta}_{k}$ dos vértices $v_{j}$ e $v_{k}$, respectivamente. Sendo assim, o vetor $\vec{\delta}_{i^{\prime}}$ é dado por:

$$
\vec{\delta}_{i^{\prime}}=\lambda \vec{\delta}_{j}+(1-\lambda) \vec{\delta}_{k}
$$

onde, o valor de $\lambda$ varia de 0 a 1 e depende da posição do ponto $i^{\prime}$ com relação aos vértices $v_{j}$ e $v_{k}$, e é dado por

$$
\lambda= \begin{cases}0, & \text { se }\left\|i^{\prime}-v_{k}\right\|>\left\|\vec{e}_{j k}\right\| \text { e }\left\|i^{\prime}-v_{k}\right\|>\left\|i^{\prime}-v_{j}\right\|, \\ \left\|i^{\prime}-v_{k}\right\| /\left\|\vec{e}_{j k}\right\|, & \text { se }\left\|i^{\prime}-v_{k}\right\| \leq\left\|\vec{e}_{j k}\right\| \text { e }\left\|i^{\prime}-v_{j}\right\| \leq\left\|\vec{e}_{j k}\right\|, \\ 1, & \text { se }\left\|i^{\prime}-v_{j}\right\|>\left\|\vec{e}_{j k}\right\| \text { e }\left\|i^{\prime}-v_{j}\right\|>\left\|i^{\prime}-v_{k}\right\| .\end{cases}
$$

Como a mola altura é uma mola longitudinal, seu coeficiente de rigidez $\kappa^{a l t}{ }_{i}^{j k}$ é calculado de forma semelhante à Equação (3.18) e é dado por

$$
\kappa_{i}^{a l t}{ }_{i}^{j k}=\frac{1}{\left\|i^{\prime}-v_{k}\right\|}
$$

Semelhantemente às molas torcionais e semi-torcionais, as molas altura também devem complementar um sistema composto por molas longitudinais.

Bottasso et al. [17] propuseram um método intitulado Ball-vertex que emprega uma abordagem parecida com a da mola altura. A diferença entre o Ball-vertex e a mola altura é sutil, 
porém com grandes implicações na qualidade da malha movimentada, como será mostrado a seguir. A versão de Bottasso projeta o deslocamento interpolado em $i^{\prime}$ sobre a reta definida por $v_{i}$ e $i^{\prime}$, ou seja, a força no vértice $v_{i}$ é dada por:

$$
\vec{f}_{B_{i}}^{j k}=\kappa_{i}^{a l t j k}\left[\left(\vec{\delta}_{i^{\prime}}-\vec{\delta}_{i}\right) \frac{\vec{e}_{i i^{\prime}}}{\left\|\vec{e}_{i i^{\prime}}\right\|}\right] \frac{\vec{e}_{i i^{\prime}}}{\left\|\vec{e}_{i i^{\prime}}\right\|}
$$

Note que a projeção não acontece na Equação (3.35). Além disso, na Ball-vertex, o valor de $\lambda$ na interpolação do vetor deslocamento em $i^{\prime}$ não é restringido entre 0 e 1.

A Figura 3.13 apresenta visualmente a diferença entre empregar a mola altura proposta nesta tese e o método Ball-vertex de Bottasso et al. [17]. Em ambos os casos, o domínio da malha foi submetido à mesma deformação e o sistema linear foi resolvido de forma semelhante. É possível notar que o método Ball-vertex não foi capaz de movimentar a malha sem o surgimento de elementos negativos, os quais estão em destaque na Figura 3.13(b). Note porém, que nenhum elemento negativo é gerado se as molas altura forem empregadas, veja a Figura 3.13(c). Além disso, também foram realizados testes com deformações pequenas no domínio (cerca de 10 vez menor que o empregado na Figura 3.13), mas a qualidade da malha movimentada é superior quando molas altura são empregadas.

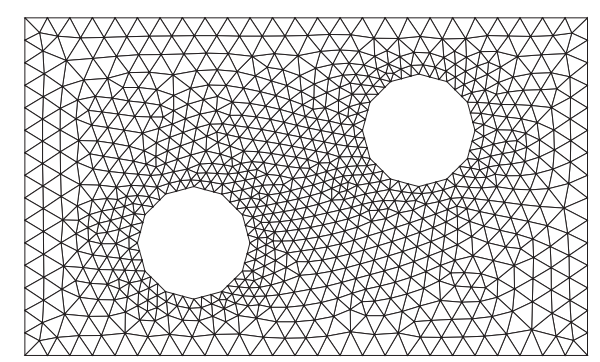

(a) malha original

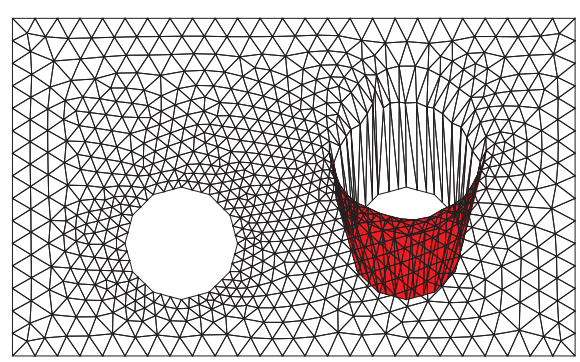

(b) Ball-vertex

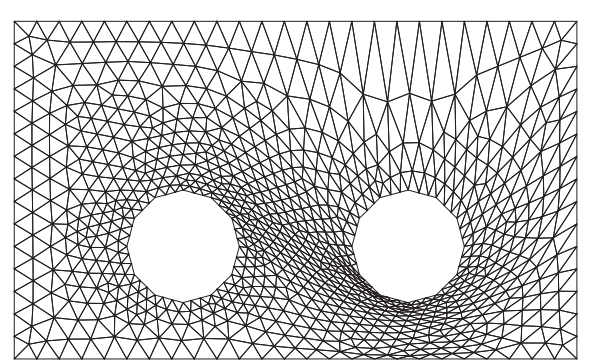

(c) Mola altura

Figura 3.13: Comparação entre a mola altura e o método Ball-vertex de Bottasso et al. [17]. 


\subsection{Comparação entre molas}

Nesta seção é feita uma comparação entre os resultados gerados pela aplicação de malhas dinâmicas com diferentes configurações de molas. As configurações comparadas são as seguintes:

1. Configuração 1: Molas longitudinais,

2. Configuração 2: Molas semi-torcionais,

3. Configuração 3: Molas longitudinais e molas semi-torcionais,

4. Configuração 4: Molas altura, e

5. Configuração 5: Molas longitudinais e molas altura.

A qualidade das malhas é aferida por duas métricas distintas: ângulo mínimo e razão de aspecto. A primeira avalia a qualidade dos triângulos pelo valor do menor ângulo interno. A segunda, mede a razão de aspecto, $Q_{R A}$, do triângulo de acordo com a seguinte fórmula:

$$
Q_{R A}=\frac{A}{\ell_{\max }^{2}},
$$

onde $A$ é a área do triângulo e $\ell_{\max }$ o comprimento de sua maior aresta.

O valor do ângulo mínimo varia, obviamente, entre $0^{\circ}$ e $60^{\circ}$. A razão de aspecto varia de 0 a 1 , pois o valor foi normalizado de acordo com a qualidade do triângulo eqüilátero, que é 0.433013. Quanto maior for o valor das medidas, melhor a qualidade dos triângulos.

Em [80], Shewchuk mostra gráficos de isolinhas de várias medidas de qualidade de triângulos, incluindo as duas utilizadas aqui. As Figuras 3.14(a) e 3.14(b) foram extraídas de [80] e consideram fixos dois vértices nas coordenadas $(0,0)$ e $(1,0)$ do triângulo enquanto que o terceiro vértice pode variar livremente. Os gráficos mostram o valor das métricas em função da posição do terceiro vértice.

A Figura 3.15 mostra um exemplo onde o domínio da malha sofre uma grande deformação, em que o círculo interior da esquerda é movido em direção ao círculo da direita. Note que a malha original é de boa qualidade e possui refinamento diferenciado sobre o domínio. Foi utilizada uma grande deformação para explicitar as diferenças entre os resultados. Trata-se, porém, de uma deformação abusiva que requer a utilização de mecanismos mais sofisticados para controlar a malha dinâmica, como o apresentado na Seção 4.2. Para cada malha apresentada na Figura 3.15 são mostrados histogramas das qualidades dos elementos considerando as métricas ângulo mínimo (histograma da esquerda) e razão de aspecto ((histograma da direita)). Observando a figura, é possível verificar que a configuração 2 (mola seme-torcional) 


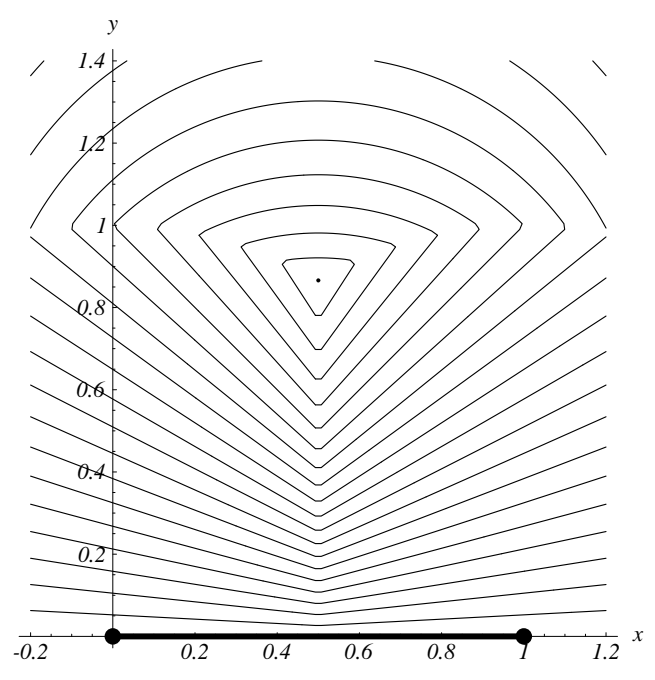

(a) Ângulo mínimo

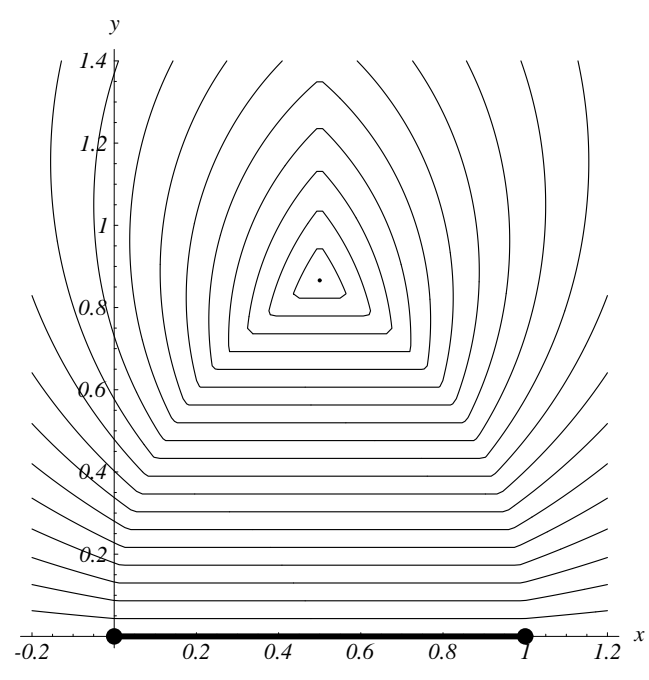

(b) Razão de aspecto

Figura 3.14: Isolinhas das métricas utilizadas para a qualidade de triângulos.

foi a que apresentou o pior resultado, pois não foi capaz de evitar células inválidas (os histogramas têm uma barra vertical em zero). Os resultados alcançados pelas configurações 1 e 3 são parecidos. A razão para isso se deve ao fato das molas semi-torcionais contribuirem pouco nas forças aplicadas nos vértices, já que todos os elementos são próximos dos equiláteros. As configurações 4 e 5 foram as que apresentaram os melhores resultados, as quais utilizam molas altura. Surpreendentemente, a configuração 5 forneceu piores resultados que a 4 . 
Malha original
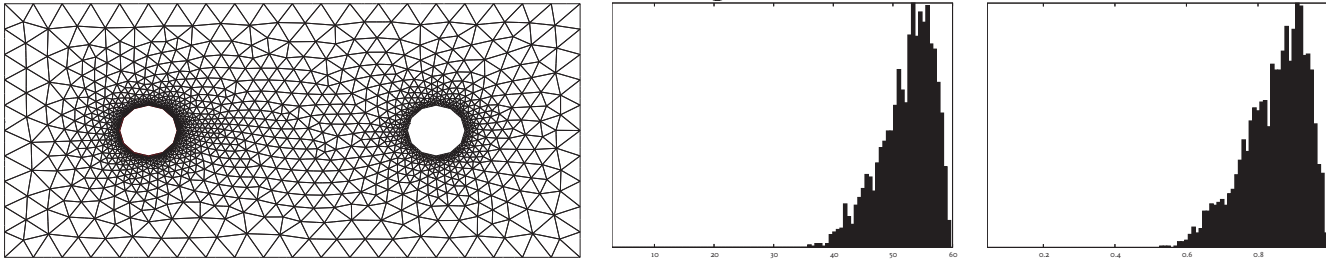

Configuração 1: Molas longitudinais
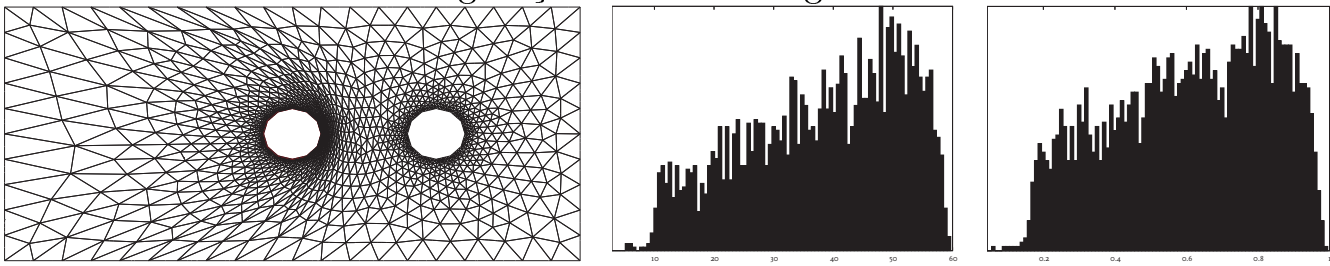

Configuração 2: Molas semi-torcionais
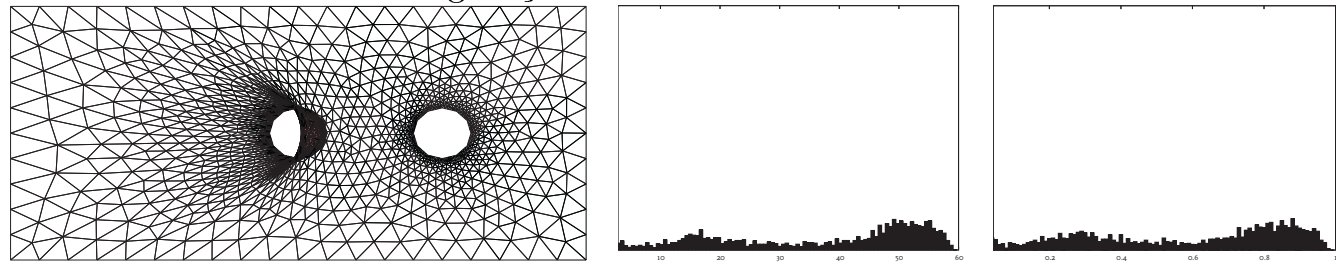

Configuração 3: Molas longitudinais e molas semi-torcionais
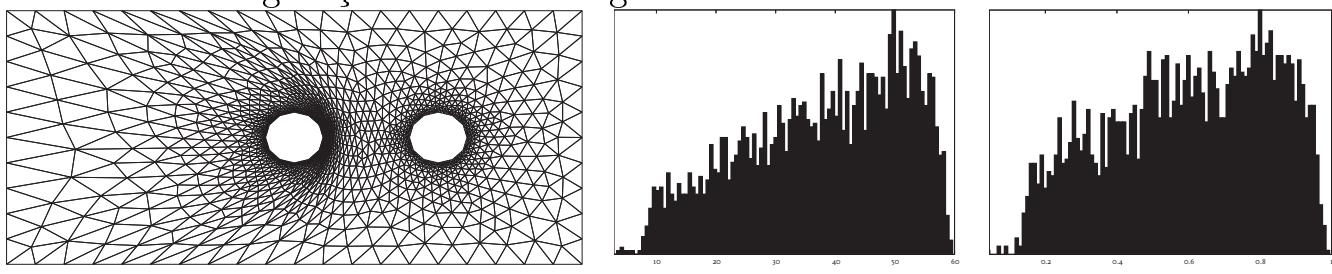

Configuração 4: Molas altura
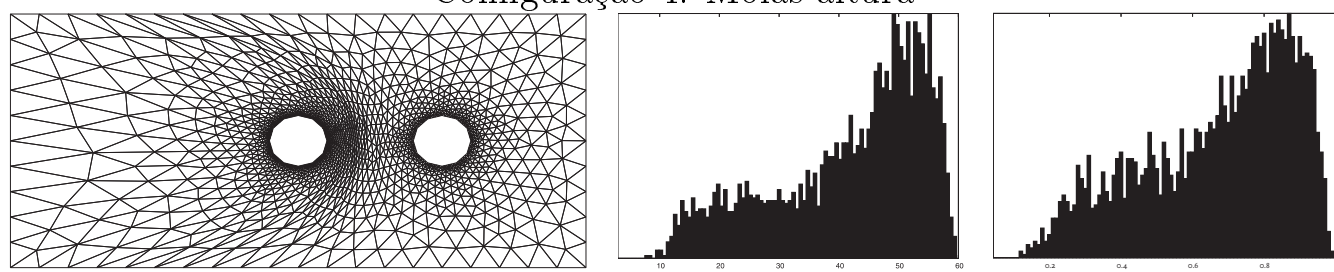

Configuração 5: Molas longitudinais e molas altura
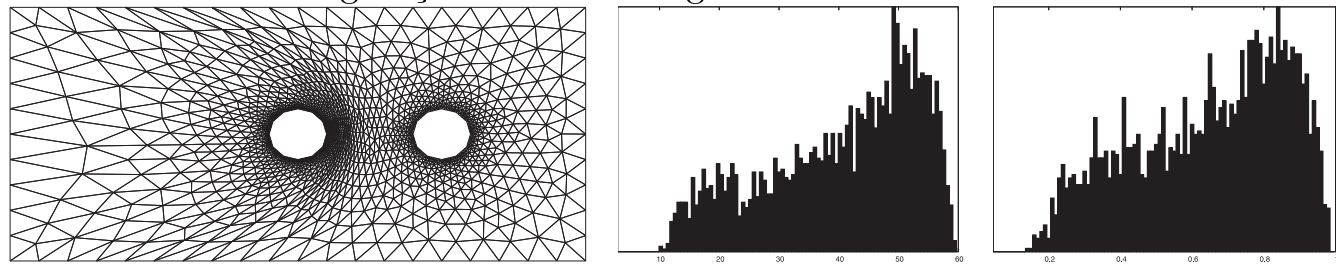

Figura 3.15: Comparação entre molas bidimensionais. 


\section{Capítulo 4}

\section{A execução da malha dinâmica}

Uma vez montado o sistema de equações que regem a malha dinâmica, é necessário resolvê-lo a fim de encontrar os deslocamentos para os vértices presentes no interior da malha sendo movimentada. Neste capítulo são apresentadas algumas considerações sobre como o sistema pode ser resolvido.

O sistema linear pode ser resolvido de várias formas. Considere, no entanto, a solução iterativa pelo método de Gauss-Seidel onde o novo deslocamento do vértice iterado $v_{i}, \vec{\delta}_{i}^{n e w}$, depende dos deslocamentos calculados anteriormente, $\vec{\delta}^{\text {old }}$. Por exemplo, no caso das molas longitudinais, o valor de $\vec{\delta}_{i}^{n e w}$ é obtido por:

$$
\vec{\delta}_{i}^{\text {new }}=\frac{\sum_{v_{w} \in V\left(\aleph_{v_{i}}\right)} \kappa_{i w} \vec{\delta}_{w}^{\text {old }}}{\sum_{v_{w} \in V\left(\text { « } v_{i}\right)} \kappa_{i w}}
$$

onde $w$ são valores obtidos de acordo com a conectividade da malha. Observe que $\vec{\delta}_{i}^{\text {new }}$ é dado pela média dos deslocamentos vizinhos ponderada pelos coeficientes de rigidez das molas. O lado esquerdo da Equação (4.1) muda dependendo da configuração de molas que compõem a malha dinâmica.

O Algoritmo 1 descreve como a malha dinâmica pode ser implementada com molas longitudinais e resolvida pelo método numérico de Gauss-Seidel para solucionar o sistema linear. Para que o algoritmo resolva sistemas compostos por outras molas, basta alterar a equação que calcula $\vec{\delta}_{i}^{n e w}$. Note que o algoritmo não desloca de fato os vértices da malha, ele apenas atualiza vetores deslocamento atribuídos aos mesmos.

\subsection{Os vértices ativos}

No algoritmo 1, o critério de parada é controlado por um valor $\epsilon$ fornecido pelo usuário. Seu término ocorre apenas quando os deslocamentos relativos de todos os vértices forem menores 


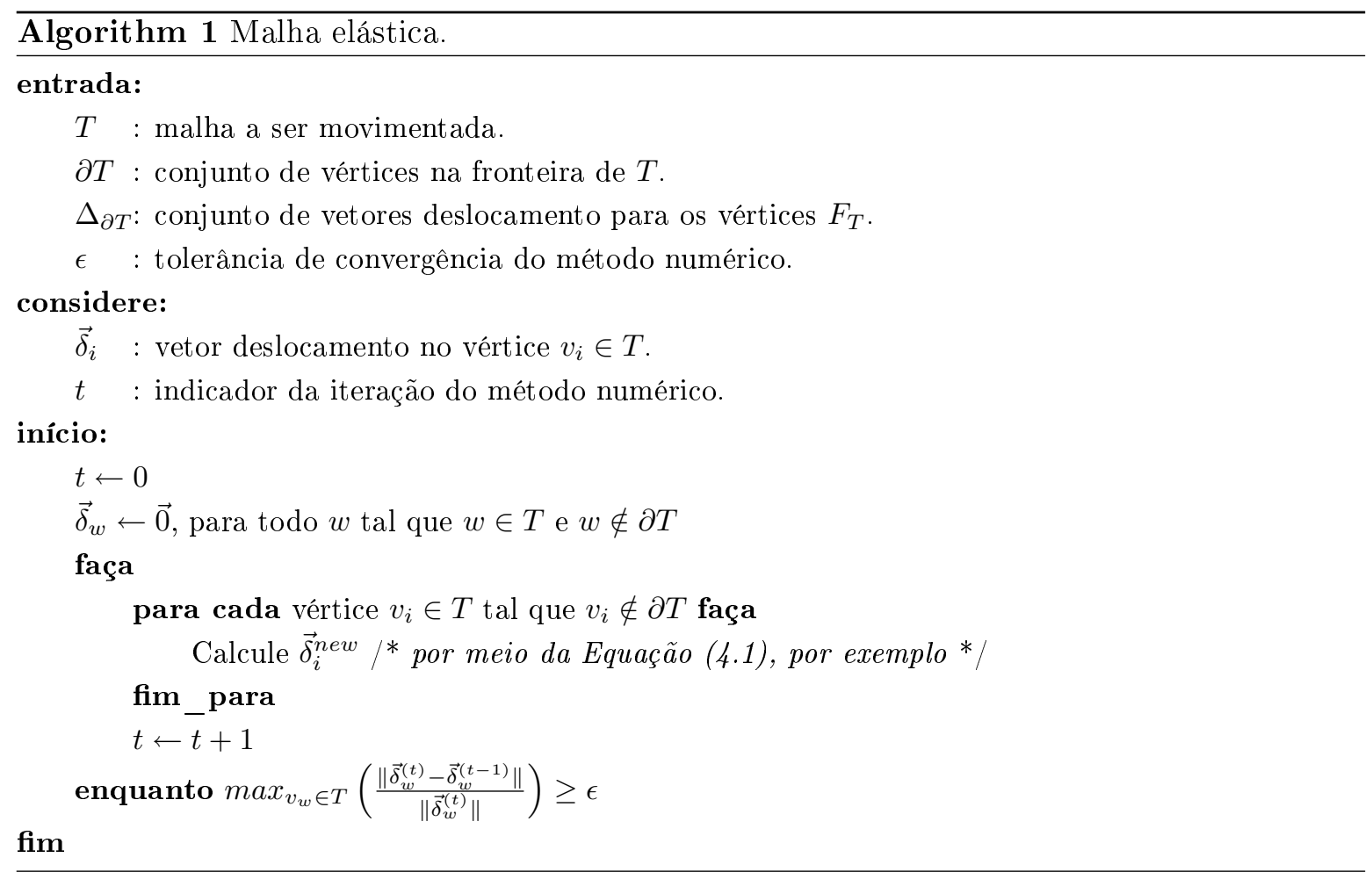

que $\epsilon$. Deslocamento relativo, neste contexto, significa o acréscimo normalizado no vetor deslocamento do vértice iterado realizado pela última iteração, isto é,

$$
\frac{\left\|\vec{\delta}_{w}^{(t)}-\vec{\delta}_{w}^{(t-1)}\right\|}{\left\|\vec{\delta}_{w}^{(t)}\right\|}
$$

onde $w$ refere-se ao vértice iterado. O primeiro comentário que pode ser feito sobre essa estratégia é que todos os vértices são julgados da mesma forma, quer estejam em regiões mais refinadas (arestas menores) ou regiões mais grosseiras (arestas maiores). Note porém, que as regiões mais grosseiras são menos sensíveis ao deslocamento relativo que as regiões mais refinadas. Sendo assim, é mais interessante que a influência do deslocamento relativo varie de acordo com o refinamento local da malha movimentada. Isso pode ser feito da seguinte forma:

$$
\max _{v_{w} \in T}\left(\frac{\left\|\vec{\delta}_{w}^{(t)}-\vec{\delta}_{w}^{(t-1)}\right\|}{e_{\min }^{w}}\right) \geq \epsilon
$$

onde $e_{\min }^{w}$ é o comprimento da menor aresta incidente no vértice iterado $v_{w}$. O valor de $e_{\min }^{w}$ é calculado apenas no início do processo, antes mesmo do movimento da fronteira. Note que com essa nova estratégia, o valor de $\epsilon$ é mais intuitivo. Por exemplo, se $\epsilon=0.1$, então a parada acontecerá somente se para cada vértice $v_{w}$ de $T$ o deslocamento relativo for menor que 0.1. $e_{\text {min }}^{w}$. Ou seja, $\epsilon$ pode ser entendido como um fator porcentagem da menor aresta, esta por sua vez pode variar dependendo do refinamento da malha. Dessa forma, o critério 
de parada é mais relaxado em regiões onde a malha é mais grosseira e mais apertado onde a malha é mais refinada.

Note que todos os vértices internos da malha são processados no laço aninhado do Algoritmo 1. A conseqüência disso é que pode ocorrer desperdício de processamento, principalmente nas últimas iterações do método numérico em que poucos vértices têm seus vetores deslocamento alterados. Além disso, a seqüência em que os vértices são visitados influencia diretamente no tempo de processamento e na convergência do método numérico utilizado. A ordem de processamento mais indicada é aquela em que os vértices são iterados em camadas (como em casca de cebola) começando da fronteira para o interior da malha.

Uma das contribuições desta tese é uma técnica capaz de aumentar o desempenho computacional, controlar a seqüência de processamento dos vértices e também controlar o critério de parada. A técnica proposta utiliza um mecanismo baseado em vértices ativos. A técnica é bastante simples e faz uso de rótulos nos vértices. São utilizados três rótulos:

- ativo: o vértice pode ser processado.

- inativo: o vértice não está sendo processado.

- fixo: o vértice não pode se mover.

Será utilizada a notação de conjunto para referir aos vértices com o mesmo rótulo, são eles: $\mathcal{A}$ para ativos, $\mathcal{I}$ para inativos e $\mathcal{F}$ para fixos. Como cada vértice pode possuir apenas um rótulo, os conjuntos são disjuntos. Além disso, o conjunto $\mathcal{A}$ e o $\mathcal{I}$ têm seus elementos dispostos em uma seqüência dada pela ordem de entrada dos elementos.

Em uma etapa de pré-processamento, todos os vértices da malha são inicialmente rotulados de acordo com o seguinte procedimento:

1. Todos os vértices pertencentes à fronteira da malha são rotulados como fixos.

2. Todos os vértices que estão diretamente conectados aos vértices fixos, que possuem deslocamento não nulo, são marcados como ativos.

3. Todos os vértices que não foram rotulados nos passos anteriores são marcados como inativos.

Apenas os vértices ativos devem ser iterados. Observe que $\mathcal{A}$ é iniciado com os vértices do interior que são adjacentes à fronteira da malha, com isso, os primeiros vértices iterados são os que possivelmente sofrerão maior deslocamento. Os vértices ativos e inativos podem ter seus rótulos alternados. Um vértice ativo se torna inativo quando seu deslocamento relativo 
for insignificante (menor que $\epsilon$ ). Se, todavia, seu movimento for significativo, além do vértice permanecer ativo, todos os vértices inativos adjacentes a ele tornam-se ativos. Quando um vértice ativo é processado, ele é removido do início da seqüência $\mathcal{A}$. A estratégia de inserção de elementos ao final da fila é feita de tal forma que os vértices recentemente ativados são adicionados primeiro e em seguida o vértice iterado.

O Algoritmo 2 descreve o procedimento de malha dinâmica utilizando o mecanismo de vértices ativos. Será utilizado o termo iteração global significando uma passagem pela seqüência de vértices $\mathcal{A}$ (laço externo), e iteração local para referir ao processamento de um vértice individualmente (laço interno). Observe que a parada é controlada também por um valor máximo de iterações globais, $N_{\max }$. Isso é importante em situações em que o método numérico não converge.

A abordagem de vértices ativos concentra o processamento da malha dinâmica nas regiões mais afetadas pelo deslocamento da fronteira. Isso pode ser verificado no exemplo apresentado na Figura 4.1. A deformação da malha é dada pelo deslocamento do círculo da esquerda levemente para baixo, o da direita permanece estático. Os vértices ativos (círculos verdes maiores) e os fixos (círculos vermelhos menores) estão em destaque. O número de vértices ativos $(\#(\mathcal{A}))$ é mostrado na legenda de cada estágio.

\subsection{Grandes deformações em pequenas etapas}

É sabido que o sistema de molas se comporta melhor quanto menor for a deformação no domínio da malha. Em muitas aplicações, as alterações no domínio são pequenas e a malha dinâmica apresenta bons resultados, mesmo utilizando apenas molas longitudinais. No entanto, existem aplicações que envolvem grandes deformações e pode acontecer da malha dinâmica falhar, quer seja por permitir a presença de elementos inválidos, quer seja pela divergência do método numérico empregado. A técnica apresentada nesta seção permite gerenciar a execução da malha dinâmica em contextos envolvendo grandes deformações.

Como discutido anteriormente, a deformação no domínio é dada por vetores deslocamento atribuídos aos vértices da fronteira da malha. A deformação na geometria do domínio está diretamente relacionada com a magnitude dos vetores deslocamento. A idéia central da técnica proposta é atingir o deslocamento desejado em etapas, onde cada etapa objetiva realizar uma fração do deslocamento requerido. A questão que surge é como realizar o particionamento dos vetores deslocamento tal que em cada etapa a malha dinâmica alcance resultados aceitáveis. Além disso, as etapas devem ser calibradas de tal forma que as anteriores não produzam malhas com elementos muito finos (razão de aspecto baixa), pois isto pode inviabilizar as 


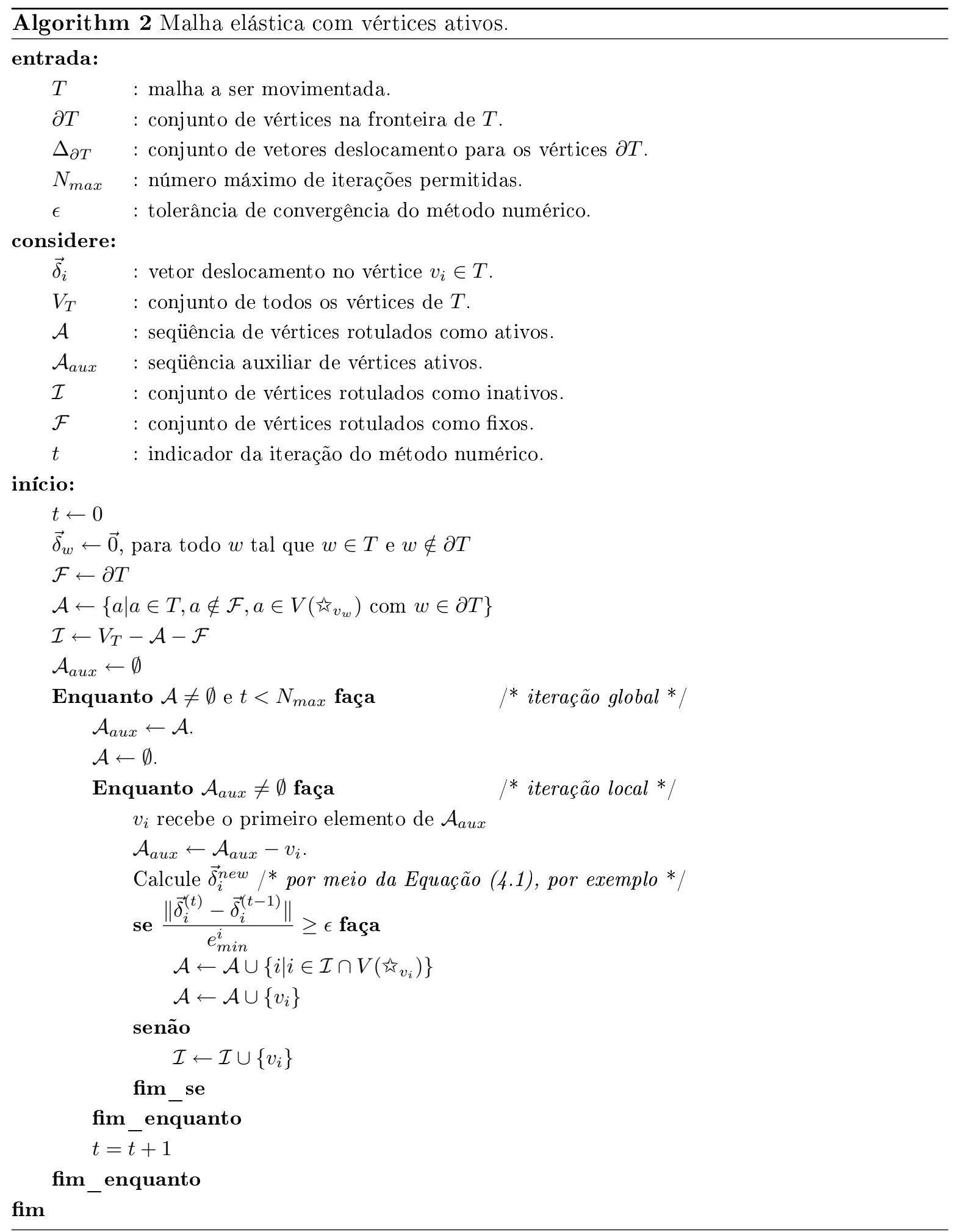




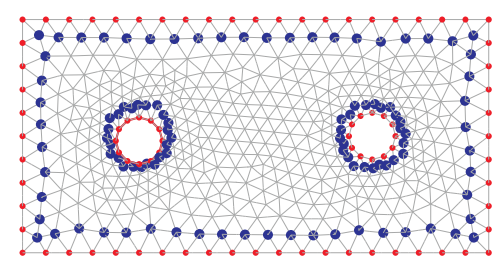

(a) Início, $\#(\mathcal{A})=104$.

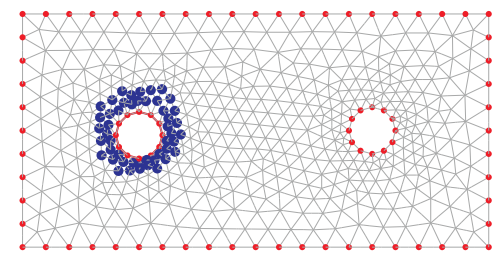

(c) Iteração $1, \#(\mathcal{A})=48$.

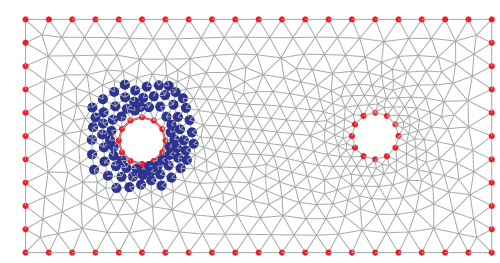

(e) Iteração $2, \#(\mathcal{A})=77$.

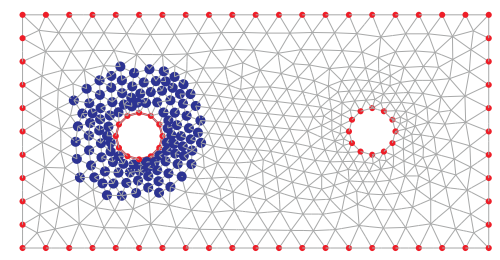

(g) Iteração $3, \#(\mathcal{A})=108$.

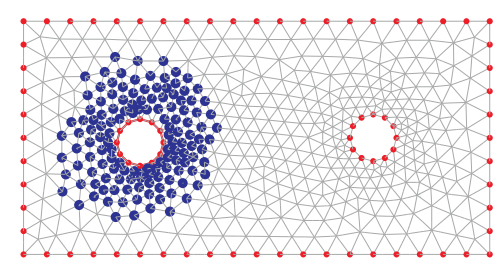

(i) Iteração $4, \#(\mathcal{A})=134$.

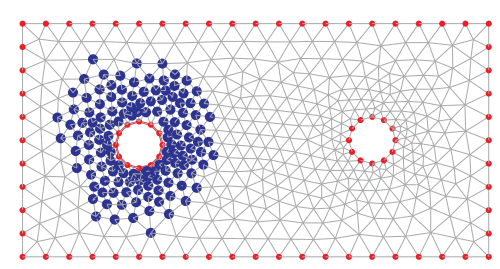

(k) Iteração $5, \#(\mathcal{A})=133$.

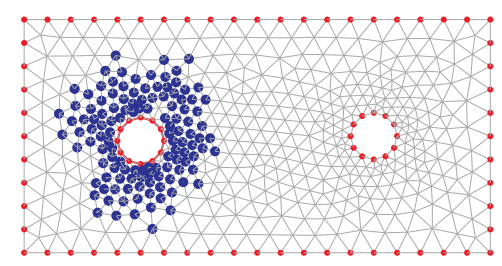

(b) Iteração $9, \#(\mathcal{A})=122$.

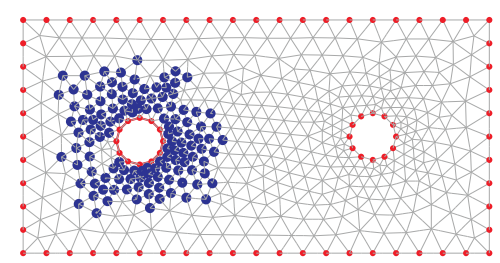

(d) Iteração $10, \#(\mathcal{A})=123$.

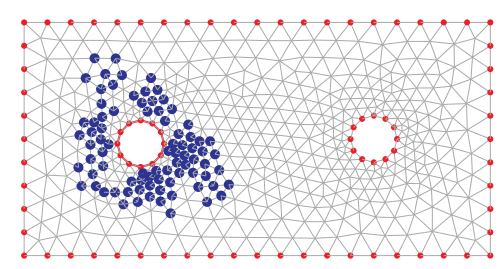

(f) Iteração $11, \#(\mathcal{A})=82$.

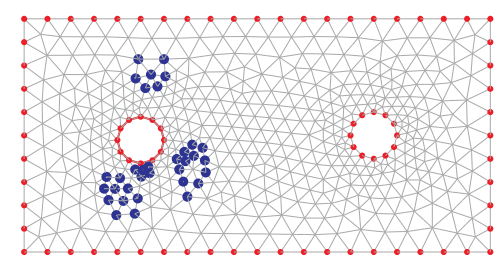

(h) Iteração $12, \#(\mathcal{A})=34$.

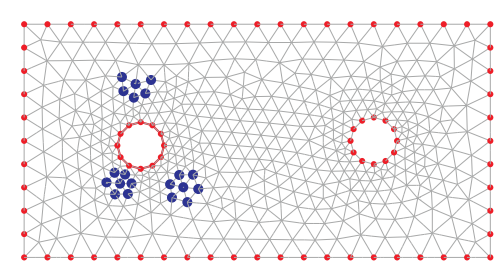

(j) Iteração $13, \#(\mathcal{A})=20$.

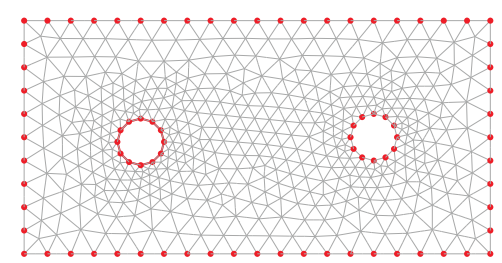

(1) Iteração $14, \#(\mathcal{A})=0$.

Figura 4.1: A estratégia de vértices ativos. 


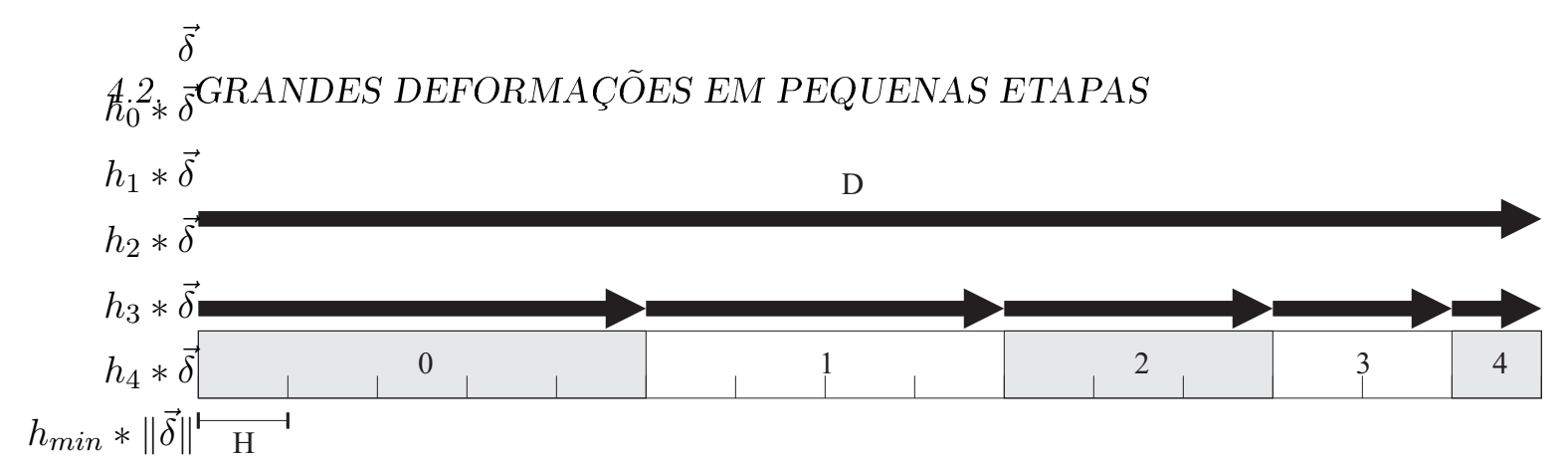

Figura 4.2: Valores de $h$ para $n_{p}=5$.

etapas seguintes. Sendo assim, cada etapa precisa evitar elementos inválidos como também preservar a qualidade dos elementos para que o restante do processo seja viável.

Seja $\partial T$ o conjunto de vértices pertencentes ao bordo da malha. Seja $\Delta_{\partial T}$ o conjunto de vetores deslocamento associados aos vértices $\partial T$, ou seja, os que determinam a deformação imposta no domínio. Assim, para todo vértice $v_{i} \in \partial T$ existe um único $\vec{\delta}_{i} \in \Delta_{\partial T}$. O deslocamento da fronteira em cada etapa do movimento é dado por $\Delta_{H}$, que é o conjunto formado pelos vetores de $\Delta_{\partial T}$ escalados segundo uma dada constante $0 \leq h \leq 1$, isto é, $\Delta_{H}=\left\{\vec{u} \mid \vec{u}=h \vec{\delta}, \forall \vec{\delta} \in \Delta_{\partial T}\right\}$. Assim, o valor de $h$ é o que controla a amplitude do deslocamento de cada etapa de movimento. Além disso, o valor de $h$ deve ser pequeno o suficiente para que viabilize uma malha movimentada livre de células inválidas. Portanto, o problema consiste em encontrar uma seqüência adequada $h_{0}, h_{1}, \ldots, h_{N-2}, h_{N-1}$, onde $\sum_{j=0}^{N-1} h_{j}=1$ e $N$ é o número de etapas de movimento. Esta seqüência é encontrada iterativamente conforme o procedimento descrito no Algoritmo 3, comentários sobre o algoritmo são feitos a seguir.

Por meio do valor $n_{p}$, o usuário sugere o número de pequenos passos que devem ser executados para realizar o deslocamento total em questão. Note porém, que $n_{p}$ é apenas uma sugestão inicial, pois o Algoritmo 3 pode aumentar o número de passos automaticamente quando necessário. Isto é, o valor de $h_{\min }$ é reduzido sempre que a malha movimentada após um dado passo for inaceitável.

A Figura 4.2 ilustra os valores de $h$ considerando $n_{p}=5$. Observe que o vetor deslocamento de entrada $\vec{\delta} \in \Delta_{\partial T}$ é dividido em 5 vetores proporcionais aos valores de $h$, os quais são múltiplos de $h_{\text {min }}$.

Sempre que a malha dinâmica é chamada, ela movimenta a malha $T$ conforme a deformação dada por $\Delta_{H}$, o qual é formado pelos vetores de $\Delta_{\partial T}$ escalados por $h$.

O Algoritmo 3 assume que seja possível determinar se a malha movimentada pela malha dinâmica é aceitável ou não. Essa avaliação da malha movimentada pode ser feita de várias maneiras, a mais simples delas consiste em verificar a existência de células inválidas. Porém, critérios mais sofisticados envolvendo a qualidade dos elementos podem ser incorporados ao 


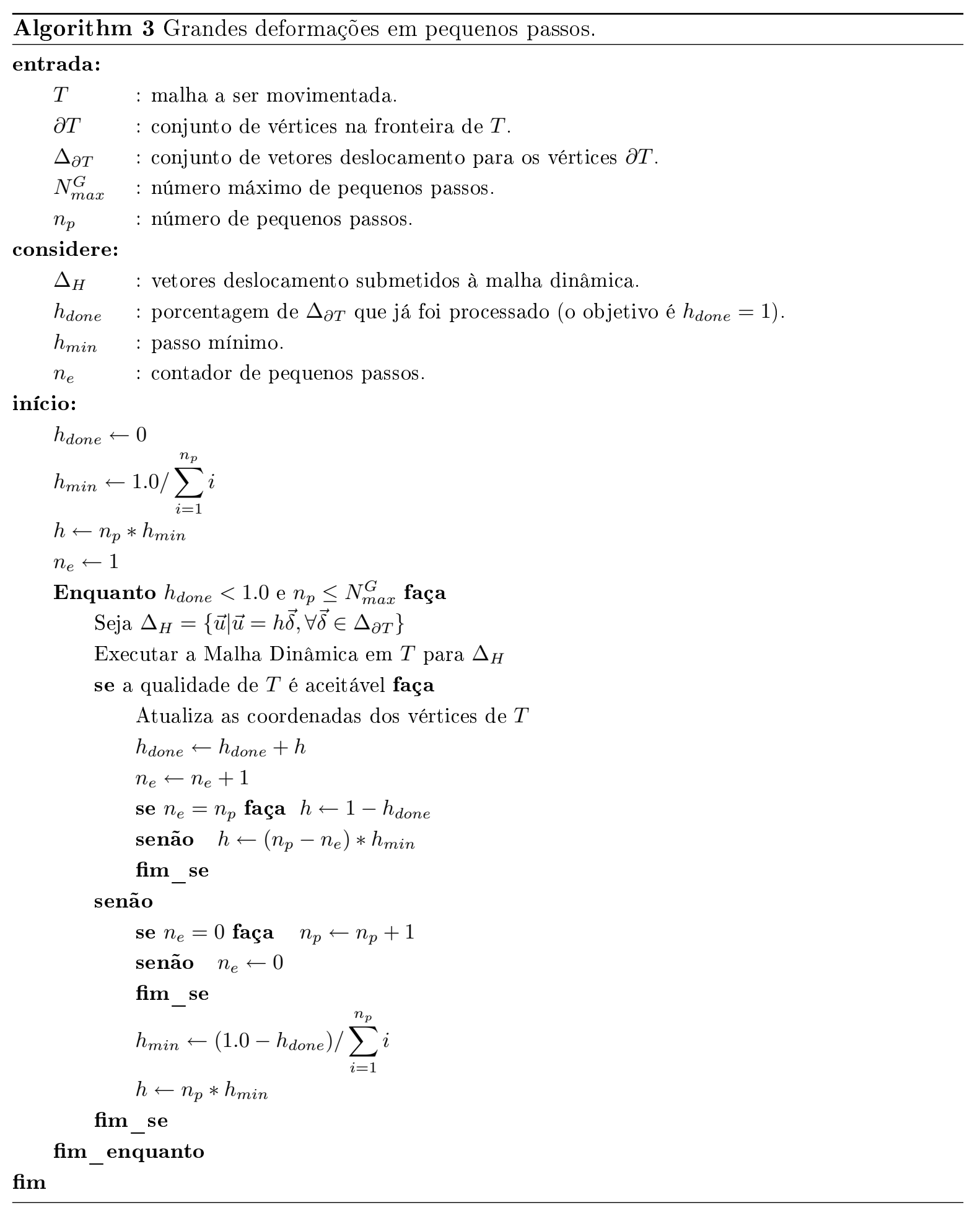


algoritmo.

Se o resultado da malha dinâmica for aceitável, a malha é de fato movimentada, ou seja, as coordenadas dos vértices são atualizadas. Por outro lado, se o resultado não for aceitável, o valor de $h$ é reduzido, o que aumenta as chances da malha dinâmica produzir resultados aceitáveis na próxima iteração.

Nem sempre a malha dinâmica é capaz de ajustar a malha à nova descrição do domínio, mesmo quando é utilizado o proposto mecanismo de pequenos passos. Nesses casos, o valor $N_{\text {max }}^{G}$ é utilizado para controlar a parada do Algoritmo 3 em casos de insucesso, evitando um laço infinito. Note que $N_{\max }^{G}$ fornece um valor máximo para $n_{p}$, que, por sua vez, só é incrementado quando a malha dinâmica falha.

O mecanismo de deformação em pequenos passos foi submetido ao seguinte caso de teste. A malha original mostrada na Figura 4.3(a) sofreu a deformação mostrada na Figura 4.3(b). A malha é composta por 1625 vértices e 3012 células. Foram utilizados os seguintes parâmetros: $n_{p}=200$ e $N_{\max }^{G}=205$. A malha dinâmica foi aplicada com três configurações diferentes de molas: (1) molas longitudinais apenas, (2) molas longitudinais e semi-torcionais, e (3) molas longitudinais e altura. As malhas resultantes, após rodar as três configurações, estão apresentadas na Figura 4.3. Na legenda sob cada malha é mostrado o valor de $h_{\text {done }}$, que é a porcentagem do deslocamento desejado que foi alcançada sem a aparição de elementos inválidos. Note que apenas a configuração com molas longitudinais não foi capaz de realizar a deformação desejada, sendo que o $h_{\text {done }}$ máximo alcançado foi de 0.773134 . Os resultados obtidos com molas semi-torcionais e com molas altura são semelhantes. 


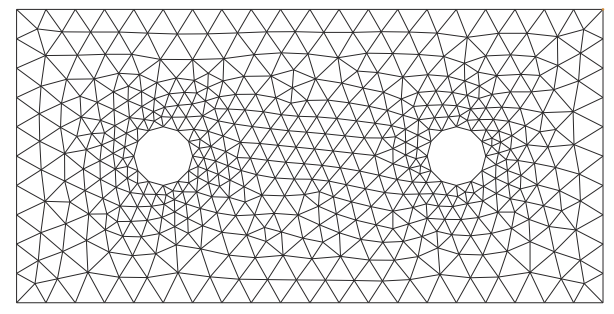

(a) Malha Original

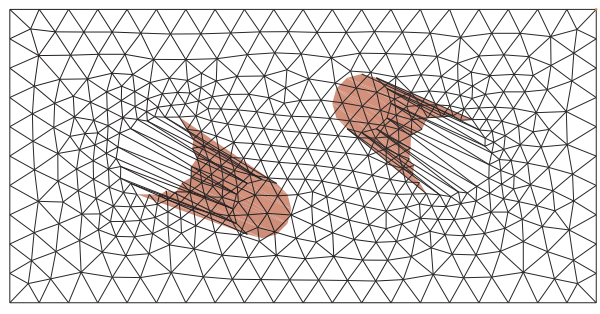

(b) Deformação da fronteira

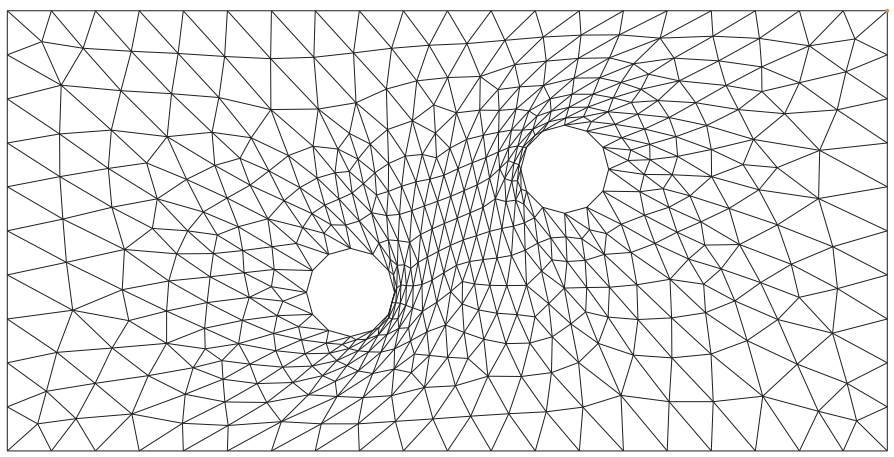

(c) Longitudinais $\left(h_{\text {done }}=0.773134\right)$

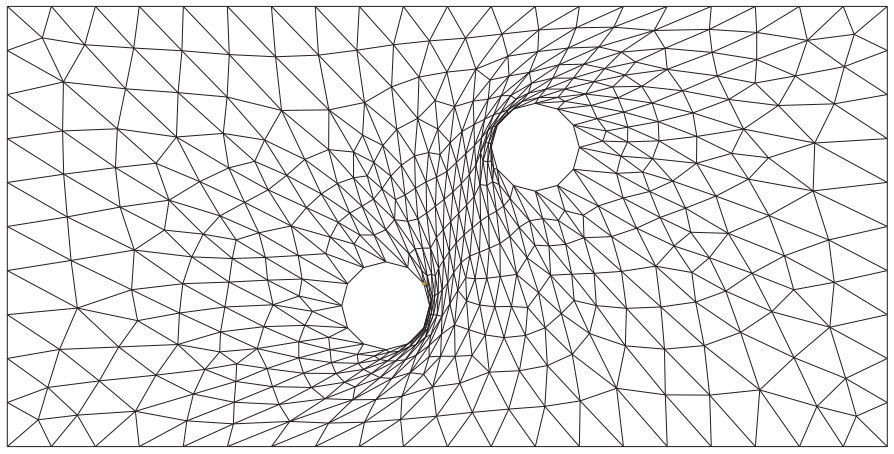

(d) Longitudinais e semi-torcionais $\left(h_{d o n e}=1.0\right)$

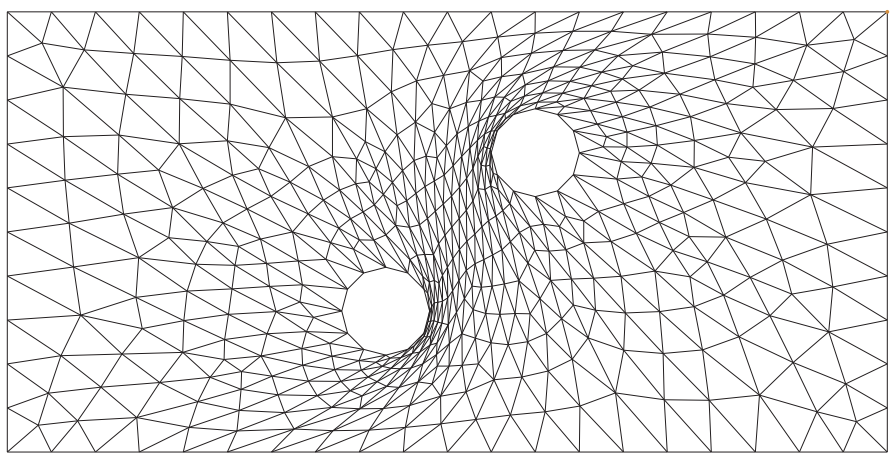

(e) Longitudinais e altura $\left(h_{\text {done }}=1.0\right)$

Figura 4.3: Grandes deformações em pequenos passos. 


\section{Capítulo 5}

\section{Malha dinâmica tridimensional}

Neste capítulo é apresentado como as molas longitudinais, torcionais, semi-torcionais e altura, apresentadas no capítulo anterior, podem ser aplicadas para movimentar malhas volumétricas.

\subsection{Molas longitudinais 3D}

Como descrito na seção 3.1, a cada aresta da malha é atribuida uma mola com coeficiente de rigidez é dado pela Equação (3.18). Como no caso 2D, as molas longitudinais 3D também podem ser implementadas com e sem o acoplamento das coordenadas. A extensão sem realizar o acoplamento de coordenadas é trivial, basta acrescentar uma equação para a coordenada $z$ na Equação (3.19), ou seja

$$
\begin{aligned}
& \left(\vec{f}_{i}\right)_{x}=\sum_{v_{j} \in V\left(\vec{\kappa} v_{i}\right)} \kappa_{i j}\left[\left(\vec{\delta}_{j}\right)_{x}-\left(\vec{\delta}_{i}\right)_{x}\right], \\
& \left(\vec{f}_{i}\right)_{y}=\sum_{v_{j} \in V\left(\preccurlyeq v_{i}\right)} \kappa_{i j}\left[\left(\vec{\delta}_{j}\right)_{y}-\left(\vec{\delta}_{i}\right)_{y}\right], \\
& \left(\vec{f}_{i}\right)_{z}=\sum_{v_{j} \in V\left(\preccurlyeq v_{i}\right)} \kappa_{i j}\left[\left(\vec{\delta}_{j}\right)_{z}-\left(\vec{\delta}_{i}\right)_{z}\right] .
\end{aligned}
$$

A versão com acoplamento também é simples de ser estendida, no caso a força em um vértice $v_{i}$ é calculada pela Equação (5.2) (veja Figura 5.1). 


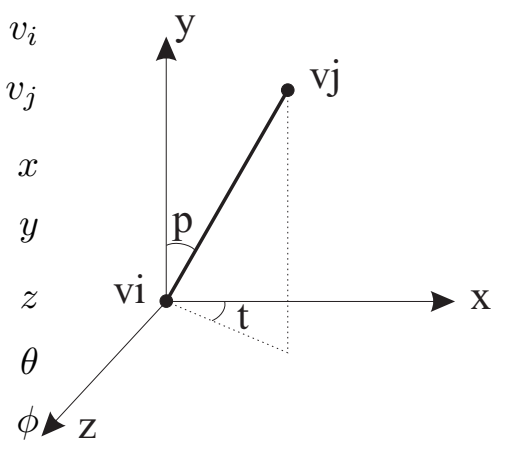

Figura 5.1: Mola longitudinal 3D com acoplamento de coordenadas.

$$
\begin{aligned}
&\left(\vec{f}_{i}\right)_{x}=\sum_{v_{j} \in V\left(\vec{\Downarrow} v_{i}\right)} \kappa_{i j} {\left[\left(\vec{\delta}_{j}-\vec{\delta}_{i}\right)_{x} \cos (\theta) \operatorname{sen}(\phi)+\left(\vec{\delta}_{j}-\vec{\delta}_{i}\right)_{y} \operatorname{sen}(\theta) \operatorname{sen}(\phi)\right.} \\
&\left.+\left(\vec{\delta}_{j}-\vec{\delta}_{i}\right)_{z} \cos (\phi)\right] \cos (\theta) \operatorname{sen}(\phi), \\
&\left(\vec{f}_{i}\right)_{y}=\sum_{v_{j} \in V\left(\vec{\Downarrow} v_{i}\right)} \kappa_{i j}\left[\left(\vec{\delta}_{j}-\vec{\delta}_{i}\right)_{x} \cos (\theta) \operatorname{sen}(\phi)+\left(\vec{\delta}_{j}-\vec{\delta}_{i}\right)_{y} \operatorname{sen}(\theta) \operatorname{sen}(\phi)\right.\left.+\left(\vec{\delta}_{j}-\vec{\delta}_{i}\right)_{z} \cos (\phi)\right] \operatorname{sen}(\theta) \operatorname{sen}(\phi), \\
&\left(\vec{f}_{i}\right)_{z}=\sum_{v_{j} \in V\left(\vec{\Downarrow} v_{i}\right)} \kappa_{i j}\left[\left(\vec{\delta}_{j}-\vec{\delta}_{i}\right)_{x} \cos (\theta) \operatorname{sen}(\phi)+\left(\vec{\delta}_{j}-\vec{\delta}_{i}\right)_{y} \operatorname{sen}(\theta) \operatorname{sen}(\phi)\right. \\
&\left.+\left(\vec{\delta}_{j}-\vec{\delta}_{i}\right)_{z} \cos (\phi)\right] \operatorname{sen}(\phi) .
\end{aligned}
$$

As mesmas deficiências da mola longitudinal 2D estão presentes na versão 3D. Vale salientar, no entanto, que na versão 3D elementos inválidos podem surgir com mais facilidade, pois, os vértices podem cruzar faces, além de arestas. Nas seções seguintes são apresentados alguns dos esforços realizados no sentido de impedir o surgimento de células inválidas 3D.

\subsection{Molas torcionais em tetraedros}

As molas torcionais 3D em elementos tetraédricos não são uma extensão direta da versão 2D para triângulos, segundo apresentada na Seção 3.3.1. É necessário controlar o volume dos elementos, e não apenas as áreas como no caso bidimensional. No entanto, os vértices dos tetraedros possuem ângulos sólidos, que não são facilmente controláveis. Além disso, simplesmente controlar as áreas das faces dos tetraedros com molas torcionais 2D não é suficiente para impedir que o elemento se torne inválido. Sendo assim, fazer uso de molas torcionais em elementos 3D não é uma tarefa trivial. 
Uma possível solução é controlar o volume dos tetraedros de uma maneira alternativa que considere ângulos planares ao invés de sólidos. Essa é justamente a estratégia adotada nos trabalhos presentes na literatura. Dentre eles, dois merecem destaque: o de Degand e Farhat [31] e o de Burg [18].

A proposta de Degand e Farhat não faz uso de molas torcionais tridimensionais de fato. Ao invés disso, eles posicionam adequadamente molas torcionais 2D no interior do elemento tetraédrico para controlar seu volume. Esta estratégia será descrita a seguir com maiores detalhes.

O trabalho de Burg [18] é o que mais se aproxima de uma proposta para molas torcionais 3D. Ele se baseia nas molas torcionais 2D de Farhat et al. [36] (descrito na seção 3.3.1) e a estende para o caso 3D. Burg apresenta uma nova formulação que considera a dinâmica dos elementos volumétricos, e não de triângulos como fizeram Degand e Farhat. Inicialmente, o autor apresenta como a nova formulação é desenvolvida para triângulos equipados com molas torcionais 2D e afirma que tal formulação se reduz exatamente naquela apresentada por Farhat et al. [36]. Em seguida, Burg mostra como a nova formulação pode ser facilmente estendida para tratar tetraedros. Em nenhum momento, no entanto, ângulos sólidos são considerados.

A estratégia de Degand e Farhat [31] consiste em inserir triângulos fictícios dentro dos tetraedros e anexar molas torcionais $2 \mathrm{D}$ aos vértices dos triângulos inseridos.

Seja $\tau_{\text {pqrs }}$ um tetraedro com volume $V_{\text {pqrs }}$. Para impedir a colisão do vértice $v_{s}$ com a face oposta $t_{p q r}$, considera-se um triângulo fictício $t_{s j q}$ dentro de $\tau_{p q r s}$ que esteja no plano perpendicular à face $t_{p q r}$, veja a Figura 5.2. Observe que, se $V_{p q r s} \rightarrow 0$ porque o vértice $v_{s}$ tende a colidir com a face $t_{p q r}$, então a área de $t_{s j q}$ também tende a zero. Portanto, controlar a área do triângulo $t_{s j q}$ via molas torcionais $2 \mathrm{D}$ previne o vértice $v_{s}$ de atravessar a face $t_{p q r}$, veja a Figura 5.3.

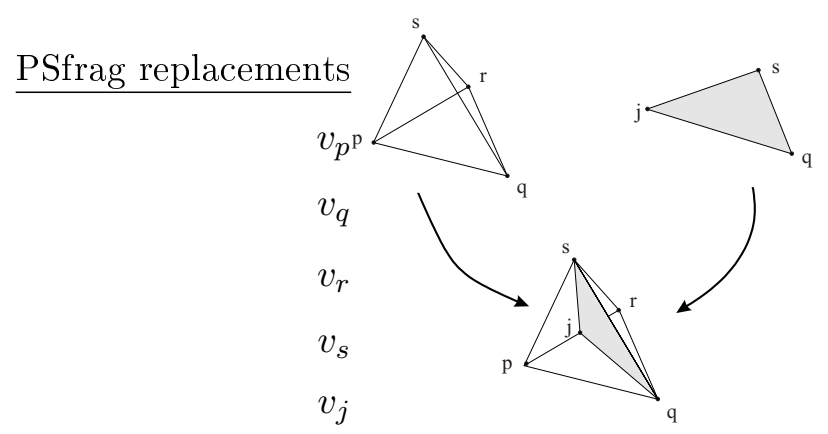

Figura 5.2: Inseção de um triângulo fictício dentro de um tetraedro.

A transferência da dinâmica das molas torcionais $2 \mathrm{D}$ do triângulo $t_{s j q}$ para o tetraedro 


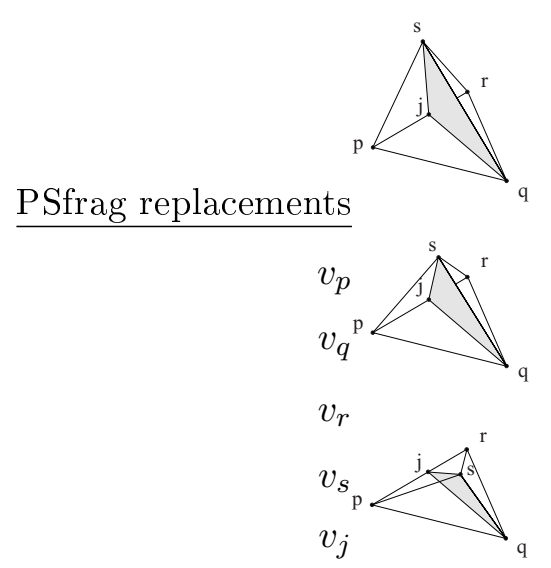

Figura 5.3: Controle do volume do tetraedro.

$\tau_{p q r s}$ é feita de maneira direta, veja a Figura 5.4. As forças elásticas das molas torcionais de $t_{s j q}$ são computadas (como descrito na Seção 3.3.1) e transferidas para os vértices do tetraedro $\tau_{p q r s}$. Observe que o vértice fictício $v_{j}$ do triângulo $t_{s j q}$ não possui um vetor deslocamento correspondente, como é o caso dos vértices reais. A solução utilizada foi interpolar o vetor deslocamento de $v_{j}$ a partir dos vértices $v_{p}$ e $v_{r}$.

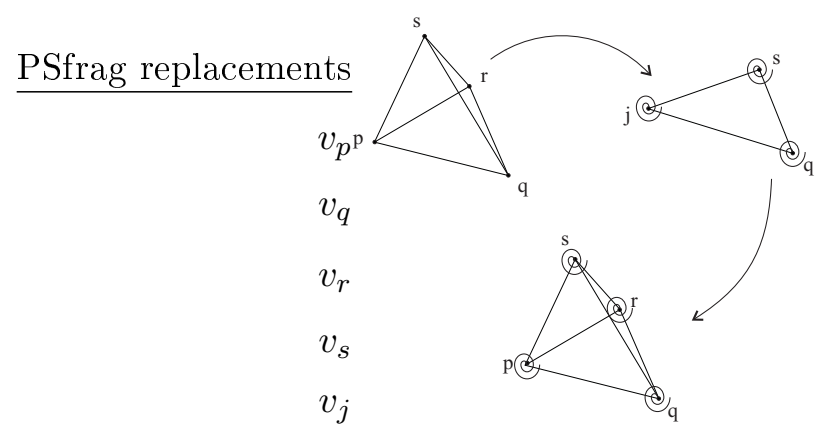

Figura 5.4: Equipando o tetraedro com molas torcionais.

Como existem quatro vértices no tetraedro, são necessárias quatro configurações de triângulos, como apresentado na Figura 5.5. Entretanto, deve-se notar que para cada vértice é possível inserir três triângulos diferentes para impedir que ele atravesse a face oposta, cada triângulo influenciando a rigidez do tetraedro em uma direção diferente. Isso permite fazer um melhor controle do ângulo sólido no vértice. Para um triângulo com razão de aspecto ruim, pode ser uma tarefa dispendiosa determinar qual triângulo melhor previne o vértice de cruzar a face oposta. Para que isso seja evitado, os autores propoem a utilização dos três triângulos simultaneamente para cada vértice do tetraedro, o que gera a configuração de 12 triângulos apresentada na Figura 5.6. 
$v_{q}$
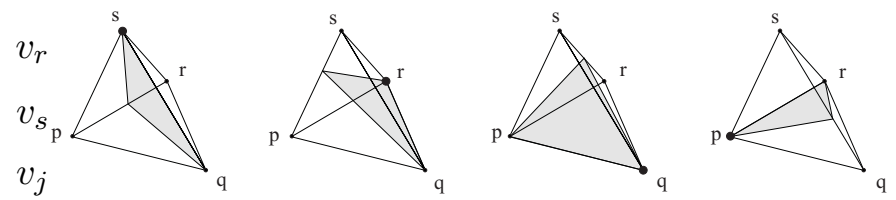

Figura 5.5: Configuração de quatro triângulos por tetraedro.
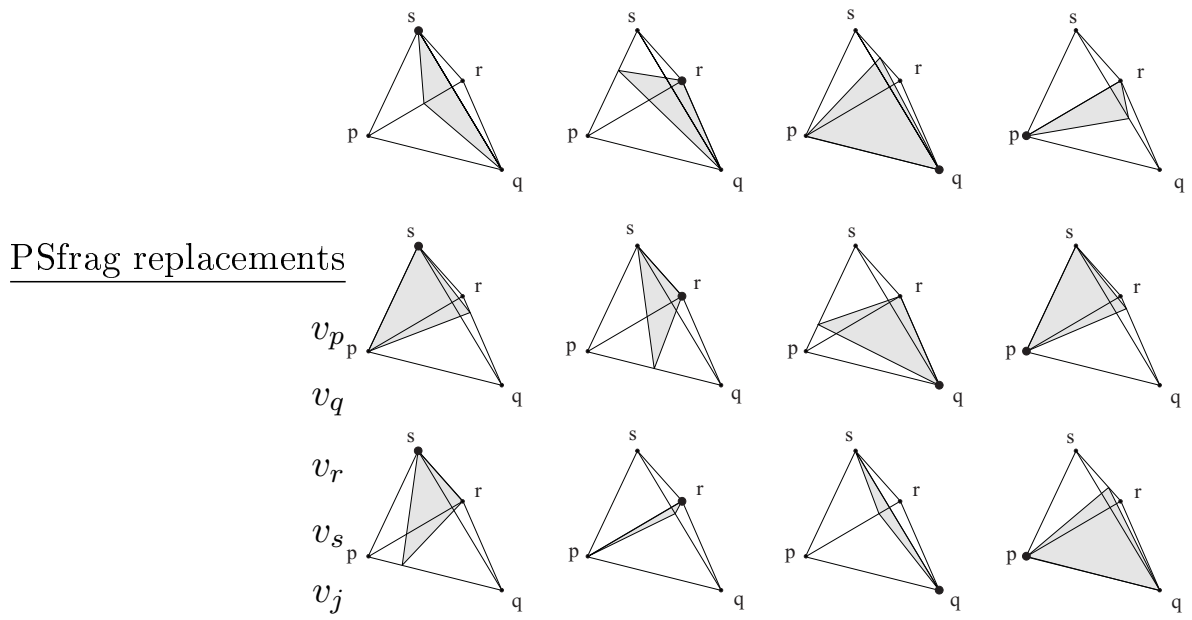

Figura 5.6: Configuração de doze triângulos por tetraedro.

Segundo os autores, as duas configurações de triângulos extras (quatro ou doze) geram bons resultados. Porém, a configuração com doze triângulos produz um melhor posicionamento do vértice em cada iteração, a um custo computacional maior, obviamente.

\subsection{Molas semi-torcionais em Tetraedros}

As molas semi-torcionais também foram adaptadas para o contexto tridimensional. Nesta seção serão apresentados dois trabalhos, o de Murayama et al. [65] e o de Zeng e Ethier [112], ambos fazem uso de molas semi-torcionais para controlar ângulos diedrais entre faces.

A principal diferença entre as molas semi-torcionais 2D e 3D é que as últimas controlam ângulos entre faces ao invés de ângulos entre arestas. As molas semi-torcionais no contexto 3D serão chamadas de molas semi-torcionais diedrais. A função destas molas é impedir que vértices atravessem faces. Considere a Figura 5.7, onde uma mola é utilizada para controlar o ângulo diedral entre as faces $t_{p q r}$ e $t_{s r q}$. A notação $\varphi_{q r}^{p s}$ será utilizada para designar uma mola semi-torcional presente no ângulo diedral na aresta $e_{p s}$ e agindo sobre a mola longitudinal presente na aresta $e_{q r}$, como é o caso da Figura 5.7. Da mesma forma como explicado na Seção 3.3.2, a versão 3D também transfere seu coeficiente de rigidez diretamente para a mola 


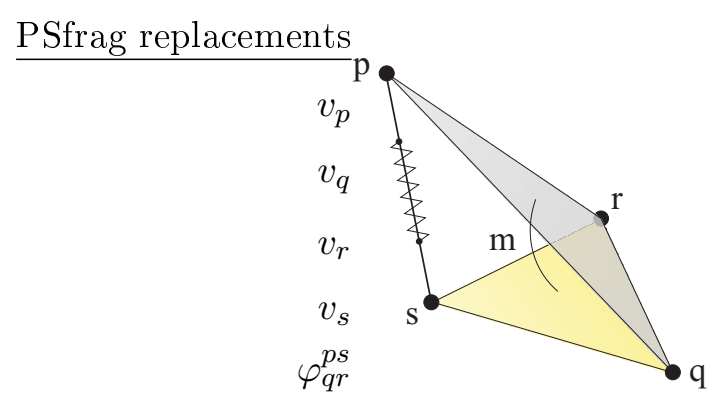

Figura 5.7: Mola semi-torcional diedral para controlar um dos ângulos diedral de um tetraedro.

longitudinal oposta. O seu coeficiente de rigidez, por sua vez, é calculado substituindo-se o ângulo entre arestas pelo ângulo diedral na Equação (3.21).

A proposta de Murayama et al. [65] sugere a adição de molas semi-torcionais tanto 2D quanto 3D. Para evitar que vértices atravessem arestas, molas semi-torcionais 2D são dispostas nos ângulos internos dos quatro triângulos que formam as faces do tetraedro. Além disso, o volume do tetraedro é controlado por seis molas semi-torcionais diedrais, uma em cada aresta do elemento. Cada tetraedro, portanto, é equipado com 18 molas semi-torcionais, 12 nos ângulos internos das faces e 6 nos ângulos diedrais internos do tetraedro.

Zeng e Ethier [112] também propuseram a utilização de molas semi-torcionais em elementos tetraedrais. A abordagem é muito parecida com a de Murayama et al., a única diferença é que não são utilizadas as molas nos ângulos internos das faces, mas apenas molas semi-torcionais diedrais. Portanto, cada tetraedro é equipado com apenas 6 molas semi-torcionais, uma para cada aresta.

Refletir o comportamento de molas torcionais em molas longitudinais, como é o caso das molas semi-torcionais, não necessariamente evita que elementos inválidos apareçam. Essa deficiência raramente impede a utilização do método em aplicações práticas de malha dinâmica, como por exemplo em CFD. Isso porque quando se tem elementos inválidos iminentes, a malha geralmente já apresenta tetraedros com razão de aspecto inadequada para as simulações seguintes. Em outras palavras, a geração de uma nova malha já seria necessária independentemente do surgimento de elementos inválidos.

\subsection{Molas altura em tetraedros}

Além das molas torcionais e semi-torcionais, outros mecanismos também foram propostos para impedir o surgimento de elementos inválidos em malhas tetraédricas, como por exemplo 


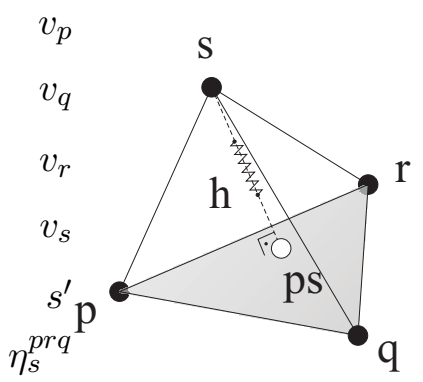

Figura 5.8: Exemplo de altura 3D em tetraedro.

o baseado em molas altura 3D.

As molas altura 3D são simples e é basecamente a extensão direta da versão 2D descrita na Seção 3.3.3. Considere a Figura 5.8, na qual uma mola altura 3D, denotada por $\eta_{s}^{p r q}$, é utilizada para impedir que o vértice $v_{s}$ atravesse a face oposta $t_{p q r}$ em um tetraedro $\tau_{p q r s}$. A mola altura em questão liga o vértice $v_{s}$ à sua projeção $s^{\prime}$ na face oposta.

A força produzida por uma mola altura no tetraedro segue a mesma fórmula descrita para o caso bidimensional (ver Equação (3.35)). O vetor deslocamento de $s^{\prime}$, denotado por $\vec{\delta}_{s^{\prime}}$, é obtido a partir dos deslocamentos atribuidos aos vértices da face oposta $t_{p q r}$. Sejam $\lambda_{p}, \lambda_{q} \mathrm{e}$ $\lambda_{r}$ as coordenadas baricêntricas de $s^{\prime}$ em relação a $t_{p q r}$, ou seja: $\lambda_{p} v_{p}+\lambda_{q} v_{q}+\lambda_{r} v_{r}=s^{\prime}$. Os valores de $\lambda$ devem ser positivos, o que não acontece se $s^{\prime}$ for projetado fora do triângulo $t_{p q r}$. Por isso, é feito o seguinte procedimento sobre as coordenadas baricêntricas:

1. Se alguma coordenada $\lambda_{i}$, com $i \in\{p q r\}$, for menor que zero, então $\lambda_{i}$ passa a valer zero.

2. Seja $\lambda_{\text {total }}=\lambda_{p}+\lambda_{q}+\lambda_{r}$.

3. $\lambda_{i}^{\prime}=\lambda_{i} / \lambda_{\text {total }}$, para $i=p, q, r$.

Feito esse procedimento, o vetor $\vec{\delta}_{s^{\prime}}$ é dado por

$$
\vec{\delta}_{s^{\prime}}=\lambda_{p}^{\prime} \vec{\delta}_{p}+\lambda_{q}^{\prime} \vec{\delta}_{q}+\lambda_{r}^{\prime} \vec{\delta}_{r}
$$

Um tetraedro deve ser equipado com quatro molas altura, uma para cada vértice do elemento, ou seja, o tetraedro $\tau_{p q r s}$ é equipado com as seguintes molas altura: $\eta_{s}^{p r q}, \eta_{r}^{s p q}, \eta_{p}^{q r s}$ e $\eta_{q}^{s r p}$.

Opcionalmente, pode-se também empregar molas altura 2D nos triângulos das faces, neste caso são adicionadas três molas para cada triângulo, conforme descrito na Seção 3.3.3. O tetraedro é equipado com 16 molas altura no total. 


\subsection{Comparação entre molas}

Nesta seção é feita uma comparação entre os resultados promovidos pela aplicação de malhas dinâmicas 3D com diferentes configurações de molas. As configurações comparadas são as seguintes:

1. Configuração 1: Molas longitudinais,

2. Configuração 2: Molas semi-torcionais diedrais,

3. Configuração 3: Molas semi-torcionais diedrais e molas longitudinais,

4. Configuração 4: Molas semi-torcionais diedrais, molas semi-torcionais nas faces e molas longitudinais,

5. Configuração 5: Molas altura 3D,

6. Configuração 6: Molas altura 3D e molas longitudinais, e

7. Configuração 7: Molas altura 3D, molas altura 2D nas faces e molas longitudinais.

A qualidade das malhas é aferida pela razão de aspecto do tetraedro, denotada por $\beta$, dada pela seguinte fórmula:

$$
\beta=\frac{V}{\ell_{\max }^{3}},
$$

onde $V$ é o volume do tetraedro e $\ell_{\max }$ o comprimento de sua maior aresta. Quanto maior for o valor de $\beta$ mais próximo do eqüilátero é o elemento. Os histogramas apresentados nesta seção mostram o número de ocorrência de elementos em intervalos de qualidade. Neles, o valor da qualidade está normalizado pela qualidade de um tetraedro equilátero, e, portanto, varia de 0 a 1.

A malha utilizada para produzir os resultados desta seção é composta por 2674 vértices e 13738 tetraedros. A malha possui dois bordos, um cubo externo e uma esfera no centro.

A deformação é dada deslocando-se o bordo esférico em direção a uma das quinas do cubo. A Figura 5.9 mostra esse deslocamento, são apresentadas apenas as células do bordo da malha e as células invertidas pelo deslocamento. A malha dinâmica foi aplicada com vértices ativos e utilizando a estratégia de pequenos passos com os parâmetros $n_{p}=100$ e $N_{\max }^{G}=105$. Todas as configurações foram capazes de efetuar o deslocamento desejado e sem ivalidar células. Os histogramas dos resultados obtidos estão apresentados na Figura 5.9. Pode-se perceber que as configurações que promoveram os melhores resultados foram as 1,3 e 7; pois foram as 


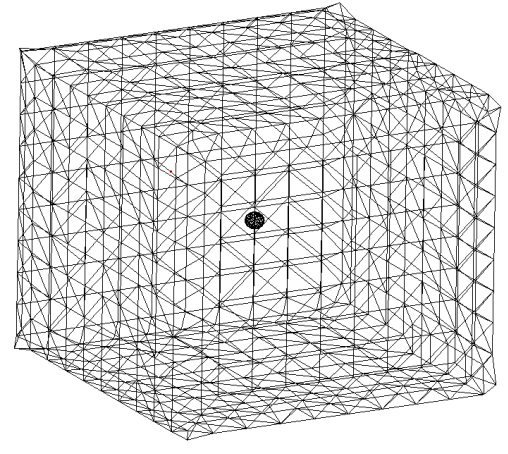

(a) Malha original.

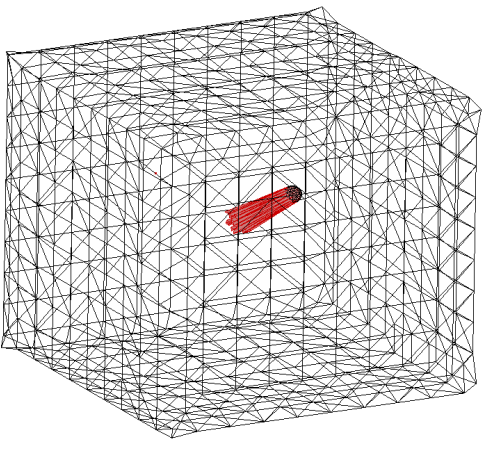

(b) Malha deslocada.

Figura 5.9: Deslocamento do bordo esférico interior da malha volumétrica.

que mais impediram o surgimento de elemtnos com qualidade inferior a 0.2. Dentre todas, a configuração 7 foi a que obteve o melhor resultado. 


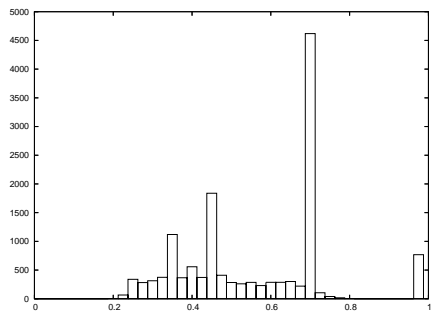

(a) Malha original

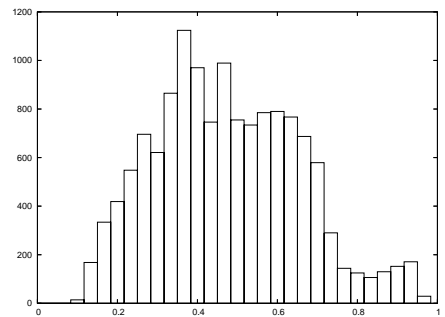

(b) Configuração 1

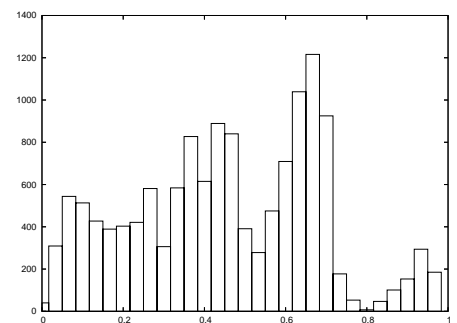

(c) Configuração 2

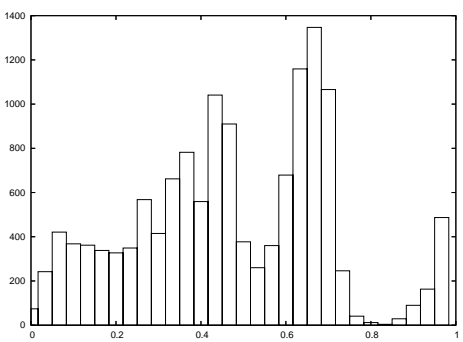

(f) Configuração 5

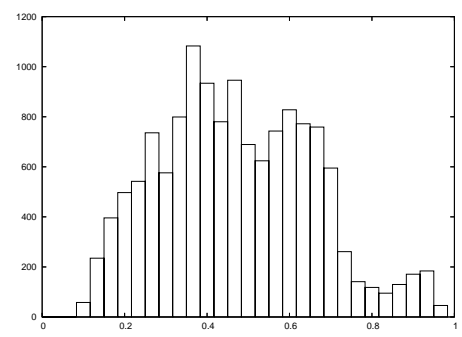

(d) Configuração 3

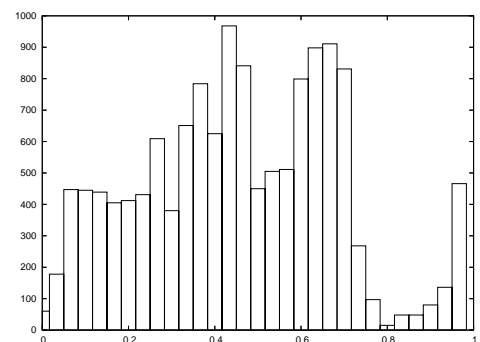

(g) Configuração 6

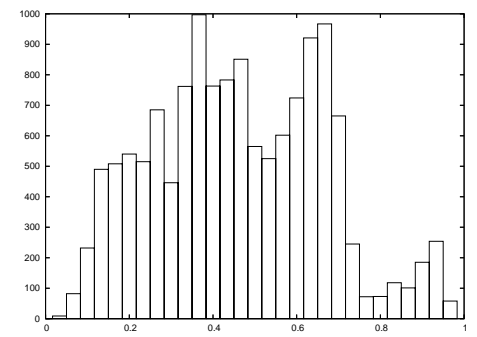

(e) Configuração 4

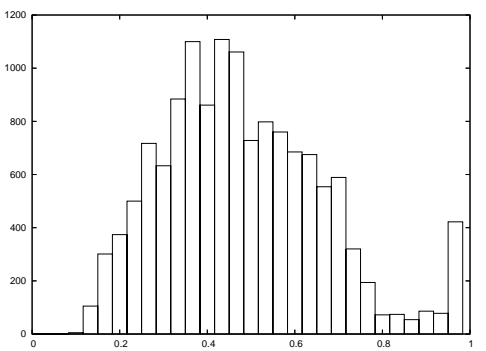

(h) Configuração 7

Figura 5.10: Comparação entre molas 3D. 


\section{Capítulo 6}

\section{O movimento da fronteira da malha}

Nos capítulos anteriores foi discutida a utilização de malhas dinâmicas para movimentação de malhas bidimensionais e tridimensionais. Nos dois casos, a malha dinâmica considera estática a sua fronteira, ou seja, os vetores deslocamento ali atribuídos não são alterados durante o processo dinâmico.

Em muitas aplicações, a deformação da fronteira do domínio da malha é realizada automaticamente e este movimento pode comprometer células da própria fronteira. Observe que a aplicação da malha dinâmica como apresentada nos capítulos anteriores não pode corrigir tais problemas, pois esta não é capaz de corrigir os elementos inválidos da fronteira. Uma solução para esse problema é mover a fronteira da malha antes de aplicar a malha dinâmica clássica para propagar as deformações da fronteira nos vértices do interior. Neste capítulo, é apresentado como a técnica de malha dinâmica pode ser usada como uma ferramenta de correção automática da fronteira da malha.

A Figura 6.1 ilustra este cenário em um domínio 2D simples. Suponha que exista uma malha no interior do retângulo, a qual não está apresentada para não tornar a figura confusa. Porém, o triângulo $a b c$ da malha é apresentado para ilustrar os efeitos da deformação da fronteira sobre a malha. Suponha que a aplicação tenha controle apenas sobre os vértices do topo do retângulo, para os quais foram atribuídos os vetores deslocamento apresentados na Figura 6.1(b). Note o que acontece na geometria do domínio após o deslocamento parcial da fronteira na Figura 6.1(c). Note também que o triângulo abc passa a ter sua orientação invertida, ou seja, passa a ser um elemento inválido. Para se obter o resultado da Figura 6.1(d), é necessário mover outros vértices da fronteira, no caso, aqueles nos lados verticais do retângulo.

O domínio apresentado na Figura 6.1 é bastante simples, o que facilita a correção da fronteira. Pois, o domínio retangular continua sendo retangular após o processo de movimentação. 
- deformação-imposta: termo utilizado para designar o conjunto de vetores deslocamento que devem permanecer inalterados durante todo o processo, ou seja, é o conjunto que descreve a modificação desejada na geometria do domínio. A deformação-imposta corresponde aos vetores em destaque na Figura 6.2(b).

- deformação-adicional: termo utilizado para designar o conjunto de vetores deslocamento da fronteira que foram modificados para amenizar o impacto da deformação-imposta na geometria do domínio, ou seja, designa a parte corrigida da fronteira. De uma maneira geral, a deformação-adicional ocorre apenas em uma região próxima adjacente à deformação-imposta. A deformação-adicional corresponde aos vetores deslocamentos utilizados para deslocar as linhas curvas da Figura 6.2.

- deformação-geral: este termo refere-se à deformação total realizada na fronteira, isto é, o resultado obtido após a aplicação da deformação-imposta e da deformação-adicional. A deformação-geral corresponde aos vetores deslocamentos utilizados para gerar o domínio da Figura 6.2(d).

A metodologia apresentada neste capítulo, é uma proposta de como realizar automaticamente a deformação-adicional de tal maneira que a deformação-geral não produza um modelo muito diferente do original (antes da deformação). Em outras palavras, a geometria do modelo antes e depois da deformação-geral devem ser intuitivamente parecidos. Nenhum rigor científico, no entanto, será aplicado para medir a proximidade das descrições geométricas.

A intenção é propor uma maneira de se obter a deformação-adicional por meio de malha dinâmica. Para criar um sistema de molas adequado para movimentar a fronteira, é proposto neste trabalho um novo tipo de mola, a mola conservativa, apresentada a seguir.

\subsection{Molas conservativas}

O papel das molas conservativas é adicionar forças ao sistema de molas que contribuam para a "conservação" do aspecto original da fronteira. As molas conservativas são utilizadas para realizar a citada deformação-adicional. Seja $v_{i}$ um vértice da fronteira que deve ser movido. Seja $v_{i}^{o}$ a posição original de $v_{i}$, ou seja, antes de ser realizado qualquer movimento. A mola conservativa é uma mola longitudinal que liga um dado vértice, $v_{i}$, a um ponto fictício situado na sua posição original, $v_{i}^{o}$, e tem comprimento de equilíbrio nulo. Portanto, a mola procura manter o vértice próximo de sua posição original. A Figura 6.3 ilustra a aplicação de molas conservativas em uma curva (a extensão para superfícies é direta). A Figura 6.3(a) mostra a malha original. A Figura 6.3(b) mostra o que acontece quando o bordo, no caso apenas os 


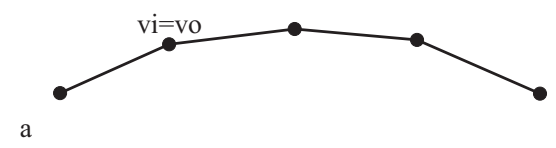

$\underline{\text { PSfrag replacements }}$

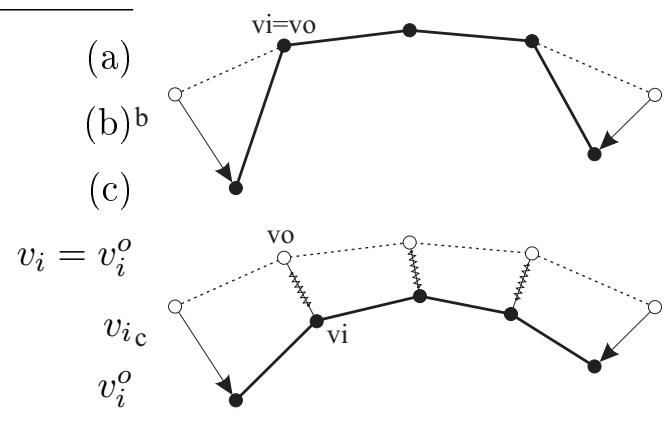

Figura 6.3: Molas conservativas agindo sobre um curva.

dois vértices da extremidade, são movidos. A Figura 6.3(c) mostra a malha final onde cada vértice do interior tem uma mola conservativa conectando-os às suas posições originais.

A força $\overrightarrow{f_{i}^{c}}$ exercida por uma mola conservativa anexada ao vértice $v_{i}$ é dada por:

$$
\vec{f}_{i}^{c}=-\kappa^{c} \vec{\delta}_{i}
$$

onde $\kappa^{c}$ é o coeficiente de resistividade da mola e $\vec{\delta}_{i}$ é o vetor deslocamento de $v_{i}$.

\subsubsection{Configuração da malha dinâmica com molas conservativas}

Para encontrar a posição de equilíbrio dos vértices, é necessário combinar as molas conservativas com outros tipos de molas, ou seja, deve-se resolver o sistema composto por equações do tipo:

$$
\overrightarrow{f_{i}^{c}}+\overrightarrow{f_{i}}=0
$$

onde $\vec{f}_{i}$ é o somatório das forças exercidas em $v_{i}$ pelas molas tradicionais (longitudinais, semitorcionais, altura, etc).

Em muitas situações é desejável que se tenha controle sobre a influência das molas conservativas no sistema. Em outras palavras, é desejável que o usuário tenha controle para determinar pouca $\left(\vec{f}_{i}^{c}<\vec{f}_{i}\right)$ ou muita $\left(\vec{f}_{i}^{c}>\vec{f}_{i}\right)$ conservação da fronteira original. Embora este ajuste possa ser feito por meio da Equação (6.1), ele não seria intuitivo do ponto de vista do usuário, pois seria necessário encontrar valores adequados para $\kappa^{c}$. Isso é particularmente difícil porque essa calibração depende do grau de refinamento local da malha, pois $\vec{f}_{i}$ depende do tamanho das arestas e/ou das áreas dos elementos vizinhos. Portanto, fá-se necessária uma 
alternativa mais simples para calibrar as forças $\vec{f}_{i}^{c}$ e $\vec{f}_{i}$, a qual pode ser feita alterando-se a Equação (6.2) para

$$
\alpha_{c} \vec{f}_{i}^{c}+\left(1-\alpha_{c}\right) \vec{f}_{i}=0
$$

onde $0 \leq \alpha_{c} \leq 1$ é uma constante de calibração definida pelo usuário. Observe que quando $\alpha_{c}=1$ apenas a mola conservativa exerce força e o vértice permanece em sua posição original. Por outro lado, quando $\alpha_{c}=0$ a força de conservação é nula e o sistema se torna a malha dinâmica clássica.

Diferentes tipos de molas podem ser considerados para gerar a força $\overrightarrow{f_{i}}$. Na discussão que se segue, foram utilizadas molas longitudinais e semi-torcionais, mas outras configurações também são possíveis. A força $\vec{f}_{i}$ pode ser calculada por

$$
\overrightarrow{f_{i}}=\sum_{v_{j} \in V\left(\widehat{\aleph}_{v_{i}}\right)} \kappa_{i j}^{n c}\left(\vec{\delta}_{j}-\vec{\delta}_{i}\right),
$$

(compare com a Equação (3.12)). O valor de $\kappa_{i j}^{n c}$ é o somatório dos coeficientes de rigidez de todas as molas que controlam a aresta $e_{i j}$. Por exemplo, se a malha da fronteira for uma triangulação com molas longitudinais e semi-torcionais, então o coeficiente $\kappa_{i j}^{n c}$ é dado pela Equação (3.34).

O método de Gauss-Seidel pode ser utilizado para resolver o sistema formado por equações do tipo (6.3), $\forall v_{i} \in T$. Substituindo-se a Equação (6.1) e a Equação (6.4) na Equação (6.3) obtem-se que

$$
\begin{aligned}
& 0=-\alpha_{c} \kappa^{c} \vec{\delta}_{i}+\left(1-\alpha_{c}\right) \sum_{v_{j} \in V\left(\text { 光 } v_{i}\right)} \kappa_{i j}^{n c}\left(\vec{\delta}_{j}-\vec{\delta}_{i}\right) \\
& \vec{\delta}_{i}\left[\alpha_{c} \kappa^{c}+\left(1-\alpha_{c}\right) \sum_{v_{j} \in V\left(\widehat{\kappa} v_{i}\right)} \kappa_{i j}^{n c}\right]=\left(1-\alpha_{c}\right) \sum_{v_{j} \in V\left(\overleftrightarrow{\kappa} v_{i}\right)} \kappa_{i j}^{n c} \vec{\delta}_{j} \\
& \vec{\delta}_{i}=\frac{\left(1-\alpha_{c}\right) \sum_{v_{j} \in V\left(\text { « } v_{i}\right)} \kappa_{i j}^{n c} \vec{\delta}_{j}}{\alpha_{c} \kappa^{c}+\left(1-\alpha_{c}\right) \sum_{v_{j} \in V\left(\aleph_{v_{i}}\right)} \kappa_{i j}^{n c}}
\end{aligned}
$$

Os efeitos do parâmetro $\alpha_{c}$ em uma malha 1D podem ser percebidos na Figura 6.4. A malha original é a linha horizontal em negrito, cujos vértices extremos são $v_{a}$ e $v_{b}$. A deformação imposta é dada pelo deslocamento do vértice $v_{b}$ para $v_{b^{\prime}}$ por meio do vetor $\vec{\delta}_{b}$. A Figura 6.4 mostra simultaneamente os resultados após aplicar a malha dinâmica com molas conservativas 


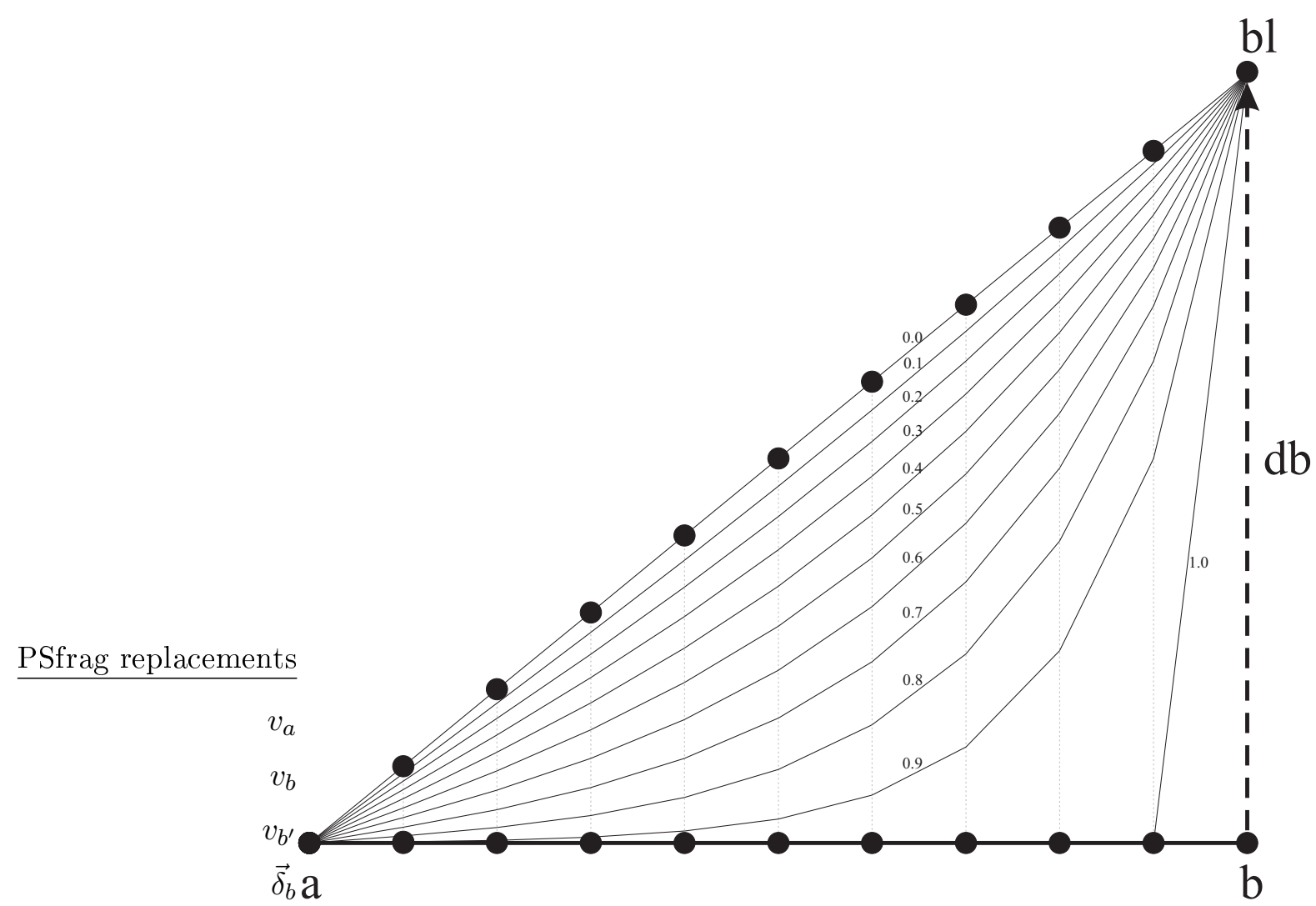

Figura 6.4: Efeitos do parâmetro $\alpha_{c}$ em malhas dinâmicas com molas conservativas.

com o parâmetro $\alpha_{c}$ valendo os seguintes valores: $0.0,0.1,0.2,0.3,0.4,0.5,0.6,0.7,0.8,0.9$, e 1.0 .

\subsection{Remodelagem automática da geometria de um avião}

O projeto de asas de aviões tradicionalmente é feito com o auxilio de ensaios em tunel de vento e simuladores computacionais de escoamento de fluídos. Este trabalho normalmente requer várias etapas que alternam, ensaios e mudanças na geometria da asa, até que se obtenham os resultados desejados. No caso dos ensaios computacionais, este processo envolve várias chamadas do simulador para diferentes geometrias de asa. Estas chamadas computam propriedades do fluido tais como distribuição de pressão e arrasto sobre a asa do avião. Estas propriedades são usadas para alimentar o processo de otimização da geometria da asa. O processo de modificação da asa geralmente é caro computacionalmente, pois podem ser requeridas centenas de iterações simulador/otimização [72]. O número de execuções pode ser reduzido consideravelmente se o processo de otimização da geometria da asa também puder ser automatizado. Uma técnica disponível é conhecida como projeto inverso. 
O projeto inverso emprega informações como (1) a descrição geométrica inicial da asa; (2) a distribuição de pressão sobre a asa para a geometria inicial; (3) a distribuição de pressão desejada especificada pelo usuário; e (4) um conjunto de especificações opcionais na forma de restrições. Com estes dados é produzida uma nova geometria que aproxima as características da asa desejadas pelo engenheiro projetista.

Nesta aplicação está sendo considerado um cenário onde as simulações de escoamento de fluidos são feitas em um domínio tridimensional e a ferramenta que implementa a técnica de projeto inverso opera sobre malhas bidimensionais. Apesar de rodarem em dimensões diferentes, estas duas ferramentas podem ser acopladas. Suponha, para isso, uma malha volumétrica definida ao redor do avião que se deseja processar. Planos de corte perpendiculares à asa do avião são posicionados na malha volumétrica. A interseção entre os planos de corte e a asa do avião definem curvas, que serão chamadas de perfis. A ferramenta de projeto inverso pode ser executada sobre malhas 2D localizadas sobre os planos de corte e modificar a geometria dos perfís da asa. Com a nova descrição geométrica dos perfis, um novo avião com a asa modificada pode ser remodelado por ferramentas CAD e uma nova malha volumétrica pode ser gerada. Este é um processo difícil de ser automatizado e geralmente a intervenção humana é requerida em duas tarefas: (1) na remodelagem do avião para produzir a nova geometria da asa e (2) na geração da nova malha volumétrica.

Uma das propostas desta tese é apresentar uma metodologia inovadora baseada em malhas dinâmicas capaz de automatizar o acoplamento entre a ferramenta de projeto inverso (2D) e o simulador de escoamento de fluidos (3D).

A Figura 6.5 ilustra a metodologia proposta. Na Figura 6.5a, é apresentada a superfície do avião, a malha volumétrica não é mostrada para evitar confusão visual. Na Figura 6.5b, são posicionados três planos de corte sobre a asa do modelo. Na Figura 6.5c é apresentado o conjunto de perfis dados pela interseção dos planos de corte e a asa, estes perfis são chamados de perfis-velhos. A ferramenta de projeto inverso modifica a geometria dos perfis-velhos produzindo os perfis-novos, esta etapa do processo é representada na Figura 6.5d. Com base nas informações geométricas contidas nos dois conjuntos de perfis, a geometria da asa do avião é modificada. A reconstrução da geometria é representada pela Figura 6.5e. A alteração da asa causa problemas tanto na malha superficial (fronteira da malha volumétrica) quanto na volumétrica. Esses problemas são corrigidos por meio de técnicas baseadas em malha dinâmica. O resultado é uma malha modificada e corrigida, pronta para ser utilizada novamente pelo simulador 3D.

A malha representando a geometria do avião é obtida diretamente da malha volumétrica, isto é, são células do bordo, e será chamada de malha-superficial. Portanto, dois tipos de 


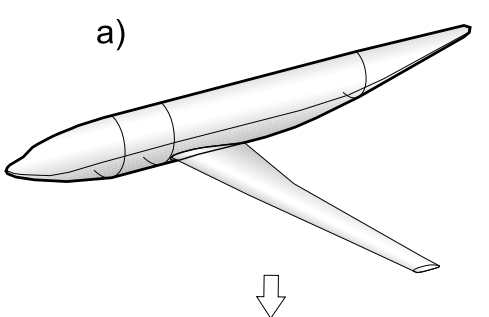

b)

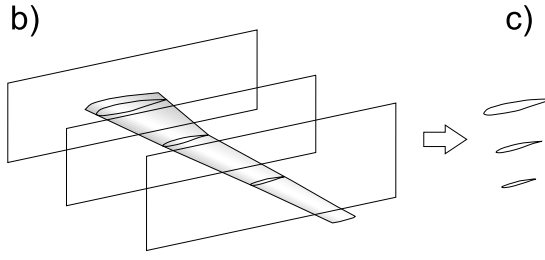

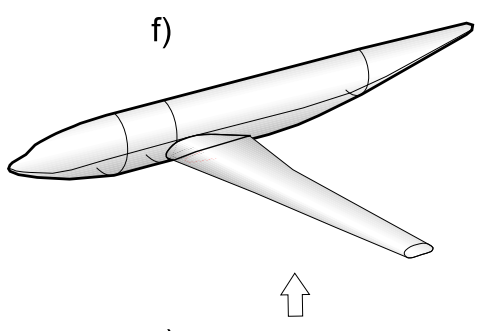

e)

Figura 6.5: Integração entre projeto inverso (2D) e simulador de escoamento de fluidos (3D).

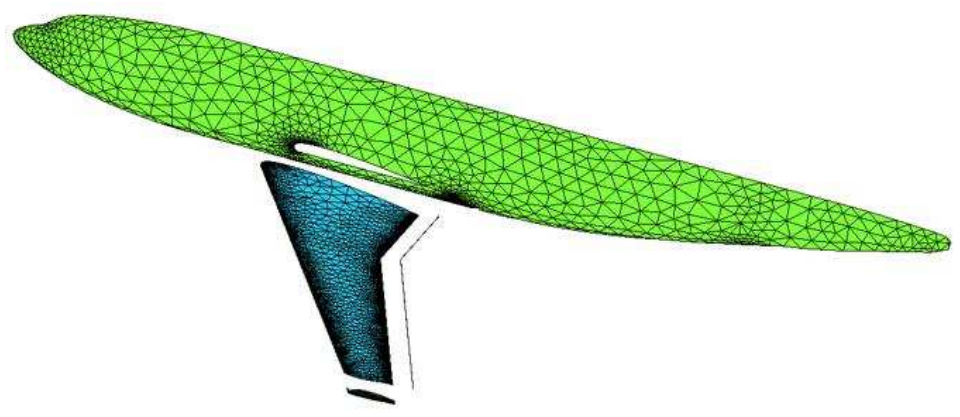

Figura 6.6: O modelo de avião composto por quatro grupos: $G_{F}, G_{A s a}, G_{B F}$ e $G_{P A}$.

malhas estão envolvidas no processo descrito, uma composta por triângulos e outra composta por tetraedros.

Para exemplificar a metodologia proposta, será apresentado um caso específico. O modelo de avião tratado no exemplo a seguir é bastante simples. Este é composto por fuselagem, asa, bordo de fuga e ponta-de-asa. As células da malha superficial relativas a cada componente definem grupos. Será utilizada a notação $G_{A s a}, G_{B F}, G_{P A}$ e $G_{F}$ para referenciar os grupos dos componentes asa, bordo de fuga, ponta-de-asa e fuselagem, respectivamente. Por exemplo, $G_{A s a}$ é composto por todos os triângulos da malha-superficial sobre a asa do avião. Os grupos são importantes porque eles possibilitam que diferentes técnicas de malha dinâmica sejam aplicadas em diferentes componentes do modelo. A Figura 6.6 mostra o modelo do avião e seus quatro grupos.

A transferência da informação geométrica dos perfis-novos (2D) para o modelo do avião (3D) é feita em diferentes estágios. A ordem de processamento dos componentes é a seguinte: $G_{A s a}, G_{B F}, G_{P A}$ e $G_{F}$. Todos esses componentes são movidos por malha dinâmica usando 


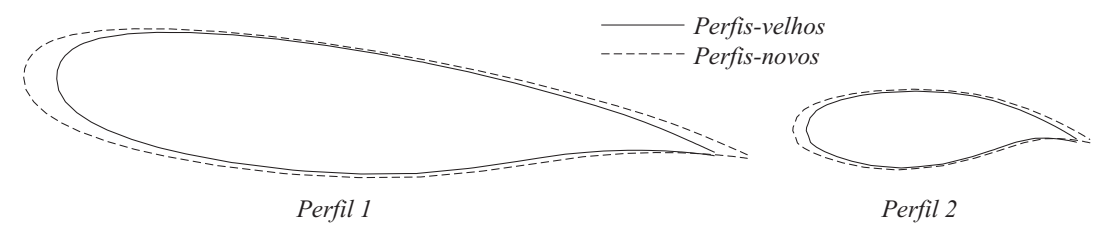

Figura 6.7: Os conjuntos perfis-velhos e perfis-novos tratados nesta seção.

molas conservativas, descritas na Seção 6.1.

Na prática, as modificações geométricas do conjunto de perfis causadas pelo projeto inverso são pequenas em escala se comparadas com as dimensões do modelo. Entretanto, para mostrar a robustez da técnica proposta, foi empregada uma deformação nos perfis bem maior que a usual. A Figura 6.7 mostra os conjuntos de perfis utilizados para produzir os resultados apresentados aqui. Foram utilizados apenas dois planos de corte, assim cada conjunto é composto por apenas dois perfis. Porém, a utilização de mais de cortes, implica em mais informação para modificar o modelo, o que aumenta as chances de se obter melhores resultados com o modelo final.

\subsubsection{Tratamento da asa}

Para realizar o movimento do grupo $G_{A s a}$, é necessário obter vetores deslocamento a partir dos conjuntos de perfis. Estes vetores deslocamento são vetores que levam os pontos dos perfis-velhos aos pontos correspondentes, assumindo que existam, dos perfis-novos. Os vetores deslocamento carregam consigo então a informação necessária para a reconstrução geométrica da asa. Apenas um conjunto restrito de vértices do grupo $G_{A s a}$ recebem vetores deslocamento diretamente dos perfís, a saber, aqueles que estão mais próximos dos perfis. Este conjunto de vértices é denotado por $V_{P}^{a s a}$.

Assumindo que os vetores deslocamento não necessariamente pertencem à nenhum bordo do grupo $G_{A s a}$, a malha dinâmica deve ser aplicada de uma maneira diferente à explicada anteriormente. Os únicos vértices fixos são os de $V_{P}^{a s a}$, todos os outros vértices do grupo, independentemente de serem de bordo ou do interior, são tratados normalmente pela malha dinâmica. Para mover a asa do caso tratado (Figura 6.6), foi utilizado $\alpha_{c}=0.0$ (ver Equação $(6.5))$.

Após a ação da malha dinâmica, a fronteira de $G_{\text {Asa }}$ é deslocada. Este deslocamento pode causar problemas nas componentes adjacentes à asa. A Figura 6.8 ilustra os problemas causados pelo movimento do grupo $G_{A s a}$. Na figura é mostrado em cores diferentes a malha superficial do modelo antes e após a movimentação de $G_{A s a}$. As ampliações mostram os 


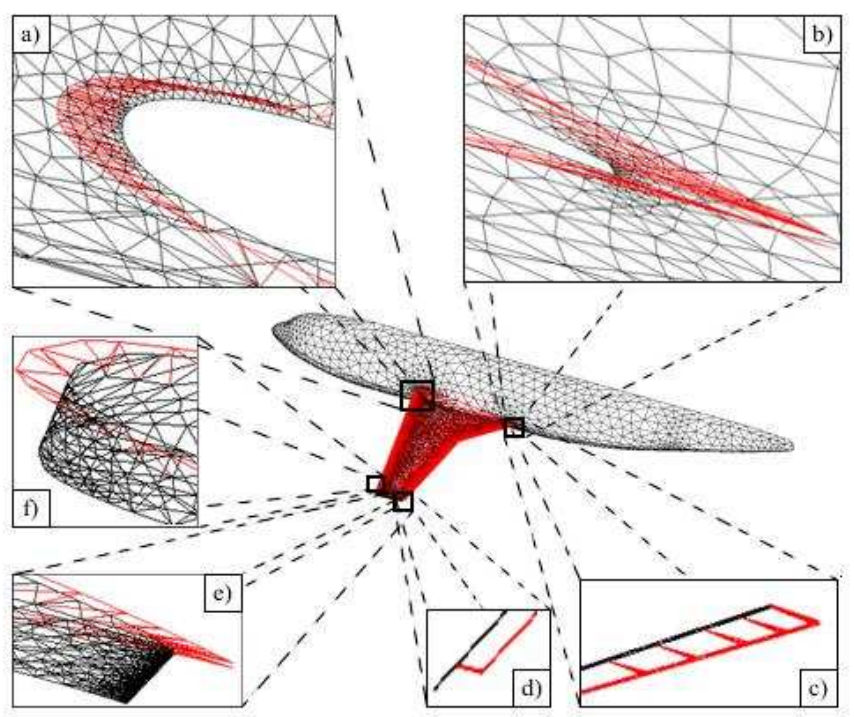

Figura 6.8: Problemas causados no modelo devido ao movimento da asa.

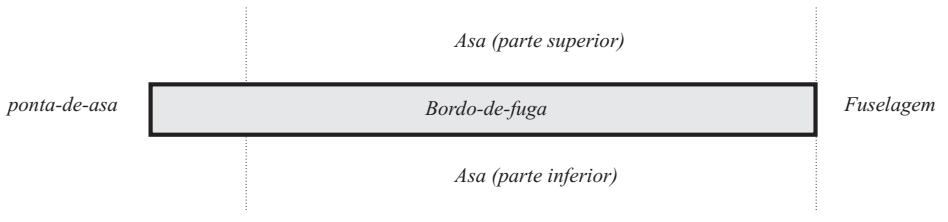

Figura 6.9: Esquema de compartilhamento da fronteira do bordo-de-fuga com as outras componentes do avião.

problemas causados nas componentes adjacentes. O grupo $G_{A s a}$ foi omitido para explicitar os problemas. Em (a) e (b) pode-se perceber que células inválidas acontecem na fuselagem. Os problemas ocorridos no bordo-de-fuga são mostrados em (c) e (d), e em (e) e (f) os problemas na ponta-de-asa.

\subsubsection{Tratamento do bordo-de-fuga}

Considerando apenas o bordo-de-fuga, grupo $G_{B F}$, seu bordo é dado por uma curva, referida por $\partial_{T E}$. A curva $\partial_{T E}$ é também compartilhada pelos componentes asa, ponta-de-asa e fuselagem. Este compartilhamento pode ser visto esquematicamente na Figura 6.9. O grupo $G_{A s a}$ foi movido antes do tratamento do grupo $G_{B F}$, desta forma as partes da curva $\partial_{T E}$ adjacentes à asa também são deformadas. Esse movimento parcial de $\partial_{T E}$ pode induzir problemas como os mostrados na Figura 6.10.

O tratamento do grupo $G_{B F}$ é feito em dois estágios: (1) correção do bordo $\partial_{T E}$ de $G_{B F}$ 


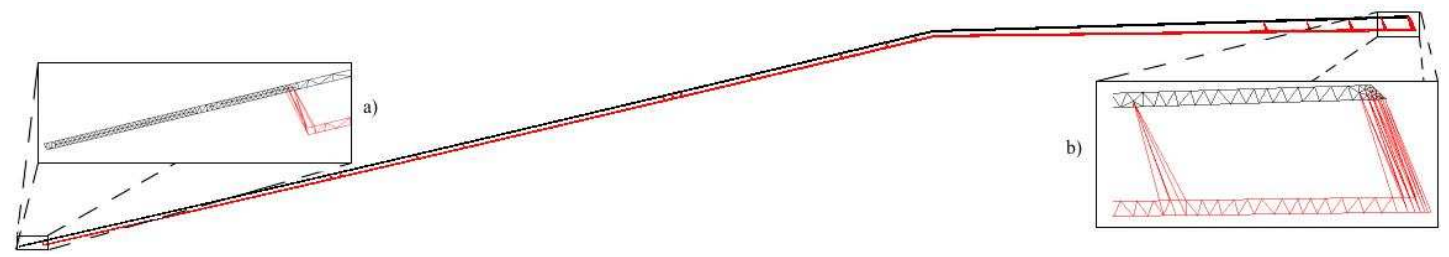

Figura 6.10: Detalhes dos problemas causados na componente bordo-de-fuga devido ao movimento da asa.

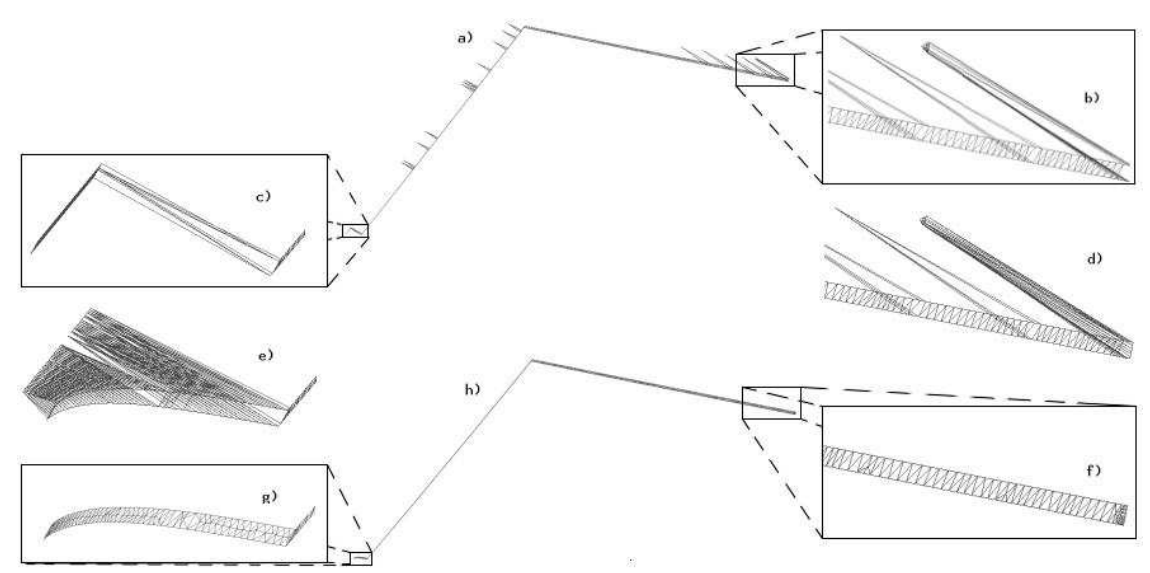

Figura 6.11: Correção da componente bordo-de-fuga.

e (2) correção da malha superficial definida por $G_{B F}$.

No primeiro estágio é utilizada uma versão 1D da malha dinâmica com molas conservativas. Neste exemplo, para a região de $\partial_{T E}$ adjacente à ponta-de-asa, o parâmetro utilizado foi $\alpha_{c}=0.3$, e para a região adjacente à fuselagem $\alpha_{c}=0.0$ (ver Equação (6.5)). No segundo estágio, foi usada a versão 2D de malha dinâmica com molas conservativas com o parâmetro $\alpha_{c}$ nulo.

A Figura 6.11 ilustra o processo de correção do bordo-de-fuga. Em (a) é apresentado o bordo-de-fuga com os efeitos causados pelo movimento do componente asa e em (b) o resultado da correção. As ampliações mostradas em (d) e (e) mostram o resultado após a correção do bordo.

Concluidas as correções no bordo-de-fuga, as fronteiras entre grupos não são mais deslocadas, apenas seus nós interiores são modificados. Desta forma, o tratamento da ponta-de-asa e da fuselagem é mais simples do que o tratamento dos grupos anteriores. 


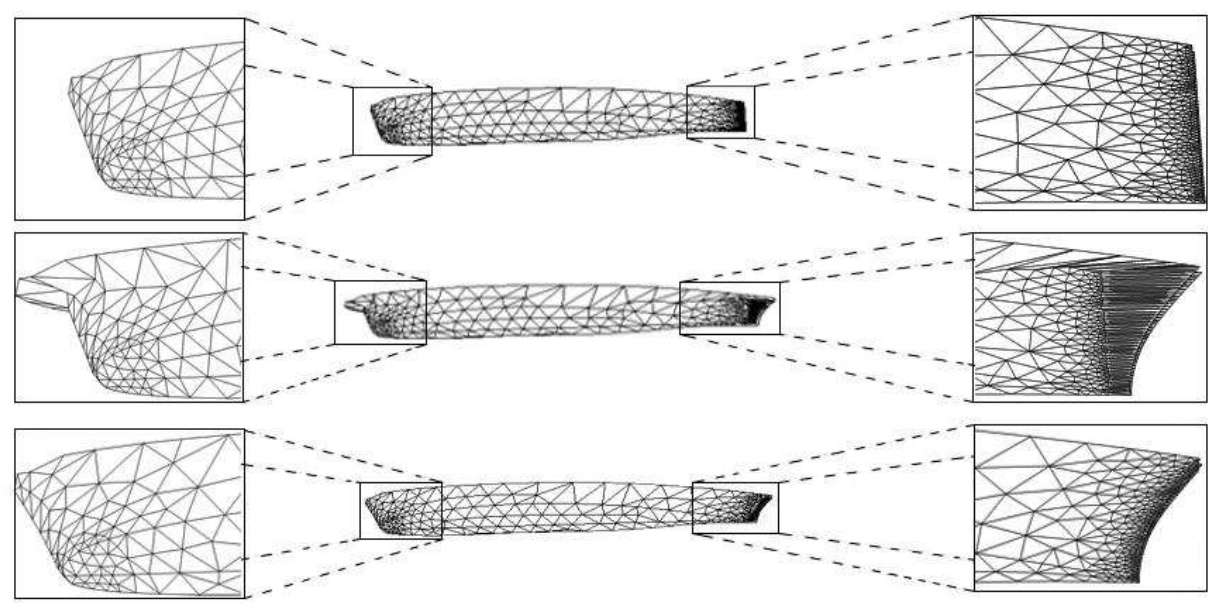

Figura 6.12: Correção da componente ponta-de-asa.

\subsubsection{Tratamento da ponta-de-asa}

A dificuldade em tratar a ponta-de-asa é que esta pode assumir diferentes formas geométricas. Estas podem variar desde superfícies planas até complexas winglets. Por isso, este é o componente onde as molas conservativas têm maior importância.

Para a geometria específica deste exemplo, as molas conservativas não desempenham um papel muito importante, assim o parâmetro $\alpha_{c}$ da Equação (6.5) foi ajustado em 0.2.

O processo de correção da componente ponta-de-asa é mostrado na Figura 6.12. A figura apresenta, de cima para baixo, a malha original antes de qualquer deformação, a malha após o movimento da asa e do bordo-de-fuga e finalmente após a correção. Pode-se verificar que a malha corrigida recupera com êxito a forma geométrica original na parte frontal da ponta-deasa (à esquerda na figura). O aspecto curvado na parte traseira (à direita na figura) é causado pela correção do bordo-de-fuga, veja a Figura 6.11(g).

\subsubsection{Tratamento da Fuselagem}

Os problemas causados na fuselagem devido ao movimento da asa e do bordo-de-fuga também são tratados por malhas dinâmicas com molas conservativas. No exemplo ilustrativo, foi utilizado $\alpha_{c}=0.0$ (veja a Equação (6.5)), pois quanto mais livre a malha dinâmica, maiores as chances de correção dos elementos inválidos. Note que a fuselagem foi a única componente a apresentar tais elementos. O valor $\alpha_{c}=0.0$, causa, obviamente, uma deformação na forma geométrica da fuselagem. Esta deformação, porém, é pequena e não compromete os resultados do processo de otimização da asa. 

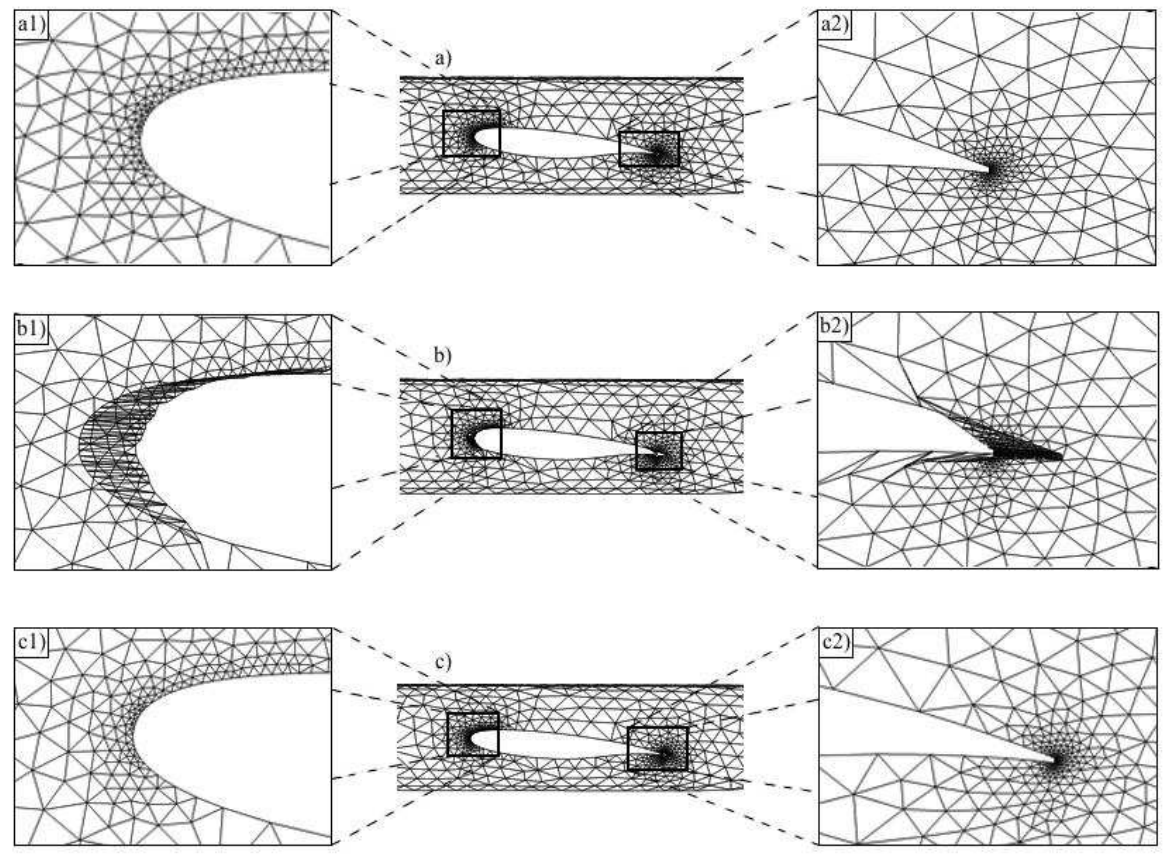

Figura 6.13: Correção da componente fuselagem.

Os passos de tratamento da fuselagem podem ser vistos na Figura 6.13. Em (a), (b) e (c) são apresentadas, respectivamente, a malha original, a malha após o movimento da asa e do bordo-de-fuga, e a malha após a correção da fuselagem. Pode-se notar comparando-se (a1) com (c1) e (a2) com (c2) que a qualidade da malha da malha movimentada é semelhante à da malha original.

\subsubsection{O movimento da malha volumétrica}

A malha superficial é bordo da malha volumétrica, desta forma, as correções na malha superficial afetam diretamente a malha volumétrica. Portanto, a malha dinâmica 3D deve ser empregada para corrigir problemas e melhorar a qualidade da malha volumétrica deformada. No exemplo tratado, a malha volumétrica é composta por 96693 tetraedros e 22402 vértices. Para movê-la, foram utilizadas molas longitudinais e semi-torcionais.

Embora as aplicações potenciais para o emprego da metodologia proposta sejam as relacionadas com projeto inverso e simulador de escoamento de fluidos, o foco deste trabalho objetiva resultados geométricos. Em outras palavras, não foi realizada simulação de escoamento de fluidos na malha modificada para verificar sua adequação. Ao invés disso, a malha volumétrica modificada é avaliada em termos da qualidade de seus elementos. A métrica utilizada é a razão 
de aspecto e é dada por

$$
\beta=\frac{V}{\ell_{\max }^{3}},
$$

onde $V$ é o volume do tetraedro e $\ell_{\max }$ o comprimento de sua maior aresta. Quanto maior o valor de $\beta$, melhor a qualidade. Valores negativos de $\beta$ indicam tetraedros inválidos, ou seja, houve cruzamento de faces e arestas.

A tabela 6.1 fornece valores de qualidade que ajudam a verificar os resultados obtidos. Os valores $\beta_{\min }$ e $\beta_{\max }$ são, respectivamente, o menor e o maior valor de $\beta$ na malha analisada, e $\bar{\beta}$ refere-se à média aritmética de $\beta$ considerando-se todos os elementos da malha. O número de tetraedros inválidos também são mostrados na tabela 6.1. Os valores da tabela foram adquiridos para a mesma malha em quatro estágios diferentes:

1. Malha original: malha original sem movimentação.

2. Asa movimentada: malha após a movimentação da asa, conforme descrito na Seção 6.2.1.

3. Modelo corrigido: malha após a movimentação dos componentes adjacentes à asa.

4. Malha final: malha após todo o processo de movimentação, incluindo o movimento da malha volumétrica.

Tabela 6.1: Medições de qualidade dos elementos da malha volumétrica.

\begin{tabular}{|l|l|l|l|l|}
\hline Estágios & $\beta_{\min }$ & $\beta_{\max }$ & $\bar{\beta}$ & Inválidos \\
\hline Malha original & 0.008182 & 0.109553 & 0.0361731 & 0 \\
\hline Asa movimentada & -0.073921 & 0.107143 & 0.0236085 & 17160 \\
\hline Modelo corrigido & -0.073921 & 0.107143 & 0.0223170 & 18441 \\
\hline Malha final & 0.004392 & 0.107143 & 0.0361874 & 0 \\
\hline
\end{tabular}

Analisando as entradas da tabela 6.1, pode-se perceber que, apesar da grande deformação do domínio, todos os elementos inválidos foram corrigidos. Como esperado, o valor de $\bar{\beta}$ da Malha final é maior que o da Malha original, porém note que a degradação é pequena. Este fato pode ser melhor percebido por meio da Figura 6.14 onde pode ser vista a distribuição das medidas de qualidade $\beta$ considerando Malha original e a Malha final. Pode-se perceber na Figura 6.14 que os gráficos são quase idênticos. 


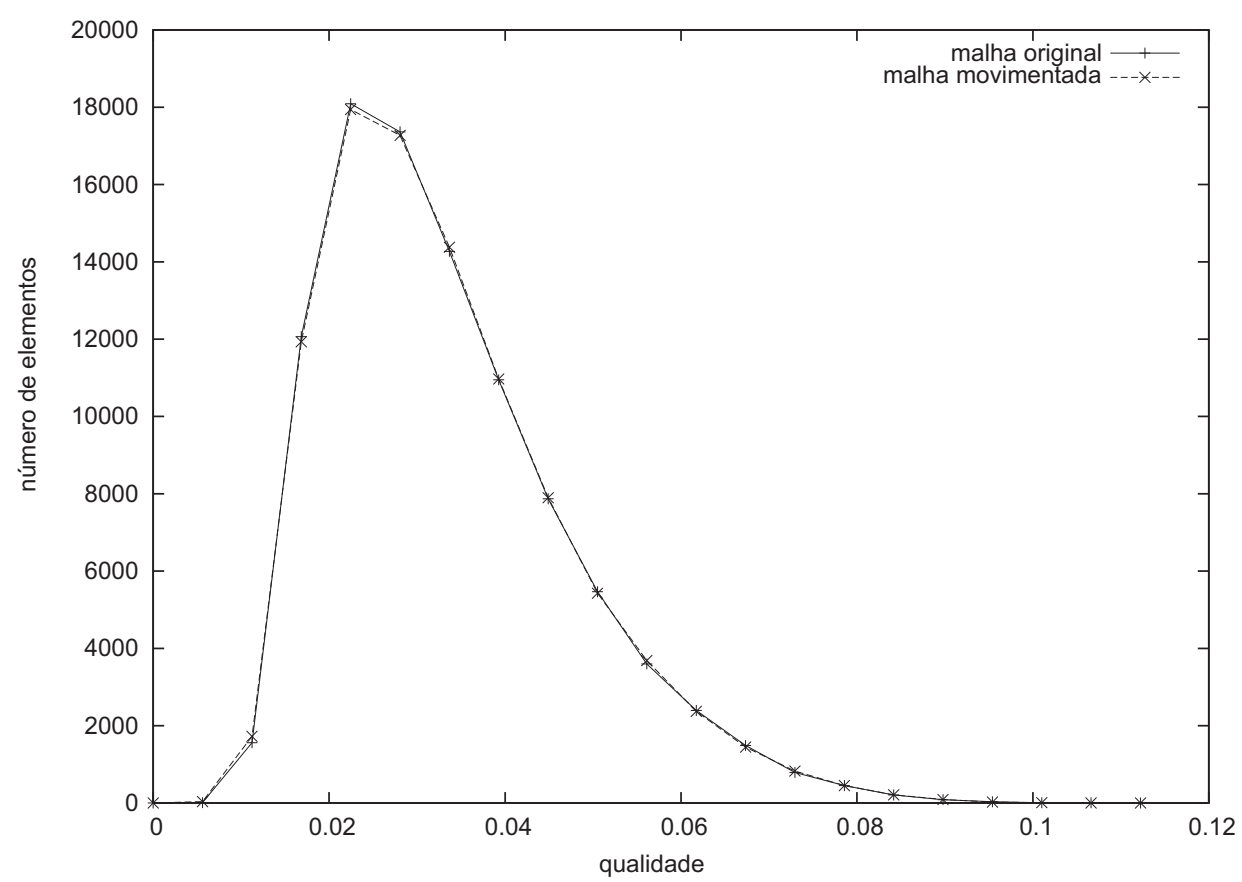

Figura 6.14: Qualidade dos elementos da malha original e da malha final. 


\section{Capítulo 7}

\section{Remalhamento de triangulações}

\section{superficiais}

Malhas superficiais são comumente utilizadas para representar a forma de objetos em aplicações computacionais. Muitas dessas malhas são freqüentemente geradas via algoritmos de reconstrução ou via representações implícitas de isosuperfícies. Algoritmos de reconstrução são amplamente utilizados em contextos onde é necessário criar representações computacionais de objetos no mundo real. Para isso, o objeto em questão é varrido por scanner tridimensional que gera um conjunto de pontos representando a superfície do modelo. Algoritmos de reconstrução identificam possíveis conectividades entre os pontos do conjunto para criar malhas. Uma característica comum em malhas produzidas por este processo é a abundância de vértices, que está diretamente relacionada com a resolução do dispositivo. Além disso, redundância de vértices é também comum em malhas produzidas por estes processos. Portanto, as malhas geradas por tais processos, especialmente quando automatizados, raramente são satisfatórias para o processamento seguinte. Ferramentas automáticas para redução de complexidade de tais modelos têm estimulado um considerável número de trabalhos em simplificação de malhas [62, 43, 5, 41]. Além da redução de complexidade, tem-se tembém uma frequente demanda por métodos capazes de melhorar a qualidade das malhas, isto é, promover uma melhor amostragem de vértices bem como a regularidade dos elementos. Este processo de melhoramento é conhecido como remalhamento.

O Remalhamento de superfícies é uma ferramenta importante para várias aplicações em diversos contextos tais como, modelagem, edição, animação e simulação. É uma área de pesquisa que tem recebido considerável atenção nos últimos anos, o que tem, por conseguinte, proporcionado o surgimento de um grande número de técnicas com os mais variados propósitos. Alliez et al. [3] fizem uma boa revisão dos principais métodos para remalhamento de superfícies. 
Nessa revisão, eles dão uma possível definição para remalhamento de superfícies como: "o processo, que recebendo uma malha de entrada, calcula uma outra malha cujos elementos satisfazem algum requisito de qualidade ao mesmo tempo em que aproxima a superfície de entrada." Qualidade, neste caso, depende da aplicação para a qual a malha é destinada. Ela pode estar relacionada com amostragem, regularidade, tamanho e formato dos elementos. As técnicas para remalhamento não necessariamente precisam alterar a malha de entrada, elas podem, alternativamente, criar uma nova malha desde o princípio.

Neste trabalho é proposto um novo método chamado ANTS. O nome é um acrônimo para Anisotropic Triangulations on Surfaces. O ANTS é um método prático para remalhamento de superfícies a fim de gerar triangulações anisotrópicas. Suas principais características são:

- Capacidade de remalhar triangulações descrevendo modelos com geometria complexa.

- Funciona alterando a superfície diretamente, isto é, não emprega qualquer tipo de parametrização para realizar as alterações na malha.

- Capacidade de preservar detalhes geométricos da superfície de entrada.

- Promover malhas de alta qualidade para simulações numéricas.

- Processa o remalhamento considerando tanto simplificação (redução de vértices) quanto refinamento (inclusão de vértices).

- Emprega movimento de nós durante o remalhamento.

Em [3] os autores listam quais são os principais requisitos envolvidos no remalhamento de superfícies. Estes requisitos estão listados a seguir com comentários a respeito de como o ANTS atende tais requisitos:

- validade: a malha produzida deve ser uma malha válida. Isso geralmente significa que ela deve ser uma variedade simples, e tipicamente fechada (sem bordos). No estágio atual de desenvolvimento do ANTS, ele é capaz de remalhar variedades com bordo gerando sempre malhas válidas. Mais ainda, a idéia central do método pode ser facilmente estendida para proporcionar também remalhamento de não-variedades.

- qualidade: A qualidade dos elementos das malhas é crucial para a robustez e a estabilidade numérica, tanto para simulação numérica quanto para processamento geométrico. Em aplicações envolvendo elementos finitos, por exemplo, malhas compostas por elementos próximos dos regulares são preferíveis, tanto em termos de geometria como de 
conectividade. Malhas de alta qualidade são requeridas para minimizar os erros numéricos da solução [79]. O ANTS foi criado com o intuito de gerar malhas para serem utilizadas em simulações numéricas. Portanto, uma grande ênfase foi dada para que os triângulos gerados atingissem níveis aceitáveis de qualidade. Como será visto mais adiante, os elementos gerados pelo ANTS procuram obedecer a uma função que determina quais seriam os tamanhos desejados de elementos sobre o domínio. Sendo assim, a qualidade dos elementos está intimamente ligada às propriedades dessa função. Para se obter malhas de boa qualidade é necessário que a função seja adequadamente suave, isto é, não determine tamanhos muito diferentes em uma pequena vizinhança. Além disso, o ANTS foi desenvolvido para que possibilitasse a geração de malhas tanto anisotrópicas quanto isotrópicas.

- Fidelidade: A malha gerada deve aproximar a forma geométrica original mantendo, ao mesmo tempo, o número de elementos da malha abaixo de um determinado limiar. Idealmente, a resolução da malha gerada deve ser a mínima possível tal que os critérios de fidelidade sejam satisfeitos. Isto envolve a escolha de uma métrica para o erro da aproximação, bem como decidir entre interpolação e aproximação. A fidelidade geométrica é mantida pelo ANTS através da definição de uma métrica e um limiar fornecido pelo usuário. Qualquer alteração na malha só é permitida se o limiar estabelecido for obedecido. Sendo assim, o usuário tem o controle de quão fiel a malha gerada deve ser. Além disso, o ANTS identifica, em uma fase de pré-processamento, as principais linhas e pontos característicos do modelo e preserva estas entidades durante o remalhamento, isso faz com que quinas e pontas presentes na malha original estejam presentes na produzida. Finalmente, a malha gerada é uma interpolação da original, uma vez que todos os vértices da primeira estão sobre a última.

- Entrada discreta: Os métodos recebem como entrada uma malha discreta, que é geralmente uma aproximação de algum modelo original contínuo possivelmente desconhecido. Quando a malha não é uma discretização adequada do modelo original, a tarefa de obtenção da maioria das informações geométricas (vetor normal, plano tangente, estimativa de curvatura) é dificultada. Além disso, a malha de entrada pode ter diversos defeitos com relação ao modelo original. Por exemplo, malhas geradas por reconstrução a partir de nuvens de pontos podem possuir artefatos de aliasing e faltar importantes características presentes no modelo original. Este item de certa forma entra em conflito com o item fidelidade. No caso do ANTS a fidelidade geométrica é colocada em primeiro plano. Se for necessário fazer correções na malha original, estas devem ocorrer em alguma etapa 
de pré-processamento.

- Grandes conjuntos de dados: Escaneadores 3D modernos geram grandes conjuntos de dados uma vez que a taxa de amostragem é aumentada para garantir que detalhes geométricos sejam obtidos. Como resultado, a amostragem e a triangulação não são sensíveis à forma e existem, portanto, muitas redundâncias nos dados. O ANTS é um método que pode ser facilmente paralelizado, o que o torna adequado para o processamento de malhas grandes. Neste trabalho, no entanto, o paralelismo do algoritmo não é tratado.

- Incerteza: A malha de entrada pode ter ruídos. O ANTS pode tratar superfícies pouco ruidosas desde que sejam feitos ajustes adequados nos parâmetros de entrada do método. Porém, em superfícies muito ruidosas, é aconselhável que seja realizado algum pré-processamento para eliminar ruídos.

- Correspondência: Uma questão comum a todas as técnicas refere-se a como encontrar a localização correspondente de um novo vértice sobre a superfície de entrada. Tal correspondência é tipicamente encontrada via parapetrização da malha de entrada. Este é um problema complexo que pode ser computacionalmente caro, ter problemas quanto à precisão ou mesmo impor restrições sobre a malha de entrada. Isto é particularmente problemático quando as operações de remalhamento são executadas em um domínio 2D, pois o mapeamento de estruturas não triviais 3D (possivelmente uma malha com número arbitrário de genus e buracos) para um domínio paramétrico 2D inevitavelmente introduz distorções métricas e pode levar a perda de informações importantes. Além disso, se a parametrização é combinada com segmentação de malha, é bem possível que sejam encontradas dificuldades próximas aos bordos dos segmentos. Existem técnicas que são livres de parametrizações e que trabalham diretamente sobre a superfície fazendo modificações locais na malha tais como adição, remoção e reposicionamento de vértices. Durante tais modificações, os vértices da malha são forçados a permanecerem sobre a malha de entrada. Esta abordagem pode ser encontrada em diferentes técnicas [40, 39, 48, 47, 1, 101, 92]. As modificações são realizadas em 3D (as quais são computacionalmente caras) ou em um plano tangente (as quais são mais rápidas, porém menos precisas). Se operações locais são utilizadas, então as armadilhas das técnicas baseadas em parametrizações globais são evitadas. As distorções causadas pelo mapeamento de uma malha 3D em um domínio 2D paramétrico pode ser consideravelmente reduzidas utilizando-se sobreposição de segmentos [92]; e o acúmulo de erro (freqüentemente causados pelas operações locais) pode ser minimizado pela constante comparação 
com uma aproximação suave da geometria original (por exemplo, usando triângulos PN [102] ou retalhos contínuos [105]). O ANTS é uma técnica que não faz qualquer tipo de parametrização, seja global ou local, para realizar o remalhamento.

Ao se elaborar uma técnica para remalhamento, é necessário avaliar os principais requisitos que devem ser obedecidos. Muitos requisitos são antagônicos, como, por exemplo, a qualidade da malha produzida e a rapidez de processamento. Portanto, é necessário estabelecer um compromisso entre os dois requisitos. O ANTS foi desenvolvido para que atendesse, até certo ponto, os dois critérios. Todavia, uma maior ênfase foi dada no sentido de fazer com que o método atendesse prioritariamente critérios de qualidade da malha produzida, sem perder de vista, obviamente, fatores ligados ao desempenho computacional.

A seguir são apresentados os principais trabalhos sobre remalhamento de superfícies, quer sejam planares ou curvilíneas, quer sejam para triangulações isotrópicas ou anisotrópicas. Muito embora alguns dos trabalhos citados aqui não compartilham o mesmo objetivo do ANTS, isto é, remalhamento anisotrópico de superfícies com geometria complicada, eles são mencionados por contribuírem, diretamente ou indiretamente, para a formulação do método proposto. Uma revisão das técnicas para remalhamento de superfícies pode ser encontrada em [3].

Algumas técnicas fazem uso de parametrização da superfície em regiões planares. O problema dessa estratégia é que a técnica de remalhamento fica limitada ao tratamento de superfícies homeomórficas a discos. Se superfícies mais gerais precisam ser tratadas, então é necessário recortá-las e uní-las novamente e, neste caso, a qualidade do remalhamento tende a se degradar nas regiões próximas à costura. Além disso, realizar parametrização global de objetos grandes e detalhados pode ser um desafio considerável. Uma alternativa à parametrização são as técnicas baseadas em operadores de remalhamento local (quebra de arestas, colapsação de arestas, flipping de arestas e reposicionamento de vértices) pois estes geralmente oferecem maior flexibilidade ao processo de remalhamento. Todavia, é necessário tomar cuidado ao aplicar tais operadores, pois estes podem modificar o formato geométrico do modelo. O método proposto neste trabalho não faz uso de qualquer tipo de parametrização para efetuar o remalhamento.

Métodos baseados na triangulação de Delaunay apóiam-se no teste do circuncírculo vazio para determinar como os nós devem ser conectados para gerar a malha. Este teste determina se o circuncírculo de um dado triângulo da malha é vazio, ou seja, se o círculo não contém algum outro vértice da malha. Para uma triangulação ser Delaunay o teste deve ser verdadeiro para todos os triângulos. O refinamento Delaunay, originalmente proposto por Chew [27], baseia- 
se no aparato teórico oferecido pelo referido teste. Novos pontos são inseridos sempre no circuncentro de triângulos com qualidade insatisfatória. O refinamento é caracterizado por seguir o princípio do ponto mais distante, isto é, sempre que um triângulo não satisfizer o critério de qualidade desejado, então o algoritmo insere um ponto dentro do domínio que é o localmente mais distante de todos os outros pontos presentes no domínio. Quando o processo de refinamento termina, a qualidade desejada dos elementos é automaticamente satisfeita. O desafio no caso é garantir que o processo terminará em algum momento. Um ponto interessante sobre o refinamento Delaunay é que o teste do circuncírculo fornece o aparato teórico necessário para provar o término do algoritmo, desde que determinadas condições de entrada sejam satisfeitas. Ruppert [70] mostrou como adaptar a técnica de refinamento Delaunay de Chew para gerar malhas com refinamento diferenciado sobre um domínio 2D. Shewchuk [77, 78] propôs uma extensão do método de Ruppert para tratar domínios poliedrais 3D sem ângulos agudos, a versão considerando ângulos agudos também foi proposta [26, 25, 68].

Em domínios bidimensionais, esse teste é rápido de ser aplicado e conduz a bons resultados, além de fornecer base teórica para triangulações isotrópicas. Todavia, o mesmo não pode ser dito quando este é adaptado para funcionar em domínios superficiais ou quando a triangulação gerada deve apresentar características anisotrópicas. No entanto, a técnica de refinamento Delaunay é explorada em diversos trabalhos. Chew [28] propôs uma adaptação do teste do circuncírculo vazio para domínios superficiais curvilíneos e então criou o primeiro método para refinamento Delaunay de superfícies. O trabalho de Chew [28] foi adaptado por Boissonnat e Oudot [11] para remalhar superfícies gerais, isto é, superfícies implícitas, modelos CSG e superfícies poliedrais. Cheng et. al [23, 24] propuseram um método para remalhar superfícies dinâmicas definidas por um conjunto finito de esferas. O método adapta dinamicamente a triangulação sobre uma superfície que sofre alterações em forma, curvatura e topologia. Cheng et. al [26] propuseram uma técnica para gerar triangulações sobre superfícies implícitas e paramétricas suaves sem bordo oferecendo garantias teóricas sobre a topologia e geometria da superfície bem como garantias sobre os tamanhos e qualidades dos elementos. Dey et. al [32] introduziram um algoritmo para remalhamento de superfícies poligonais que reamostra uma malha de entrada por meio de refinamento Delaunay e produz uma malha com a mesma topologia e geometria aproximada. Além disso, os elementos da malha gerada têm razão de aspecto limitada e os autores provam que o algoritmo termina se a malha de entrada aproximar adequadamente uma superfície suave.

Métodos baseados em avanço de fronteira [7, 45] para remalhamento de superfícies também estão presentes na literatura. Löhner [61] propôs um método de remalhamento baseado em avanço de fronteira capaz de lidar com superfícies de geometria complicada. Ao invés de fazer 
uso de funções analíticas para aproximar a geometria, o método trabalha diretamente sobre a triangulação de entrada. Para fazer isso, a superfície de entrada é separada em retalhos cujos bordos fornecem as curvas de partida para o processo de avanço de fronteira, para recobrir a superfície original com novos triângulos. Outro trabalho que merece menção é o de Schreiner et al. $[75,76]$ que se baseia nas idéias de reconstrução de superfícies a partir de nuvens de pontos, principalmente na técnica de Scheidegger et al. [74], para fazer o remalhamento. Os autores advogam que a técnica funciona para qualquer modelo de entrada onde se possa calcular a curvatura e fazer projeção de pontos sobre sua superfície, incluindo modelos definidos por nuvens de pontos. O processo de avanço de fronteira é guiado por uma função de espaçamento isotrópica que determina o tamanho dos triângulos de acordo com a curvatura da superfície de entrada. Outros métodos baseados em avanço de fronteira são [87, 34].

A suavização de malhas é geralmente utilizada como uma etapa de pós-processamento para melhorar a qualidade dos elementos da malha. No entanto, movimento de vértices tem sido cada vez mais empregado como parte integrante de métodos para remalhamento. Percebendo essa tendência, Bossen e Hechbert [15] propuseram uma nova forma de classificar métodos de geração de malhas. Muito embora a classificação foi proposta para geração de malhas, ela também é pertinente para remalhamento de superfícies. A classificação se baseia na organização dos passos principais dos algoritmos. Mesmo havendo casos híbridos, os autores propuseram quatro classes principais:

1. Triangulação coletiva (veja a Figura 7.1(a)): escolhe a posição inicial dos vértices sobre o domínio, gera a triangulação a partir deles (geralmente pela triangulação de Delaunay) e então, opcionalmente, melhora a malha usando algum método de suavização. O problema com esta abordagem é que um posicionamento ruim dos vértices iniciais pode acarretar em uma malha com topologia ruim.

2. Triangulação incremental (veja a Figura 7.1(b)): Insere os vértices um de cada vez, atualizando a triangulação após cada inserção. Um passo opcional de suavização é aplicado para melhorar a qualidade da malha final.

3. Geração flexivel com triangulação posterior (veja a Figura 7.1(c)): Posiciona os vértices sobre o domínio. Em seguida, num laço feito para cada vértice da malha ocorre suavização e inserção/remoção de vértices para se obter um controle adequado do número de vértices da malha. Finalmente é realizada a triangulação dos vértices para se obter a triangulação resultante.

4. Geração flexivel com retriangulação (veja a Figura 7.1(d)): diferente da geração flexí- 
vel com pós-triangulação, onde a malha só é gerada no final, aqui a triangulação está presente durante todo o processo. Esta classe considera suavização, inserção/remoção e retriangulação para cada vértice iterado no laço principal do método.
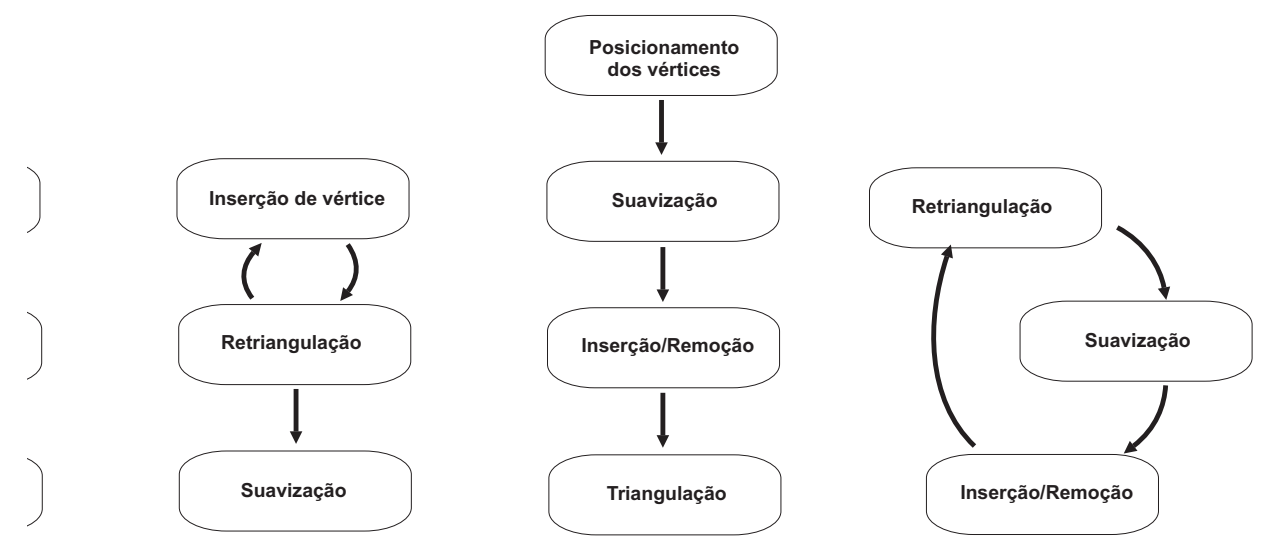
(a) Triangulacao
Cole- (b) mental
lação Posterior
(d) Flexível com Retriangula- tiva

Figura 7.1: Classes de métodos para geração de malhas.

O método proposto neste trabalho pode ser classificado como flexível com retriangulação.

Os métodos flexíveis geralmente fazem a suavização simulando o comportamento físico de dinâmica de partículas. Eles também usam alguma abordagem para fazer o controle da densidade de vértices presentes no domínio, pois, geralmente não se sabe a priori quantos vértices são necessários para se obter uma malha com triângulos obedecendo algum critério de qualidade. O número de vértices poderia ser estimado por meio da área ou volume do domínio, para os casos bidimensionais ou tridimensionais respectivamente. No entanto, mesmo que a quantidade ideal de vértices seja conhecida, a dificuldade ainda reside em como distribuí-los. Uma solução seria utilizar um esquema adaptativo onde é feito um controle da densidade local dos vértices distribuídos sobre o domínio. Para isso dois casos são levados em consideração:

- Inclusão de novos vértices: se o número de vértices for pequeno, então eles estarão relativamente distantes entre si, podendo contribuir para formação de elementos grandes e de formato inadequado; portanto, é necessário adicionar novos vértices.

- Eliminação de vértices: se o número de vértices for grande, a malha resultante pode conter mais vértices que o necessário promovendo um número elevado de elementos, portanto é interessante remover alguns vértices. 
Com este processo, o número de vértices é ajustado dinamicamente. A grande questão que surge é como garantir a parada do algoritmo, pois uma seqüência infinita de inserções e remoções pode acontecer facilmente.

Turk [101] introduziu o primeiro trabalho que faz uso de simulação física de partículas para fazer remalhamento de superfícies. A simulação é empregada para espalhar um certo número de novos vértices sobre a superfície. O procedimento é simples e produz malhas isotrópicas satisfatórias para superfícies sem quinas e pontas.

Surazhsky e Gotsman [92] introduzem um algoritmo interessante capaz de produzir malhas com alto grau de regularidade, isto é, a grande maioria dos vértices possuem seis triângulos incidentes. O método é conhecido como remalhamento explícito de superfícies. O termo explícito é utilizado para indicar que o método funciona diretamente na malha de entrada ao invés de modificá-la indiretamente através, por exemplo, de parametrizações globais, no entanto, parametrizações locais são realizadas. A técnica faz uso de um processo chamado otimização de malhas baseada em área que cumpre a tarefa de espalhar os vértices adequadamente sobre a superfície do modelo. Como observado pelos autores em [91, 93], a estratégia de equalização das áreas dos triângulos da malha tem um efeito surpreendente, pois embora não produza elementos quase eqüiláteros, os vértices são espalhados adequadamente. O processo de espalhamento dos vértices sobre o domínio é feito intercalando-se otimização de área e flipping de arestas. Como pós-processamento, os autores aplicam uma etapa de regularização da conectividade da malha.

Alliez et al. [6] criaram uma técnica de remalhamento interativo de superfícies baseado em parametrização global. A malha original é representada por uma série de mapas 2D no espaço paramétrico que são usados para criar o chamado mapa de controle. O controle da densidade de vértices sobre a superfície é feito aplicando-se a técnica de amostragem por difusão de erro, que foi originalmente criada para processamento de imagens.

Alliez et al. [4] e Surazhsky et al. [90] propuseram métodos para remalhamento baseados na relaxação de Lloyd [58]. Tal relaxação é obtida substituindo-se os pontos geradores do diagrama de Voronoi pelos centróides de suas respectivas células de Voronoi. Para utilizar a relaxação de Lloyd, os métodos parametrizam a malha inicial em um plano, sendo que o primeiro método faz parametrização global e o segundo parametrizações locais com sobreposição.

Vorsatz et al. [104] propuseram um método para remalhamento de superfícies que é sensível às características geométricas da malha original. O método primeiro ajusta o número de vértices a um dado valor fornecido pelo usuário via inserção de vértices e colapsação de arestas. Em seguida, a superfície é globalmente parametrizada; os vértices são distribuídos no espaço parametrizado via suavização laplaciana e logo depois trazidos de volta ao domínio 
superficial. Neste processo, as linhas características do modelo inicial são perdidas. Para solucionar este problema, é feito um processo que move os vértices em direção às linhas e vértices característicos da superfície. As linhas características não são explicitamente identificadas em uma etapa de pré-processamento, ao invés disso, um campo de curvatura é calculado e este campo influencia o movimento dos vértices em direção às regiões de maior curvatura. Sendo assim, nenhum parâmetro é requerido do usuário para montar tal campo. Este método possui diversos problemas práticos o maior deles é devido à parametrização global. Para contornar este problema, Vorsatz et al. [103] adaptaram a técnica para evitar o mapeamento global. Isso é feito identificando-se explicitamente as quinas da superfície e controlando o processo de remalhamento para evitar que elas sejam danificadas. Além disso, o método faz uso de parametrização local para movimentar os vértices. No caso, apenas a sub-malha correspondente à estrela do vértice movido é parametrizada. A conseqüência disso é que o movimento é consideravelmente limitado, já que o vértice deve permanecer sobre a sub-malha em questão.

Botsh e Lobbelt [16] propuseram uma abordagem de remalhamento para modelagem com multiresolução (em inglês multiresolotion modeling). O método de retriangulação utilizado para gerar triangulações uniformes baseia-se diretamente nos trabalhos [92, 90, 103].

Frey e Borouchaki $[39,40]$ propuseram uma abordagem de remalhamento que funciona em dois estágios. Primeiro, a malha de entrada é submetida a um processo de simplificação utilizando os operadores locais de colapsação de arestas, flipping de arestas e reposicionamento de nós. A saída desta primeira etapa é chamada malha geométrica, por oferecer fidelidade ao modelo inicial, podendo inclusive apresentar características anisotrópicas. A etapa seguinte processa a malha geométrica a fim de gerar uma nova malha com características adequadas para computações com elementos finitos. Para isso, um suporte geométrico ( $G^{1}$ contínuo) é construído sobre a malha geométrica e é utilizado tanto para guiar os operadores de remalhamento local (inserção, remoção, flipping e movimento) quanto para definir uma métrica geométrica. Esta métrica cumpre o papel de limitar a distância entre as arestas da malha gerada à superfície do modelo.

Todos os métodos discutidos até aqui são para produzir malhas isotrópicas. Os métodos citados a seguir se propõem a gerar malhas com características anisotrópicas. Alguns dos métodos não são propriamente para remalhamento, mas são incluídos na discussão por apresentarem idéias interessantes que podem ser aproveitadas de alguma forma em técnicas de remalhamento.

Esforços têm sido feitos no intuito de gerar triangulações anisotrópicas com garantia de qualidade. Como acontece no caso isotrópico, os métodos capazes de oferecer tal garantia são aqueles baseados na triangulação de Delaunay. Para o caso anisotrópico, os esforços nessa 
direção também envolvem a triangulação de Delaunay.

Sabe-se que dado um conjunto de pontos no espaço euclidiano, a triangulação de Delaunay oferece uma forma canônica para conectar tais vértices. A triangulação de Delaunay anisotrópica é construída em variedades riemannianas e pode manter algumas das valiosas propriedades da triangulação de Delaunay euclidiana, como observado por Leibon e Letscher [54]. No entanto, as triangulações de Delaunay anisotrópicas não existem para um conjunto arbitrário de pontos, e certos requerimentos de densidade devem ser obedecidos para que a triangulação represente precisamente tanto a topologia quanto a geometria de uma variedade Riemanniana. A construção de triangulações de Delaunay anisotrópicas é um problema consideravelmente mais difícil que a versão euclidiana. Em uma variedade riemanniana pode não haver uma única linha dando a menor distância entre dois pontos. Além disso, o teste do circuncírculo vazio não é bem definido, uma vez que podem existir várias esferas passando por três pontos de uma variedade riemanniana. Todavia, a diferença entre a triangulação de Delaunay anisotrópica e a euclidiana pode ser minimizada se for assumido que a amostragem de pontos é suficiente grande em uma dada vizinhança da variedade. Leibon e Letscher [54] provaram que se uma variedade riemanniana for adequadamente amostrada, então a triangulação de Delaunay existe e é única e mantem as mesmas propriedades das triangulações do espaço euclidiano. Os autores também apresentam algoritmos para construir a triangulação. Para fins práticos, porém, a proposta não é adequada, pois, não se pode garantir a priori que os pontos de entrada satisfazem o critério de amostragem.

Labelle e Shewchuk [53] propuseram um método para refinamento de triangulações de Delaunay anisotrópicas em domínios bidimensionais. O método segue uma abordagem diferente da tradicional que analisa e modifica a triangulação diretamente. Ao invés disso, Labelle e Shewchuk propuseram uma aproximação do diagrama de Voronoi anisotrópico e realizam o refinamento no próprio diagrama. A triangulação só é de fato gerada no final do processamento. Além disso, os autores provam que o algoritmo termina e a malha gerada obedece a critérios de qualidade se algumas restrições na entrada forem obedecidas. Boissonnat et. al [50] propuseram uma alternativa para a construção dos diagramas de Voronoi anisotrópicos como também uma variante do algoritmo de Labelle e Shewchuk.

Vários métodos baseados em heurísticas fazem uso de recursos provenientes da triangulação de Delaunay, muito embora a triangulação produzida não seja necessariamente Delaunay. Por exemplo, em contextos anisotrópicos o critério Delaunay é modificado e utilizado para governar o processo de flipping de arestas [83, 56, 14].

Castro Díaz e Hecht [21] descrevem um método para remalhar superfícies tanto com triangulações isotrópicas quanto anisotrópicas. O processo é bastante simples e se baseia em 
aplicar adequadamente os operadores de remalhamento local. O remalhamento se dá pelo processamento de arestas. Um novo vértice é inserido se o comprimento da aresta for considerado grande. Arestas consideradas pequenas são colapsadas e um dos vértices é eliminado. Estas operações são seguidas de flipping de arestas se necessário. Finalmente, a malha gerada passa por um processo final de otimização global em duas etapas: (i) os vértices interiores com menos de três arestas incidentes são eliminados e (ii) os vértices são movimentados por um procedimento de suavização inteligente $[19,38]$. Para auxiliar no processo de projeção de pontos sobre a superfície os autores utilizam um suporte geométrico. Este suporte é criado utilizando o algoritmo de Farin [37] que constrói uma superfície $G^{1}$ pela colagem de retalhos menores sobre os quais são definidas superfícies de Bezier.

Em [82, 84, 85] Shimada introduziu uma nova abordagem para gerar malhas isotrópicas utilizando como base simulação física de partículas. A idéia é inspirada no comportamento natural das bolhas, as quais tendem a formar padrões hexagonais quando confinadas em um domínio fechado. Tal comportamento oferece uma boa configuração para a localização dos vértices (centro das bolhas) de uma malha isotrópica. O método de empacotamento de bolhas é composto por dois passos principais: empacotamento das bolhas e conexão dos vértices. $\mathrm{Na}$ primeira etapa, o método realiza o posicionamento dos vértices da malha distribuindo bolhas no domínio. A distribuição das bolhas segue a seguinte ordem: (1) vértices, (2) arestas, (3) faces e (4) interior do domínio. Em (2), (3) e (4), as bolhas são criadas e então movimentadas sobre o domínio para que se consiga uma boa distribuição das mesmas. Para movimentar as bolhas, o método roda uma simulação seguindo o modelo dinâmico de forças de atração e repulsão. A força é modelada como uma aproximação da força de van der Waal, que simula o comportamento molecular. A simulação roda até que as bolhas encontrem posições estáveis, ou seja, as forças entre elas estejam balanceadas. Uma boa configuração das bolhas é aquela que minimiza tanto as sobreposições quanto as falhas. Para isso, durante a simulação é feito um controle do número de bolhas para evitar o excesso (demasiada sobreposição no domínio) ou escassez (falha no domínio) de bolhas. Quando as bolhas já estiverem posicionadas e estáveis, os vértices da malha são então dispostos nos centros das bolhas. Para completar o processo, a malha é contruída por avanço de fronteira a fim de se obter uma triangulação de Delaunay.

A idéia de empacotamento de bolhas foi estendida para o caso anisotrópico. Os trabalhos $[83,86,110]$ adaptaram o método para criar triangulações anisotrópicas em superfícies curvas em $\mathbb{R}^{3}$; e os trabalhos $[108,107,109]$ estenderam-na para gerar malhas anisotrópicas tetraedrais e hexa-dominantes. Em ambas as extensões a diferença do método tradicional de empacotamento de bolhas para o caso anisotrópico se dá em dois aspectos: (1) o uso de bolhas elipsoidais e (2) o uso de um critério Delaunay modificado para conectar os vértices de tal 
modo que considere a anisotropia do domínio.

Li et al $[56,57]$ propuseram uma abordagem baseada em "mordidas"(bitting) para gerar malhas isotrópicas 2D combinando a abordagem por avanço de fronteira com empacotamento de esferas. Morder significa consumir uma região do domínio. No caso isotrópico, cada mordida tem o formato de um círculo. Para adequar esse método ao caso anisotrópico as mordidas passam a ter o formato de uma elipse, que são definidas por tensores métricos definidos sobre o domínio.

Bossen e Heckbert [15, 14] propuseram um método para geração de malhas simpliciais anisotrópicas bidimensionais. Seu método faz uso de suavização por simulação física; controle da densidade de vértices no domínio por meio de refinamento/simplificação de malha; e retriangulação da malha. O método recebe como entrada um polígono delimitando o domínio e um campo de tensores métricos para definir a anisotropia sobre o domínio. Inicialmente, o método gera uma triangulação de Delaunay com restrição sobre o polígono de entrada. Em seguida, para que a malha inicial passe a respeitar a anisotropia, o método itera os vértices, sendo que em cada iteração ocorrem os seguintes passos: (1) um vértice aleatório é escolhido e reposicionado por meio de uma simulação física de forças entre vértices; (2) a malha é retriangulada para respeitar o deslocamento do vértice; e (3) se necessário, ocorre controle de densidade local pela inserção ou remoção de vértices. Como o passo de retriangulação é efetuado sempre que um vértice é iterado, a malha está presente durante todo o processo. A presença da malha é interessante por três motivos: (1) descarta o uso de uma estrutura auxiliar para fazer a busca dos vértices mais próximos (vizinhos); (2) não precisa de um método para fazer a triangulação final dos pontos; e (3) possibilita que a qualidade dos elementos seja medida em qualquer instante durante o processo, permitindo a parada do algoritmo assim que os elementos satisfizerem uma determinada condição fornecida pelo usuário.

Como mencionado, vários dos métodos citados contribuíram, direta ou indiretamente, para a criação do método de remalhamento proposto, o ANTS. Os capítulos a seguir apresentam detalhes sobre o ANTS. O próximo capítulo descreve como é feita a detecção das linhas e pontos relevantes para a descrição da forma geométrica da malha de entrada. Estas linhas e pontos são determinantes para a criação das estruturas-de-controle, que por sua vez são de fundamental importância para que as principais características geométricas da malha de entrada sejam preservadas durante o processo de remalhamento. Além das estruturas-decontrole, o remalhamento é também guiado por uma função de espaçamento, que é responsável por informar qual é o espaçamento desejado entre vértices sobre o domínio. As funçôes de espaçamento podem ser isotrópicas ou anisotrópicas, o que determina o tipo de malha que será produzida. O Capítulo 9 descreve como uma função de espaçamento anisotrópica é calculada 
a partir da malha de entrada. Uma vez calculadas as estruturas-de-controle e a função de espaçamento a partir da malha de entrada, o processo de remalhamento é executado, conforme descrito no Capítulo 10. Finalmente, no Capítulo 11 mostra os resultados obtidos e também conclusões sobre o método proposto. 


\section{Capítulo 8}

\section{As estruturas de controle geométrico}

Neste capítulo é mostrado como são identificadas as estruturas que representams as principais características geométricas do modelo representado pela malha de entrada. Tais estruturas são de fundamental importância para que o processo de remalhamento preserve o formato original da superfície.

As características geométricas podem ser facilmente identificadas analisando-se as quinas do modelo representado pela malha de entrada. Por exemplo, verificando-se as quinas da malha representando um cubo (veja a Figura 8.1) pode-se facilmente identificar que tal modelo possui as seguintes características geométricas principais: oito pontos (vértices do cubo), doze linhas (arestas do cubo) e seis sub-superfícies (faces do cubo).

Se as características geométricas de um dado modelo forem mantidas durante o processo de ramalhamento, a malha produzida terá uma forma geométrica parecida com a original. Essa é justamente a idéia por trás do método proposto para manter a forma geométrica do modelo remalhado. Dá-se o nome de estruturas-de-controle, denotado por C, ao conjunto das principais características geométricas de uma superfície.

Existem vários trabalhos na literatura que tratam da identificação das principais características geométricas de malhas superficiais [51, 63, 49, 100]. A técnica apresentada neste capítulo é baseada principalmente na proposta por Tilch and Löhner [100].

O processo de extração das estruturas-de-controle do modelo é baseado na identificação das arestas-quina da superfície inicial. Tais arestas são facilmente identificadas analisandose o ângulo formado entre os vetores normais de faces adjacentes. Seja $\Phi$ um valor definido pelo usuário, se o ângulo entre as normais for maior que $\Phi$, então a aresta é considerada de quina. Além disso, para superfícies com bordo, todas as arestas de bordo são consideradas arestas-quina. Para a maioria dos exemplos, é suficiente que o valor de $\Phi$ esteja no intervalo $30^{\circ} \leq \Phi \leq 50^{\circ}$. 

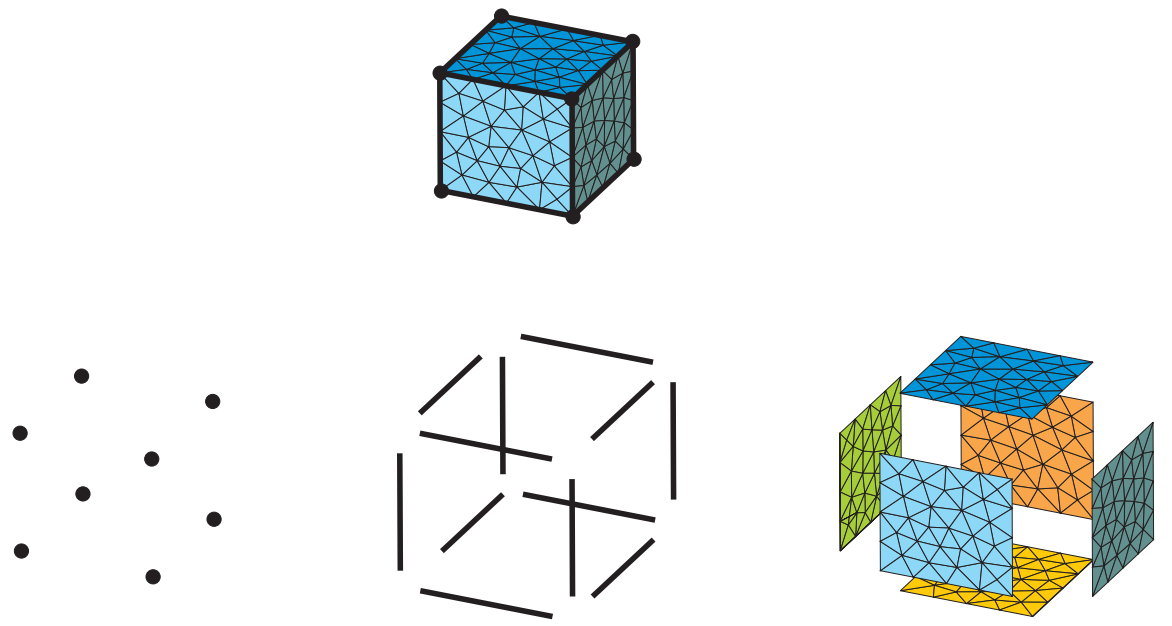

Figura 8.1: Características geométricas em um cubo.

Considere grau-de-quina de um vértice $v_{i}$, denotado por $\partial\left(v_{i}\right)$, como o número de arestasquina incidentes naquele vértice. Na Figura 8.2, estão indicados vértices com graus-de-quina iguais a 1,2 e 3 .

Uma vez marcadas todas as arestas-quina da malha superficial, elas são utilizadas no processo de identificação das estruturas-de-controle. O conjunto estruturas-de-controle pode ser dividido em quatro subconjuntos, são eles: cantos-de-controle, linhas-de-controle, pontasde-controle e superfícies-de-controle, os quais são respectivamente denotados por $C_{C}, C_{L}, C_{T}$ e $C_{S}$.

Uma estrutura-de-controle em particular será denotada utilizando-se um índice, por exemplo, $C_{i}$ refere-se a uma estrutura-de-controle qualquer, que pode ser um canto-de-controle, linha-de-controle, ponta-de-controle ou superfície-de-controle. O índice também será usado para referenciar elementos de $C_{C}, C_{L}, C_{T}$ e $C_{S}$. Por exemplo, $C_{L_{i}} \in C_{L}$ e $C_{L_{j}} \in C_{L}$ referemse a duas linhas-de-controle distintas.

Um canto-de-controle, $C_{C_{i}} \in C_{C}$, é um vértice $v$ da malha tal que:

- $\partial(v)>2$, ou

- $\partial(v)=2$ e o ângulo entre as duas arestas-quina incidentes em $v$ for menor que $\Psi$ (geralmente $\left.\Psi=180^{\circ}-1.2 \Phi\right)$.

Uma ponta-de-controle, $C_{T_{i}} \in C_{T}$, é um vértice $v$ da malha tal que $\partial(v)=1$.

Uma linha-de-controle, $C_{L_{i}} \in C_{L}$, é um conjunto de vértices e arestas da malha formando uma curva discretizada tal que:

- um vértice $v \in C_{L_{i}}$ se e somente se $\partial(v)=2$ e $v \notin C_{C}$ e 


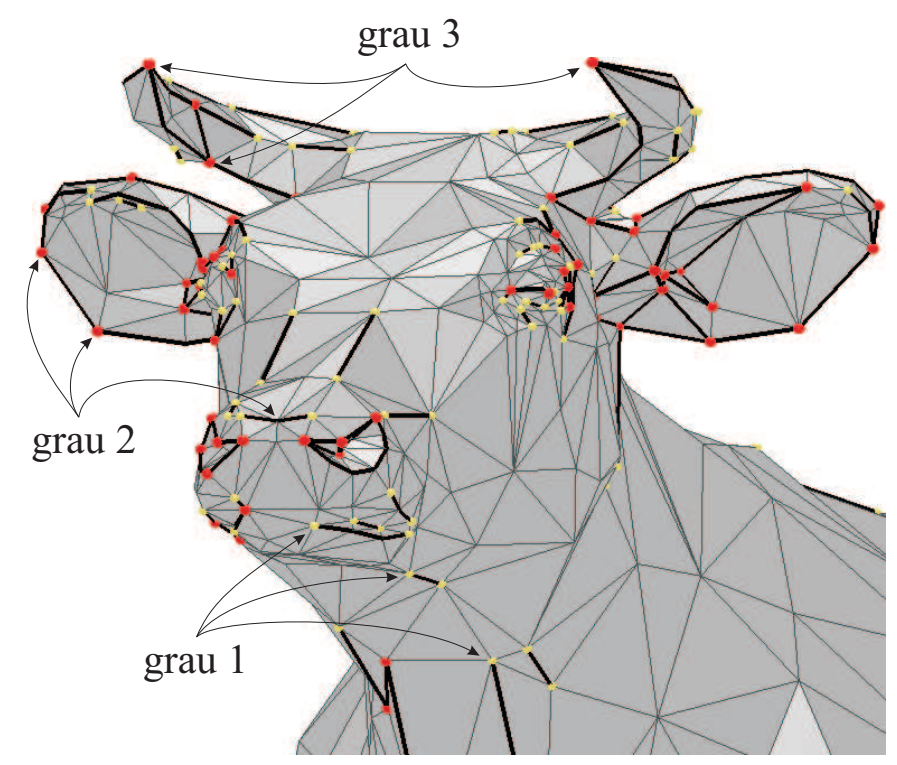

Figura 8.2: Ilustração graus-de-quina de vertices.

- uma aresta $e_{j k} \in C_{L_{i}}$ se e somente se $e_{j k}$ for aresta-quina e $v_{j} \in C_{L_{i}}$ ou $v_{k} \in C_{L_{i}}$.

Note que as linhas-de-controle podem formar ciclos ou ter em suas extremidades vértices pertencentes a $C_{C}$ ou $C_{T}$.

Finalmente, uma superfície-de-controle, $C_{S_{i}} \in C_{S}$, é um conjunto de triângulos, arestas e faces da malha tal que:

- um triângulo $t \in C_{S_{i}}$ se for possível construir um caminho célula-a-célula entre $t$ e qualquer triângulo em $C_{S_{i}}$ sem cruzar qualquer aresta em $C_{L}$.

- uma aresta $e \in C_{S_{i}}$ se seus triângulos adjacentes pertencerem a $C_{S_{i}}$.

- um vértice $v \in C_{S_{i}}$ se todas as células incidentes em $v$ pertencerem a $C_{S_{i}}$.

As estruturas-de-controle em uma superfície estão exemplificadas nas Figuras 8.2 e 8.3, as linhas-de-controle são as arestas em negrito e os cantos-de-controle e as pontas-de-controle são os vértices em destaque.

Quando todas as estruturas-de-controle tiverem sido identificadas, pode-se opcionalmente realizar um processamento sobre elas a fim de eliminar algumas arestas desnecessariamente marcadas como arestas-quina. Para isso foi utilizado o procedimento descrito em [100] para melhorar a fidelidade das linhas-de-controle. Para cada extremidade de cada linha-de-controle, um critério relaxado $(1.2 \Phi)$ para determinar arestas-quina é aplicado para remover, em seqüência, a aresta da extremidade da linha-de-controle. Se a aresta da extremidade não for considerada uma aresta-quina segundo o novo critério relaxado, ela é removida e a próxima aresta 
é avaliada. Em seguida um critério mais apertado $(0.8 \Phi)$ é utilizado para colocar de volta na linha-de-controle algumas das arestas que foram removidas. Note que este processo de simplificação pode remover completamente ou parcialmente uma linha-de-controle; portanto, é fundamental que os conjuntos $C_{C}, C_{T}$ e $C_{S}$ sejam atualizados após a simplificação. Os efeitos deste procedimento simplificador de linhas-de-controle pode ser verificado na Figura 8.3; na Figura 8.3(a) não foi utilizado o simplificador enquanto que na Figura 8.3(b) ele foi utilizado.

Além de serem de fundamental importância para o processo de remalhamento, as estruturasde-controle também são utilizadas durante a construção de uma função de espaçamento anisotrópica sobre $G$, como será visto no próximo capítulo. 


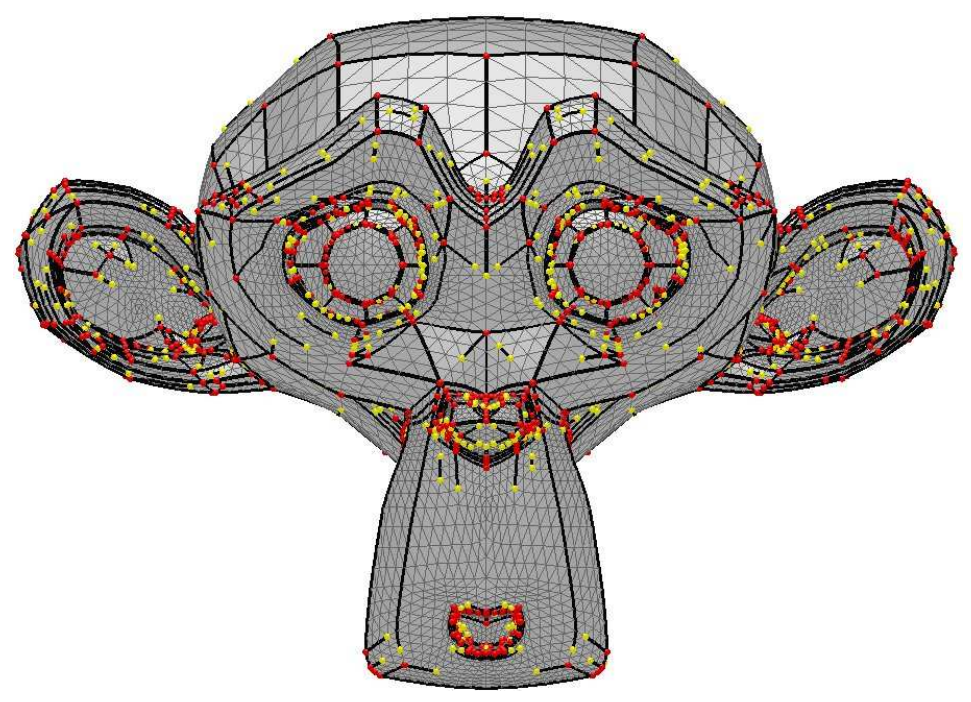

(a) Sem simplicação

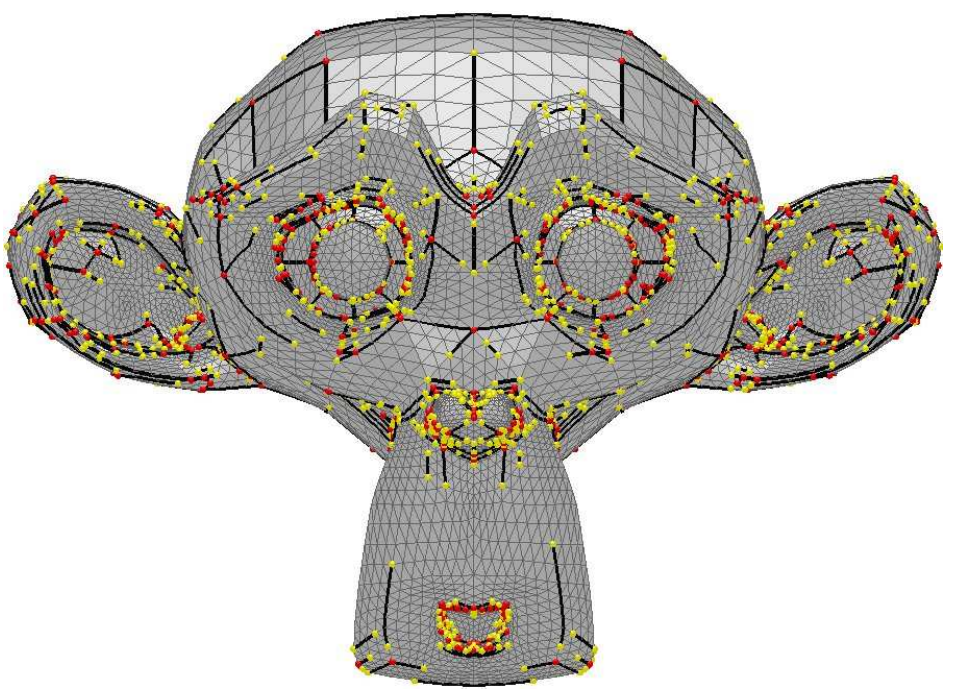

(b) Com simplicação

Figura 8.3: Efeito do processo simplificador de linhas-de-controle. 


\section{Capítulo 9}

\section{A função de espalhamento}

É sabido que diferentes aplicações requerem malhas com características diferenciadas, mesmo que estas estejam definidas sobre o mesmo domínio. Portanto, não se pode, a priori, afirmar que uma dada malha é mais adequada que outra sem considerar qual é a aplicação envolvida. Por exemplo, em computação gráfica é comum a utilização de malhas para apenas representar a forma geométrica de um dado modelo. Neste caso, as malhas mais adequadas são aquelas com o menor número de elementos, desde que a fidelidade à forma geométrica não seja comprometida. Sendo assim, triângulos dos mais variados formatos e tamanhos podem ser utilizados para compor a malha, desde que cada um deles ofereça uma aproximação local adequada do modelo. Por outro lado, em aplicações envolvendo simulações numéricas de fluidos, as malhas mais adequadas são as que oferecem compromisso adequado entre desempenho computacional e precisão numérica. Quanto menor o número de triângulos, maior a eficiência computacional, porém, maiores as chances da precisão numérica ser degradada. Neste caso, tanto o tamanho dos elementos quanto o formato e disposição dos mesmos influenciam a precisão da simulação. Geralmente, os elementos mais adequados são os eqüiláteros. Em muitas situações são necessários refinamentos diferenciados sobre o domínio. Por exemplo, em simulações estruturais as malhas possuem elementos menores em regiões onde a concentração de pressão é maior ao passo que elementos maiores são utilizados nas outras regiões. Em outros casos, no entanto, malhas compostas por elementos mais finos e longos que os usuais podem oferecer um melhor compromisso entre desempenho e precisão, este é o caso das malhas anisotrópicas. Por exemplo, na camada limite em volta da asa de um avião ou ao longo das frentes de choque em vôos supersônicos, elementos com razão de aspecto da ordem de 100.000 por 1 podem ser apropriados [79]. Portanto, para que um procedimento possa gerar malhas adequadas para variadas aplicações é necessário adotar algum critério que estabeleça quais são os tamanhos e os formatos desejados de elementos nas diferentes regiões do domínio, este é o papel das 
funçôes de espaçamento.

Uma função de espaçamento estabelece para cada ponto do domínio qual é o tamanho e o formato desejáveis de um elemento da malha naquele ponto. A forma mais comumente empregada de função de espaçamento é especificando o tamanho desejado de aresta para um ponto do domínio. No caso de malhas superficiais, o controle das arestas é suficiente para controlar o formato dos elementos. Por exemplo, se uma função de espaçamento estabelece que cada ponto do domínio requer arestas de tamanho 1, a malha ideal é aquela composta por elementos eqüiláteros de lado 1. Em malhas volumétricas, no entanto, isso não é suficiente, pois os indesejados tetraedros slivers têm comprimentos de arestas parecidos.

Este trabalho propõe-se a tratar tanto malhas isotrópicas quanto anisotrópicas. Para que possam ser geradas malhas isotrópicas, é suficiente especificar apenas o tamanho desejado do elemento em cada ponto do domínio, e assume-se que o triângulo seja o mais próximo do eqüilátero quanto possível. Já no caso de malhas anisotrópicas, as funçôes de espaçamento são mais elaboradas, pois o tamanho desejado deve variar em direções deferentes. Observe que o caso isotrópico é um caso particular do anisotrópico, o qual ocorre quando o tamanho desejado é o mesmo em qualquer direção, como será verificado no decorrer deste capítulo.

\subsection{Construção de uma função de espaçamento}

Uma função de espaçamento pode ser obtida de diferentes formas. Em simulações numéricas, por exemplo, estimadores de erros a priori ou a posteriori baseados em uma simulação inicial podem ser utilizadas para definir uma função de espaçamento para uma simulação em particular. Em aplicações envolvendo malhas superficiais, parece razoável que a função de espaçamento seja definida por meio das principais curvaturas da superfície em cada ponto do domínio. Dessa forma, uma maior densidade de pontos é requerida em regiões de maior curvatura ao passo que uma menor densidade em regiões de menor curvatura. Nesta seção é descrita uma abordagem para se definir uma função de espaçamento anisotrópica a partir de uma superfície discretizada.

\subsubsection{Os parâmetros $S_{\min }$ e $S_{\max }$}

O processo de construção de uma função de espaçamento é guiado por dois parâmetros fornecidos pelo usuário, a saber: $S_{\min }$ e $S_{\max }$. Estes valores são, respectivamente, os limitantes inferior e superior para os raios dos elipsóides definidos por $H$. Esses limitantes servem para evitar que a função de espaçamento construída requeira arestas muito grandes em regiões planas ou demasiadamente pequenas sobre detalhes muito finos da superfície. Portanto, os raios 
dos elipsóides nunca devem ser menores que $S_{\min }$ nem maiores que $S_{\max }$. Observe que estes valores fornecem uma maneira indireta de controlar o comprimento das arestas da triangulação após o remalhamento. Para isso, os valores $S_{\text {min }}$ e $S_{\text {max }}$ limitam os autovalores $\xi_{i}, i=1,2,3$, dos tensores métricos de $H$ (ver Equação (2.3)) da seguinte forma

$$
\frac{1}{S_{\max }^{2}} \leq \xi_{i} \leq \frac{1}{S_{\min }^{2}}
$$

O papel de $S_{\min }$ e $S_{\max }$ ficará evidente no decorrer deste capítulo.

\subsubsection{Estimativa de tensores métricos nos vértices de uma malha}

Tem-se como objetivo estimar um tensor métrico para cada vértice de uma malha denominada $G$. Para definir um tensor, no entanto, é necessário que se conheça as curvaturas principais e as direções principais em cada vértice da malha. Existem vários métodos presentes na literatura para este propósito [29, 71, 99]. Neste trabalho foi empregada a estratégia de se aproximar a vizinhança de um dado vértice da malha por uma quádrica [44, 40], e então calcular as curvaturas a partir desta.

Seja $v$ um vértice de $G$ para o qual pretende-se atribuir um tensor métrico $M_{v}$. Primeiramente, seleciona-se um conjunto de pontos da malha na vizinhança de $v$, seja $V_{v}$ este conjunto. A Seção 9.1.3 descreve como este conjunto pode ser obtido. Os pontos $V_{v}$ são aproximados por uma quádrica pelo método dos mínimos quadrados [98]. Para isso, deve-se determinar um sistema de coordenadas local, denotado por $\Im$, centrado em $v$, sobre o qual a quádrica será definida.

Para definir $\Im$ é necessário que primeiro seja estimado o vetor normal à superfície em $v$. Este vetor será denotado por $\vec{n}_{v}$, e pode ser aproximado pela seguinte equação:

$$
\vec{n}_{v}=\frac{\sum_{t \in \star_{v}} \vec{n}_{t} A(t)}{\sum_{t \in \star_{v}} A(t)},
$$

em que $\overrightarrow{n_{t}}$ é o vetor normal ao triângulo $t$ incidente em $v$ e $A(t)$ a sua área, conforme descrito em [67].

Seja $\pi_{v}$ o plano tangente a $v$, isto é, ortogonal a $\vec{n}_{v}$. Sejam $\vec{\chi}_{v}$ e $\vec{\gamma}_{v}$ dois vetores unitários ortogonais entre si e paralelos a $\pi_{v}$ tal que $\vec{n}_{v}=\left(\vec{\chi}_{v} \times \vec{\gamma}_{v}\right)$. Assim, o sistema de coordenadas local pode ser representado pela quádrupla $\Im\left(v, \vec{\chi}_{v}, \vec{\gamma}_{v}, \vec{n}_{v}\right)$, em que $v$ é a origem. O sitema de coordenadas está ilustrado na Figura 9.1. A notação $(\chi, \gamma, \zeta)$ são as coordenadas do sistema local $\Im$ e $(x, y, z)$ são as coordenadas do sistema global.

Considere a quádrica que passe por $v$ (a origem de $\Im$ ) e um dado ponto $(\chi, \gamma, \zeta)$ pertencente à superfície que será aproximada. A quádrica pode ser representada pela seguinte equação: 


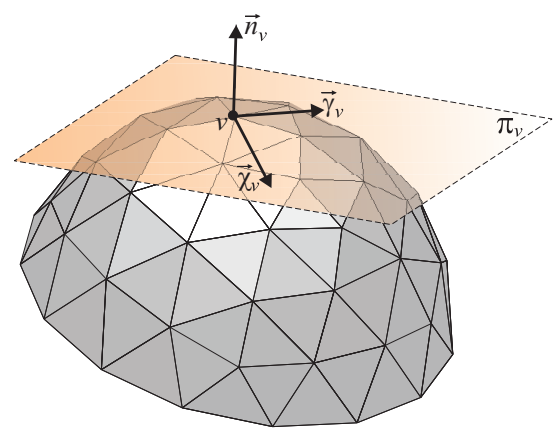

Figura 9.1: O sistema de coordenadas local $\Im\left(v, \vec{\chi}_{v}, \vec{\gamma}_{v}, \vec{n}_{v}\right)$ definido a partir do vértice $v$ para o cálculo da quádrica.

$$
a \chi^{2}+b \chi \gamma+c \gamma^{2}-\zeta=0
$$

na qual $a, b$ e $c$ são coeficientes a serem determinados de tal forma que a quádrica aproxime adequadamente os vértices $v_{i} \in V_{v}$. Sendo assim, obtêm-se um sistema de $m$ equações lineares, com $m=\#\left(V_{v}\right)$. Na forma matricial, o sistema é dado por:

$$
\left(\begin{array}{ccc}
\chi_{1}^{2} & \chi_{1} \gamma_{1} & \gamma_{1}^{2} \\
\chi_{2}^{2} & \chi_{2} \gamma_{2} & \gamma_{2}^{2} \\
\vdots & \vdots & \vdots \\
\chi_{m}^{2} & \chi_{2} \gamma_{m} & \gamma_{m}^{2}
\end{array}\right)\left(\begin{array}{c}
a \\
b \\
c
\end{array}\right)=\left(\begin{array}{c}
\zeta_{1} \\
\zeta_{2} \\
\vdots \\
\zeta_{m}
\end{array}\right)
$$

na qual $\left(\chi_{i}, \gamma_{i}, \zeta_{i}\right)$, com $i=1, \ldots, m$, são as coordenadas do vértice $v_{i} \in V_{v}$ convertidas para $\Im$.

Geralmente, o sistema 9.4 possui mais equações do que incógnitas, isto é, $m>3$. Neste caso, foi utilizado o método dos mínimos quadrados para aproximá-lo, e, portanto, o sistema original na forma $A X=B$ é aproximado por $A^{t} A \tilde{X}=A^{t} B$, sendo $\tilde{X}$ a solução por mínimos quadrados.

Uma vez que os coeficientes $a, b$ e $c$ foram encontrados, as curvaturas e direções principais são calculadas a partir da quádrica.

\section{Estimativa das curvaturas principais}

A geometria diferencial clássica [96] fornece ferramentas para se computar as curvaturas e direções principais da quádrica em questão. Para isso, considere que a superfície quádrica, denotada por $\digamma: U \subset R^{2} \rightarrow R^{3}$, seja descrita da seguinte forma:

$$
\digamma(\chi, \gamma)=(x(\chi, \gamma), y(\chi, \gamma), z(\chi, \gamma))
$$


em que $(\chi, \gamma) \in U$ e $x(\chi, \gamma)=\chi, y(\chi, \gamma)=\gamma$, e $z(\chi, \gamma)=a \chi^{2}+b \chi \gamma+c \gamma^{2}$.

Considere $\overrightarrow{\boldsymbol{F}}_{\chi}(\chi, \gamma)$ e $\overrightarrow{\boldsymbol{F}}_{\gamma}(\chi, \gamma)$ vetores tangentes à quádrica no ponto $q=(\chi, \gamma) \in \pi_{v}$ dados pelas seguintes expressões:

$$
\begin{aligned}
& \vec{\digamma}_{\chi}(\chi, \gamma)=\left(\frac{\partial x(\chi, \gamma)}{\partial \chi}, \frac{\partial y(\chi, \gamma)}{\partial \chi}, \frac{\partial z(\chi, \gamma)}{\partial \chi}\right)=(1,0,2 a \chi+b \gamma)^{2} \\
& \vec{\digamma}_{\gamma}(\chi, \gamma)=\left(\frac{\partial x(\chi, \gamma)}{\partial \gamma}, \frac{\partial y(\chi, \gamma)}{\partial \gamma}, \frac{\partial z(\chi, \gamma)}{\partial \gamma}\right)=(0,1, b \chi+2 c \gamma)^{2}
\end{aligned}
$$

A primeira e a segunda forma quadrática de uma superfície de classe $C^{2}$ ou superior (note que a quádrica satisfaz este requisito), para todo ponto $q=(\chi, \gamma) \in U$, são dadas, respectivamente, por:

$$
\Phi_{1}\left(\vec{w}_{q}\right)=E(\chi, \gamma) \alpha^{2}+F(\chi, \gamma) \alpha \beta+G(\chi, \gamma) \beta^{2}
$$

e

$$
\Phi_{2}\left(\vec{w}_{q}\right)=e(\chi, \gamma) \alpha^{2}+f(\chi, \gamma) \alpha \beta+g(\chi, \gamma) \beta^{2}
$$

$\forall \vec{w}_{q}=\alpha \vec{\digamma}_{\chi}(\chi, \gamma)+\beta \vec{\digamma}_{\gamma}(\chi, \gamma)$, onde $E(\chi, \gamma), F(\chi, \gamma), G(\chi, \gamma)$ são os coeficientes da primeira forma quadrática, que ,no caso da superfície quádrica $\digamma$, são dados por

$$
\begin{aligned}
E(\chi, \gamma) & =\vec{\digamma}_{\chi}(\chi, \gamma) \cdot \vec{\digamma}_{\chi}(\chi, \gamma)=1+(2 a \chi+b \gamma) \\
F(\chi, \gamma) & =\vec{\digamma}_{\chi}(\chi, \gamma) \cdot \vec{\digamma}_{\gamma}(\chi, \gamma)=(2 a \chi+b \gamma)(b \chi+2 c \gamma) \\
G(\chi, \gamma) & =\vec{\digamma}_{\gamma}(\chi, \gamma) \cdot \vec{\digamma}_{\gamma}(\chi, \gamma)=1+(b \chi+2 c \gamma) .
\end{aligned}
$$

E, $e(\chi, \gamma), f(\chi, \gamma), g(\chi, \gamma)$ são os coeficientes da segunda forma quadrática dados por

$$
\begin{aligned}
e(\chi, \gamma) & =\vec{\digamma}_{\chi \chi}(\chi, \gamma) \cdot(0,0,1)=2 a \\
f(\chi, \gamma) & =\vec{\digamma}_{\chi \gamma}(\chi, \gamma) \cdot(0,0,1)=b, \\
g(\chi, \gamma) & =\vec{\digamma}_{\gamma \gamma}(\chi, \gamma) \cdot(0,0,1)=2 c
\end{aligned}
$$

com

$$
\begin{aligned}
& \vec{\digamma}_{\chi \chi}(\chi, \gamma)=\left(\frac{\partial^{2} x(\chi, \gamma)}{\partial \chi^{2}}, \frac{\partial^{2} y(\chi, \gamma)}{\partial \chi^{2}}, \frac{\partial^{2} z(\chi, \gamma)}{\partial \chi^{2}}\right) \\
& \vec{\digamma}_{\chi \gamma}(\chi, \gamma)=\left(\frac{\partial^{2} x(\chi, \gamma)}{\partial \chi \partial \gamma}, \frac{\partial^{2} y(\chi, \gamma)}{\partial \chi \partial \gamma}, \frac{\partial^{2} z(\chi, \gamma)}{\partial \chi \partial \gamma}\right) \\
& \vec{\digamma}_{\gamma \gamma}(\chi, \gamma)=\left(\frac{\partial^{2} x(\chi, \gamma)}{\partial \gamma^{2}}, \frac{\partial^{2} y(\chi, \gamma)}{\partial \gamma^{2}}, \frac{\partial^{2} z(\chi, \gamma)}{\partial \gamma^{2}}\right) .
\end{aligned}
$$


Sejam $\kappa_{1}$ e $\kappa_{2}$ as curvaturas principais da quádrica definida em um ponto $q \in \pi_{v}$. Sabe-se, pela geometria diferencial clássica, que a curvatura média $\kappa_{m}(\chi, \gamma)=\frac{\kappa_{1}+\kappa_{2}}{2}$ e a curvatura de Gauss $\kappa_{g}(\chi, \gamma)=\kappa_{1} . \kappa_{2}$ em $\digamma(\chi, \gamma)$, com $q=(\chi, \gamma) \in \pi_{v}$, podem ser calculadas com base nos coeficientes das formas quadráticas por:

$$
\begin{aligned}
\kappa_{m}(\chi, \gamma) & =\frac{1}{2}\left(\frac{e(\chi, \gamma) G(\chi, \gamma)-2 f(\chi, \gamma) F(\chi, \gamma)+E(\chi, \gamma) g(\chi, \gamma)}{E(\chi, \gamma) G(\chi, \gamma)-F(\chi, \gamma)^{2}}\right) \\
\kappa_{g}(\chi, \gamma) & =\frac{e(\chi, \gamma) g(\chi, \gamma)-f(\chi, \gamma)^{2}}{E(\chi, \gamma) G(\chi, \gamma)-F(\chi, \gamma)^{2}}
\end{aligned}
$$

Mais precisamente, deve-se encontrar os valores de $\kappa_{1}$ e $\kappa_{2}$ para o ponto de origem do sistema de coordenadas local $\Im$. Lembre-se que $v$ é essa origem, ao qual será atribuído o tensor métrico $M_{v}$. Sendo assim, considere $q=q_{o}=(0,0)$ na Equação (9.9). Aplicando a Equação (9.19) e a Equação (9.20) no ponto de interesse $q_{o}$, obtêm-se o seguinte sistema:

$$
\left\{\begin{array}{c}
\kappa_{1}+\kappa_{2}=4 a c-b^{2}, \\
\kappa_{1} \cdot \kappa_{2}=2(a+c),
\end{array}\right.
$$

em que as curvaturas $\kappa_{1}$ e $\kappa_{2}$ são raízes de uma equação do segundo grau e dadas por

$$
\kappa_{1}=\frac{2(a+c)+\sqrt{(2(a+c))^{2}-4\left(4 a c-b^{2}\right)}}{2}
$$

$\mathrm{e}$

$$
\kappa_{2}=\frac{2(a+c)-\sqrt{(2(a+c))^{2}-4\left(4 a c-b^{2}\right)}}{2} .
$$

\section{Estimativa das direções principais de curvatura}

A partir dos valores obtidos pelos procedimentos descritos acima, é possível estimar as direções principais $\vec{d}_{1}$ e $\overrightarrow{d_{2}}$ associadas respectivamente com as curvaturas $\kappa_{1}$ e $\kappa_{2}$.

A geometria diferencial clássica afirma que, para um ponto $q=(\chi, \gamma) \in \pi_{v}$, o vetor $\vec{d}_{i}=\alpha \vec{\digamma}_{\chi}(\chi, \gamma)+\beta \vec{\digamma}_{\gamma}(\chi, \gamma)$ é uma direção principal relacionada com a curvatura principal $\kappa_{i}$, $i \in 1,2$, se, e somente se, os valores $\alpha$ e $\beta$ satisfazem o seguinte sistema de equações:

$$
\left\{\begin{array}{l}
\left(e(\chi, \gamma)-\kappa_{i} E(\chi, \gamma)\right) \alpha+\left(f(\chi, \gamma)-\kappa_{i} F(\chi, \gamma)\right) \beta=0 \\
\left(f(\chi, \gamma)-\kappa_{i} F(\chi, \gamma)\right) \alpha+\left(g(\chi, \gamma)-\kappa_{i} G(\chi, \gamma)\right) \beta=0
\end{array}\right.
$$

Para o ponto de origem $q_{o}=(0,0)$ da quádrica, têm-se que

$$
\left\{\begin{array}{cccc}
\left(2 a-\kappa_{i}\right) \alpha+b \beta & = & 0 \\
b \alpha+ & \left(2 c-\kappa_{i}\right) \beta & = & 0
\end{array}\right.
$$


que é um sistema homogêneo. Utilizando-se, por exemplo, a primeira equação do sistema 9.25, tem-se que $\vec{d}_{i}=\left(\alpha, \frac{\left(\kappa_{i}-2 a\right) \alpha}{b}\right)$, com $i \in 1,2$.

Uma vez que as curvaturas e direções principais para o vértice base $v$ foram calculadas, resta apenas montar o tensor métrico. Para isso, considere $\kappa_{\max }=\max \left\{\kappa_{1}, \kappa_{2}\right\}$ e sua direção principal correspondente como $\vec{d}_{\text {max }}$, e, semelhantemente, $\kappa_{\min }=\min \left\{\kappa_{1}, \kappa_{2}\right\}$ com direção $\vec{d}_{\text {min }}$. O tensor métrico é montado de acordo com a Equação $(2.3)$, sendo que $\xi_{1}=\kappa_{\max }$, $\xi_{2}=\kappa_{\text {min }}, \xi_{3}=\kappa_{\max }, \vec{\nu}_{1}=\vec{d}_{\text {max }}, \vec{\nu}_{2}=\vec{d}_{\min }$ e $\vec{\nu}_{3}=\vec{n}_{v}$.

\section{Estimativa de tensores métricos sobre linhas-de-controle}

A forma de estimar tensores métricos para os vértices de uma malha como apresentado anteriormente é utilizada apenas para vértices pertencentes às superfícies-de-controle ou aos pontas-de-controle. Para vértices pertencentes às linhas-de-controle ou em cantos-de-controle, os tensores são estimados via interpolação.

Existem casos, no entanto, em que um vértice $v_{i} \in C_{L} \cup C_{C}$ não possui qualquer vértice pertencente a uma superfície-de-controle. Nestes casos, $v_{i}$ recebe um tensor métrico isotrópico onde

$$
\xi_{i}=\left(\frac{1}{S_{\min }^{2}}+\frac{1}{S_{\max }^{2}}\right) \frac{1}{2}=\left(\frac{S_{\min }+S_{\max }}{2 S_{\min } S_{\max }}\right)^{2}
$$

para $i=1,2,3$, onde $S_{\min }$ e $S_{\max }$ são os parâmetros descritos na Seção 9.1.1.

\subsubsection{O conjunto de vértices $V_{v}$}

O processo de construção da quádrica descrito na Seção 9.1.2 depende da escolha apropriada de um conjunto de vértices $V_{v}$ na vizinhança do vértice sobre o qual se está calculando as principais curvaturas. Nesta seção é apresentado como são selecionados os vértices para formar o conjunto $V_{v}$.

Considere um disco $\omega_{v}$ centrado em $v$ sobre a superfície, conforme mostrado na Figura 9.2. Um vértice $v_{j}$ está contido no disco se o comprimento do caminho geodésico ${ }^{1}$ de $v$ até $v_{j}$ for menor que o raio do disco. O raio do disco $\omega_{v}$ é calculado como o dobro da média dos comprimentos das arestas incidentes em $v$.

Nem todos os vértices contidos no disco $\omega_{v}$ devem ser incluídos em $V_{v}$. Um vértice $v_{j} \in G$ é inserido em $V_{v}$ se :

\footnotetext{
${ }^{1} \mathrm{O}$ caminho geodésico é o menor caminho entre dois pontos tomado sobre a superfície. Neste trabalho, ele pode ser computado de forma grosseira.
} 


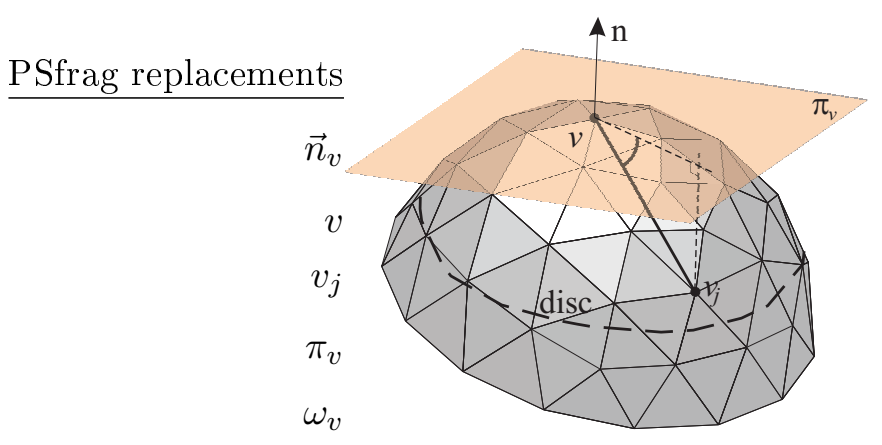

Figura 9.2: Seleção dos vértices $V_{v}$.

- $v_{j}$ e $v$ pertencem à mesma superfície-de-controle e o ângulo formado entre o plano $\pi_{v} \mathrm{e}$ o segmento de reta $\overline{v_{j} v}$ for menor que $25^{\circ}$ (veja Figura 9.2), ou

- $v_{j}$ é um vértice incidente em $v$.

\subsection{Ajuste da função de espaçamento}

Uma vez que um tersor métrico tenha sido associado com cada vértice de $G$, são realizadas algumas operações para ajustar melhor os tamanhos requeridos pelos tensores.

O primeiro ajuste realiza uma escala sobre os tensores a fim de encolher seus respectivos elipsóides. Esta operação de escala é responsável por aumentar o número de triângulos na malha resultante.

Seja $M$ um tensor métrico tridimensional com autovalores $\xi_{i}$ e autovetores $\vec{\nu}_{i}, i=1,2,3$. O tensor $M$ escalado por um fator $\epsilon_{s}$ é dado por

$$
\left[\begin{array}{lll}
\overrightarrow{\nu_{1}} & \overrightarrow{\nu_{2}} & \vec{\nu}_{3}
\end{array}\right]\left[\begin{array}{ccc}
\epsilon_{s} \xi_{1} & 0 & 0 \\
0 & \epsilon_{s} \xi_{2} & 0 \\
0 & 0 & \epsilon_{s} \xi_{3}
\end{array}\right]\left[\begin{array}{ccc}
\overrightarrow{\nu_{1}} & \overrightarrow{\nu_{2}} & \vec{\nu}_{3}
\end{array}\right]^{t}
$$

Note que o processo descrito na Seção 9.1.2 cria tensores métricos sobre superfícies-decontrole definindo elipsóides com raios iguais aos raios de curvatura. Porém, se o processo de remalhamento gerar arestas com comprimentos iguais aos raios de curvatura, a malha tende a ser muito grosseira. Para ilustrar este fato considere um exemplo unidimensional onde se queira aproximar uma circunferência com arestas. Se o tensor métrico não sofrer uma escala de redução, então a malha gerada possuirá apenas seis arestas, o que é claramente uma aproximação grosseira do modelo. 

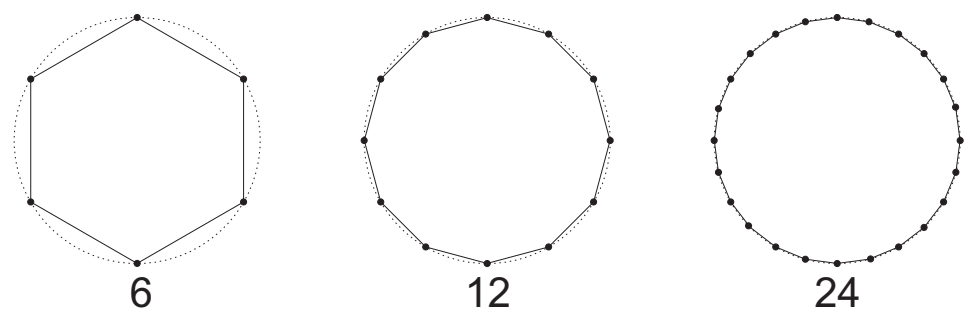

Figura 9.3: Efeito do parâmetro $n_{e}$ para os valores 6, 12 e 24 .

Para contornar este problema, uma escala é aplicada sobre todos os tensores métricos de $G$. O fator de escala $\epsilon_{s}$ é dado pela seguinte fórmula:

$$
\epsilon_{s}=\frac{1}{2 \operatorname{sen}\left(\pi / n_{e}\right)}
$$

onde $n_{e} \geq 6$ é um parâmetro indicando quantas arestas devem ser utilizadas para amostrar uma circunferência. A Figura 9.3 apresenta o efeito de deferentes valores de $n_{e}$ na aproximação. Note que a escala é adimensional, o que significa que ela é aplicada de igual modo independente do tamanho do elipsóide. Geralmente, $n_{e}=24$ é suficiente para uma boa amostragem.

Após a escala, é realizada uma operação denominada enquadramento. Esta operação tem a função de ajustar explicitamente os autovalores dos tensores métricos a fim de satisfazer a restrição imposta pela Equação (9.1). Para isso, os raios de elipsóides com comprimentos maiores que $S_{\max }$ são reduzidos para $S_{\max }$ (ver Seção 9.1.1). Este é um caso não raro que ocorre em regiões planas da superfície. Semelhantemente, os raios com comprimentos menores que $S_{\min }$ são aumentados para $S_{\text {min }}$. Este é o caso de vértices descrevendo detalhes muito finos do modelo, muitas vezes é desejável fazer uma aproximação de superfície mais grosseira em tais regiões para reduzir o número de elementos da malha final.

A Figura 9.4 ilustra a criação de uma função tamanho sobre a superfície de um toro (Figura 9.4(b)). A fim de prover uma melhor forma para visualização da função de espaçamento, apenas os elipsóides de um subconjunto de vértices são mostrados. A Figura 9.4(c) (notoriamente confusa) mostra os elipsóides extraídos diretamente das quádricas. A Figura 9.4(a) mostra o efeito da etapa de escala $\left(\epsilon_{s}=25\right)$. Finalmente, a Figura 9.4(d) mostra o efeito da operação enquadramento.

As etapas descritas acima são capazes de produzir funções de espaçamento suaves desde que a superfície seja também suave. No entanto, em modelos mais realistas tais etapas não são suficientes para garantir funçôes de espaçamento suaves. Como a suavidade é de fundamental importância para produzir malhas de boa qualidade, uma etapa final de suavização é aplicada, como descrito na seção seguinte. 


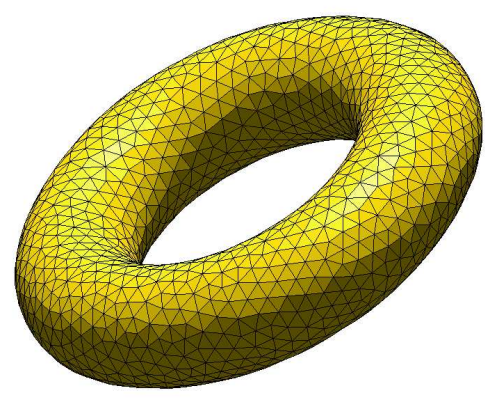

(a)

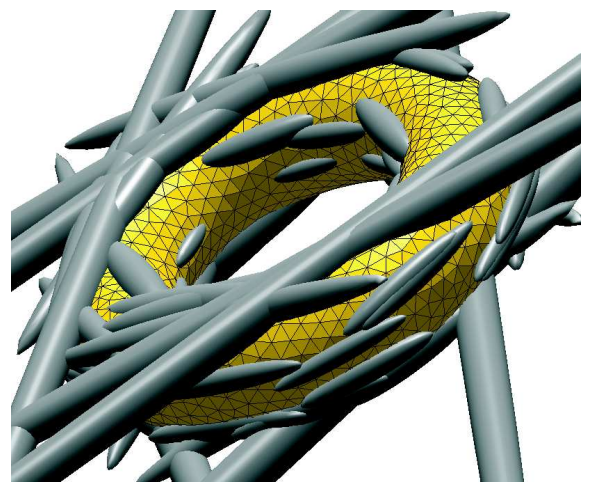

(c)

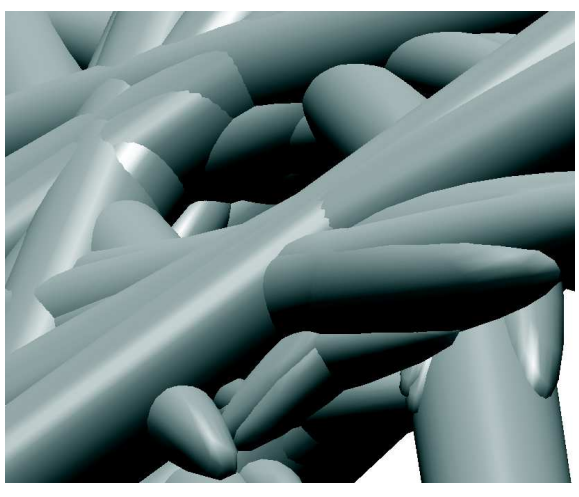

(b)

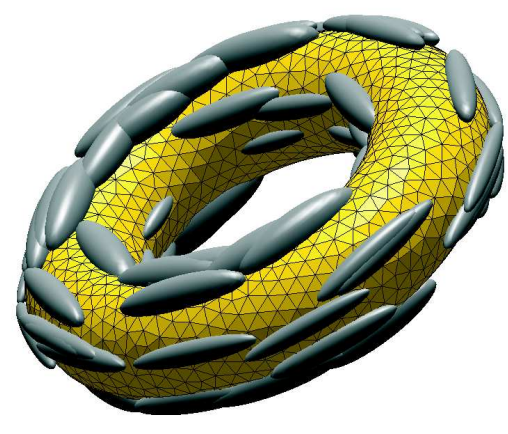

(d)

Figura 9.4: Construção de uma função de espaçamento sobre a superfície de um toro. 


\subsubsection{Suavização de funções de espaçamento}

Como argumentado previamente, sabe-se que variações bruscas na função de espaçamento geralmente degradam a qualidade da malha resultante. Uma das formas de reduzir o impacto das funçôes de espaçamento na malha resultante é por meio de suavização. Em espaços isotrópicos, alguns métodos foram propostos, como o de Löhner [60, 59], o de Borouchaki et al. [12] e o de Owen e Saigal [66]. Estes métodos podem ser facilmente adaptados para atuarem em domínios anisotrópicos. De fato, Borouchaki et al. descrevem tal extensão para o método proposto por eles. No entanto, esta adaptação suaviza apenas os raios dos elipsóides (autovalores) deixando intocadas suas principais direções (autovetores). Ou seja, elas tendem a não manter o nível desejado de anisotropia. Li et al. [55] propuseram um método capaz de suavizar funções de espaçamento anisotrópicas tanto em termos de autovalores quanto autovetores.

Nesta seção são descritos dois métodos de suavização: o de Borouchaki et al. [12] e o de Li et al. [55]. Em seguida é feita uma comparação entre eles.

\section{H-Correction [12]}

Borouchaki et al. propuseram um método para controlar a variação de tamanhos em funções de espaçamento. O método é descrito inicialmente para o caso isotrópico e então é generalizado para o caso anisotrópico.

Considere uma função de espaçamento, $H$, definida por meio de uma malha de fundo $G$ em um domínio $\Omega$. Para realizar a suavização, é necessário determinar localmente a variação de tamanhos em $\Omega$. Os autores oferecem duas formas diferentes de medir tal variação. A primeira, conhecida como H-variation, mede o gradiente de $H$. A segunda, chamada $H$-Shock, considera a razão entre os comprimentos (medidos no espaço euclidiano) de duas arestas adjacentes. O procedimento de suavização $H$-Correction consiste em reduzir consistentemente as métricas definidas em $H$ a fim de limitar a variação, quer medida via $H$-variation ou via $H$-shock, a um valor fornecido pelo usuário.

Considere o caso isotrópico, onde o tamanho desejado em um ponto $P$ é dado por $h(P)$. O comprimento de uma aresta $e_{p q}$ da malha de fundo $G$ pode ser calculada por

$$
\ell_{P Q}=\left\|\vec{e}_{p q}\right\| \int_{0}^{1} \frac{1}{h(t)} d t
$$

onde $h(t)$ é uma função de interpolação monotônica tal que $h(0)=h(P)$ e $h(1)=h(Q)$.

O H-variation relacionado com a aresta $e_{p q}$, denotado por $H v\left(e_{p q}\right)$, é dado por 


$$
H v\left(e_{p q}\right)=\frac{h(Q)-h(P)}{\left\|\vec{e}_{p q}\right\|}
$$

O $H$-shock relacionado com a aresta $e_{p q}$, denotado por $H s\left(e_{p q}\right)$, é dado por

$$
H s\left(e_{p q}\right)=\max \left(\frac{h(Q)}{h(P)}, \frac{h(P)}{h(Q)}\right)^{1 / \ell_{P Q}} .
$$

Os valores $H v$ e $H s$ quando referidos a vértices são dados como o maior valor dentre todas as arestas adjacentes àquele vértice, ou seja:

$$
H v\left(v_{p}\right)=\max _{v_{q} \in V\left(\mho_{v_{p}}\right)} H v\left(e_{p q}\right)
$$

e

$$
H s\left(v_{p}\right)=\max _{v_{q} \in V\left(\text { « } v_{p}\right)} H s\left(e_{p q}\right) .
$$

Por definição, o H-variation e o H-shock de uma função de espaçamento são dados pelo valor máximo das medidas $H v\left(v_{p}\right)$ e $H s\left(v_{p}\right)$, respectivamente, considerando todos os vértices.

A extensão das métricas para o caso geral anisotrópico é simples. O valor de $h$ é calculado considerando uma dada direção, no caso, a direção da aresta em questão $\vec{e}_{p q}$. Ou seja, para a aresta $e_{p q}, h(P)=S_{p}\left(\vec{e}_{p q}\right)$ e $h(Q)=S_{q}\left(\vec{e}_{p q}\right)$. Além disso, o comprimento $\ell_{P Q}$ da Equação (9.29) é substituído pela Equação (2.9).

Os autores fornecem duas variações para o procedimento de suavização H-correction, dependendo de qual medida de variação deve ser empregada, se $H$-variation ou se $H$-shock.

Considere primeiro a versão baseada no H-variation, denotada por Hv-correction. Neste caso, quando uma métrica é reduzida, seu elipsóide correspondente pode ter seu formato alterado. A intenção é limitar o H-variation ao longo de uma aresta $e_{p q}$ a um valor $H V_{\text {lim }}$, isto é $H v\left(e_{p q}\right) \leq H V_{l i m}$. Assim, no caso isotrópico, as novas especificações de tamanho nos vértices $v_{p}$ e $v_{q}$ são dados por:

$$
\begin{aligned}
& h(P)=\min \left(h(P), h(Q)+H V_{l i m}\left\|\vec{e}_{p q}\right\|\right), \\
& h(Q)=\min \left(h(Q), h(P)+H V_{l i m}\left\|\vec{e}_{p q}\right\|\right) .
\end{aligned}
$$

No caso anisotrópico, o operador min é substituído pelo operador interseção entre tensores métricos, conforme descrito em [13], portanto:

$$
\begin{aligned}
& M_{p}=M_{p} \cap M_{q}\left(1+H V_{l i m} d_{p q}^{p}\right)^{-2}, \\
& M_{q}=M_{q} \cap M_{p}\left(1+H V_{l i m} d_{p q}^{q}\right)^{-2} .
\end{aligned}
$$


Note que a correção ao longo de uma aresta não leva em consideração a interpolação da métrica ao longo da aresta. O procedimento Hv-correction está descrito no Algoritmo 4.

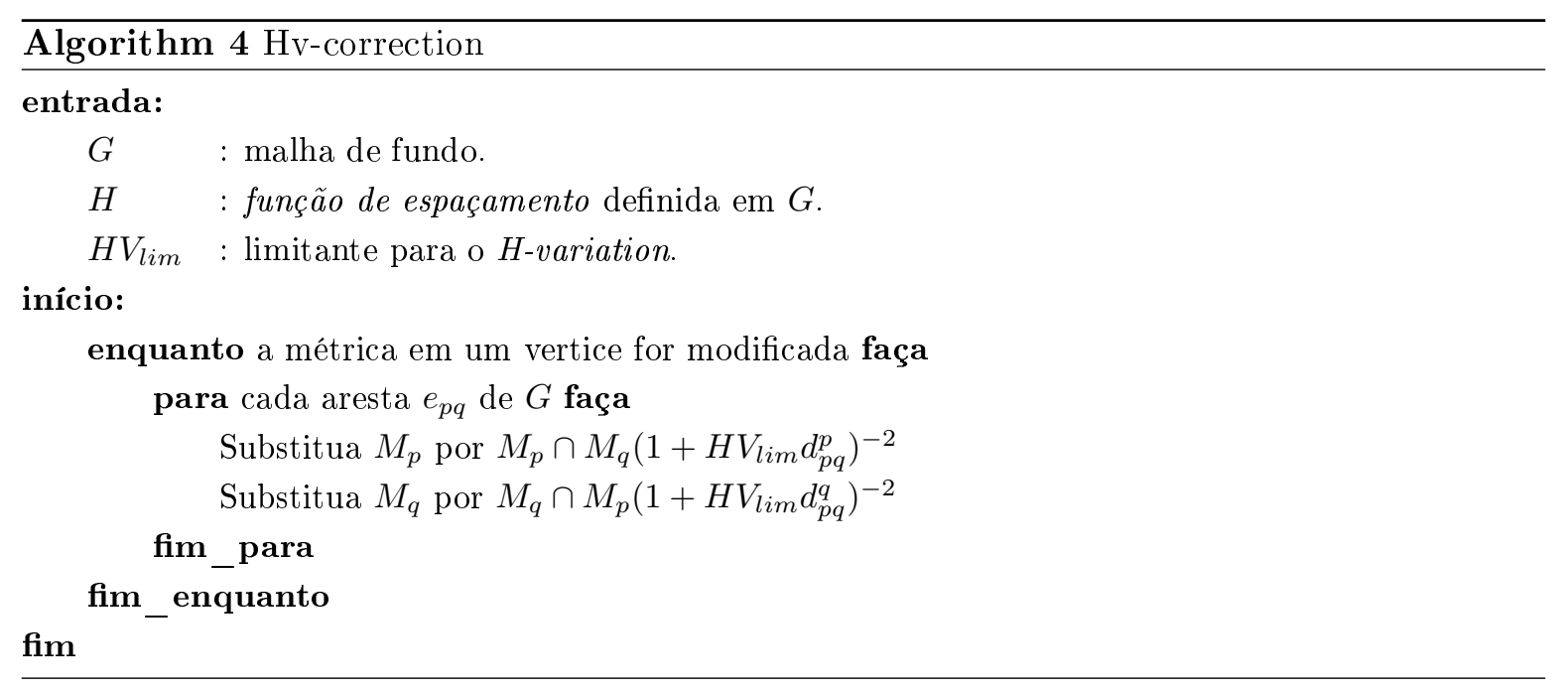

Considere agora a versão do H-correction baseada $H$-shock, denotada por Hs-correction. Neste tipo de correção os formatos dos elipsóides são preservados. Suponha que $h(P) \leq h(Q)$ para uma dada areta $e_{p q}$. Neste caso, o tamanho requerido em $v_{q}$ é que deve ser reduzido tal que o valor de $H$-shock seja limitado por um valor definido pelo usuário $H S_{l i m}$. Seja $h^{\prime}(Q)$ o novo valor de $h(Q)$ após a redução da métrica. Para facilitar os cálculos, os autores propõem uma solução aproximada para $h^{\prime}(Q)$.

Como $h^{\prime}(Q) \leq h(Q)$, tem-se que $\ell_{P Q}<\ell_{P Q}^{\prime}$, onde $\ell_{P Q}^{\prime}$ é a distância de $v_{p}$ a $v_{q}$ levando em consideração $h^{\prime}(Q)$. Seja $H s^{\prime}\left(e_{p q}\right)$ o novo $H$-shock considerando $h^{\prime}(Q)$. Tem-se que:

$$
H s^{\prime}\left(e_{p q}\right)=\left(\frac{h(P)}{h^{\prime}(Q)}\right)^{1 / \ell_{P Q}^{\prime}} \leq\left(\frac{h(P)}{h^{\prime}(Q)}\right)^{1 / \ell_{P Q}}=H s\left(e_{p q}\right) \eta^{1 / \ell_{P Q}},
$$

onde $\eta=h^{\prime}(Q) / h(Q)$. Para se ter $H s^{\prime}\left(e_{p q}\right) \leq H S_{l i m}$, é suficiente satisfazer a inequação

$$
H s\left(e_{p q}\right) \eta^{1 / \ell_{P Q}} \leq H S_{l i m}
$$

conseqüentemente

$$
\eta \leq\left(\frac{H S_{l i m}}{H s\left(e_{p q}\right)}\right)^{\ell_{P Q}}
$$

Em síntese, supondo que $h^{\prime}(Q) \leq h(Q)$, o valor de $h(Q)$ deve ser reduzido por um fator $\eta$ menor ou igual que $\left(H S_{\text {lim }} / H s\left(e_{p q}\right)\right)^{\ell_{P Q}}$, para que o $H$-shock associado com $e_{p q}$ seja menor que $H S_{\text {lim }}$. Note que $\eta$ não é um valor ótimo. 
No caso anisotrópico, a verificação da aresta $e_{p q}$ também é simples. Basta assumir que $h(P)=S_{p}\left(\vec{e}_{p q}\right)$ e $h(Q)=S_{q}\left(\vec{e}_{p q}\right)$ e reduzir $M_{q}$ para $M_{q} / \eta^{2}$. O Algoritmo 5 descreve como aplicar iterativamente o $\mathrm{Hs}$-correction para suavizar uma função de espaçamento.

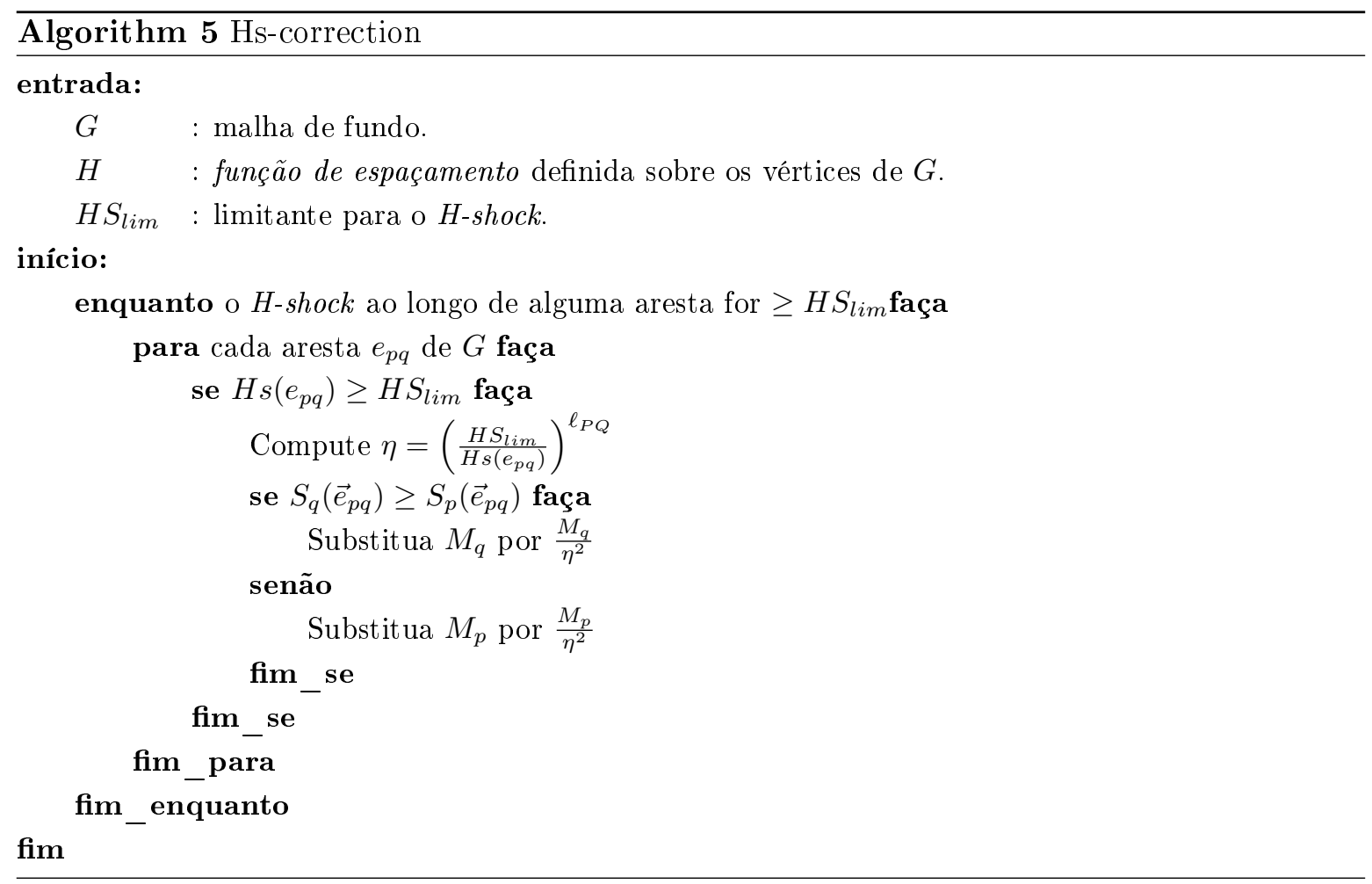

\section{O método de Li et. al [55]}

Li et al. propuseram um procedimento para suavizar funçôes de espaçamento anisotrópias. Diferentemente do método descrito na seção anterior, onde apenas os autovalores são alterados, a proposta de Li et al. também modifica os autovetores dos tensores. A descrição do método de suavização dado a seguir corresponde ao método implementado neste trabalho, e possui pequenas diferenças com relação ao método original proposto pelos autores.

O método utiliza uma métrica capaz de quantificar a variação entre dois tensores vizinhos. Sejam $v_{p}$ e $v_{q}$ dois vértices vizinhos, sobre os quais estão definidos os tensores métricos $M_{p}$ e $M_{q}$, respectivamente. Seja $\vec{u}_{i}$ um vetor direção unitário qualquer associado com $M_{i}$. A métrica $\gamma_{L}\left(\vec{u}_{p}, \vec{u}_{q}\right)$ que quantifica a variação entre as métricas $M_{p}$ e $M_{q}$ considerando as direções $\vec{u}_{p}$ e $\vec{u}_{q}$, respectivamente, é dada por:

$$
\gamma_{L}\left(\vec{u}_{p}, \vec{u}_{q}\right)=e^{\frac{\left|S_{p}\left(\vec{u}_{p}\right)-S_{q}\left(\vec{u}_{q}\right)\right|}{\left\|\vec{e}_{p q}\right\|}}
$$

onde $S_{i}\left(\vec{u}_{i}\right)$ é dado pela Equação $(2.15)$. A idéia é então modificar os tensores métricos de 
tal forma que a métrica $\gamma_{L}$ entre tensores vizinhos seja sempre menor que um dado valor $\gamma_{L_{0}}$ fornecido pelo usuário.

Considere os seguintes rótulos para os tensores: (i) tensor-esfera, onde os três autovalores são iguais; (ii) tensor-esferóide, onde apenas dois autovalores são idênticos; e (iii) tensorelipsóide, onde todos os autovalores diferem entre si.

Seja $R\left(M_{w}\right)$ a razão de aspecto do tensor métrico $M_{w}$ dada por:

$$
R\left(M_{w}\right)=\sqrt{\frac{\xi_{\max }}{\xi_{\min }}},
$$

onde $\xi_{\max }$ e $\xi_{\max }$ são respectivamente o maior e o menor autovalor de $M_{w}$.

O processo de suavização procura então reduzir as diferenças entre tensores métricos adequadamente de tal forma a satisfazer um limitante estabelecido pelo usuário. Neste caso, porém, uma métrica $M_{w}$ pode sofrer alterações tanto nas principais direções (autovetores $\vec{\nu}_{i}$, veja Equação (2.3)) quanto nos tamanhos requeridos $S_{w}\left(\vec{\nu}_{i}\right)$ (que estão intimamente relacionados com os autovalores). O processo de suavização segue as seguintes diretivas:

- Se dois tensores apresentarem diferentes tamanhos, então o maior é reduzido.

- Se para dois tensores vizinhos $M_{p}$ e $M_{q}$ tem-se que $R\left(M_{p}\right)>R\left(M_{q}\right)$, então as direções de $M_{p}$ são preservadas e as de $M_{q}$ podem ser alteradas.

- Se dois tensores com alto $R$ estiverem próximos, todas as principais direções são mantidas.

O par de vetores direção $\left(\vec{u}_{p}, \vec{u}_{q}\right)$ da Equação (9.41) é formado por autovetores. Para se comparar duas métricas, nem sempre é necessário fazer a correspondência de cada autovetor de uma métrica com outro autovetor da outra métrica. A seleção dos pares de autovetores se dá pela verificação do tipo dos tensores métricos envolvidos. Suponha que $R\left(M_{p}\right)>R\left(M_{q}\right)$, três casos são possíveis: (i) se $M_{p}$ é qualquer e $M_{q}$ é um tensor-esfera, então não é necessário estabelecer qualquer par; (ii) se $M_{p}$ e $M_{q}$ são tensores-esferóides, então se encontra apenas um par, o das direções polares ${ }^{2}$; e (iii) se $M_{p}$ é um tensor-elipsóide e $M_{q}$ é qualquer, então deve-se encontrar os três pares. Neste último caso, os pares são feitos minimizando-se os maiores ângulos entre vetores.

Suponha $R\left(M_{p}\right)>R\left(M_{q}\right)$. Considere o fator $\alpha$, que é calculado pela seguinte expressão:

$$
\alpha=\frac{\left(R\left(M_{q}\right)-1\right) R\left(M_{p}\right)}{\left(R\left(M_{p}\right)-1\right) R\left(M_{q}\right)}
$$

\footnotetext{
${ }^{2}$ A direção polar de um tensor-esferóide corresponde ao autovetor associado com o autovalor diferenciado.
} 
onde $0 \leq \alpha \leq 1$, com $\alpha=0$ se algum dos tensores for isotrópico (tensor-esfera) e $\alpha=1$ se os dois tensores tiverem a mesma razão de aspecto.

O fator $\alpha$ é utilizado na fórmula a seguir que ajusta um dos autovetores do tensor menos anisotrópico, no caso $M_{q}$,

$$
\left.\vec{\nu}_{i}^{q}\right|_{n e w}=(1-\alpha) \vec{\nu}_{i}^{p}+\alpha \vec{\nu}_{j}^{q}
$$

onde $\vec{\nu}_{j}^{q}$ é o autovetor de $M_{q}$ que deve ser ajustado, pois assumimos que $R\left(M_{p}\right)>R\left(M_{q}\right)$; $\left.\vec{\nu}_{i}^{q}\right|_{\text {new }}$ é a nova direção de $\vec{\nu}_{j}^{q}$; e $\vec{\nu}_{i}^{p}$ é o autovetor de $M_{p}$ fazendo par com $\vec{\nu}_{j}^{q}$.

O ajuste de dois tensores métricos $M_{q}$ e $M_{p}$ vizinhos é realizado pelo seguinte procedimento. Primeiro encontra-se os pares adequados de autovetores, se existirem. Em seguida, para cada $\operatorname{par}\left(\vec{\nu}_{i}^{p}, \vec{\nu}_{j}^{q}\right)$ tenta-se fazer o ajuste direcional aplicando-se a Equação (9.44). Finalmente, ajusta-se os autovalores, o que se dá em três passos:

1. Calcule $S_{p}\left(\vec{\nu}_{i}^{p}\right)$ e $S_{q}\left(\vec{\nu}_{j}^{q}\right)$.

2. Compute a métrica $\gamma_{L}\left(\vec{\nu}_{i}^{p}, \vec{\nu}_{j}^{q}\right)$ segundo a Equação (9.43).

3. Se $\gamma_{L}\left(\vec{\nu}_{i}^{p}, \vec{\nu}_{j}^{q}\right)<\gamma_{L_{0}}$ então não é necessário fazer a redução; caso contrário, a redução é realizada nos seguintes termos: se $S_{q}\left(\vec{\nu}_{j}^{q}\right)>S_{p}\left(\vec{\nu}_{i}^{p}\right)$ então reduza $S_{q}\left(\vec{\nu}_{j}^{q}\right)$; senão, reduza $S_{p}\left(\vec{\nu}_{i}^{p}\right)$

Suponha que $M_{q}$ tenha que ter algum autovalor alterado. Seja $\left.S_{q}\left(\vec{\nu}_{j}^{q}\right)\right|_{\text {new }}$ o tamanho reduzido relativo a $S_{q}\left(\vec{\nu}_{j}^{q}\right)$ que se deseja encontrar. Para que a redução estabeleça $\gamma_{L}\left(\vec{\nu}_{i}^{p}, \vec{\nu}_{j}^{q}\right)=$ $\gamma_{L_{0}}$, é necessário que:

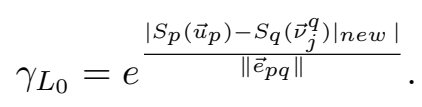

Portanto, o novo tamanho reduzido é dado por:

$$
\left.S_{q}\left(\vec{\nu}_{j}^{q}\right)\right|_{n e w}=\left\|e_{p q}\right\| \ln \left(\gamma_{L_{0}}\right)+S_{p}\left(\vec{u}_{p}\right)
$$

Após processar todos os pares, os tensores são montados novamente na forma matricial conforme a Equação (2.3).

Uma comparação visual dos três métodos de suavização descritos anteriormente pode ser feita analisando-se a Figura 9.5. Para simplificar a vizualização, são apresentados os tensores métricos de apenas alguns vértices da malha, os quais são escolhidos aleatoriamente. A Figura 
9.5(a) apresenta a função de espaçamento inicial, a qual foi submetida a nove processos de suavização independentes. As Figuras 9.5(b), 9.5(e) e 9.5(h) mostram os efeitos após a aplicação de 5 iterações do método $H$-variation com os parâmetros $H V_{l i m}=0.25, H V_{l i m}=0.1 \mathrm{e}$ $H V_{l i m}=0.025$, respectivamente. Note que quanto menor o valor de $H V_{l i m}$, mais isotrópicos se tornam os tensores. Os efeitos de se aplicar 5 iterações do método $H$-shock estão apresentados nas Figuras 9.5(c), 9.5(f) e 9.5(i), sob os parâmetros $H S_{\text {lim }}=1.25, H S_{\text {lim }}=1.1 \mathrm{e}$ $H S_{\text {lim }}=1.025$ respectivamente. Note que os tensores são escalados uniformemente durante a suavização. É possível notar também que, comparado com os outros métodos, o H-Shock é que o realiza a redução mais acentuada dos raios dos elipsóides (veja a Figura 9.5(i)), o que conseqüentemente requer um número mais elevado de elementos após o remalhamento. Finalmente, as Figuras 9.5(d), 9.5(g) e 9.5(j) mostram os resultados após se aplicar a adaptação do método de Li et al. sob os parâmetros $\gamma_{L_{0}}=1.25, \gamma_{L_{0}}=1.1$ e $\gamma_{L_{0}}=1.025$. Note que o método não apenas reduz os raios dos elipsóides, mas também altera a forma dos elipsóides. Por exemplo, o tensor-esfera presente na Figura 9.5(a) se torna um tensor-esferóide após a suavização, o que não acontece nos outros métodos. 


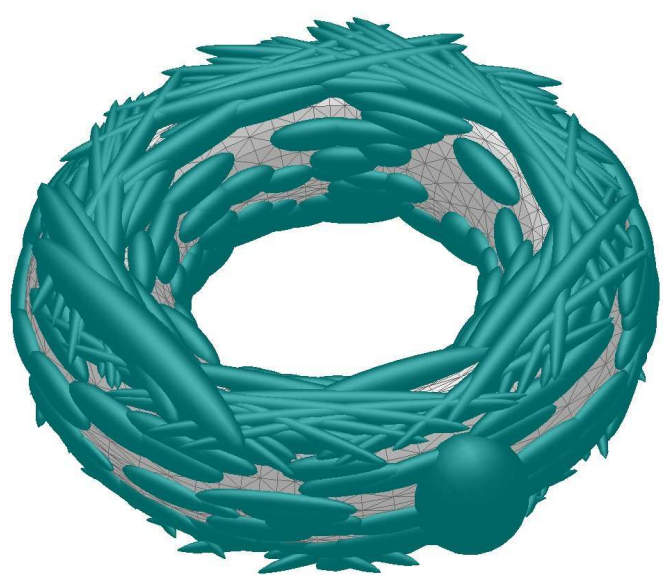

(a) Antes da correção

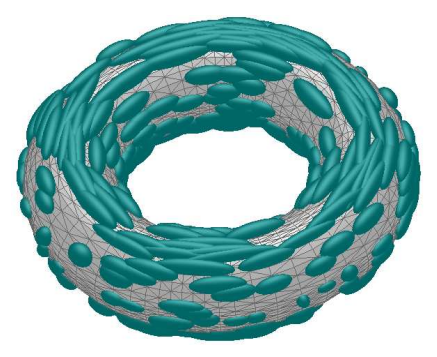

(b) $H V_{\text {lim }}=0.25$

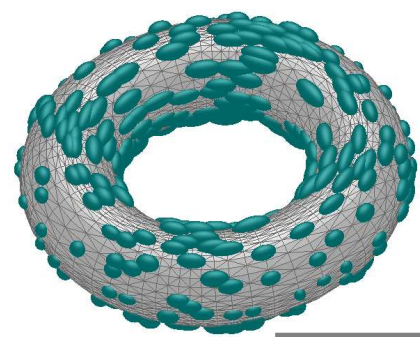

(e) $H V_{\text {lim }}=0.1$

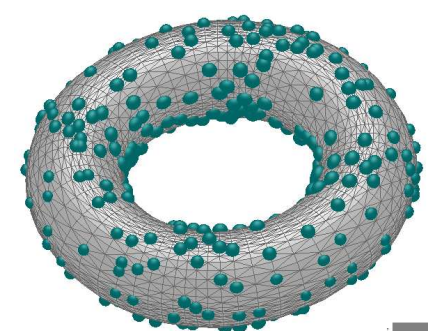

(h) $H V_{\text {lim }}=0.025$

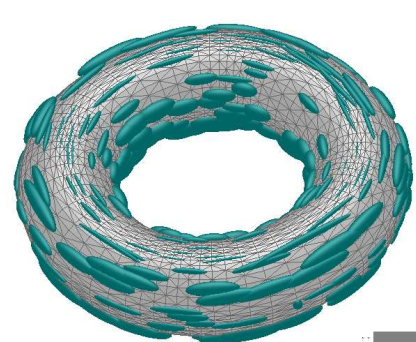

(c) $H S_{\text {lim }}=1.25$

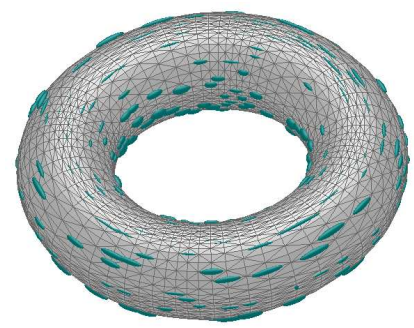

(f) $H S_{\text {lim }}=1.1$

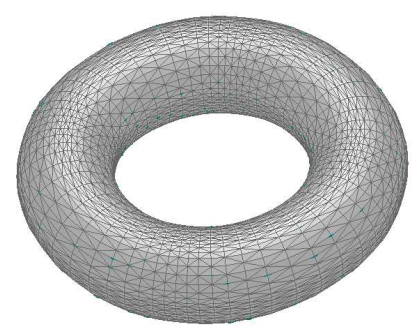

(i) $H S_{\text {lim }}=1.025$

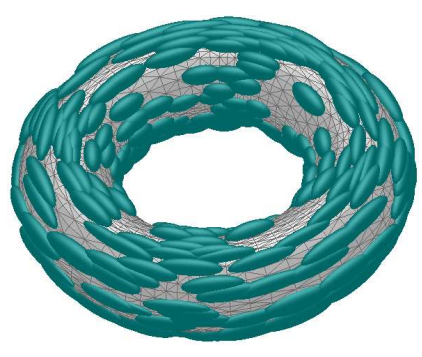

(d) $\gamma_{L_{0}}=1.25$

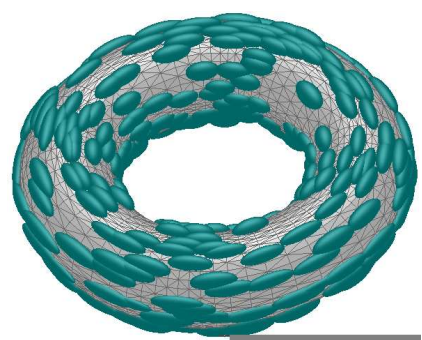

(g) $\gamma_{L_{0}}=1.1$

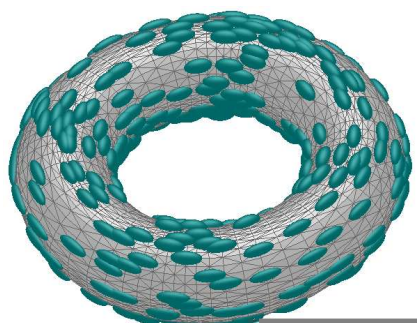

(j) $\gamma_{L_{0}}=1.025$

Figura 9.5: Comparação entre métodos de suavização de funções de espaçamento. 


\section{Capítulo 10}

\section{O processo de remalhamento}

Neste capítulo será descrito o funcionamento do ANTS, o método proposto neste trabalho para remalhamento de surperfícies.

O método recebe como entrada uma triangulação superficial $T$. Logo no início do procedimento é feita uma cópia exata de $T$, denominada $G$, que servirá como aparato geométrico para que o algoritmo mantenha a forma superficial da malha sendo processada. A malha $G$ permanece inalterada durante todo o processo, ao passo que a malha $T$ sofre constantes transformações. O símbolo $T_{i n}$ será utilizado para denominar a malha $T$ no início do processo, ou seja, a malha de entrada antes de qualquer alteração. Similarmente, $T_{\text {out }}$ será utilizado para denominar a malha $T$ final, isto é, após ter sito executado todo o processo de remalhamento.

O método ANTS constitui-se dos seguintes passos gerais:

1. Identificar as estruturas-de-controle em $T_{i n}$.

2. Criar $G$ como uma cópia de $T_{i n}$.

3. Identificar as estruturas-de-controle em $G$.

4. Definir uma size-function sobre $G$.

5. Remalhar $T_{\text {in }}$ até gerar $T_{\text {out }}$.

Os passos 1 e 3 foram descritos na Seção 8. A partir do passo 2, duas malhas estão presentes no processo, isto é, $T$ e $G$. O passo 4 define tensores métricos sobre os vértices de $G$, como descrito no Capítulo 9. O passo 5 é descrito em detalhes no restante desse capítulo.

Note que dois conjuntos de estruturas-de-controle estão presentes no processamento. Uma definida sobre $T$, que será referida por $C^{T}$, e outra sobre $G$, denominada $C^{G}$. Como $T$ é modificada durante o processo de remalhamento, os elementos de $C^{T}$ também são alterados. 
Muito embora $C^{T}$ seja modificado pelo remalhamento, é necessário que a forma geométrica das linhas e superfícies de controle de $C^{T}$ estejam sobre suas correspondentes em $C^{G}$. Portanto, faz-se necessária uma associação entre os elementos de $C^{T}$ e os de $C^{G}$, para que se saiba precisamente onde as projeções devem ocorrer. Essa associação é feita ligando-se cada vértice de $T$ a um vértice de $G$. No início do processo, existe uma correspondência um-para-um entre os vértices de $T$ e $G$ e a associação é trivial, pois as duas malhas são idênticas. À medida que o remalhamento ocorre, as associações são atualizadas para manter a coerência entre as estruturas-de-controle.

O processo de remalhamento ocorre pela execução de operadores de remelhamento, a saber: (i) inserção de vértices, (ii) colapsação de arestas, (iii) flipping de arestas e (iv) movimento de vértices. O funcionamento básico do ANTS consiste em selecionar um vértice de $T$ e acionar os operadores de remalhamento adequados conforme a necessidade local da malha. O termo iteração-vértice será utilizado para designar este processo de seleção e remalhamento a partir de um vértice.

Durante uma iteração-vértice, os operadores são chamados em uma sequência predeterminada, como pode ser visto no Algoritmo 6. Os operadores de remalhamento são executados conforme as seguintes regras. Primeiro, tenta-se executar o operator de movimento, sendo que ele só é chamado se a densidade local nas proximidades do vértice iterado não for nem muito alta nem muito baixa. Se o critério de densidade for obedecido, mas a movimentação do vértice comprometer a forma geométrica da superfície, a movimentação é desfeita. Se, no entanto, todas as condições forem favoráveis para a movimentação do vértice, ele é de fato deslocado e o operador de flipping de arestas é chamado para melhorar a qualidade local da malha. Em seguida, verifica-se novamente a densidade local da superfície nas vizinhanças do vértice iterado. Se a densidade for muito alta, executa-se o operador de colapsação de aresta para remover o vértice iterado. Porém, a colapsação só é de fato realizada se não houver alterações significativas na forma geométrica da superfície. Se a colapsação de fato ocorrer, o operador de movimento é executado imediatamente após a colapsação para todos os vértices que eram inicialmente adjacentes ao vértice removido. Finalmente, se a densidade local for considerada baixa, o operador de inserção de vértice é executado para aumentar a densidade local. Neste caso, um novo vértice é inserido sobre alguma aresta adjacente ao vértice iterado. Da mesma forma que para os outros operadores, a inserção também só ocorre se ela não alterar significativamente a forma geométrica da superfície.

Uma vez apresentada a idéia geral do método proposto, as próximas seções descrevem mais 


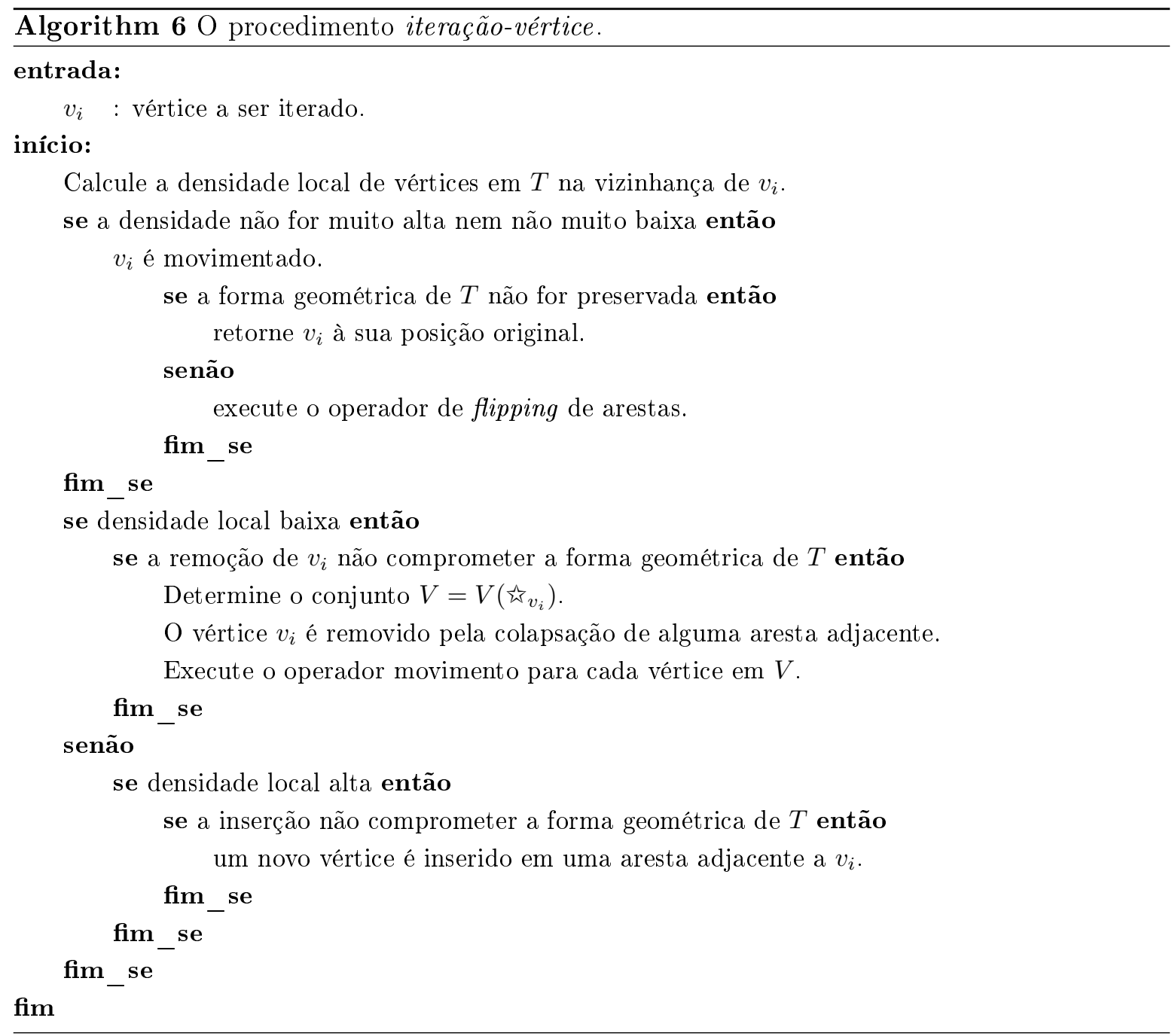


detalhadamente o processo de remalhamento.

\subsection{Gerenciamento dos vértices iterados}

É necessário fazer um gerenciamento dos vértices para decidir qual vértice deve ser selecionado para uma iteração-vértice. Este gerenciamento é feito via rotulação de vértices, onde cada nó de $T$ recebe um dos seguintes rótulos:

- ativo

- inativo

- adormecido

Uma vez que cada vértice recebe apenas um rótulo, é possível agrupá-los em três conjuntos distintos: $\mathcal{A}$ o conjunto de vértices ativos; $\mathcal{I}$ o conjunto de vértices inativos e $\mathcal{D}$ o conjunto de vértices adormecidos. Além disso, os elementos do conjunto $\mathcal{A}$ e $\mathcal{D}$ estão dispostos conforme a ordem de chegada dos vértices aos conjuntos. Os elementos de $\mathcal{I}$ não precisam obedecer ordem alguma.

Os vértices rotulados como ativos são aqueles prontos para serem submetidos a uma iteração-vértice. No início do processamento, todos os vértices de $T$ são adicionados em $\mathcal{A}$ e, conseqüentemente, os conjuntos $\mathcal{I}$ e $\mathcal{D}$ estão vazios.

Quando um vértice $v_{i}$ ativo é submetido a uma iteração-vértice, ele se torna inativo ou adormecido. Note, portanto, que o conjunto $\mathcal{A}$ se tornará vazio em algum momento. A transição de ativo para inativo ocorre quando nenhum operador de remalhamento foi de fato executado durante a iteração de $v_{i}$. Portanto, um vértice inativo é aquele que possivelmente não precisará ser processado novamente. De fato, isso ocorrerá se os vértices de sua estrela permanecerem inalterados. Se, por outro lado, alguma modificação ocorrer na estrela (devido a iteração-vértice de algum vértice adjacente), o vértice volta a se tornar ativo. Sendo assim, é possível que um vértice rotulado como inativo se torne ativo novamente.

A transição de ativo para adormecido ocorre quando algum operador de remalhamento foi chamado durante o processamento do vértice ativo $v_{i}$. Um vértice rotulado como adormecido deve se tornar ativo futuramente para que o remalhamento local seja concluído. Quando um vértice se torna adormecido, todos os seus vértices adjacentes que forem ativos ou inativos também se tornam adormecidos.

Sempre que o conjunto $\mathcal{A}$ se tornar vazio e o conjunto $\mathcal{D}$ possuir algum vértice, todos os elementos de $\mathcal{D}$ passam para $\mathcal{A}$, a esta transição dá-se o nome de reiniciação. O termo 
$\mathcal{A}=V_{T}$

$\mathcal{D}=\emptyset$

10.2. CRITÉT円ЮPARA PRESERVAR A FORMA GEOMÉTRICA DA SUPERFÍCIE 123

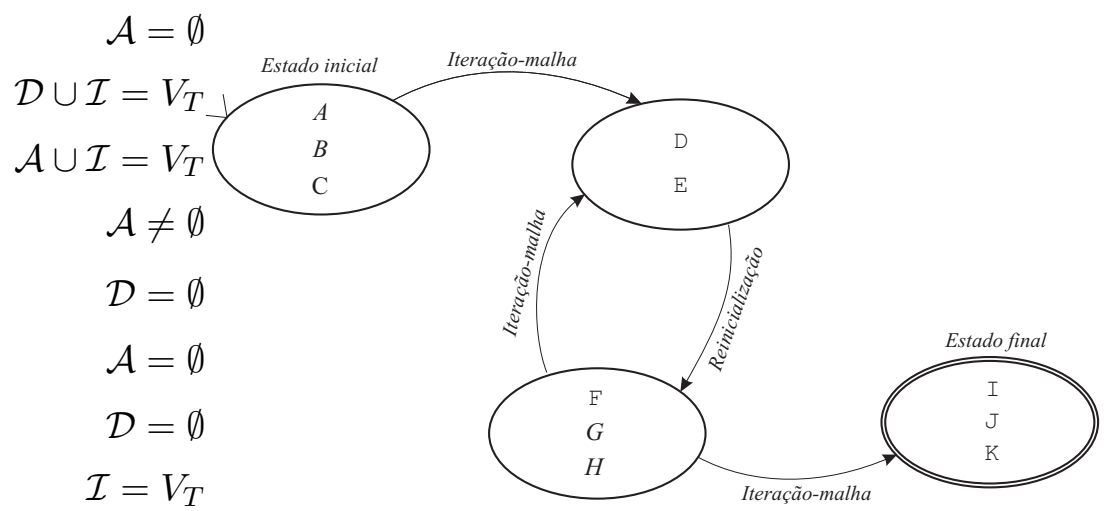

Figura 10.1: Diagrama de estados da rotulação dos vértices.

iteração-malha será utilizado para referenciar ao conjunto de iterações-vértice necessárias para se alcançar $\mathcal{A}=\emptyset$ partindo-se de $\mathcal{A} \neq \emptyset$ e $\mathcal{D}=\emptyset$. O diagrama da Figura 10.1 ilustra os possíveis estados dos conjuntos $\mathcal{A}, \mathcal{I}$ e $\mathcal{D}$ durante o remalhamento. O processo inicia com todos os vértices de $T$ rotulados como ativos $\left(\mathcal{A}=V_{T}\right)$. Após uma iteração-malha, $\mathcal{A}=\emptyset$ e todos os vértices atuais da malha estão distribuidos em $\mathcal{I}$ e $\mathcal{D}\left(\mathcal{I} \cup \mathcal{D}=V_{T}\right)$. O diagrama apresenta um laço entre os dois estados intermediários, onde ocorrem sucessivas reiniciaçôes/iteraçôesmalha. Quando o método converge, o estado final dos conjuntos tem todos os vértices de $T$ rotulados como inativos, o que significa que a malha não precisa mais sofrer qualquer remalhamento.

\subsection{Critério para preservar a forma geométrica da superfície}

Uma das grandes dificuldades em remalhamento de superfícies está em preservar a forma geométrica do modelo. Qualquer um dos operadores de remalhamento (insersão, remoção, flipping ou movimento) pode modificar a forma da superfície. Portanto, torna-se necessário adotar algum critério para verificar se a alteração introduzida pelo operador causa deformações na forma.

O método proposto utiliza uma métrica, chamada qualidade geométrica, denotada por $Q_{G}$, que determina a fidelidade de um triângulo de $T$ com relação à geometria inicial $G$. Os triângulos de $T$ devem estar próximos dos planos tangentes definidos nos seus vértices, sendo que estes planos devem ser obtidos a partir de $G$. Seja $t_{a b c} \in T$ um triângulo definido pelos vértices $v_{j} \in T, j=a, b, c$. A qualidade geométrica de $t_{a b c}$ é dada por:

$$
Q_{G}\left(t_{a b c}\right)=\min _{j \in a, b, c}\left\langle\vec{n}_{j}, \vec{n}_{t}\right\rangle
$$

onde $\langle.,$.$\rangle denota o produto escalar, \vec{n}_{t}$ é o vetor normal unitário do triângulo $t_{a b c}$, e $\vec{n}_{j}$ o vetor 


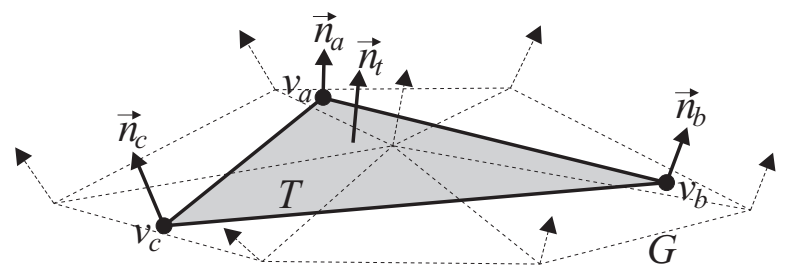

Figura 10.2: Entidades envolvidas no cálculo da métrica $Q_{G}$.

normal unitário interpolado em $v_{j}$ a partir de $G$. A Figura 10.2 ilustra as entidades envolvidas, onde a malha $G$ é apresentada com arestas tracejadas e a malha $T$ com arestas em negrito.

Sabe-se que o protudo escalar de dois vetores unitários é igual ao cosseno do ângulo entre os vetores, assim $0 \leq Q_{G} \leq 1$. Quanto maior for o valor de $Q_{G}$, maior a fidelidade do triângulo $t_{a b c}$, pois, mais alinhados estão os vetores normais $\vec{n}_{t}(\mathrm{em} T)$ e $\vec{n}_{j}(\mathrm{em} G)$.

Durante a iteração-vértice de um vértice $v_{i}$, a métrica $Q_{G}$ é utilizada da seguinte forma. A métrica $Q_{G}$ computa a qualidade de todos os triângulos pertencentes à $\star_{i}$ após qualquer operador ser executado. Se $Q_{G}$ for maior que um dado valor $\cos \left(\theta_{Q_{G}}\right)$ para todos os triângulos avaliados (estrela de $v_{i}$ ), então as modificações do operador são aceitas, caso contrário, a operação é desfeita. Maiores detalhes sobre como $Q_{G}$ é aplicada para verificar os efeitos de cada operador podem ser vistos nas seções 10.3.3, 10.3.4, 10.3.1 e 10.3.2.

O valor do ângulo $\theta_{Q_{G}}$, portanto, fornece um critério para controlar a fidelidade da forma superficial de $T$ com relação a $G$. Se valores altos (próximos de 1 ) forem fornecidos para $Q_{G}$, menor a fidelidade de $T$, porém mais liberdade se tem para remalhar, o que proporciona maiores condições para se obter triângulos de melhor qualidade. Sendo assim, o valor de $\theta_{Q_{G}}$ fornece um meio de se ajustar o compromisso entre fidelidade geométrica e qualidade dos triângulos. Recomenda-se, no entanto, que a qualidade esteja no intervalo $0.9848 \leq Q_{G} \leq 0.7071$, isto é, $10^{\circ} \leq \theta_{Q_{G}} \leq 45^{\circ}$. Na maioria dos testes realizados foi utilizado $\theta_{Q_{G}}=30^{\circ}$.

A Figura 10.3 apresenta os efeitos para diferentes escolhas de $Q_{G}$. Na figura, a malha inicial apresentada na Figura 10.3(a) foi submetida ao mesmo processo de simplificação, porém com diferentes valores para $Q_{G}$. Note que para $Q_{G}=\cos \left(10^{\circ}\right)$ (Figura 10.3(b)), a métrica impede que os operadores modifiquem a malha nas regiões onde a curvatura é mais acentuada.

\subsection{Operações de remalhamento}

Todas as operações descritas a seguir são chamadas a partir do vértice iteradado, o qual é denotado por $v_{i}$. 


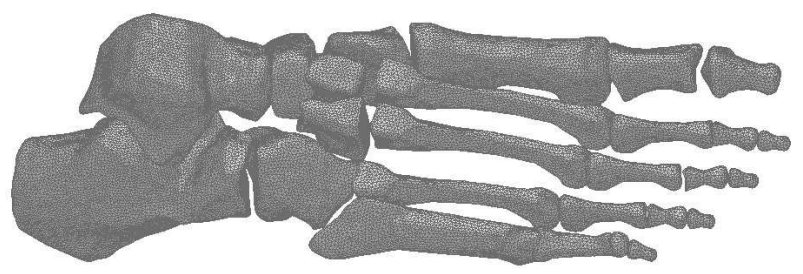

(a) Malha inicial

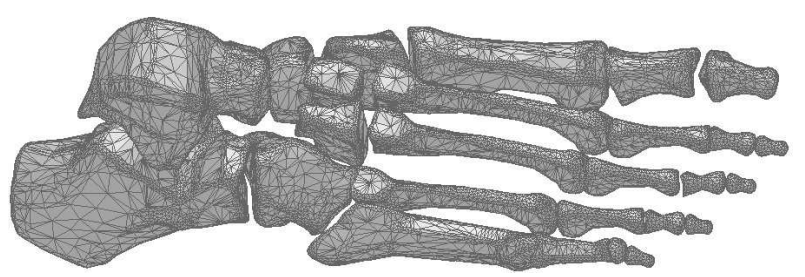

(b) $Q_{G}=\cos \left(10^{\circ}\right)$

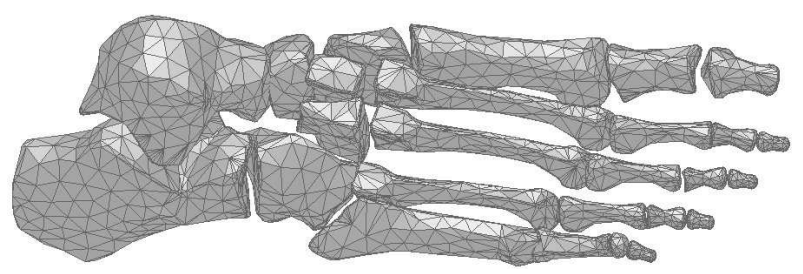

(c) $Q_{G}=\cos \left(30^{\circ}\right)$

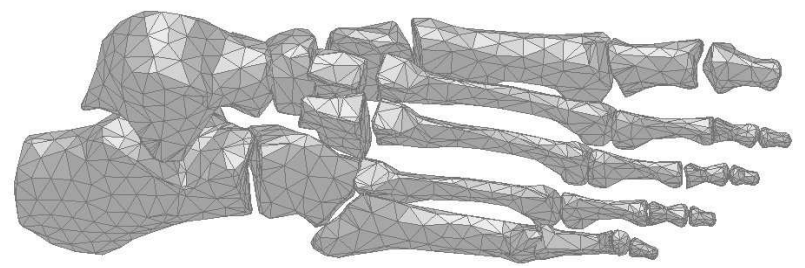

(d) $Q_{G}=\cos \left(45^{\circ}\right)$

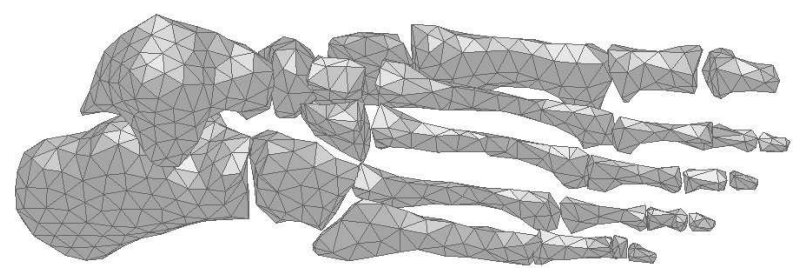

(e) $Q_{G}=\cos \left(60^{\circ}\right)$

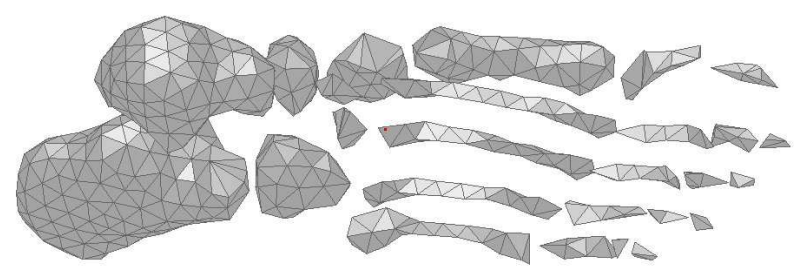

(f) $Q_{G}=\cos \left(90^{\circ}\right)$

Figura 10.3: Efeitos da métrica $Q_{G}$ no processo de remalhamento. 


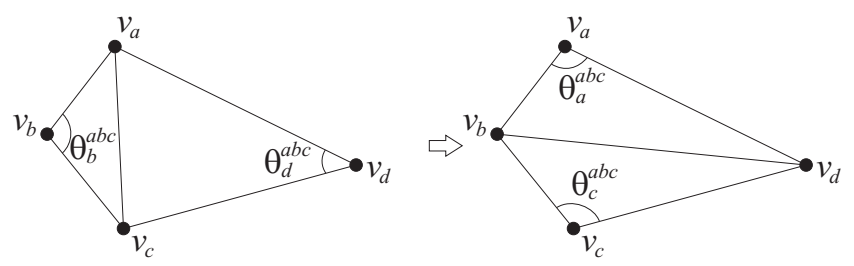

Figura 10.4: Flipping de uma aresta.

\subsubsection{Flipping de arestas}

A operação de flipping de arestas objetiva melhorar a qualidade local dos elementos da malha. Esta operação é amplamente utilizada em métodos para geração de triangulações de Delaunay, os quais se baseiam no critério do circuncírculo vazio [27]. Este critério é bem definido e facilmente computado para geração de triangulações isotrópicas em domínios bidimensionais planares. No entanto, o mesmo não pode ser dito quando se trata de domínios superficiais curvilíneos, muito embora existam propostas como a de Chew [28]. Além de ser computacionalmente caro de ser calculado, o critério modificado de Chew é aplicável apenas em superfícies suaves. O teste do circuncírculo também tem sido modificado para contemplar triangulações anisotrópicas [83, 56, 14], porém, ainda não foi proposta uma alternativa para o critério que garanta triangulações de Delaunay anisotrópicas mesmo para domínios bidimensionais planares. Como o método Ants se propõe a remalhar triangulações anisotrópicas superficiais, o critério do circuncírculo vazio não se mostrou apropriado. A opção escolhida procura melhorar a qualidade dos elementos pela diminuição do maior ângulo interno dos triângulos.

Sejam $e_{a c}$ e $e_{b d}$ as diagonais do quadrilátero $q_{a b c d}$, conforme ilustrado na Figura 10.4. O flipping da diagonal $e_{a c}$ para $e_{b d}$ ocorre se os seguintes testes forem simultaneamente verdadeiros:

- A aresta $e_{a c}$ não pertence a alguma linha-de-controle, isto é, $e_{a c} \notin C_{L}$.

- O maior ângulo interno dos triângulos envolvidos diminui, isto é, $\max \left\{\theta_{a b c}^{b}, \theta_{c d a}^{d}\right\}>$ $\max \left\{\theta_{d a b}^{a}, \theta_{b c d}^{c}\right\}$ (veja Equação (2.12)).

- $Q_{G}\left(t_{a b d}\right)>\cos \left(\theta_{Q_{G}}\right)$ e $Q_{G}\left(t_{b c d}\right)>\cos \left(\theta_{Q_{G}}\right)$.

O primeiro teste apenas assegura que linhas-de-controle sejam preservadas. O segundo teste procura melhorar a qualidade dos triângulos pela diminuição do maior ângulo interno dos triângulos envolvidos. O terceiro teste garante que a qualidade geométrica da superfície seja mantida após o flipping.

O operador de flipping é chamado a partir de um vértice $v_{i}$ a fim de melhorar, quando possível, a qualidade dos elementos incidentes em $v_{i}$. Para isso, procura-se realizar o flipping 


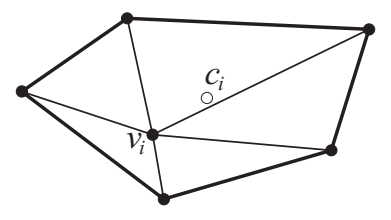

(a)

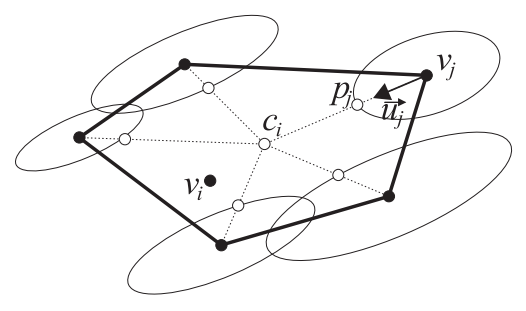

(b)

Figura 10.5: Movendo um vértice pertencente a uma superfície-de-controle.

em todas as arestas pertencente ao $v_{i}$. Sempre que o flipping de fato ocorrer, o $v_{i}$ é atualizado. O processo termina quando não for possível aplicar o flipping a alguma aresta de 烦 $v_{i}$.

\subsubsection{Movimento de vértices}

Foi desenvolvida uma nova estratégia para se efetuar movimento de vértices em domínios com características anisotrópicas. A idéia baseia-se no operador laplaciano de suavização, que é conhecido tanto por sua simplicidade como também por ser computacionalmente barato.

No método proposto, o procedimento para movimentar um vértice $v_{i}$ depende do tipo de estrutura-de-controle à qual o vértice pertence.

Suponha que o vértice $v_{i}$ pertença a uma superfície-de-controle. Neste caso, a nova posição de $v_{i}$, denotada por $v_{i}$ ', é obtida em dois passos. Observe a Figura 10.5. Primeiro, o centróide $c_{i}$ é calculado a partir de $V\left(\aleph_{i}\right)$ (veja a Figura 10.5(a)), ou seja

$$
c_{i}=\frac{1}{\#\left(V\left(\aleph v_{i}\right)\right)} \sum_{v_{j} \in V\left(\preccurlyeq v_{i}\right)} v_{j}
$$

O centróide $c_{i}$ é utilizado no lugar de $v_{i}$ (veja a Figura 10.5(b)) na seguinte equação de deslocamento

$$
v_{i}^{\prime}=\frac{\sum_{v_{j} \in V\left(\text { « } v_{i}\right)}\left(\left\|c_{i}-v_{j}\right\| S_{j}\left(\overrightarrow{u_{j}}\right)^{2}\right)^{-1} p_{j}}{\sum_{v_{j} \in V\left(\text { औ } v_{i}\right)}\left(\left\|c_{i}-v_{j}\right\| S_{j}\left(\overrightarrow{u_{j}}\right)^{2}\right)^{-1}}
$$

onde $\overrightarrow{u_{j}}=\left(c_{i}-v_{j}\right) /\left\|c_{i}-v_{j}\right\| ; p_{j}=v_{j}+S_{j}\left(\overrightarrow{u_{j}}\right) \overrightarrow{u_{j}}$; e $S_{j}\left(\overrightarrow{u_{j}}\right)$ é o tamanho de aresta desejado em $v_{j}$ na direção definida por $\overrightarrow{u_{j}}$ (veja Equação $(2.15)$ ).

A estratégia proposta para movimentar vértices merece alguns comentários. Primeiro, apenas uma iteração move $v_{i}$ para uma localização estável. Isso se deve ao fato de não se 


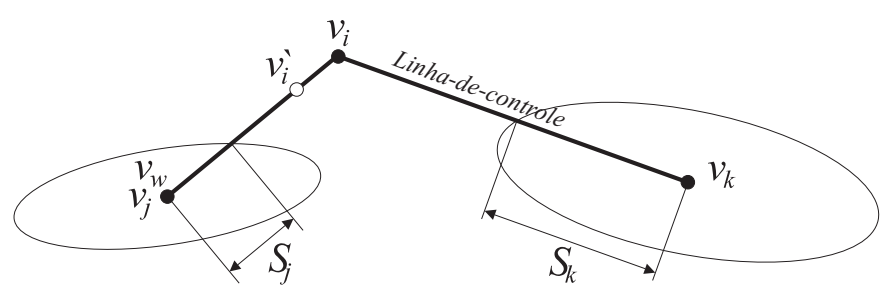

Figura 10.6: Movendo um vértice pertencente a uma linha-de-controle.

utilizar $v_{i}$ para fornecer informações de posição e tamanhos desejados, uma vez que estas informações são obtidas a partir do centróide $c_{i}$. Esta é a razão pela qual o centróide foi escolhido ao invés de $v_{i}$. Segundo, a Equação (10.3) leva em consideração a função tamanho em $v_{j}$, o que mantém $v_{i}$ perto dos vértices requerendo arestas menores. Terceiro, a estratégia funciona para funções de espaçamento tanto isotrópicas quanto anisotrópicas, desde que estas sejam suaves sobre o domínio. A suavidade das funçôes de espaçamento é fundamental tanto para a convergência do método proposto quanto para a qualidade dos elementos gerados, conforme discutido no capítulo 9.

Quando o vértice $v_{i}$ pertence a uma linha-de-controle, a estratégia de movimentação é a seguinte. Para evitar problemas durante a projeção do vértice sobre $G$ após seu movimento, o vértice é movido sobre a linha-de-controle que pertence. Veja a Figura 10.6. Sejam $v_{j}$ e $v_{k}$ dois vértices adjacentes a $v_{i}$, todos pertencendo à mesma $C_{L_{i}}$. Seja $P_{j k}=\left\|v_{i}-v_{j}\right\|+\left\|v_{i}-v_{k}\right\|$ o perímetro euclidiano de $v_{j}$ a $v_{k}$ medido sobre $C_{L_{i}}$. Seja $v_{w} \in\left\{v_{j}, v_{k}\right\}$ o vértice mais distante de $v_{i}$ segundo a métrica definida em $v_{w}$, isto é, $v_{w}$ tal que $d_{i w}^{w}=\max \left\{d_{i j}^{j}, d_{i k}^{k}\right\}$ (na Figura $10.6, v_{w}=v_{j}$ ). A equação utilizada para calcular a nova posição de $v_{i}$ é dada por

$$
v_{i}^{\prime}=v_{w}+\left(P_{j k} \frac{S\left(v_{w}\right)}{S\left(v_{j}\right)+S\left(v_{k}\right)}\right) \frac{\left(v_{i}-v_{w}\right)}{\left\|v_{i}-v_{w}\right\|}
$$

Se $v_{i}$ for uma ponta-de-controle, então a mesma estratégia de movimentação de vértices em superfície-de-controle (Equação (10.3)) é aplicada.

O operador de movimentação não é executado para todo vértice iterado. De fato, para um vértice $v_{i}$ ser movimentado, ele precisa satisfazer os seguintes critérios:

- $v_{i}$ não pode ser um canto-de-controle, isto é, $v_{i} \notin C_{C}$, e

- $\Theta_{\min }<\bar{\ell}^{i}<2 \Theta_{\max }$.

O primeiro critério assegura que nenhum vértice classificado como canto-de-controle é movimentado. O segundo critério evita que o operador de movimento seja aplicado apenas onde a densidade de vértices é muito baixa (limite inferior) ou muito alta (limite superior). Em 
outras palavras, a movimentação não ocorre em cenários requerendo explicitamente inserção ou remoção de vértices. Isto oferecendo, portanto, maior agilidade ao processo.

Se, por outro lado, os critérios forem satisfeitos, a nova posição é calculada de acordo com as estratégias descritas acima (Equações 10.3 e 10.4). Em seguida, os vértices são projetados em suas respectivas estrutura-de-controle, com exceção dos vértices em pontas-de-controle, que são projetados nas linhas-de-controle adjacentes.

Finalmente, para que a movimentação do vértice seja de fato efetuada a qualidade geométrica deve ser obedecida. Sendo assim, a métrica $Q_{G}$ (Equação (10.1)) é avaliada para todos os triângulos incidentes no vértice movimentado. Se a qualidade for satisfatória, o vértice é movido; caso contrário, a movimentação é descartada.

\subsubsection{Inserção de vértices}

Para inserir um novo vértice $v_{\text {new }}$ em $T$ são necessárias duas informações: (1) a exata localização $p_{\text {new }}$ onde o vértice deve ser inserido e (2) sobre qual elemento $\rho \in T$ (aresta ou célula) o ponto $p_{\text {new }}$ está posicionado. Esta última informação é necessária para se atualizar a conectividade da malha a fim de incluir $v_{\text {new }}$. A ordem com que $p_{\text {new }}$ e $\rho$ são encontrados difere dependendo da estratégia de refinamento empregado.

Em algoritmos para refinamento de triangulações de Delaunay [27, 70, 77], por exemplo, primeiro é feita uma busca por algum triângulo cuja qualidade está abaixo de um dado limiar. Em seguida, $p_{\text {new }}$ é calculado como sendo o circuncentro do triângulo. Finalmente, uma busca para encontrar o elemento $\rho$ é realizada. O circuncentro é uma boa escolha porque, em triangulações de Delaunay, ele contribui positivamente na distribuição dos vértices sobre o domínio. Note que $p_{\text {new }}$ pode cair fora do domínio, o que requer um tratamento especial. Além disso, em malhas superficiais curvas o circuncentro pode facilmente não tangenciar a superfície, o que significa que é necessário projetá-lo.

A outra estratégia consiste em primeiro encontar $\rho$ e então calcular $p_{n e w}$ dentro do próprio $\rho$. O ponto $p_{\text {new }}$ pode ser, por exemplo, o baricentro de $\rho$. Note que, neste caso, a operação de inserção pode ser realizada mais rapidamente que a primeira estratégia porque é necessária apenas uma busca (ao invés de duas) e são descartados a projeção e o tratamento especial para pontos fora do domínio. O problema que surge, entretanto, é a dificuldade de se encontrar o elemento (aresta ou face) apropriado para a inserção de um novo ponto no domínio tal que ofereça uma boa distribuição dos vértices. Em geral, as malhas seguindo essa segunda estratégia tendem a possuir qualidade inferior se comparada com a primeira estratégia.

Neste trabalho, novos vértices são inseridos nos pontos médios de arestas. A inserção se enquadra, portanto, na segunda estratégia descrita acima. Porém, existe uma desvantagem na 
opção adotada. Sabe-se que um novo vértice deve ser posicionado o mais distante possível dos demais vértices presentes na malha para que se obtenha uma melhor distribuição de vértices. A questão é que esta posição dificilmente cai sobre uma aresta. Porém, isto não é um problema no caso do método proposto porque o operador de movimento será executado posteriormente e deslocará o vértice recentemente inserido para uma posição mais apropriada na malha.

Seja $v_{i}$ o vértice sendo processado. As condições locais da malha na vizinhança de $v_{i}$ são analisadas para decidir se uma nova inserção deve ocorrer ou não. Para que a inserção ocorra é necessário que a densidade local de vértices seja considerada baixa. Para isso, seleciona-se $v_{j}$ como sendo o vértice adjacente a $v_{i}$ mais distante, isto é, $v_{j}$ tal que $d_{i j}=\max _{k \in V\left(\widetilde{\varkappa} v_{i}\right)}\left\{d_{i k}\right\}$. Um novo vértice é inserido se o seguinte critério for satisfeito:

$$
\left(\frac{2 \min \left\{S_{i}\left(\overrightarrow{e_{i j}}\right), S_{j}\left(\overrightarrow{e_{i j}}\right)\right\}}{S_{i}\left(\overrightarrow{e_{i j}}\right)+S_{j}\left(e_{i j}\right)}\right) \max \left\{d_{i j}^{i}, d_{i j}^{j}\right\}>\Theta_{\max }
$$

em que $S_{k}\left(\overrightarrow{e_{i j}}\right)$ é o tamanho requerido de aresta em $v_{k}$ na direção definida pela aresta $e_{i j}$ (veja Equação (2.15)). Note que quando a função de espaçamento é constante, tem-se que $S_{i}\left(\overrightarrow{e_{i j}}\right)=S_{j}\left(\overrightarrow{e_{i j}}\right)$ para toda aresta em $T$. Portanto, a Restrição 10.5 pode ser simplificada para

$$
d_{i j}>\Theta_{\max }
$$

A razão para se utilizar a Restrição 10.5 ao invés da Restrição 10.6 é que a última não evita inserções em cenários onde a métrica muda abruptamente entre vértices vizinhos. Este é o caso exemplificado na Figura 10.7. Note que, muito embora a métrica em $v_{j}$ determine que novos pontos não possam ser inseridos, a métrica em $v_{i}$ é pequena o suficiente para que a distância envolvendo as duas métricas, isto é, $d_{i j}$, seja grande. Assim, de acordo com a Restrição 10.6, a inserção deve ocorrer. O que seria uma decisão equivocada. Para exemplificar este fato, suponha que um novo vértice $v_{n e w}$ seja inserido na aresta $e_{i j}$, como ilustrado na Figura 10.7(b). A métrica interpolada em $v_{\text {new }}$ é grande o suficiente para que o operador de deleção (veja Seção 10.3.4) seja executado. O que causaria um ciclo infinito de inserções seguidas de deleções. Observe porém que a Restrição 10.5 impede tal inserção e, consequentemente, o ciclo infinito.

É possível melhorar significantemente a qualidade da malha final se um procedimento complementar for utilizado para auxiliar a decidir se um novo vértice deve ser inserido mesmo quando a Restrição 10.5 falhar. Em situações em que a Restrição 10.5 determina que um novo vértice não deve ser inserido, não se pode concluir necessariamente que a densidade de vértices local é alta o suficiente para rejeitar a inserção. Para ilustrar este fato observe a Figura 10.8. Considere, apenas por questões de simplicidade, que a função de espaçamento é constante e 


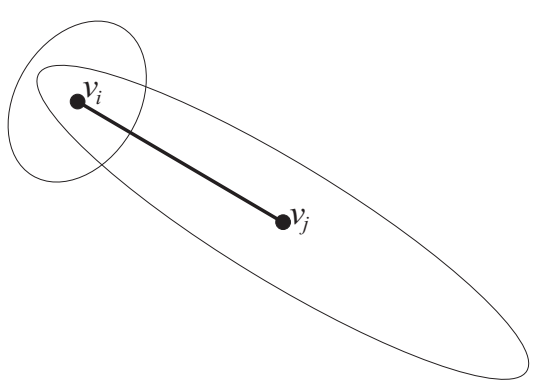

(a)

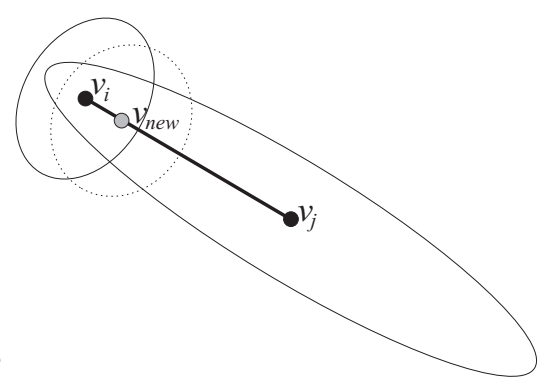

(b)

Figura 10.7: Exemplifição do problema no critério simplificado dado pela Restrição 10.6.

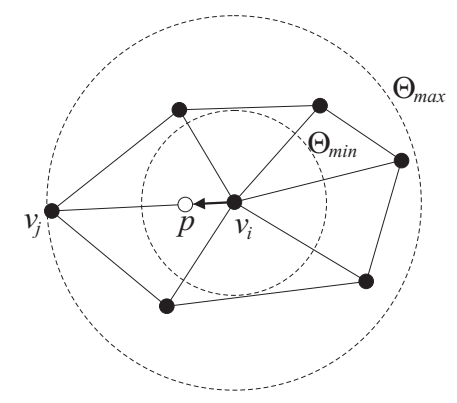

(a)

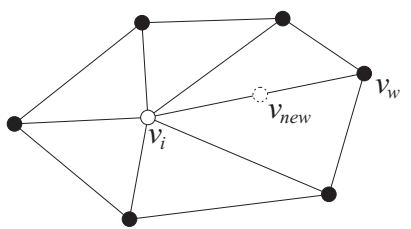

(b)

Figura 10.8: Procedimento complementar para a inserção de vértices.

isotrópica. Na Figura 10.8(a), todas as arestas estão entre $\Theta_{\min }$ e $\Theta_{\max }$, portanto a distribuição de vértices local está adequada. No entanto, a inserção de um novo vértice dentro do hexagono amostraria ainda melhor a região. Como todas as arestas incidentes em $v_{i}$ são menores que $\Theta_{\max }$, a Restrição 10.6 (como também a Restrição 10.5) falha e, consequentemente, a inserção não ocorre. Para contornar essa debilidade, o procedimento complementar de inserção proposto é executado sempre que a Restrição 10.5 falha.

O papel do procedimento complementar de inserção é tão somente realizar uma perturbação na densidade de vértices local. Para isso, o vértice $v_{i}$ é ligeiramente deslocado numa direção apropriada e em seguida a densidade local é verificada novamente. Considere a Figura 10.8. Seja $v_{i}$ o vértice sendo iterado e $v_{j}$ o vértice adjacente de $v_{i}$ tal que $d_{i j}=\max _{v_{k} \in V\left(\varkappa_{v_{i}}\right)}\left(d_{i k}\right)$ $\operatorname{com} d_{i j}>1.2071$. Seja $p$ um ponto sobre a aresta $e_{i j}$ tal que $d_{p j}^{j}=1.0$ (veja Figura 10.8(a)). $\mathrm{O}$ vértice $v_{i}$ é movido para $p$ (e projetado novamente em $G$ ). Em seguida, encontra-se a maior aresta $e_{i w}$ adjacente a $v_{i}$ na nova configuração, ou seja, $v_{w}$ tal que $d_{i w}=\max _{v_{k} \in V\left(\aleph_{v_{i}}\right)}\left(d_{i k}\right)$ (veja Figura 10.8(b)). Se a Restrição 10.5 for obedecida para $e_{i w}$, um novo vértice é inserido; caso contrário, $v_{i}$ é movido de volta à sua posição original.

Note que existe uma restrição para a existência de $v_{j}$ no procedimento acima, isto é, 


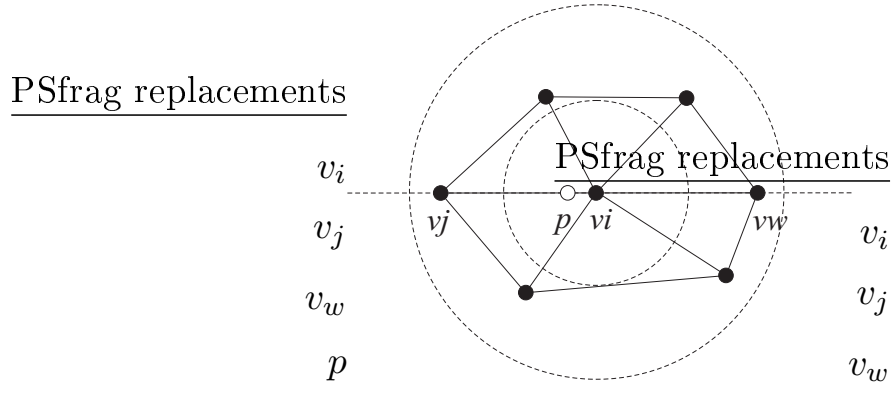

(a)

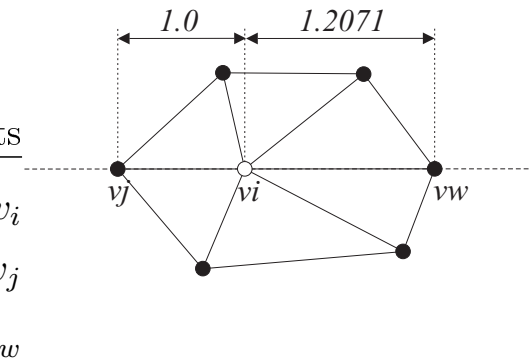

(b)

Figura 10.9: Caso limite para o procedimento complementar para inserção de vértices.

$d_{i j}>1.2071$. Se a aresta $e_{i j}$, que é a maior dentre as adjacentes, for menor que 1.2071, então o deslocamento de $v_{i}$ certamente não ocasionará a inserção de um novo vértice. Para vefiricar este fato, considere a seguinte análise do caso limite. Observe a construção apresentada na Figura 10.9, na qual é considerada uma função de espaçamento constante e isotrópica. A configuração em que o deslocamento de $v_{i}$ sobre $e_{i j}$ mais afeta o comprimento da aresta $e_{i w}$ é quando as duas arestas estão sobre uma mesma reta. Além disso, quanto maior for o comprimento de $e_{i w}$, maior a chance da inserção ocorrer; portanto, suponha $d_{i j}=d_{i w}$ (veja Figura 10.9(a)). Como $p$ dista de 1.0 de $v_{j}$, então o acréscimo em $d_{i w}$ é de $d_{i j}-1.0$. Como a inserção ocorre apenas se a distância de $v_{i}$ a $v_{w}$, após o deslocamento, for maior que $\Theta_{\max }=\sqrt{2}$, é necessário que:

$$
d_{i w}+\left(d_{i j}-1.0\right)>\Theta_{\max }
$$

mas no cenário em discussão $d_{i w}=d_{i j}$, portanto

$$
d_{i w}>\frac{\Theta_{\max }+1}{2}=1.2071
$$

O efeito do procedimento complementar pode ser percebido na Figura 10.10. A Figura 10.10(a) apresenta a malha inicial. A Figura 10.10(b) mostra o resultado após o remalhamento não aplicando o procedimento complementar de inserção. Finalmente, a triangulação da Figura 10.10(c) foi obtida utilizando-se o procedimento complementar.

\subsubsection{Remoção de vértices}

A remoção de vértices é uma operação utilizada para diminuir a densidade local de vértices da malha. Existem duas formas de se implementar a remoção de um dado vértice $v_{i}$ da malha. A primeira opção consiste em remover $v_{i}$ e suas células adjacentes produzindo um buraco, o qual 


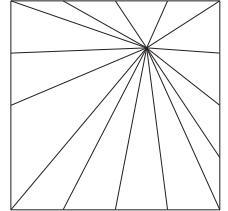

(a)

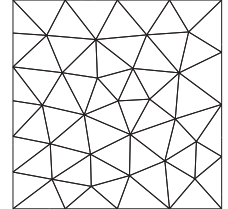

(b)

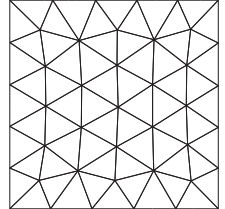

(c)

Figura 10.10: Remalhamento da triangulação original (a) sem utilizar (b) e utilizando (c) o procedimento complementar de inserção.

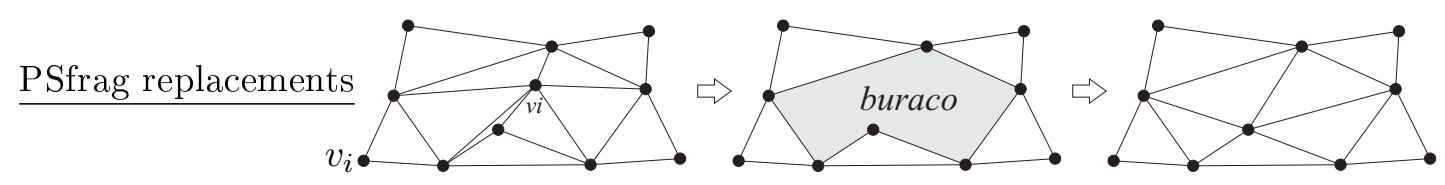

Figura 10.11: Remoção do vértice $v_{i}$ seguida de retriangulação.

é em seguida coberto com novos triângulos. A Figura 10.11 exemplifica este processo em uma malha planar. Em malhas superficiais, o recobrimento do buraco deve ser feito de tal forma que os novos triângulos aproximem a geometria da superfície, o que torna a implementação da operação consideravelmente custosa.

A segunda opção é conhecida como colapsação de aresta. Neste caso, uma aresta $e_{i j}$ incidente em $v_{i}$ é escolhida e então contraída. Tal contração elimina apenas o vértice $v_{i}$ e os triângulos incidentes em $e_{i j}$. O processo de contração está exemplificado na Figura 10.13. A colapsação de arestas oferece algumas vantagens sobre a primeira opção. Ela é mais simples de ser implementada, uma vez que não envolve cálculos geométricos, mas apenas operações topológicas. Note que diferentes escolhas da aresta a ser contraída podem interferir diferentemente na fidelidade geométrica da superfície; assim, é necessário que ela seja escolhida adequadamente. Existem casos, no entanto, em que é impossível realizar a colapsação sem criar elementos inválidos. A Figura 10.12 ilustra um caso em que a eliminação de $v_{i}$ pela contração de qualquer aresta, seja ela qual for, resulta em elementos inválidos. Felizmente, tais casos são raros; além disso, geralmente o mesmo vértice se torna removível no decorrer do método proposto, pois a iteração do método sobre os vértices adjacentes desconfiguram o caso problemático. Neste trabalho, a remoção de vértices é feita via colapsação de arestas.

A remoção de um dado vértice $v_{i}$ só ocorre após uma série de verificações, as quais checam a densidade local de vértices e a fidelidade geométrica da superfície. A maneira com que $v_{i}$ é verificado depende diretamente de qual estrutura-de-controle o vértice pertence.

Suponha que $v_{i}$ seja um canto-de-controle, isto é $v_{i} \in C_{C}$, então, neste caso, $v_{i}$ nunca é removido. 


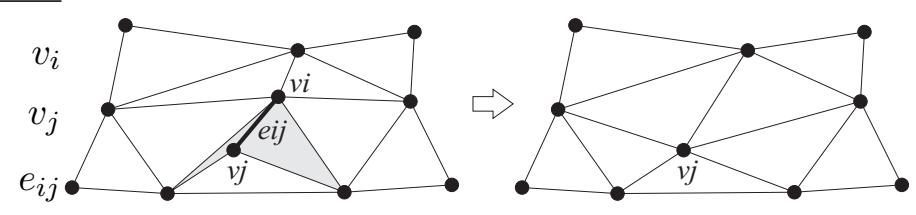

Figura 10.12: Remoção do vértice $v_{i}$ pela colapsação da aresta $e_{i j}$.

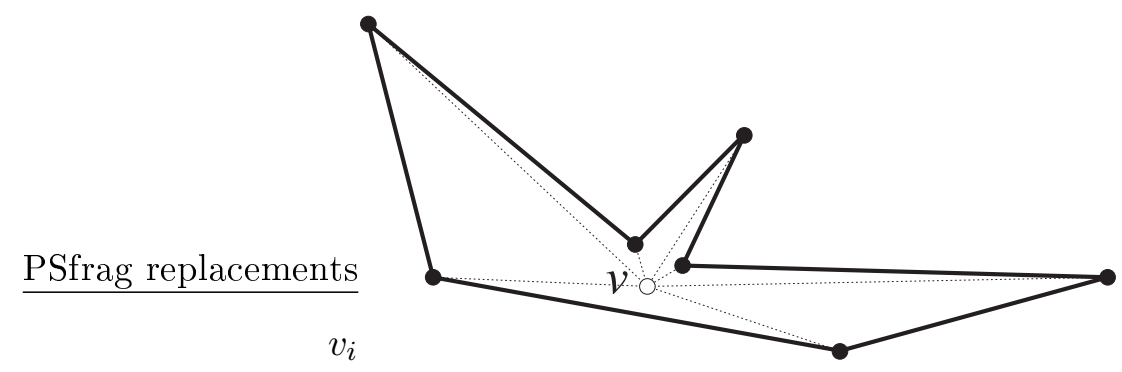

Figura 10.13: Colapsação de qualquer aresta tracejada resulta em elementos inválidos.

Se $v_{i}$ pertencer a alguma linha-de-controle, isto é $v_{i} \in C_{L}$, então é necessário que exista alguma aresta $e_{i j} \in C_{L}$, incidente em $v_{i}$, tal que $d_{i j}^{\text {max }}<\Theta_{\text {min }}$. A Figura 10.14 ilustra um caso onde o vértice $v_{i}$ deve ser removido.

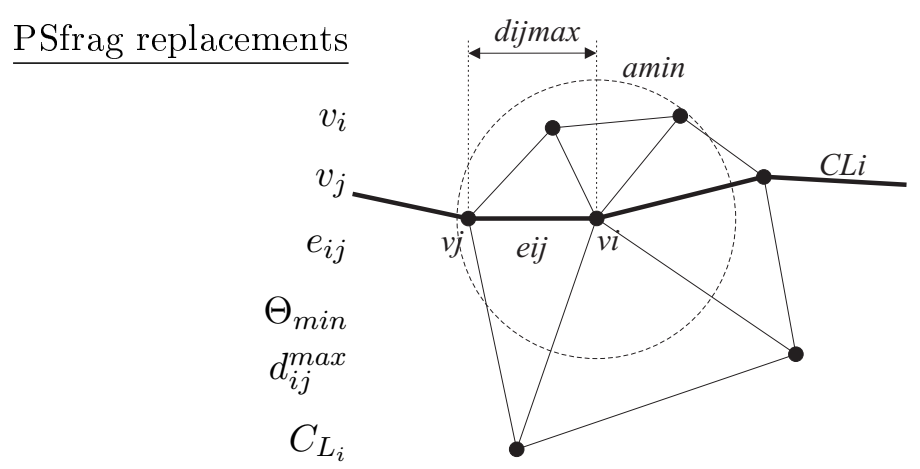

Figura 10.14: Condição para remoção de um vértice em uma linha-de-controle.

Caso $v_{i}$ seja uma ponta-de-controle, isto é $v_{i} \in C_{T}$, então é necessário que exista uma aresta $e_{i j} \in C_{L}$ tal que $v_{i} \notin C_{L}{ }^{1}$ e $d_{i j}^{\max }<\Theta_{\text {min }}$. A Figura 10.14 ilustra um caso onde o vértice $v_{i}$ deve ser removido. No caso, $v_{j}$ é um canto-de-controle.

Se $v_{i}$ pertence a uma superfície-de-controle, então vários testes devem ser realizados. $\mathrm{O}$ primeiro teste faz uma checagem grosseira da densidade local de vértices. Se $\bar{d}_{i}^{\text {max }} \geq 1$ então $v_{i}$ não deve ser removido, sendo que $\bar{d}_{i}^{\text {max }}$ é a média aritmética de $d_{i j}^{\text {max }}, \forall v_{j} \in V\left(\aleph_{v_{i}}\right)$. O papel deste teste inicial é aumentar o desempenho do método proposto, pois ele pode constatar

\footnotetext{
${ }^{1} \mathrm{~A}$ condição $v_{i} \notin C_{L}$ garante que a linha-de-controle possui apenas uma aresta, portanto o outro vértice de $e_{i j}$ deve ser ou ponta-de-controle ou canto-de-controle.
} 


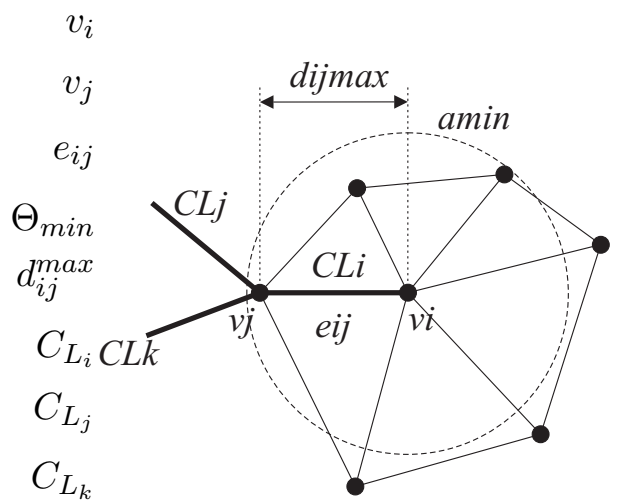

Figura 10.15: Condição para remoção de um vértice em uma ponta-de-controle.

facilmente o caso em que a remoção não deve ocorrer, o que evita a execução de testes mais criteriosos e computacionalmente mais caros. Se, por outro lado, o teste inicial falha, então mais verificações devem ser realizadas. Sejam $v_{j}$ e $v_{k}$ dois vértices adjacentes a $v_{i}$, tais que $e_{i j}$ e $e_{i k}$ sejam as duas arestas mais curtas (medidas pela Equação (2.9)) incidentes em $v_{i}$ e $d_{i j}<d_{i k}$. Para que $v_{i}$ seja removido, pelo menos uma de três condições deve ser satisfeita. A Figura 10.16 apresenta um exemplo em que cada condição é satisfeita individualmente. As ditas condições são apresentadas a seguir:

1. $e_{i j} \in C_{S}, v_{j} \in C_{S}, v_{j} \notin \mathcal{A}$ (ver Seção 10.1) e $d_{i j}^{\text {max }}<\Theta_{\text {min }}$. Veja a Figura 10.16(a). Este teste assegura que a densidade local de vértices dentro de uma superfície-de-controle é alta o suficiente para que o vértice seja removido.

2. $e_{i j} \in C_{S}, v_{j} \notin C_{S}$, e $d_{i j}^{\max }<\mu \Theta_{\min }$, onde $0.2071<\mu \Theta_{\text {min }}<0.5$. Veja a Figura 10.16(b). Este teste é necessário porque o padrão hexagonal ótimo desenhado por seis triângulos incidentes em $v_{i}$ pode não ser possível quando existe uma aresta saindo de $v_{i}$ e chegando em alguma linha-de-controle.

3. $e_{i w} \in C_{S}, v_{w} \notin C_{S}$, e $d_{i w}^{m a x}<\Theta_{\min }$, para $w=j, k$. Este teste assegura que a malha final tenha no máximo uma aresta cujo comprimento esteja entre $\mu \Theta_{\min }$ e $\Theta_{\min }$. Veja a Figura 10.16(c).

Finalmente, se os testes acima indicarem que o vértice deve ser removido, isto é feito colapsando a aresta que menos prejudique a fidelidade da superfície desde que o critério de qualidade $\theta_{Q_{G}}$ discutido na seção 10.2 seja satisfeito.

Se a remoção for de fato realizada, o seguinte processamento é efetuado em seguida para todos os vértices $v_{j}$ que eram adjacentes a $v_{i}$ antes da remoção. O operador de flipping seguido pelo operador de movimento para todos os vértices $v_{j}$. Além disso, o rótulo de todos 

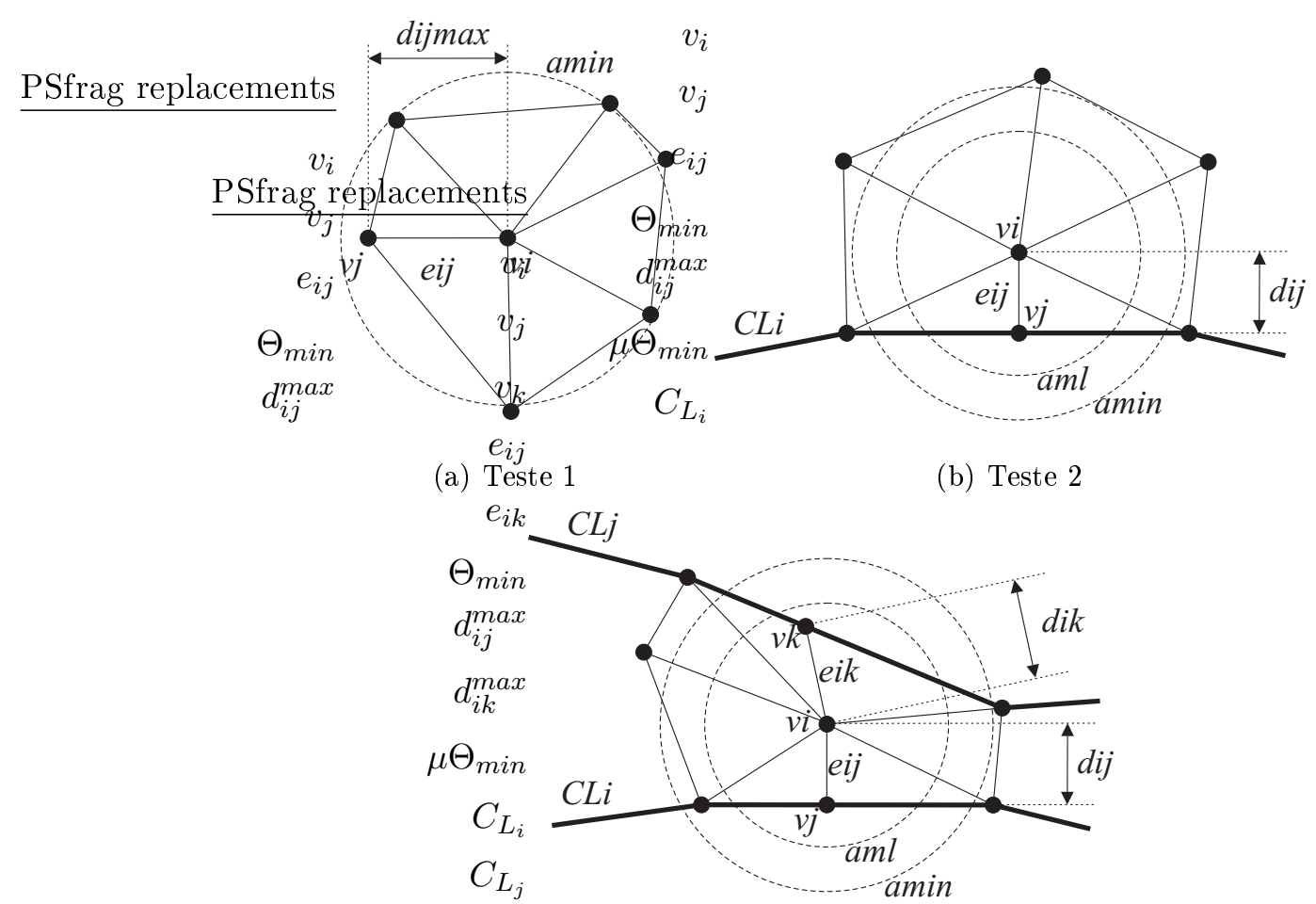

(c) Teste 3

Figura 10.16: Remoção de vértices em superfícies-de-controle.

os vértices $v_{j}$ passa para adomecido. Observe que este gerenciamento dos rótulos evita que vértices adjacentes sejam removidos durante a mesma iteração-malha.

\subsection{A parada do algoritmo}

Como comentado na Seção 10.1, o ANTS termina o remalhamento quando os conjuntos $\mathcal{A}$ e $\mathcal{D}$ estiverem simultaneamente vazios. Este é o tipo ideal de parada do algoritmo pois significa que não são necessárias quaisquer outras modificações na malha. Na prática, no entanto, existem cenários onde os conjuntos $\mathcal{A}$ e $\mathcal{D}$ não ficam vazios e o método entraria em um laço infinito de processamento. O principal fator que contribue para a não parada do algoritmo é uma função de espaçamento mal condicionada. O mal condicionamento acontece em dois aspectos:

1. a função não define tensores alinhados às principais curvaturas do modelo e

2. a função não é suave o suficiente para permitir que uma aresta da triangulação satisfaça simultameamente as métricas definidas nos seus vértices.

O primeiro item não é um problema fácil de ser resolvido, pois requer análise de curvatura da malha de entrada. A questão é que se esta malha não for uma amostragem adequada do 
modelo que ela aproxima, as curvaturas não podem ser estimadas corretamente. Uma maneira simples de amenizar este problema é ajustar adequadamente os parâmetros para detectar as estruturas-de-controle tal que estas se ajustem às quinas do modelo.

O segundo item, todavia, pode ser facilmente resolvido aplicando-se algum dos procedimentos de suavização da função de espaçamento descritos na Seção 9.2.1.

Muito embora essas soluções contribuam para a parada ideal do método, elas dependem do usuário; é desejável, entretanto, que o ANTS páre independentemente dos parâmetros definidos pelo usuário. Foi observado que após um certo número de iterações-malha o ANTS atinge um estado no qual o remalhamento não efetua alterações significantes para o melhoramento global da qualidade da malha, mesmo em casos onde um possível laço infinito tenha sido estabelecido. Sendo assim, o ANTS poderia ser parado forçosamente em qualquer momento depois que este estado de pequenas mudanças tenha sido atingido. A questão que surge é como determinar esse estado atingido, ou seja, como encontrar o número de iterações-malha mínimo, $N_{p i}$, que leve a tal estado. A seguir é apresentada a estratégia empregada para estimar $N_{p i}$.

A estimativa de $N_{p i}$ é realizada verificando-se o número de vértices em $T$ após cada iteraçãomalha. Sejam $N V_{\min }$ e $N V_{\max }$ respectivamente o menor e o maior número de vértices de $T$ atingidos durante o processo de remalhamento. Os valores $N V_{\min }$ e $N V_{\max }$ são iniciados com o número de vértices de $T_{i n}$. Após cada iteração-malha, os valores são atualizados de acordo com o número de vértices de $T$. A idéia é parar o remalhamento quando $N V_{\min }$ e $N V_{\max }$ parmenecerem estáveis durante 10 iteraçôes-malha consecutivas. Em outras palavras, sempre que $N V_{\min }$ ou $N V_{\max }$ for atualizado, o método tem 10 iteraçôes-malha para mudar algum dos dois valores, caso contrário o método é terminado. 


\section{Capítulo 11}

\section{Resultados do remalhamento}

O método proposto ANTS foi submetido a vários casos de teste, em diferentes situações, a fim de certificar sua aplicabilidade.

Para viabilizar a análise dos resultados, são apresentadas tabelas com informações relativas a cada exemplo. As informações estão agrupadas em:

1. Parâmetros ANTS. Destacam os valores utilizados para configurar o ANTS; $\Phi$ e $\Psi$ são para a detecção das estruturas-de-controle, conforme descrito na Seção 8; $S_{\text {min }}$, $S_{\max }$ e $n_{e}$ são para a construção da função de espaçamento; a suavização da função de espaçamento pode ser feita pelo método de Li (ver Seção 9.2.1) sob o parâmetro $\gamma_{L_{0}}$, ou pelo método HCorrection, sob o parâmetro $H V_{\text {lim }}$; o número de iterações de suavização $\left(N_{\text {suav }}\right)$ utilizado também é apresentado.

2. Malha de entrada. Apresenta valores relacionados à malha superficial de entrada. Além de informar o número de vértices $\left(N_{V e r t}\right)$ e de células $\left(N_{\text {tria }}\right)$, também são apresentados valores sobre as estruturas-de-controle, ou seja, número de cantos-de-controle $\left(N_{C_{C}}\right)$, linhas-de-controle $\left(N_{C_{L}}\right)$, pontas-de-controle $\left(N_{C_{T}}\right)$ e superfícies-de-controle $\left(N_{C_{S}}\right)$. Para os parâmetros não listados aqui foram utilizados os valores padrão fornecidos durante a descrição do método.

3. Malha resultante. Idem ao item anterior, porém refere-se à malha produzida pelo remalhamento.

4. Processamento. Fornece informações sobre o processo de remalhamento. São informados o número de iterações-malha $\left(N_{i t e r}\right)$ realizadas, e também quantas inserções $\left(N_{\text {ins }}\right)$, remoções $\left(N_{\text {rem }}\right)$ e movimento $\left(N_{\text {mov }}\right)$ de vértices ocorreram durante o processo. Além disso, também são mostradas informações sobre os tempos de processamento (em segundos) que foram necessários para carregar a malha na memória $\left(t_{\text {leitura }}\right)$, para identificar 
as estruturas-de-controle $\left(t_{C}\right)$, para criar a função de espaçamento anisotrópica $\left(t_{H}\right)$ e para efetuar o remalhamento em si $\left(t_{\text {remesh }}\right)$.

Para todos os exemplos são apresentadas figuras ilustrando as condições das malhas. A função de espaçamento utilizada em cada exemplo também é apresentada. Porém, para evitar confusão visual, são visualizados elipsóides apenas em alguns pontos aleatoriamente escolhidos sobre o domínio.

A qualidade da malha é computada em três conjuntos de elementos: $\Lambda_{T}, \Lambda_{C_{L}}$ e $\Lambda_{C_{S}}$. O conjunto $\Lambda_{T}$ contém todos os triângulos da malha final $T_{\text {out }}$. O conjunto $\Lambda_{C_{L}}$ contém todos os triângulos com algum vértice $v \in C_{L} \cup C_{C} \cup C_{T}$; em outras palavras, triângulos que tocam alguma linha-de-controle. $\mathrm{O}$ conjunto $\Lambda_{C_{S}}$ contém todos os triângulos de $T_{\text {out }}$ com os três vértices pertencendo a alguma superficie-de-controle, ou seja, $\Lambda_{C_{S}} \cup \Lambda_{C_{L}}=\Lambda_{T}$ e $\Lambda_{C_{S}} \cap \Lambda_{C_{L}}=\emptyset$. Essa divisão dos elementos foi feita para ajudar na análise dos resultados, pois é esperado que os elementos de pior qualidade estejam ligados às linhas-de-controle devido ao critério de remalhamento mais relaxado.

A qualidade dos triângulos nesses três conjuntos é aferida em termos do menor ângulo $\left(\alpha_{\min }\right)$ e maior ângulo $\left(\alpha_{\max }\right)$, sendo que estes são medidos de acordo com a anisotrópica interpolada em seus respectivos centróides. Esses valores de ângulos são utilizados para calcular $\bar{\alpha}_{\min }$ e $\bar{\alpha}_{\max }$ que são médias aritméticas dos valores de $\alpha_{\min }$ e $\alpha_{\max }$ considerando todos os elementos do conjunto. Além disso também são apresentados dois valores significando porcentagens de elementos com determinada propriedade, são eles: $\left(30^{\circ}<\alpha_{\min }\right)$ para elementos com menor ângulo maior que $30^{\circ}$; e $\left(\alpha_{\max }<100^{\circ}\right)$ para elementos com maior ângulo menor que $100^{\circ}$.

Além das medidas baseadas em ângulos, também são apresentados histogramas dos comprimentos normalizados das arestas das malhas. As arestas são medidas de acordo com a Equação (2.7). Este gráfico ajuda a verificar se as distâncias entre os vértices estão obedecendo a função de espaçamento.

\subsection{Exemplo 1: Ossos do pé}

O modelo para os ossos do pé tratado neste exemplo (veja Figura 11.1) é composto por 26 componentes conexas separadas, uma para cada osso. Existe sobreposição entre alguns ossos. Note que trata-se de um modelo simplificado, pois possui muitas quinas e poucos triângulos. Esta simplificação impede que as curvaturas possam ser bem aproximadas, o que, conseqüentemente, dificulta a definição de uma função de espaçamento anisotrópica adequada seguindo o procedimento proposto na Seção 9.1. Portanto, este é o caso em que uma malha 
Tabela 11.1: Informações sobre o remalhamento isotrópico uniforme dos ossos do pé.

\begin{tabular}{|l|l|l|l|l|l|l|l|}
\hline \multicolumn{2}{|c|}{ Parâmetros ANTS } & \multicolumn{2}{|l|}{ Malha de entrada } & \multicolumn{2}{|l|}{ Malha resultante } & \multicolumn{2}{|l|}{ Processamento } \\
\hline$\Phi$ & $140^{\circ}$ & $N_{\text {Vert }}$ & 2154 & $N_{\text {Vert }}$ & 22330 & $N_{\text {iter }}$ & 10 \\
$\Psi$ & $90^{\circ}$ & $N_{\text {tria }}$ & 4204 & $N_{\text {tria }}$ & 44556 & $N_{\text {ins }}$ & 23317 \\
$S_{\min }$ & - & $N_{C_{C}}$ & 438 & $N_{C_{C}}$ & 438 & $N_{\text {rem }}$ & 3141 \\
$S_{\max }$ & - & $N_{C_{L}}$ & 1383 & $N_{C_{L}}$ & 4177 & $N_{\text {mov }}$ & 95370 \\
$n_{e}$ & - & $N_{C_{T}}$ & 313 & $N_{C_{T}}$ & 309 & $t_{\text {leitura }}$ & $0.047 \mathrm{~s}$ \\
$\gamma_{L_{0}}$ & - & $N_{C_{S}}$ & 217 & $N_{C_{S}}$ & 217 & $t_{C}$ & $0.047 \mathrm{~s}$ \\
$N_{\text {suav }}$ & - & & & & & $t_{H}$ & - \\
& & & & & & $t_{H_{\text {suav }}}$ & - \\
& & & & & & $t_{\text {remesh }}$ & $16.203 \mathrm{~s}$ \\
\hline \hline
\end{tabular}

Tabela 11.2: Medições de ângulos da malha isotrópica uniforme para os ossos do pé.

\begin{tabular}{cccccc}
\hline & $\bar{\alpha}_{\min }$ & $\bar{\alpha}_{\max }$ & $\left(30^{\circ}<\alpha_{\min }\right)$ & $\left(\alpha_{\max }<100^{\circ}\right)$ & \# triângulos \\
\hline$\Lambda_{T}$ & $50.38^{\circ}$ & $71.11^{\circ}$ & $99.4479 \%$ & $99.2595 \%$ & 44556 \\
$\Lambda_{C_{L}}$ & $51.85^{\circ}$ & $69.30^{\circ}$ & $99.9757 \%$ & $99.9618 \%$ & 28812 \\
$\Lambda_{C_{S}}$ & $47.70^{\circ}$ & $74.42^{\circ}$ & $98.4820 \%$ & $97.9738 \%$ & 15744 \\
\hline \hline
\end{tabular}

isotrópica uniforme é uma boa opção. Foi realizado tal remalhamento objetivando arestas com comprimentos iguais a 0.007 da maior dimensão do bounding box do modelo. As imagens à direita da Figura 11.1 apresentam a malha isotrópica uniforme gerada a partir do modelo original. Os dados referentes ao remalhamento estão apresentados nas Tabelas 11.1 e 11.2 e na Figura 11.2.

Se o modelo de entrada não fosse uma simplificação grosseira para os ossos do pé, os ossos teriam formatos mais tubulares e as curvaturas poderiam ser aproximadas com precisão suficiente para se contruir uma função de espaçamento anisotrópica. Com o intuito de tornar o modelo mais suave, a malha isotrópica gerada anteriormente (veja a Figura 11.1) teve sua forma geométrica suavizada pelo procedimento de Taubin [95]. O resultado da suavização pode ser visto nas imagens à esquerda da Figura 11.3. A função de espaçamento anisotrópica (veja Figura 11.3) foi então definida sobre a malha suavizada. Os dados referentes a esse remalhamento podem ser vistos nas Tabelas 11.3 e 11.4 e na Figura 11.4. 

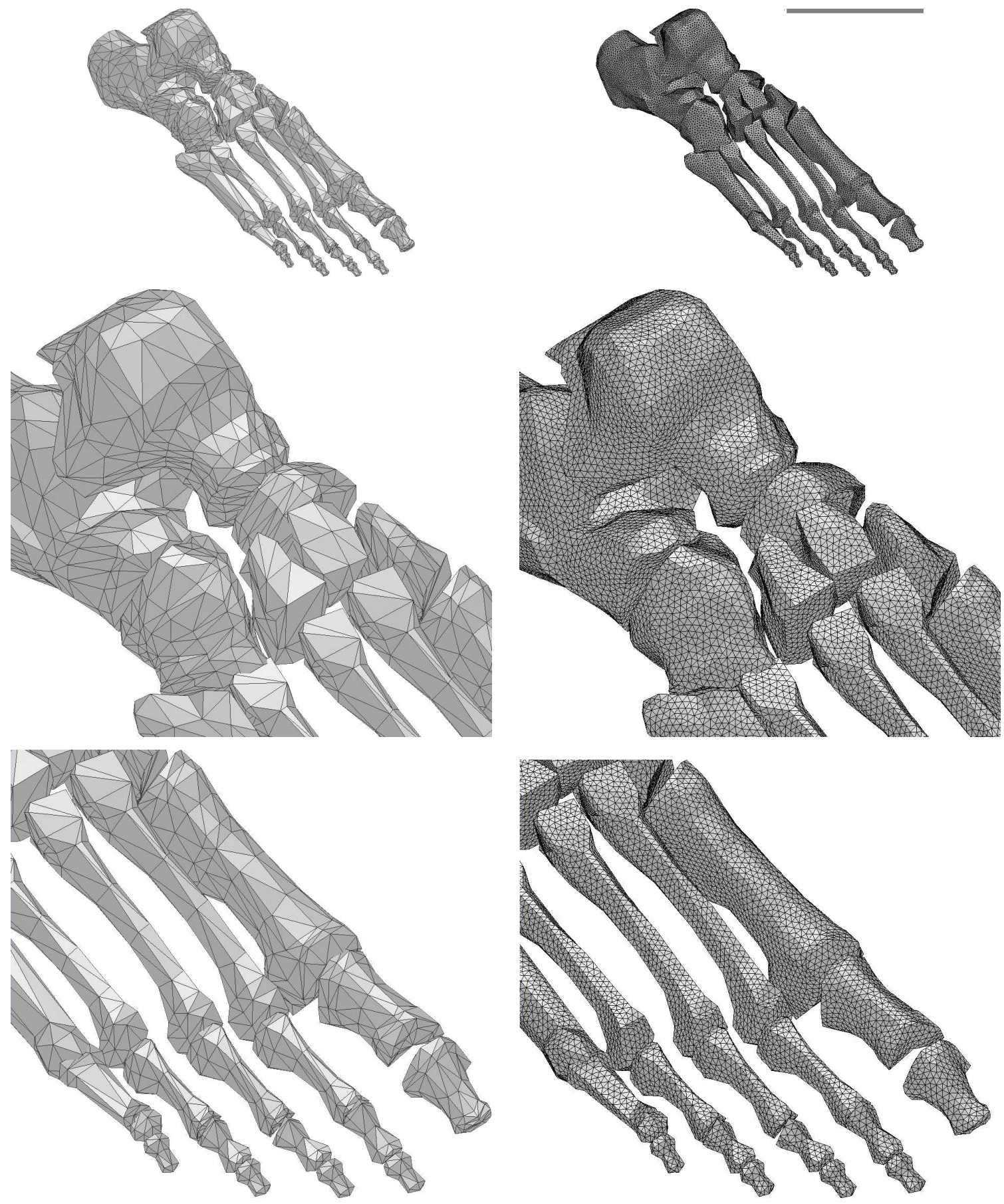

Figura 11.1: Malha original (à esquerda) e remalhamento isotrópico uniforme (à direita) dos ossos do pé. 


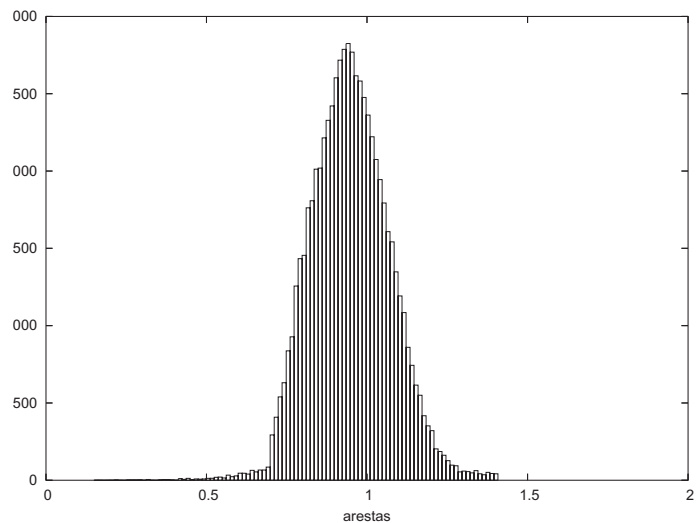

Figura 11.2: Histograma dos comprimentos de arestas da malha isotrópica uniforme dos ossos do pé.

Tabela 11.3: Informações sobre o remalhamento anisotrópico dos ossos do pé.

\begin{tabular}{|l|l|l|l|l|l|l|l|}
\hline \multicolumn{2}{|c|}{ Parâmetros ANTS } & \multicolumn{2}{|l|}{ Malha de entrada } & \multicolumn{2}{|l|}{ Malha resultante } & \multicolumn{2}{l|}{ Processamento } \\
\hline$\Phi$ & $140^{\circ}$ & $N_{\text {Vert }}$ & 22330 & $N_{\text {Vert }}$ & 23665 & $N_{\text {iter }}$ & 12 \\
$\Psi$ & $90^{\circ}$ & $N_{\text {tria }}$ & 44556 & $N_{\text {tria }}$ & 47226 & $N_{\text {ins }}$ & 16725 \\
$S_{\min }$ & 0.003 & $N_{C_{C}}$ & 27 & $N_{C_{C}}$ & 27 & $N_{\text {rem }}$ & 15390 \\
$S_{\text {max }}$ & 0.5 & $N_{C_{L}}$ & 853 & $N_{C_{L}}$ & 787 & $N_{\text {mov }}$ & 307647 \\
$n_{e}$ & 36 & $N_{C_{T}}$ & 618 & $N_{C_{T}}$ & 564 & $t_{\text {leitura }}$ & $0.563 \mathrm{~s}$ \\
$\gamma_{L_{0}}$ & 1.3 & $N_{C_{S}}$ & 28 & $N_{C_{S}}$ & 28 & $t_{C}$ & $0.484 \mathrm{~s}$ \\
$N_{\text {suav }}$ & 15 & & & & & $t_{H}$ & $2.297 \mathrm{~s}$ \\
& & & & & & $t_{H_{\text {suav }}}$ & $13.938 \mathrm{~s}$ \\
& & & & & & $t_{\text {remesh }}$ & 50.781 \\
\hline \hline
\end{tabular}

Tabela 11.4: Medições de ângulos da malha anisotrópica para os ossos do pé.

\begin{tabular}{cccccc}
\hline & $\bar{\alpha}_{\min }$ & $\bar{\alpha}_{\max }$ & $\left(30^{\circ}<\alpha_{\min }\right)$ & $\left(\alpha_{\max }<100^{\circ}\right)$ & \# triângulos \\
\hline$\Lambda_{T}$ & $50.12^{\circ}$ & $71.25^{\circ}$ & $99.7480 \%$ & $99.5299 \%$ & 47226 \\
$\Lambda_{C_{L}}$ & $50.61^{\circ}$ & $70.71^{\circ}$ & $99.8768 \%$ & $99.6921 \%$ & 42220 \\
$\Lambda_{C_{S}}$ & $45.96^{\circ}$ & $75.87^{\circ}$ & $98.6616 \%$ & $98.1622 \%$ & 5006 \\
\hline \hline
\end{tabular}



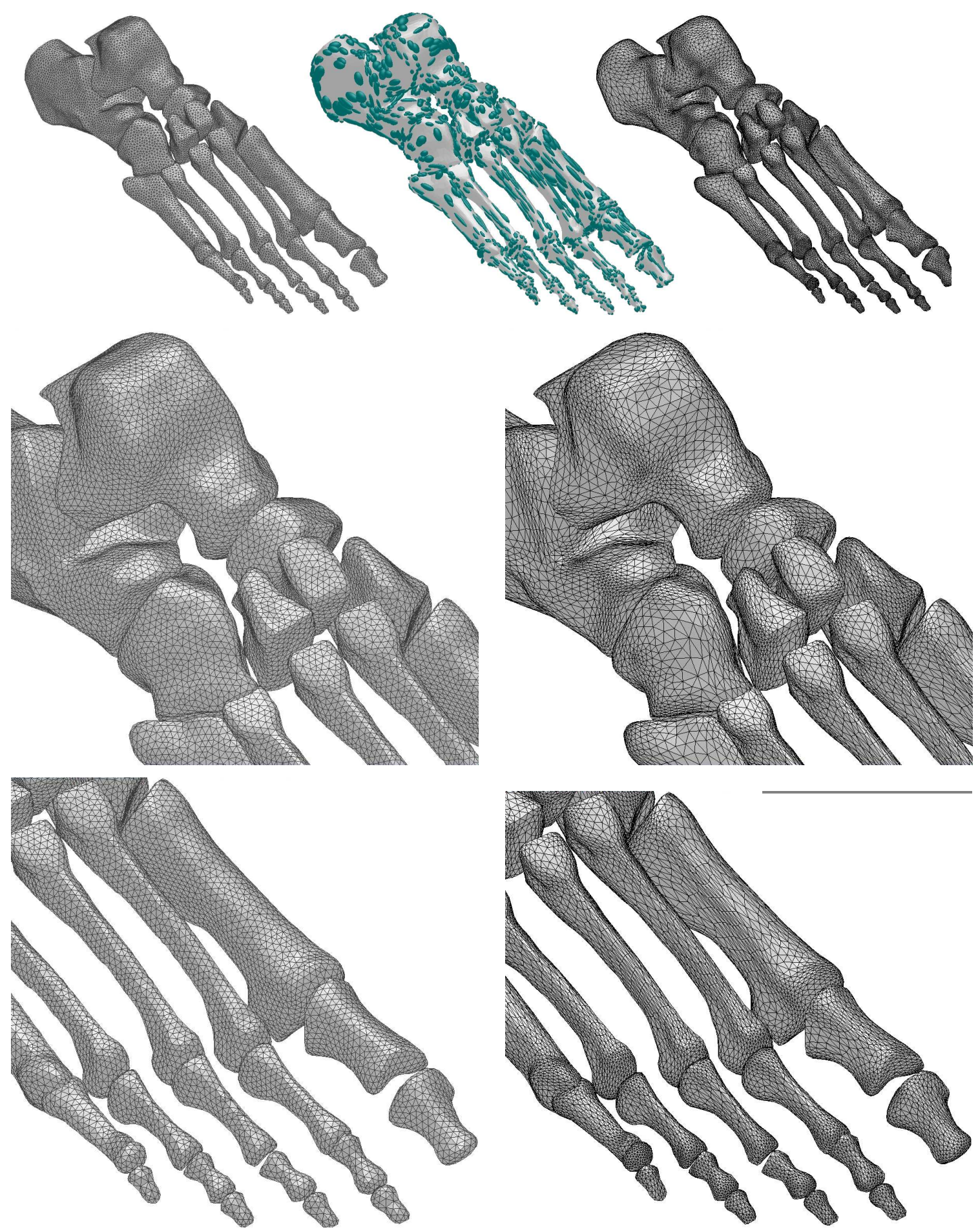

Figura 11.3: Ossos do pé após a suavização da forma (à esquerda) e após o remalhamento anisotrópico (à direita). 


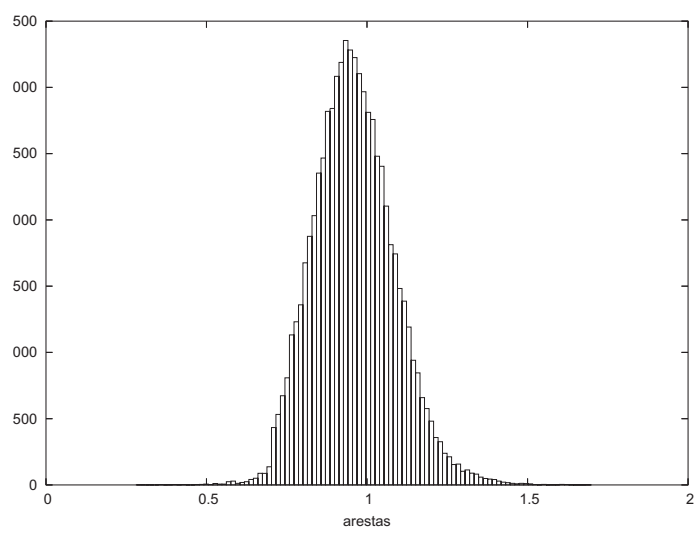

Figura 11.4: Histograma dos comprimentos de arestas da malha anisotrópica dos ossos do pé.

Tabela 11.5: Medições de ângulos para o exemplo dos vasos sangüíneos.

\begin{tabular}{cccccc}
\hline & $\bar{\alpha}_{\min }$ & $\bar{\alpha}_{\max }$ & $\left(30^{\circ}<\alpha_{\min }\right)$ & $\left(\alpha_{\max }<100^{\circ}\right)$ & \# triângulos \\
\hline$\Lambda_{T}$ & $51.27^{\circ}$ & $70.02^{\circ}$ & $99.8283 \%$ & $99.7441 \%$ & 119944 \\
$\Lambda_{C_{L}}$ & $51.29^{\circ}$ & $69.10^{\circ}$ & $99.8568 \%$ & $99.7647 \%$ & 119390 \\
$\Lambda_{C_{S}}$ & $45.77^{\circ}$ & $76.16^{\circ}$ & $93.6594 \%$ & $95.2897 \%$ & 554 \\
\hline \hline
\end{tabular}

\subsection{Exemplo 2: Vasos sanguíneos}

Neste exemplo é remalhada uma superfície representando vasos cerebrais com aneurisma. A malha inicial foi gerada a partir de imagens médicas pelo método proposto por Cebral e Löhner [22], autores estes que gentilmente forneceram a malha para este exemplo. O modelo pode ser visto na Figura 11.5 em duas perspectivas. Como se trata de uma superfície suave, poucas linhas-de-controle são detectadas, o que, por conseguinte, contribui para a qualidade da malha final. Apesar dos vasos serem tubulares, não convém definir uma função de espaçamento com anisotropia acentuada para este modelo. A anisotropia acentuada seria inadequada porque ela degradaria a qualidade da malha final uma vez que os tubos são curvos e ondulados. Sendo assim, o modelo original foi submetido ao remalhamento com anisotropia e o resultado pode ser visto na Figura 11.5. A Figura 11.6 mostra detalhes da malhas original (coluna da esquerda) e da malha anisotrópica gerada (coluna da direita). Informações referentes ao remalhamento podem ser vistas na tabela 11.6 e dados sobre a qualidade da malha gerada podem ser verificados na tabela 11.5 e na Figura 11.7. 

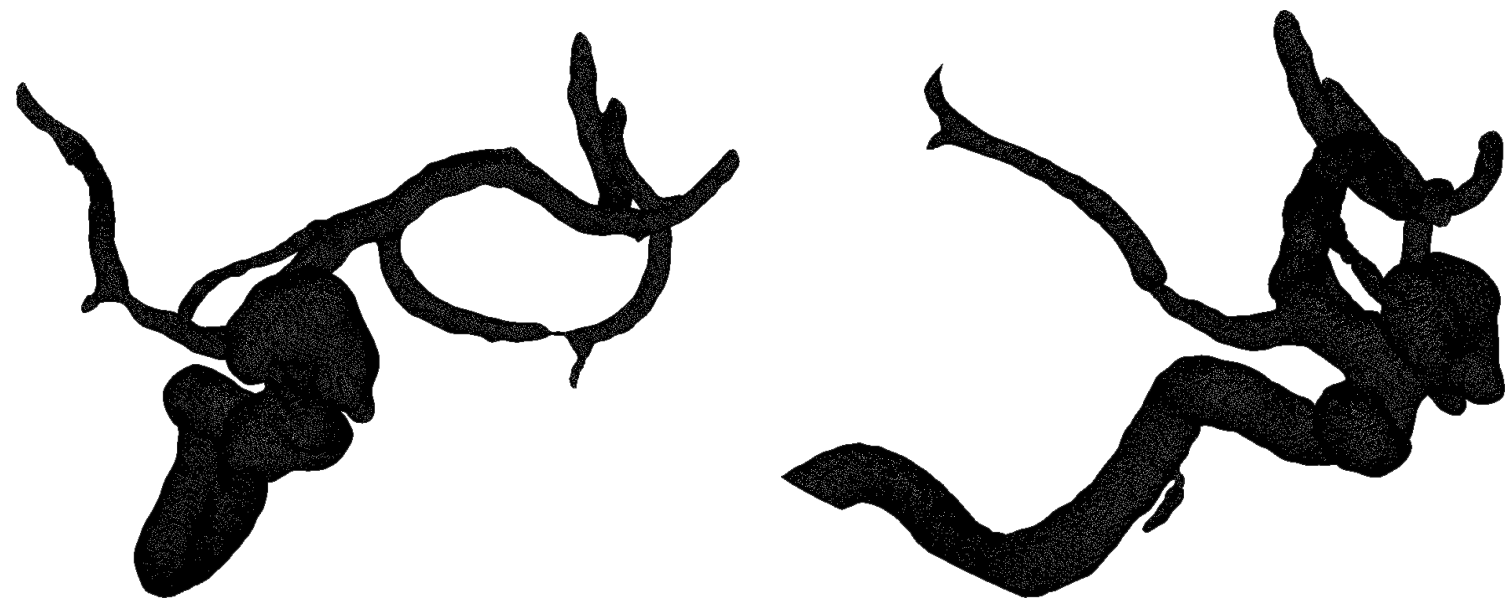

Malha original.
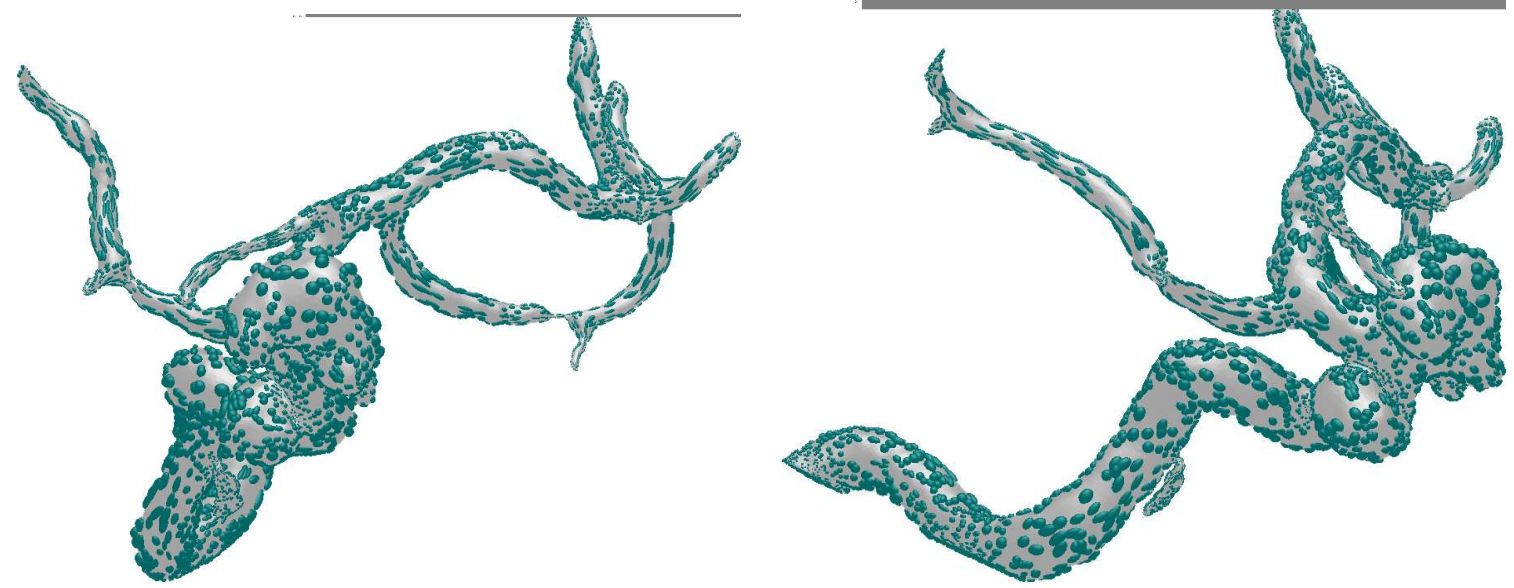

Amostragem da função de espaçamento anisotrópica.
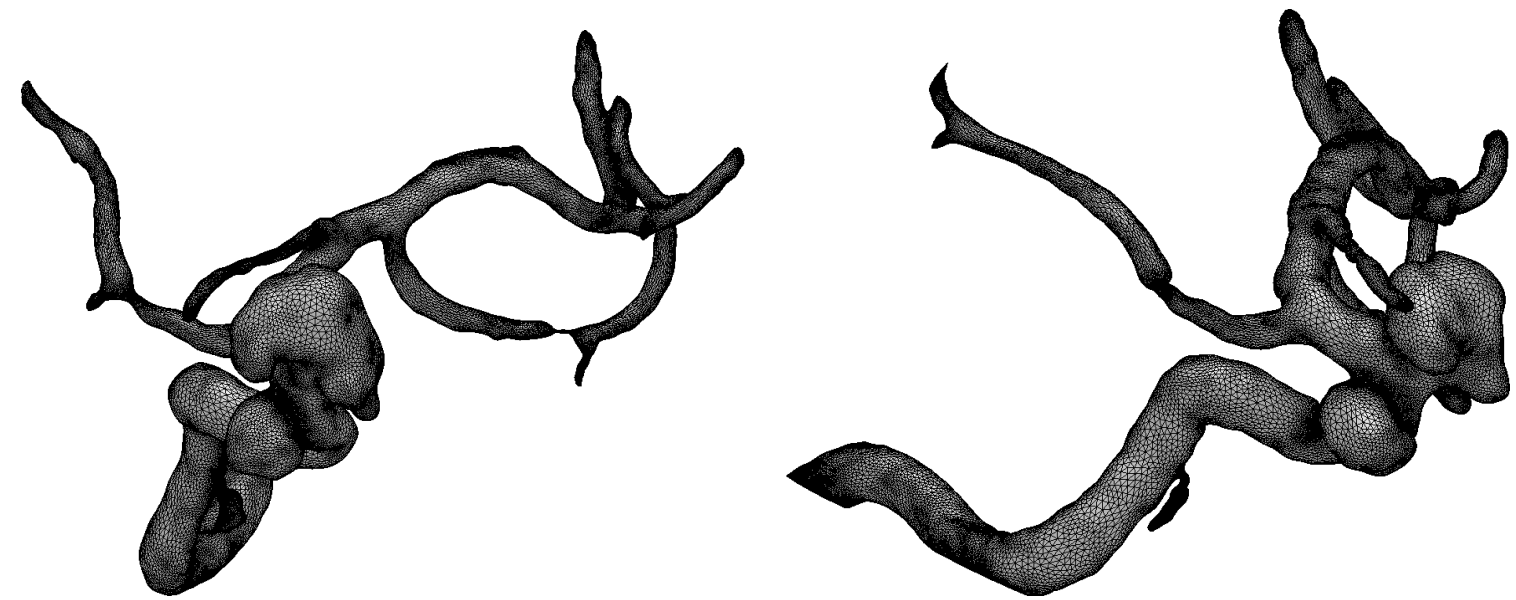

Malha final anisotrópica.

Figura 11.5: Remalhamento anisotrópico dos vasos sangüíneos. 

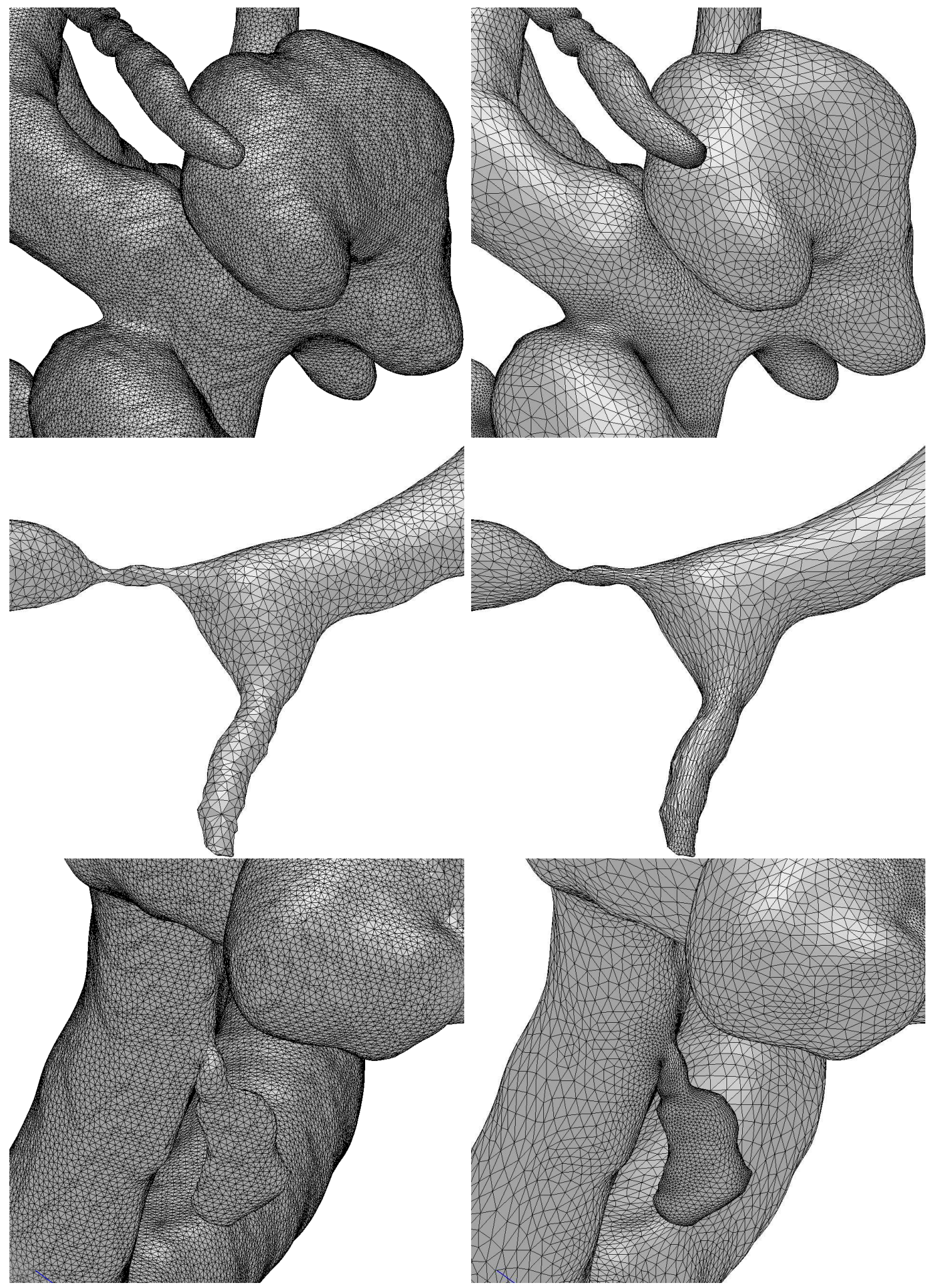

Figura 11.6: Detalhes das malhas dos vasos sangüíneos. 


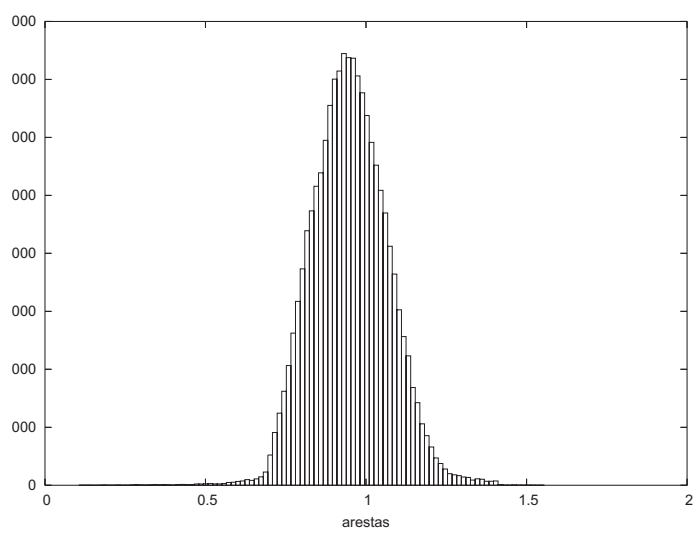

Figura 11.7: Histograma dos comprimentos de arestas da malha anisotrópica dos vasos sangüíneos.

Tabela 11.6: Informações sobre o remalhamento dos vasos sangüíneos.

\begin{tabular}{|c|c|c|c|c|c|c|c|}
\hline \multicolumn{2}{|c|}{ Parâmetros ANTS } & \multicolumn{2}{|c|}{ Malha de entrada } & \multicolumn{2}{|c|}{ Malha resultante } & \multicolumn{2}{|c|}{ Processamento } \\
\hline$\Phi$ & $100^{\circ}$ & $N_{\text {Vert }}$ & 133581 & $N_{\text {Vert }}$ & 59981 & $N_{\text {iter }}$ & 24 \\
\hline$\Psi$ & $140^{\circ}$ & $N_{t r i a}$ & 267172 & $N_{t r i a}$ & 119972 & $N_{\text {ins }}$ & 26279 \\
\hline$S_{\text {min }}$ & 0.001 & $N_{C_{C}}$ & 15 & $N_{C_{C}}$ & 15 & $N_{r e m}$ & 99879 \\
\hline$S_{\max }$ & 0.02 & $N_{C_{L}}$ & 73 & $N_{C_{L}}$ & 89 & $N_{m o v}$ & 854096 \\
\hline$n_{e}$ & 30 & $N_{C_{T}}$ & 56 & $N_{C_{T}}$ & 56 & $t_{\text {leitura }}$ & $3.937 \mathrm{~s}$ \\
\hline$H V_{l i m}$ & 1.25 & $N_{C_{S}}$ & 4 & $N_{C_{S}}$ & 4 & $t_{C}$ & $4.485 \mathrm{~s}$ \\
\hline$N_{\text {suav }}$ & 20 & & & & & $t_{H}$ & $22.531 \mathrm{~s}$ \\
\hline & & & & & & $t_{H_{\text {suav }}}$ & $67.672 \mathrm{~s}$ \\
\hline & & & & & & $t_{\text {remesh }}$ & $183.172 \mathrm{~s}$ \\
\hline
\end{tabular}




\subsection{Exemplo 3: Melhoramento de malhas geradas a partir de imagens}

Nesta subseção é mostrado como o ANTS foi utilizado para gerar malhas isotrópicas e anisotrópicas de alta qualidade sobre modelos gerados pelo método proposto por Alex Cuadros [30], o qual gera malhas superficiais e volumétricas a partir de imagens tridimensionais.

A malha apresentada à esquerda da Figura 11.8 mostra a malha superficial do crânio de um macaco. Tal malha foi gerada por Alex a partir de imagens produzidas por ressonância magnética. Embora a malha aproxime muito bem a forma contida nas imagens 3D com um número reduzido de elementos, ela não é uma malha com forma geométrica suave. Além disso, as malhas geradas não são orientadas (muitas vezes não orientáveis) e apresentam singularidades de vértices e arestas. Para que a malha produzida pudesse ser submetida ao ANTS, foi necessário primeiro alterá-la em uma etapa de pré-processamento.

Primeiro, foram removidas todas as singularidades presentes na malha por meio de duplicação de vértices. Em seguida foi executado um procedimento para orientar os elementos consistentemente. Descobriu-se então que a maioria dos modelos gerados são não orientáveis. Para tornar a orientação possível, foram removidos alguns triângulos da malha superficial sem singularidades. Porém, a remoção dos triângulos introduziu algumas singularidades de vértices que também tiveram que ser tratadas. Tanto a remoção de singularidades quanto a orientação da malha foram necessárias devido a restrições impostas pela estrutura de dados sobre a qual o ANTS foi implementado.

A próxima etapa teve por objetivo suavizar a forma geométrica da malha. O método para suavização de formas utilizado foi o proposto por Taubin [95, 94]. O método de Taubin foi escolhido por sua simplicidade, mas outros métodos mais robustos, como o proposto por Sousa et al. [88], também poderiam ser utilizados. Para que bons resultados sejam atingidos é recomendado que a malha a ser suavizada possua uma distribuição de vértices adequada. Por isso, várias medidas foram tomadas para preparar a malha para o processo de suavização. Primeiro foi aplicado o operador laplaciano apenas nos vértices que foram detectados como singulares na etapa anterior. Isso foi necessário porque as singularidades geralmente ocorrem estagnando a espessura de uma parede (espessura entre a face interior e exterior do crânio, por exemplo) e a suavização desses pontos contribui para a recuperação da espessura original da parede. Em seguida, foi efetuado o remalhamento isotrópico para tornar os comprimentos das arestas da malha mais uniformizados. No caso, a função de espaçamento do ANTS foi definida para requerer arestas medindo o comprimento médio de todas as arestas da malha original. Foram necessárias apenas 5 iterações-malha para efetuar esse remalhamento. A suavização da 

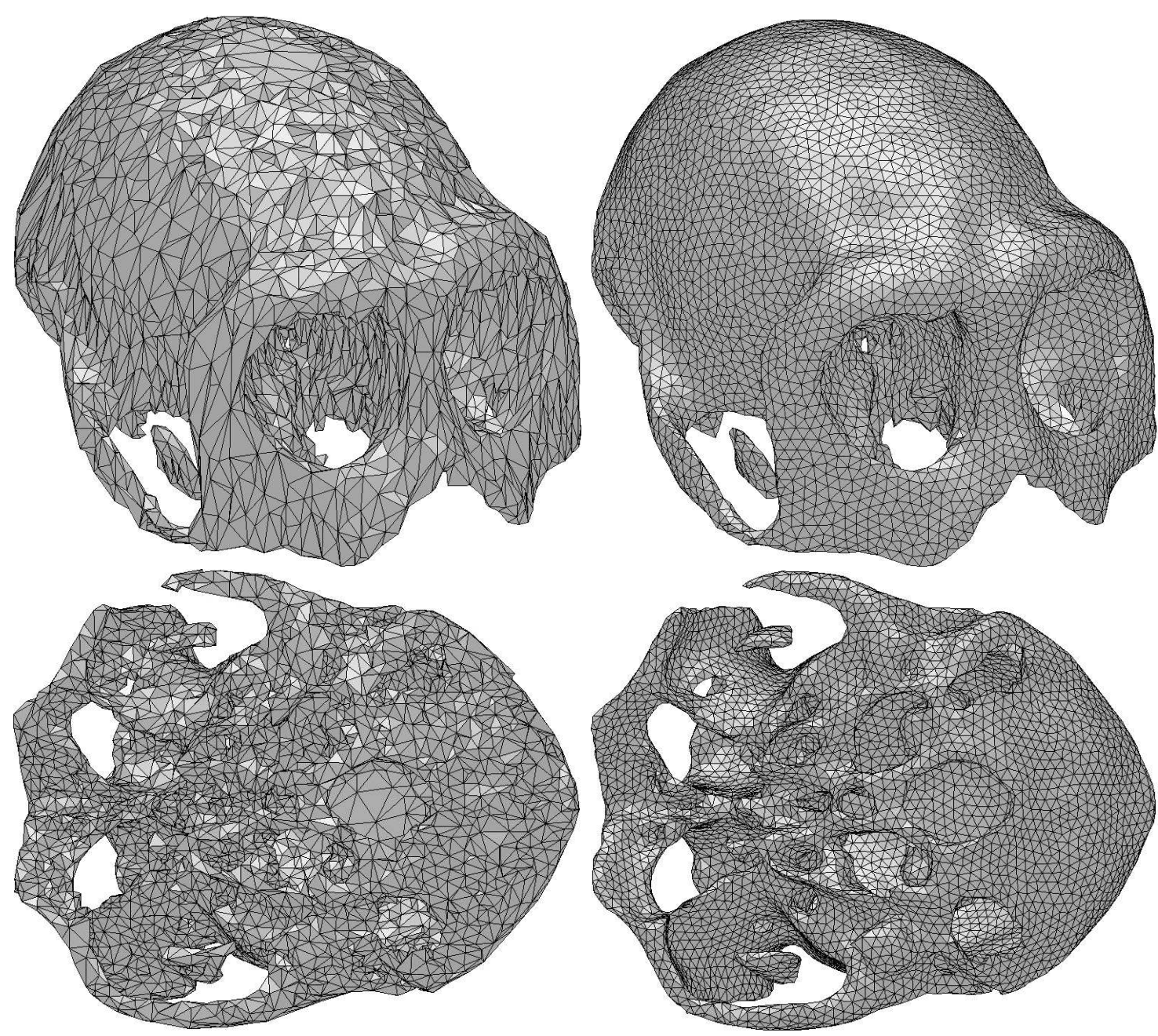

Figura 11.8: Crânio original (à esquerda) e após tratamento de suavização de forma e remalhamento isotrópico uniforme (à direita).

forma foi então realizada e o remalhamento refeito. A Figura 11.8 apresenta a malha original (à esquerda) e a malha resultante desse tratamento (à direita). As características da malha produzida podem ser vistas na Figura 11.9 e na tabela 11.7 e os dados sobre o remalhamento na tabela 11.8 .

A partir da malha suave apresentada na coluna à direita da Figura 11.8 o ANTS foi executado normalmente, ou seja, uma função de espaçamento anisotrópica foi definida (à esquerda na Figura 11.10) e o remalhamento foi efetuado. A malha final está apresentada à direita na Figura 11.10. Informações sobre o remalhamento e sobre a qualidade da malha produzida podem ser vistos nas Tabelas 11.10 e 11.9 e na Figura 11.11.

Também foi gerada uma malha isotrópica a partir da malha suave (coluna à direita da Figura 11.8). A malha produzida está apresentada na Figura 11.12. Informações sobre o 


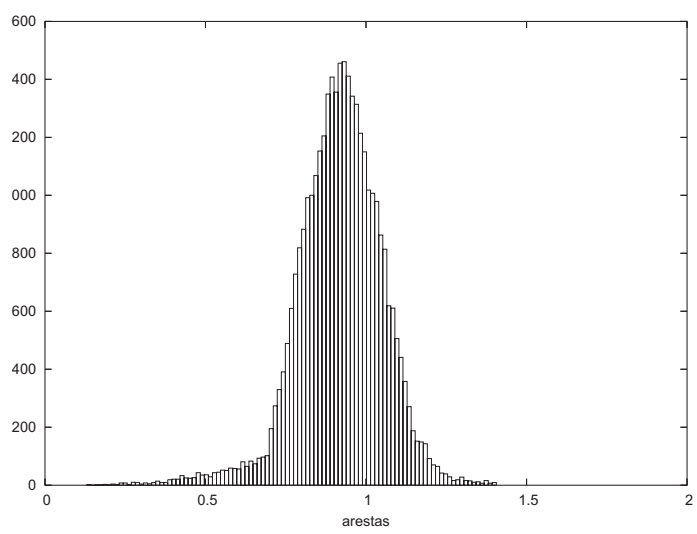

Figura 11.9: Histograma dos comprimentos de arestas da malha isotrópica uniforme do crânio.

Tabela 11.7: Medições de ângulos da malha isotrópica uniforme do crânio.

\begin{tabular}{cccccc}
\hline & $\bar{\alpha}_{\min }$ & $\bar{\alpha}_{\max }$ & $\left(30^{\circ}<\alpha_{\min }\right)$ & $\left(\alpha_{\max }<100^{\circ}\right)$ & \# triângulos \\
\hline$\Lambda_{T}$ & $49.96^{\circ}$ & $71.50^{\circ}$ & $97.8108 \%$ & $98.4363 \%$ & 22383 \\
$\Lambda_{C_{L}}$ & $52.02^{\circ}$ & $69.13^{\circ}$ & $99.9747 \%$ & $100.000 \%$ & 15804 \\
$\Lambda_{C_{S}}$ & $45.03^{\circ}$ & $77.21^{\circ}$ & $92.6128 \%$ & $94.6800 \%$ & 6579 \\
\hline \hline
\end{tabular}

Tabela 11.8: Informações sobre o remalhamento isotrópica uniforme do crânio.

\begin{tabular}{|c|c|c|c|c|c|c|c|}
\hline \multicolumn{2}{|c|}{ Parâmetros ANTS } & \multicolumn{2}{|c|}{ Malha de entrada } & \multicolumn{2}{|c|}{ Malha resultante } & \multicolumn{2}{|c|}{ Processamento } \\
\hline$\Phi$ & $140^{\circ}$ & $N_{\text {Vert }}$ & 12275 & $N_{\text {Vert }}$ & 11144 & $N_{\text {iter }}$ & 5 \\
\hline$\Psi$ & $160^{\circ}$ & $N_{\text {tria }}$ & 24643 & $N_{t r i a}$ & 22383 & $N_{\text {ins }}$ & 280 \\
\hline$S_{\text {min }}$ & - & $N_{C_{C}}$ & 1082 & $N_{C_{C}}$ & 1082 & $N_{\text {rem }}$ & 1411 \\
\hline$S_{\max }$ & - & $N_{C_{L}}$ & 2084 & $N_{C_{L}}$ & 1922 & $N_{\text {mov }}$ & 26909 \\
\hline$n_{e}$ & - & $N_{C_{T}}$ & 782 & $N_{C_{T}}$ & 672 & $t_{\text {leitura }}$ & $0.328 \mathrm{~s}$ \\
\hline$\gamma_{L_{0}}$ & - & $N_{C_{S}}$ & 120 & $N_{C_{S}}$ & 120 & $t_{C}$ & $0.281 \mathrm{~s}$ \\
\hline$N_{\text {suav }}$ & - & & & & & & - \\
\hline & & & & & & $t_{H_{\text {suav }}}$ & - \\
\hline & & & & & & $t_{\text {remesh }}$ & $4.422 \mathrm{~s}$ \\
\hline
\end{tabular}



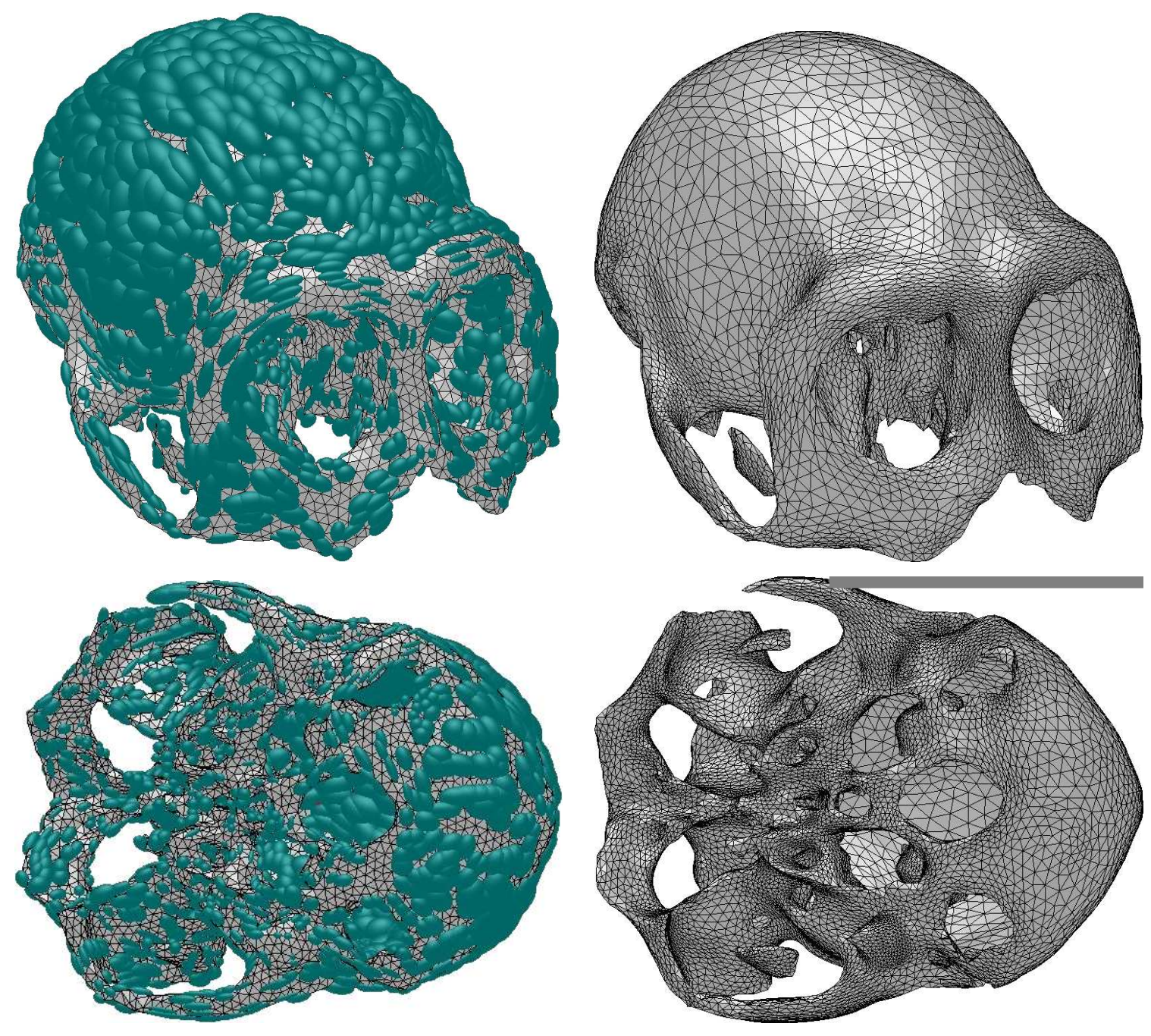

Figura 11.10: Remalhamento anisotrópico do crânio suavizado.

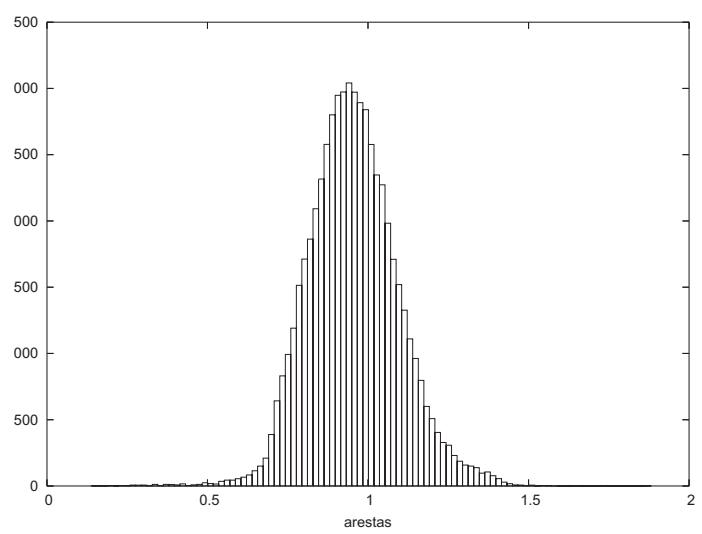

Figura 11.11: Histograma dos comprimentos de arestas da malha anisotrópica do crânio. 
Tabela 11.9: Medições de ângulos na malha anisotrópica do crânio.

\begin{tabular}{cccccc}
\hline & $\bar{\alpha}_{\min }$ & $\bar{\alpha}_{\max }$ & $\left(30^{\circ}<\alpha_{\min }\right)$ & $\left(\alpha_{\max }<100^{\circ}\right)$ & \# triângulos \\
\hline$\Lambda_{T}$ & $49.10^{\circ}$ & $72.54^{\circ}$ & $99.0101 \%$ & $98.7054 \%$ & 38389 \\
$\Lambda_{C_{L}}$ & $50.63^{\circ}$ & $70.70^{\circ}$ & $99.9227 \%$ & $99.7351 \%$ & 27175 \\
$\Lambda_{C_{S}}$ & $45.38^{\circ}$ & $77.01^{\circ}$ & $96.7986 \%$ & $96.2101 \%$ & 11214 \\
\hline \hline
\end{tabular}

Tabela 11.10: Informações sobre o remalhamento anisotrópico do crânio.

\begin{tabular}{|c|c|c|c|c|c|c|c|}
\hline \multicolumn{2}{|c|}{ Parâmetros ANTS } & \multicolumn{2}{|c|}{ Malha de entrada } & \multicolumn{2}{|c|}{ Malha resultante } & \multicolumn{2}{|c|}{ Processamento } \\
\hline$\Phi$ & $140^{\circ}$ & $N_{\text {Vert }}$ & 11144 & $N_{\text {Vert }}$ & 19152 & $N_{\text {iter }}$ & 7 \\
\hline$\Psi$ & $160^{\circ}$ & $N_{\text {tria }}$ & 22383 & $N_{\text {tria }}$ & 38389 & $N_{\text {ins }}$ & 14106 \\
\hline$S_{\text {min }}$ & 0.006 & $N_{C_{C}}$ & 1219 & $N_{C_{C}}$ & 1219 & $N_{r e m}$ & 6098 \\
\hline$S_{\max }$ & 0.5 & $N_{C_{L}}$ & 2192 & $N_{C_{L}}$ & 3048 & $N_{\text {mov }}$ & 121865 \\
\hline$n_{e}$ & 45 & $N_{C_{T}}$ & 575 & $N_{C_{T}}$ & 562 & $t_{\text {leitura }}$ & $0.281 \mathrm{~s}$ \\
\hline$\gamma_{L_{0}}$ & 1.20 & $N_{C_{S}}$ & 189 & $N_{C_{S}}$ & 189 & $t_{C}$ & $0.265 \mathrm{~s}$ \\
\hline$N_{\text {suav }}$ & 15 & & & & & & $1.015 \mathrm{~s}$ \\
\hline & & & & & & $t_{H_{\text {suav }}}$ & $7.125 \mathrm{~s}$ \\
\hline & & & & & & $t_{\text {remesh }}$ & $22.813 \mathrm{~s}$ \\
\hline
\end{tabular}



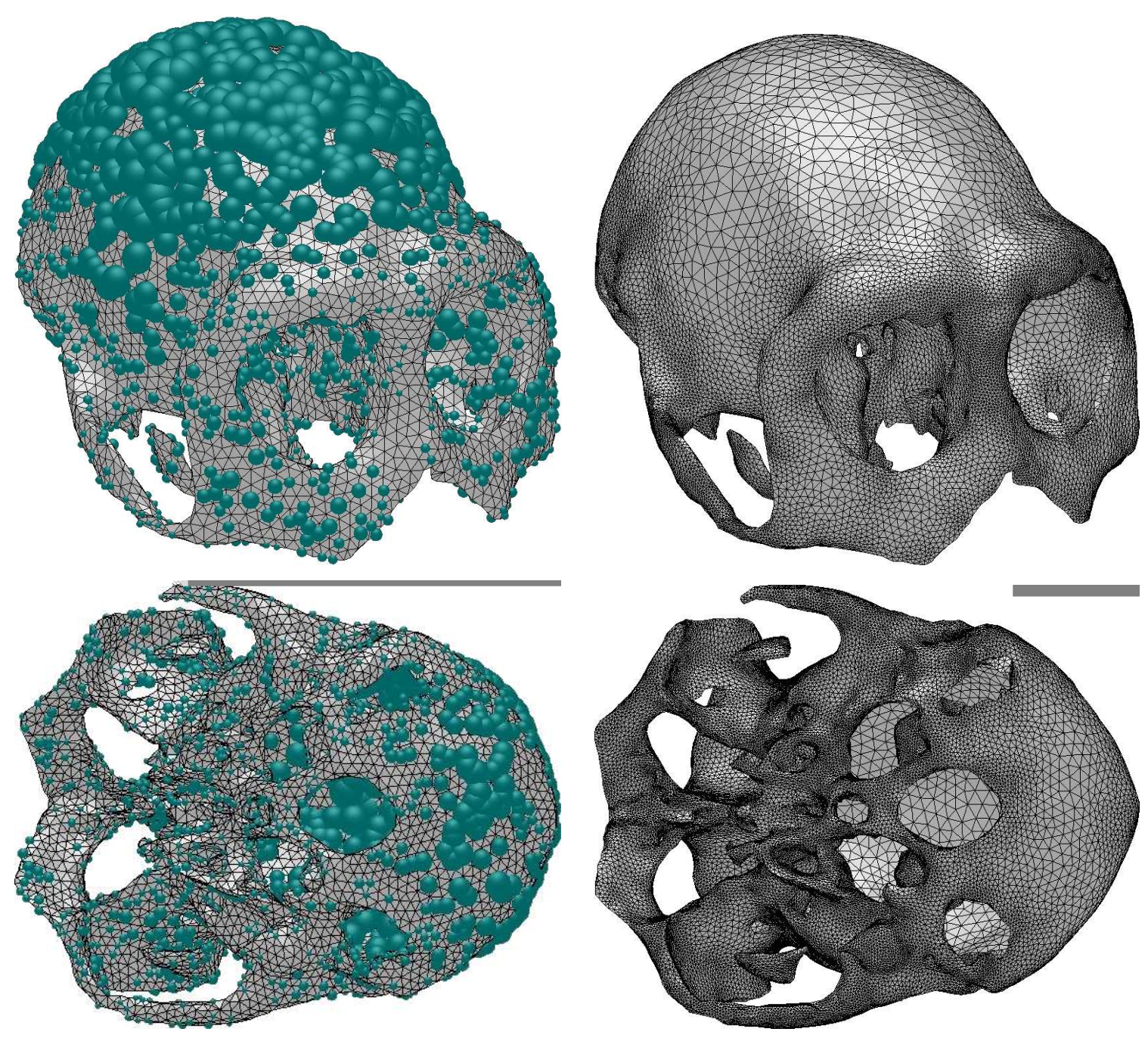

Figura 11.12: Remalhamento isotrópico do crânio suavizado.

remalhamento e sobre a qualidade da malha produzida podem ser vistos nas Tabelas $11.12 \mathrm{e}$ 11.11 e na Figura 11.13.

\subsection{Outros exemplos}

As Figuras11.14, 11.15 e 11.16 apresentam outras exemplos nos quais o ANTS foi aplicado. 


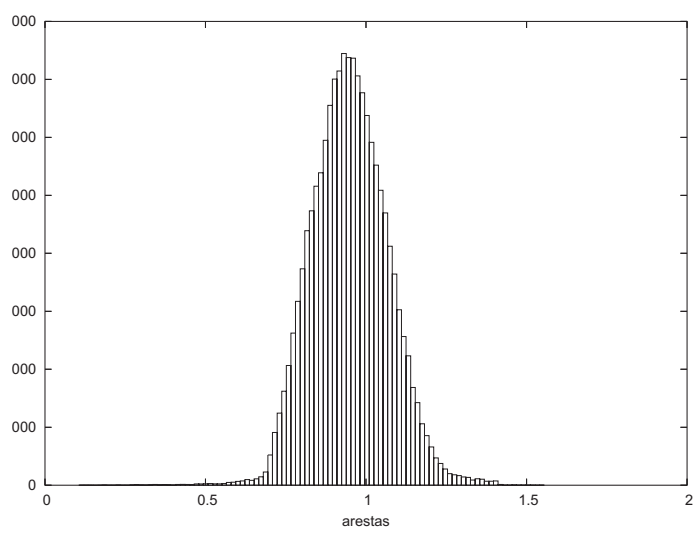

Figura 11.13: Histograma dos comprimentos de arestas da malha isotrópica do crânio.

Tabela 11.11: Medições de ângulos da malha isotrópica do crânio.

\begin{tabular}{cccccc}
\hline & $\bar{\alpha}_{\min }$ & $\bar{\alpha}_{\max }$ & $\left(30^{\circ}<\alpha_{\min }\right)$ & $\left(\alpha_{\max }<100^{\circ}\right)$ & \# triângulos \\
\hline$\Lambda_{T}$ & $50.68^{\circ}$ & $70.74^{\circ}$ & $99.5115 \%$ & $99.4548 \%$ & 100509 \\
$\Lambda_{C_{L}}$ & $51.64^{\circ}$ & $69.61^{\circ}$ & $99.9834 \%$ & $99.9591 \%$ & 78219 \\
$\Lambda_{C_{S}}$ & $47.30^{\circ}$ & $74.69^{\circ}$ & $97.8555 \%$ & $97.6851 \%$ & 22290 \\
\hline \hline
\end{tabular}

Tabela 11.12: Informações sobre o remalhamento isotrópico do crânio.

\begin{tabular}{|l|l|l|l|l|l|l|l|}
\hline \multicolumn{2}{|c|}{ Parâmetros ANTS } & \multicolumn{2}{|c|}{ Malha de entrada } & \multicolumn{2}{|c|}{ Malha resultante } & \multicolumn{2}{|l|}{ Processamento } \\
\hline$\Phi$ & $140^{\circ}$ & $N_{\text {Vert }}$ & 10870 & $N_{\text {Vert }}$ & 50232 & $N_{\text {iter }}$ & 7 \\
$\Psi$ & $160^{\circ}$ & $N_{\text {tria }}$ & 21832 & $N_{\text {tria }}$ & 100509 & $N_{\text {ins }}$ & 47165 \\
$S_{\min }$ & 0.006 & $N_{C_{C}}$ & 1352 & $N_{C_{C}}$ & 1352 & $N_{\text {rem }}$ & 7803 \\
$S_{\max }$ & 0.5 & $N_{C_{L}}$ & 2443 & $N_{C_{L}}$ & 5811 & $N_{\text {mov }}$ & 251845 \\
$n_{e}$ & 45 & $N_{C_{T}}$ & 674 & $N_{C_{T}}$ & 672 & $t_{\text {leitura }}$ & $0.282 \mathrm{~s}$ \\
$\gamma_{L_{0}}$ & 1.20 & $N_{C_{S}}$ & 228 & $N_{C_{S}}$ & 228 & $t_{C}$ & $0.265 \mathrm{~s}$ \\
$N_{\text {suav }}$ & 15 & & & & & $t_{H}$ & $0.938 \mathrm{~s}$ \\
& & & & & & $t_{H_{\text {suav }}}$ & $1.36 \mathrm{~s}$ \\
& & & & & & & \\
remesh & $49.391 \mathrm{~s}$ \\
\hline \hline
\end{tabular}




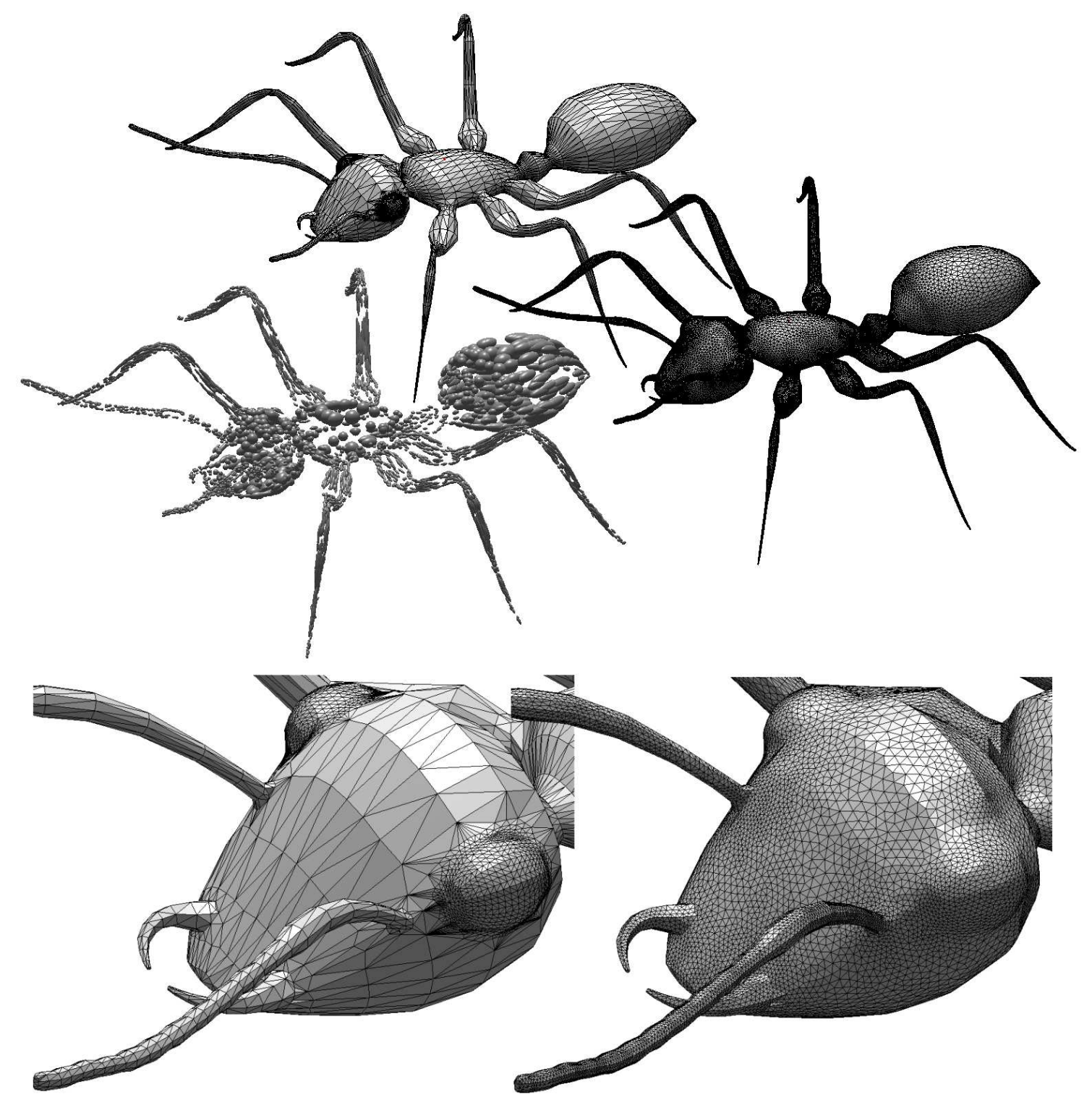

Figura 11.14: Remalhamento de uma formiga. 


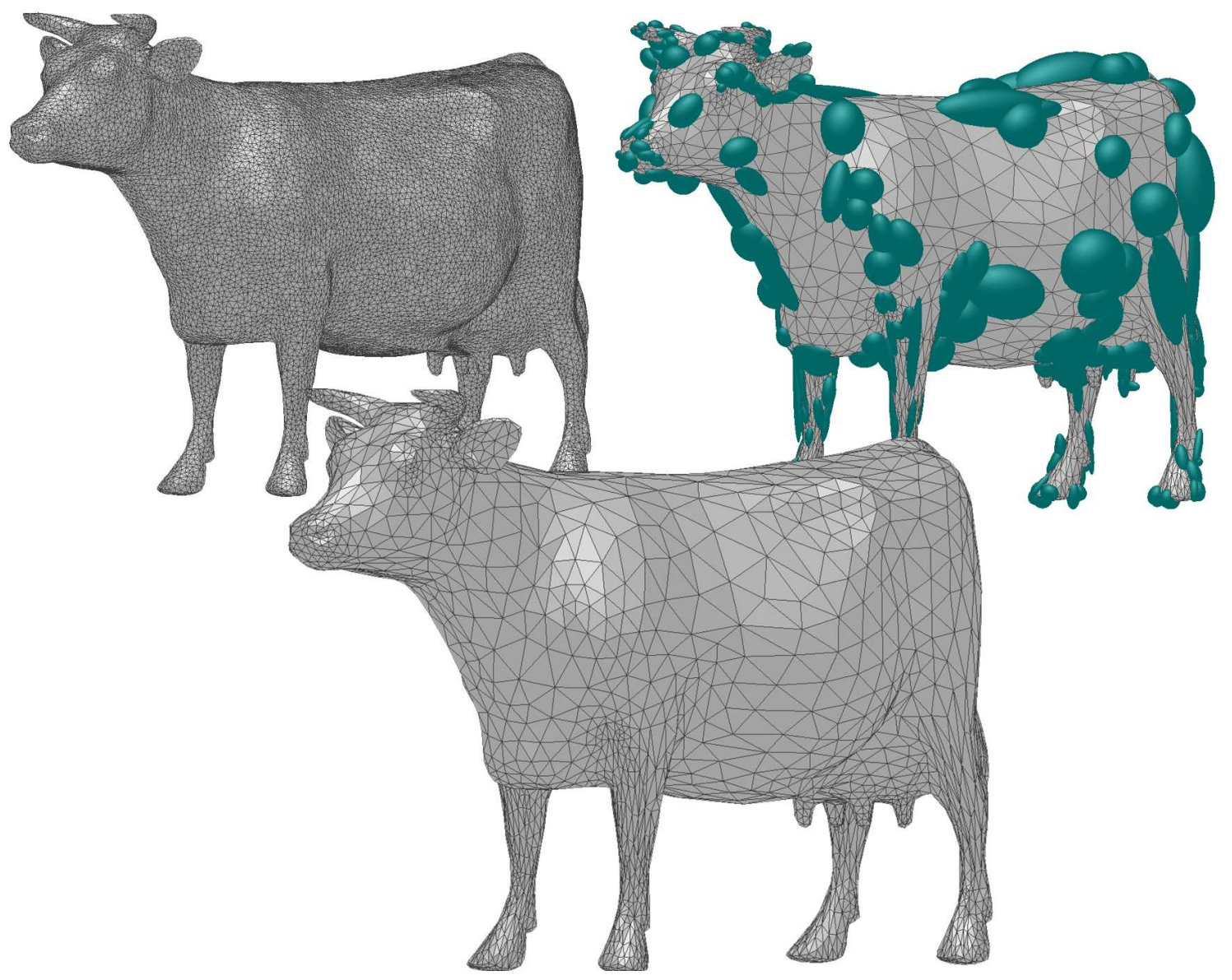

Figura 11.15: Remalhamento de uma vaca. 


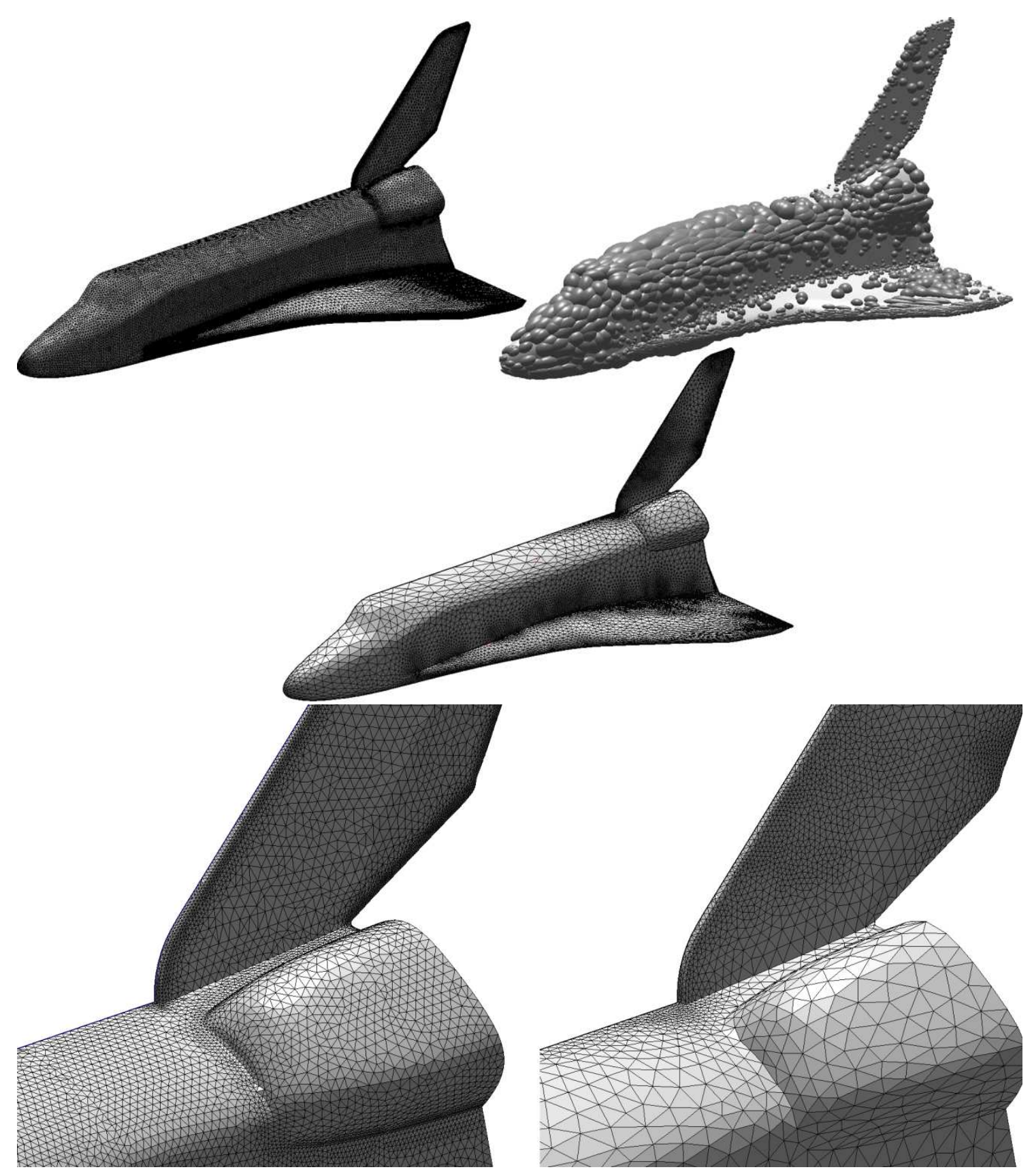

Figura 11.16: Remalhamento de um ônibus espacial. 


\section{Capítulo 12}

\section{Conclusão}

Neste capítulo são apresentadas as conclusões e sugestões para trabalhos futuros sobre os dois assuntos tratados nessa tese.

\subsection{Conclusões sobre movimento de malhas}

Neste trabalho foram apresentadas várias contribuições relacionadas com malhas dinâmicas. Dentre as principais contribuições estão: (1) a introdução das molas altura e como as mesmas podem ser empregadas em malhas triangulares e tetraedrais(2) a proposta da metodologia baseada em vértices ativos para resolver a malha dinâmica, (3) a proposta de um mecanismo para aplicar malhas dinâmicas em pequenos passos, (4) a introdução das molas conservativas para corrigir a fronteira de malhas (5) a criação de uma metodologia aplicável na indústria aeronáutica para realizar o acoplamento automático entre ferramentas de projeto inverso bidimensional e simuladores de escoamento de fluidos tridimensionais.

Nesta tese foi apresentada uma descrição detalhada do funcionamento das malhas dinâmicas e das molas mais conhecidas e comumente empregadas, são elas: as molas longitudinais [9], as molas torcionais [36, 31, 18], e as molas semi-torcionais [10, 111, 112, 65]. As molas longitudinais oferecem bons resultados em casos onde o domínio da malha é submetido a pequenas deformações. Elas podem ser implementadas com ou sem acoplamento de coordenadas. De uma maneira geral, a formulação sem acoplamento é computacionalmente mais rápida e produz melhores resultados que a versão acoplada. Porém, quando a deformação do domínio for consideravelmente pequena (menor que o comprimento da menor aresta da estrela do vértice deslocado), a proposta acoplada produz malhas de melhor qualidade, mas requer um custo computacional maior. As molas longitudinais têm uma deficiência intrínseca, pois elas não impedem que vértices cruzem suas respectivas faces opostas. Esta deficiência se deve ao fato 
da área (ou volume) do elemento não ser considerada na formulação da mola.

Para contornar essa deficiência foram propostos outros tipos de molas que complementam as molas longitudinais, dentre as mais conhecidas estão as torcionais e semi-torcionais. Estas molas controlam a área (ou volume) dos elementos por meio de ângulos entre arestas ou entre planos. Nesta tese foi proposta uma nova mola, a mola altura, que faz o controle do elemento por meio de sua altura, ao invés de ângulos. A idéia por trás da mola é bem simples e consiste tão somente em anexar uma mola longitudinal ligando o vértice controlado à sua projeção na face oposta. Na construção da malha dinâmica, as molas altura podem ser utilizadas com ou sem o complemento das molas longitudinais. Curiosamente, nos testes realizados o sistema composto por apenas molas altura produziu malhas de qualidade superior do que quando as longitudinais também eram empregadas. Se comparadas com as molas semi-torcionais, os resultados obtidos com as molas altura também são superiores .

Concomitantemente ao desenvolvimento da mola altura neste trabalho, Bottasso et al. [17] propôs o método ball-vertex que faz uso da mesma idéia básica. As diferenças são sutis, porém significativas. Os resultados obtidos pelas molas altura são superiores se comparados aos do método ball-vertex, tanto em termos de qualidade de malha quanto em desempenho computacional.

Também foram apresentadas nesta tese metodologias para a execução da malha dinâmica. O método numérico empregado para resolver o sistema de equações que formam a malha dinâmica foi o de Gauss-Seidel. Um dos fatores que contribuiu para a escolha desse método foi o fato de ele não necessitar que a matriz de coeficientes seja de fato criada em uma estrutura de dados auxiliar. Note que cada linha da matriz contém informações relativas apenas à estrela de um vértice. Sendo assim, a resolução do sistema pode ser fácil e eficientemente implementada consultando-se diretamente a estrutura de dados da malha. Além disso, o método de GaussSeidel é intuitivo e permite que cada vértice seja processado (movido) individualmente. Essa característica possibilitou a criação da estratégia de vértices ativos proposta nesta tese.

A estratégia de vértices ativos foi inicialmente desenvolvida para aumentar o desempenho computacional na aplicação do método numérico. A estratégia é simples e fácil de ser implementada. Seu funcionamento básico se dá pela marcação e gerenciamento de vértices por meio dos rótulos ativo, inativo e fixo. O rótulo ativo indica que o vértice (ou algum de seus vizinhos) teve um deslocamento significativo na iteração do método numérico anterior, e, portanto, tem grandes chances de ser movido na iteração seguinte. Por outro lado, o rótulo inativo indica que um dado vértice não teve um deslocamento significativo na iteração anterior, como também não tiveram seus vértices adjacentes; portanto, um vértice inativo não precisa ser processado na iteração seguinte. O rótulo fixo é atribuído aos vértices que fornecem a condição de con- 
torno do sistema (o deslocamento inicial da malha). Durante a aplicação do método numérico, um rótulo ativo pode se tornar inativo e vice-versa. O processamento termina quando nenhum vértice ativo estiver presente. Como apenas os vértices ativos precisam ser processados, uma economia significativa de processamento ocorre durante a solução do sistema. Essa economia é ainda mais expressiva quando a malha dinâmica deve ser aplicada em malhas volumétricas grandes cuja fronteira sofre pouca deformação.

O emprego da estratégia de vértices ativos tem a propriedade de concentrar o processamento nas regiões da malha que foram mais afetadas pelo deslocamento do bordo. Essa propriedade tem o efeito positivo na convergência do método numérico. Isso ocorre porque as equações do sistema são reordenadas durante o processamento, e as equações que sofrem maior influência das condições de contorno tendem a ser processadas primeiro.

Foi verificado experimentalmente que o emprego de vértices ativos produz malhas muito semelhantes às produzidas sem empregá-los. Porém, não foi feita nenhuma garantia teórica sobre esse resultado.

Para que a malha dinâmica possa ser utilizada em cenários envolvendo grandes deformações, é necessário que o deslocamento da fronteira do domínio seja aplicado aos poucos. Nesta tese foi proposta uma metodologia para administrar o deslocamento da fronteira até se obter a deformação desejada. Os vértices da fronteira são movidos em passos cada vez menores até alcançarem as posições desejadas. Em cada passo da fronteira, a malha dinâmica é executada para mover os vértices do interior. O processo pode ser interrompido em dois casos: (1) quando a deformação desejada for alcançada ou (2) quando a malha dinâmica produzir uma malha que não satisfaça os critérios de qualidade especificados pelo usuário. Quando ocorre o segundo caso, a malha resultante foi movida, mas não na totalidade desejada. Testes mostraram que as malhas movimentadas em pequenos passos têm qualidade superior, mesmo quando a deformação da fronteira é pequena. A determinação da quantidade de passos, bem como a amplitude dos mesmos, é feita mediante parâmetros ajustados pelo usuário. Acredita-se, porém, que seja possível fazer uma boa estimativa desses parâmetros de maneira automática, o que deve ser feito futuramente.

O emprego da abordagem de deslocamento em pequenos passos permitiu comparar a eficácia das molas longitudinais, semi-torcionais e altura sob um novo ponto de vista. Foi aplicada uma deformação no domínio, grande o suficiente para que nenhuma combinação de molas fosse capaz de corrigir a malha sem produzir elementos inválidos. A abordagem de pequenos passos foi aplicada para cada configuração de molas sob os mesmos parâmetros. As molas altura mais uma vez foram as que obtiveram maior êxito, pois conseguiram realizar a maior porcentagem do deslocamento desejado. As molas semi-torcionais propiciaram o segundo maior 
deslocamento e as molas longitudinais o terceiro.

Não são incomuns aplicações que realizam automaticamente a deformação da fronteira da malha. Em muitos casos, a deformação é aplicada apenas em regiões específicas do bordo e esse movimento parcial pode comprometer células da própria fronteira. Problemas como estes não podem ser resolvidos aplicando-se diretamente a malha dinâmica convencional sobre a malha deformada pois a fronteira permanece inalterada. Uma das propostas desta tese foi a criação de uma metodologia baseada em malhas dinâmicas para movimentar a fronteira de uma malha conservando a sua aparência original. Para isso foram criadas as molas conservativas que complementam o sistema formado por outros tipos de molas.

Foi observando o comportamento das malhas dinâmicas em superfícies que se chegou na proposta das molas conservativas. O que foi observado foi que as malhas dinâmicas eram capazes de deformar superfícies. Esta foi uma descoberta surpreendente que ainda não havia sido explorada na literatura. Porém em muitos casos as deformações extrapolavam os limites esperados e causavam problemas nas malhas. As molas conservativas foram adicionadas ao sistema para controlar a deformação. Como se trata do movimento do bordo, a geometria do domínio é alterada. Sendo assim, as molas conservativas devem ser utilizadas apenas em aplicações que não impõem restrições severas à geometria do domínio.

A malha dinâmica com molas conservativas foi amplamente utilizada na metodologia apresentada para possibilitar o acoplamento automático entre um simulador de escoamento de fluidos volumétrico com uma ferramenta de projeto inverso bidimensional. Este acoplamento é bastante complexo, pois depende de muitas variáveis tais como, o número de planos de corte utilizados, a geometria da asa, a geometria dos componentes adjacentes à asa, e a qualidade da malha superficial e volumétrica. Em muitos casos são requeridos tratamentos especiais para mover cada componente do avião. Por exemplo, uma ponta-de-asa chanfrada deve ser tratada de maneira diferente de uma winglet. A técnica proposta produziu bons resultados no que se refere às correções das componentes do avião adjacentes à asa. Pois foi capaz de corrigir elementos inválidos, como foi o caso da fuselagem no exemplo da Seção 6.2, quanto de recuperar a forma geométrica original, como foi o caso da ponta-de-asa no exemplo da Seção 6.2. Além disso, foi mostrado que também é possível utilizar malhas dinâmicas para movimentar a asa para que esta se ajuste à descrição geométrica determinada pelos perfis. Como se trata de um problema difícil e dependente de diversas variáveis, a técnica proposta pode funcionar adequadamente em alguns casos e produzir resultados impróprios em outros.

Malhas híbridas são amplamente utilizadas em simuladores de escoamento de fluidos. Os tipos de elementos comumente utilizados nesse tipo de malhas são tetraedros, hexaedros, prismas com base triangular e pirâmides com base quadrangular. Uma das sugestões para trabalhos 
futuros é o emprego das molas longitudinais, semi-torcionais e altura para mover malhas híbridas. Diferentemente das malhas simpliciais, as malhas híbridas possuem faces quadriláteras. Este fato torna não trivial a tarefa de anexar molas. Observe, por exemplo, que empregar apenas molas longitudinais sobre as arestas da malha não é suficiente. Isto se deve ao simples fato de um vértice não estar conectado diretamente a todos os outros vértices do mesmo quadrilátero. Conseqüentemente, o movimento de um vértice não afeta diretamente o vértice não adjacente. Além disso, os quatro vértices do quadrilátero podem não ser co-planares. Isso faz com que cuidados especiais sejam necessários na obtenção de informações geométricas, por exemplo, na medição de ângulos diedrais entre faces e na projeção de pontos sobre faces.

\subsection{Conclusões sobre remalhamento de malhas superficiais}

Nesta tese foi apresentado o ANTS, um método prático para remalhamento de triangulações sobre superfícies de modelos com geometria complexa. O objetivo do ANTS é gerar triangulações anisotrópicas de qualidade para simulação numérica. O método é caracterizado por realizar o remalhamento local e diretamente na superfície. Localmente porque são utilizados os operadores de inserção, remoção e deslocamento de vértices e flipping de arestas; e diretamente, por não fazer uso de qualquer tipo de parametrização, seja local ou global, para efetuar o remalhamento; ao invés disso, vértices deslocados e inseridos são sempre projetados diretamente sobre a superfície de entrada para que a fidelidade geométrica seja mantida. Para evitar que arestas e córneres do modelo de entrada sejam danificados pelo remalhamento, estas entidades são detectadas e marcadas como estruturas-de-controle no início do processo. As estruturas-de-controle alteram a maneira com que os operadores de remalhamento são executados para que as arestas e os córneres sejam mantidos. Além disso, a fidelidade geométrica da malha produzida também é controlada por uma métrica que afere a qualidade geométrica da superfície processada. Esta métrica impede que os operadores sejam de fato executados sempre que estes reduzem a qualidade abaixo de um limite previamente estabelecido. O formato, tamanho e alinhamento dos triângulos produzidos são determinados por uma função de espaçamento definida sobre o domínio. Tal função tem o papel de estabelecer a distância que deve separar quaisquer dois vértices adjacentes no domínio. A função de espaçamento pode ser isotrópica ou anisotrópica e pode ser fornecida pelo usuário como entrada para o ANTS ou pode ser definida pela análise das principais curvaturas da triangulação de entrada. O processo de remalhamento pode efetuar refinamento em uma região e simplificação em outra, dependendo apenas de como a funçẫo de espaçamento está definida. O ANTS foi aplicado em vários exemplos, mostrando-se robusto e produzindo malhas de boa qualidade. 
Poucas iterações são suficientes para produzir bons resultados. O núcleo do ANTS funciona processando vértices, ou seja, a densidade de vértices da malha é analisada localmente e dependendo das condições, os operadores de movimento, de remoção e de inserção de vértices são executados. É utilizada uma estratégia baseada em rótulos para determinar quais vértices devem ser processados. A rotulação é feita de tal maneira que vértices adjacentes não sejam processados em seqüência, isso faz com que os operadores sejam aplicados de forma distribuída sobre o domínio. Foram necessárias cerca de 10 iterações-malha para gerar a maioria dos exemplos citados no capítulo 11 .

O operador de movimento de vértices tem um papel importante no processo de remalhamento. O deslocamento de vértices é comumente utilizado apenas em um passo de pósprocessamento para suavização de malha. Porém a sua utilização durante o processo de remalhamento tem se tornado freqüente em métodos para geração de malhas e remalhamento $[82,14,4,103,92,110]$. Neste trabalho o operador de movimento foi utilizado no núcleo do processo de remalhamento, sendo que ele é sempre considerado antes de se aplicar remoção ou inserção de vértices, como o fizeram Bossen e Heckbert [15]. A vantagem em fazer isso é que a distribuição local de vértices é melhorada antes de se decidir se vértices devem ser inseridos ou removidos. Isso afeta diretamente o número final de vértices da malha, pois, os operadores de inserção e remoção podem verificar melhor as condições de densidade local antes de decidir se a operação deve ser de fato realizada. Além disso, o processamento da inserção no que tange a decisão do local preciso onde um vértice deve ser inserido é simplificado, pois o vértice não precisa ser inserido no local ótimo já que ele será movido em seguida. A desvantagem em se utilizar esta estratégia é que o operador de deslocamento pode ser acionado diversas vezes durante o processo, o que torna o método como um todo mais caro computacionalmente. Para diminuir esse impacto no desempenho, a densidade local dos vértices é aferida e a movimentação não ocorre quando for evidente que a inserção ou a remoção deve ocorrer.

Foi proposto um novo mecanismo para se calcular a nova posição dos vértices, o qual baseia-se no conhecido operador laplaciano de suavização. O movimento é realizado de forma rápida e eficaz. Entretanto, como ele é intimamente dependente da função de espaçamento definida sobre o domínio, se esta não for adequadamente suave, o movimento pode não ser efetivo e assim degradar a qualidade da malha produzida. É importante notar, porém, que mesmo estratégias baseadas em minimização de energia, como a proposta por Bossen [14], dependem da suavidade da função de espaçamento para produzir resultados satisfatórios.

A inserção de novos vértices na malha é feita sobre arestas. Isso oferece rapidez ao operador, pois basta encontrar o ponto médio da maior aresta para determinar onde o novo vértice deve ser inserido; evitando assim buscas e medições mais elaboradas para determinar o local. 
Além disso, a atualização da conectividade da malha é simples, pois envolve apenas quatro vértices e dois triângulos. Como mencionado anteriormente, a opção de inserção de vértices sobre arestas é adequada porque o operador de movimento está envolvido. Outro aspecto que merece destaque quanto à inserção é a utilização do procedimento complementar que realiza uma pequena perturbação no vértice iterado para então verificar se a inserção deve ocorrer ou não. Apesar de simples, esse procedimento elevou consideravelmente a qualidade da malha gerada.

Percebeu-se que o algoritmo pára por si só em determinadas situações. Em geral, a parada está intimamente condicionada à função de espaçamento utilizada, esta, por sua vez, deve ser bem suave e corretamente alinhada com as curvaturas do modelo original. Embora a parada de fato aconteça em alguns casos, nenhuma garantia teórica é fornecida sobre as condições da parada. Por isso, foi adotada uma estratégia para controlar a parada em termos práticos, como foi apresentado na Seção 10.4. Em geral, o valor sugerido de 10 iteraçôes-malha pode ser reduzido para 1 ou 2 quando se sabe a priori se ocorrerá refinamento ou simplificação da malha de entrada.

Gerar malhas anisotrópicas de qualidade sobre superfícies é um desafio considerável. É sabido que quanto mais suave for a função de espaçamento maiores as chances de se obter uma malha com boa qualidade. No caso de malhas anisotrópicas essa suavidade é ainda mais crítica, pois em casos onde a anisotropia é muito acentuada, uma pequena alteração no alinhamento da anisotropia pode causar o surgimento de triângulos indesejados. Além disso, não basta ter uma função de espaçamento suave se seus tensores não estiverem adequadamente alinhados com as curvaturas da superfície. O grande problema nesse caso é que quando a função de espaçamento é calculada a partir de uma malha superficial de entrada nem sempre é possível calcular adequadamente as curvaturas da superfície. Isso porque a própria malha de entrada é uma aproximação de algum modelo real e esta aproximação pode não ser adequada para se extrair as curvaturas. No caso do ANTS, a abordagem utilizada para definir uma função de espaçamento sobre a malha de entrada produz resultados aceitáveis somente quando esta for uma boa aproximação do modelo real. Isto é, a densidade de vértices deve estar adequadamente distribuída sobre o domínio. Além disso, melhores resultados são obtidos em superfícies suaves, mesmo que apresentem quinas e córneres. O cálculo das curvaturas depende do vetor normal estimado no vértice sobre o qual se está estimando o tensor métrico. O problema que surge em superfícies ruidosas é que o ruído influencia no cálculo do vetor normal, prejudicando assim a estimativa das curvaturas. Portanto, mais esforços devem ser aplicados no sentido de melhorar a estimativa do vetor normal.

Pode-se notar nos histogramas de comprimentos de arestas normalizadas do Capítulo 11 
que o pico do gráfico não coincide com o comprimento ideal de arestas que no caso é 1.0. Este fato ocorre porque os critérios de remalhamento privilegiam arestas menores às maiores.

Os efeitos negativos da função de espaçamento podem ser reduzidos se os procedimentos de suavização descritos na Seção 9.2.1 forem utilizados. Além disso, quando a malha de entrada for grossa, é aconselhável que seja feito um refinamento para aumentar o número de pontos, como foi feito no exemplo dos ossos do pé na Seção 11. Esse refinamento da malha de fundo contribui para uma melhor interpolação dos tensores métricos sobre o domínio.

Considerando o exposto a respeito de remalhamento de malhas superficiais são propostas as seguintes sugestões para trabalhos futuros:

- Estabelecer as garantias teóricas que suportam o algoritmo proposto, determinando quais são as condições em que a parada automática ocorre.

- Estender o ANTS para remalhar triangulações não-orientáveis representando não variedades.

- Adaptar o algoritmo para computação paralela.

- Estender a idéia básica de remalhamento proposta para tratar malhas volumétricas. 


\section{Referências Bibliográficas}

[1] Rassineux A., P. Villon, J-M. Savignat, and O. Stab, Surface remeshing by local hermite diffuse interpolation, Special Edition on Unstructured Mesh Generation - International Journal for Numerical Methods in Engineering 49 (2000), no. 1-2, 147-156.

[2] Juan C. Aguilar and Jonathan B. Goodman, Anisotropic mesh refinement for finite element methods based on error reduction, Journal of Computational and Applied Mathematics (2006).

[3] P. Alliez, G. Ucelli, C. Gotsman, and M. Attene, Recent advances in remeshing of surfaces, Tech. report, AIM@SHAPE Network of Excellence, 2005.

[4] Pierre Alliez, Éric Colin de Verdière, Olivier Devillers, and Martin Isenburg, Isotropic surface remeshing, Proceedings of Shape Modeling International, 2003, pp. 49-58.

[5] Pierre Alliez and Craig Gotsman, Recent advances in compression of 3d meshes, Advances in Multiresolution for Geometric Modelling. N.A. Dodgson, M.S. Floater e M.A. Sabin. Springer-Verlag, 2005.

[6] Pierre Alliez, Mark Meyer, and Mathieu Desbrun, Interactive geometry remeshing, SIGGRAPH '02: Proceedings of the 29th annual conference on Computer graphics and interactive techniques (New York, NY, USA), ACM Press, 2002, pp. 347-354.

[7] Marco Attene, Bianca Falcidieno, Michela Spagnuolo, and Geoff Wyvill, A mappingindependent primitive for the triangulation of parametric surfaces, Graph. Models $\mathbf{6 5}$ (2003), no. 5, 260-273.

[8] Ivo Babuska and A. K. Aziz, On the angle condition in the finite element method, SIAM Journal on Numerical Analysis 13 (1976), no. 2, 214-226.

[9] J. T. Batina, Unsteady euler airfoil solutions using unstructured dynamic meshes, AIAA Journal 28 (1990), no. 8, 1381-1388. 
[10] F. J. Blom, Considerations on the spring analogy, Internatinal Journal for Numerical Methods in Fluids 32 (2000), 647-668.

[11] J. D. Boissonnat and S. Oudot, Provably good surface sampling and approximation, SGP '03: Proceedings of the 2003 Eurographics/ACM SIGGRAPH symposium on Geometry processing (Aire-la-Ville, Switzerland, Switzerland), Eurographics Association, 2003, pp. 9-18.

[12] H. Borouchaki, F. Hecht, and P. Frey, Mesh gradation control, 1998, pp. 1143-1165.

[13] Houman Borouchaki, Paul Louis George, Fr\&\#233;d\&\#233;ric Hecht, Patrick Laug, and Eric Saltel, Delaunay mesh generation governed by metric specifications. part $i$ algorithms, Finite Elem. Anal. Des. 25 (1997), no. 1-2, 61-83.

[14] Frank J. Bossen, Anisotropic mesh generation with particles, Tech. Report CMU-CS-96134, CS Dept., Carnegie Mellon University, May 1996.

[15] Frank J. Bossen and Paul S. Heckbert, A pliant method for anisotropic mesh generation, 5th International Meshing Roundtable, October 1996, pp. 63-76.

[16] Mario Botsch and Leif Kobbelt, A remeshing approach to multiresolution modeling, 2004, pp. $185-192$.

[17] Carlo L. Bottasso, Davide Detomi, and Roberto Serra, The ball-vertex method : a new simple spring analogy method for unstructured dynamic meshes, Computer methods in applied mechanics and engineering 194 (2005), no. 39-41, 4244-4264.

[18] C.O.E. Burg, A robust unstructured grid movement strategy using three-dimensional torsional springs, AIAA Paper 2004-2529 34th AIAA Fluid Dynamics Conference and Exhibit, June 2004.

[19] Scott A. Canann, Michael B. Stephenson, and Ted Blacker, Optismoothing: an optimization-driven approach to mesh smoothing, Finite Elem. Anal. Des. 13 (1993), no. 2-3, 185-190.

[20] Graham F. Carey and John Tinsley Oden, Finite elements: Computational aspects, Prentice-Hall, 1984.

[21] M.J. Castro-Diaz and F. Hecht, Anisotropic surface mesh generation, Tech. report, INRIA, 1995. 
[22] Juan Raul Cebral and Rainald Löhner, From medical images to anatomically accurate finite element grids, 2001.

[23] Ho-Lun Cheng, Tamal K. Dey, Herbert Edelsbrunner, and John Sullivan, Dynamic skin triangulation, Symposium on Discrete Algorithms, 2001, pp. 47-56.

[24] _ Dynamic skin triangulation, Discrete and Computational Geometry 25 (2001), no. $4,525-568$.

[25] S. W. Cheng, T. K. Dey, E. A. Ramos, and T. Ray, Quality meshing for polyhedra with small angles, Proc. 20th Annu. Sympos. Comput. Geom., 2004, pp. 290-299.

[26] Siu-Wing Cheng, Tamal K. Dey, Edgar A. Ramos, and Tathagata Ray, Sampling and meshing a surface with guaranteed topology and geometry, SCG '04: Proceedings of the twentieth annual symposium on Computational geometry (New York, NY, USA), ACM Press, 2004, pp. 280-289.

[27] L. Paul Chew, Guaranteed-quality triangular meshes, Tech. Report TR-89-983, Department of Computer Science, Cornell University, 1989.

[28] _ Guaranteed-quality mesh generation for curved surfaces, SCG '93: Proceedings of the ninth annual symposium on Computational geometry (New York, NY, USA), ACM Press, 1993, pp. 274-280.

[29] David Cohen-Steiner and Jean-Marie Morvan, Restricted delaunay triangulations and normal cycle, SCG '03: Proceedings of the nineteenth annual symposium on Computational geometry (New York, NY, USA), ACM Press, 2003, pp. 312-321.

[30] A. J. Cuadros-Vargas and L. G. Nonato, Imesh: Generating quality meshes from images., European Conference on Computational Fluid Dynamics - ECCOMAS'06.

[31] C. Degand and C. Farhat, A three-dimensional spring analogy method for unstructured dynamic meshes, Computers and Structures 80 (2002), 305-316.

[32] T. K. Dey, G. Li, and T. Ray, Polygonal surface remeshing with delaunay refinement, 2005.

[33] Rubem Gomez Dias, Uma compressão simples para malhas irregulares com alças, Master's thesis, Pontifícia Universidade Católica do Rio de Janeiro, 2004.

[34] S. Dong, S. Kircher, and M. Garland, Harmonic functions for quadrilateral remeshing of arbitrary manifolds, Comput. Aided Geom. Des. 22 (2005), no. 5, 392-423. 
[35] H. Edelsbrunner, Geometry and topology for mesh generation, Cambridge Univ. Press, England, 2001.

[36] C. Farhat, C. Degand, B. Koobus, and M. Lesoinne, Torsional springs for twodimensional dynamic unstructured fluid meshes, Computer Methods in Applied Mechanics and Engineering 163 (1998), 231-245.

[37] G. Farin, Smooth interpolation top scattered 3-d data, Surfaces in Computer Aided Geometric Design editado por R. Barnhill and W. Boehm, North-Holland, 1982.

[38] D. Field, Laplacian smoothing and delaunay triangulations, Communications in Numerical Methods in Engineering 4 (1988), 709-712.

[39] P. Frey and H. Borouchaki, Geometric surface mesh optimization, 1998.

[40] Pascal J. Frey, About surface remeshing, IMR, 2000, pp. 123-136.

[41] Michael Garland, Quadric-based polygonal surface simplification, Ph.D. thesis, University of Illinois at Urbana-Champaign, 1999.

[42] J. E. Goodman and J. O'Rourke (eds.), Handbook of discrete and computational geometry 2nd edition, CRC Press, 2004.

[43] C. Gotsman, S. Gumhold, and L. Kobbelt, Simplification and compression of $3 d$ meshes, Tutorials on Multiresolution in Geometric Modelling editado por A. Iske, E. Quak, M.S. Floater - Springer, 2002.

[44] B. Hamann, Curvature approximation for triangulated surfaces, 1993, pp. 139-153.

[45] Erich Hartmann, A marching method for the triangulation of surfaces., The Visual Computer 14 (1998), no. 3, 95-108.

[46] Brian T. Helenbrook, Mesh deformation using the biharmonic operator, Iternation journal for numerical methods in engineering 00 (2001), no. 2, 1-30.

[47] Hugues Hoppe, Progressive meshes, SIGGRAPH '96: Proceedings of the 23rd annual conference on Computer graphics and interactive techniques (New York, NY, USA), ACM Press, 1996, pp. 99-108.

[48] Hugues Hoppe, Tony DeRose, Tom Duchamp, John McDonald, and Werner Stuetzle, Mesh optimization, SIGGRAPH '93: Proceedings of the 20th annual conference on Computer graphics and interactive techniques (New York, NY, USA), ACM Press, 1993, pp. 19-26. 
[49] A. Hubeli and M. Gross, Multiresolution feature extraction for unstructured meshes, Visualization VIS '01, 2001.

[50] Mariette Yvinec Jean-Daniel Boissonnat, Camille Wormser, Anisotropic diagrams: Labelle shewchuk approach revisited, Proceedings of the 17th Canadian Conference on Computational Geometry (CCCG'05), 2005, pp. 266-269.

[51] Leif P. Kobbelt, Mario Botsch, Ulrich Schwanecke, and Hans-Peter Seidel, Feature sensitive surface extraction from volume data, SIGGRAPH '01: Proceedings of the 28th annual conference on Computer graphics and interactive techniques (New York, NY, USA), ACM Press, 2001, pp. 57-66.

[52] Francois Labelle and Jonathan Richard Shewchuk, Anisotropic voronoi diagrams and guaranteed-quality anisotropic mesh generation, SCG '03: Proceedings of the nineteenth annual symposium on Computational geometry (New York, NY, USA), ACM Press, 2003, pp. 191-200.

[53] _ Anisotropic voronoi diagrams and guaranteed-quality anisotropic mesh generation, SCG '03: Proceedings of the nineteenth annual symposium on Computational geometry (New York, NY, USA), ACM Press, 2003, pp. 191-200.

[54] Greg Leibon and David Letscher, Delaunay triangulations and voronoi diagrams for riemannian manifolds, Proceedings of the 16th annual symposium on Computational geometry, ACM Press, 2000, pp. 341-349.

[55] X. Li, J. Remacle, N. Chevaugeon, and M. Shephard, Anisotropic mesh gradation control, Thirteenth International Meshing Roundtable, (Williamsburg, VA), Sandia National Laboratories, 2004.

[56] Xiang-Yang Li, Shang-Hua Teng, and Alper Üngör, Biting ellipses to generate anisotropic mesh, 8th International Meshing Roundtable, 1999, pp. 97-108.

[57] _ Biting: Advancing front meets sphere packing, International Journal of Numerical Methods in Engineering (IJNME) 49 (2000), no. 1-2, 61-81.

[58] S. Lloyd, Least square quantization in pcm, IEEE Trans. Inform. Theory 28 (1982), no. 2, $129-137$.

[59] Rainald Löhner, Adaptive remeshing for transient problems, Computer Methods in Applied Mechanics and Engineering 75 (1989), 195-214. 
[60] _ Extensions and improvements of the advancing front grid generation technique, Communications in Numerical Methods in Engineering 12 (1996), 683-702.

[61] _ _ Regridding surface triangulations, J. Comput. Phys. 126 (1996), no. 1, 1-10.

[62] David Luebke, Benjamin Watson, Jonathan D. Cohen, Martin Reddy, and Amitabh Varshney, Level of detail for $3 d$ graphics, Elsevier Science Inc., New York, NY, USA, 2002.

[63] Kwan-Liu Ma and Victoria Interrante, Extracting feature lines from 3d unstructured grids, VIS '97: Proceedings of the 8th conference on Visualization '97 (Los Alamitos, CA, USA), IEEE Computer Society Press, 1997, pp. 285-ff.

[64] M. Mäntylä, An introduction to solid modeling, Computer Science Press, 1988.

[65] M. Murayama, K. Nakahashi, and K. Matsushima, Unstructured dynamic mesh for large movement and deformation, 40th Aerospace Sciences Meeting and Exhibit, January 2002, pp. AIAA-2002-0122.

[66] S. Owen and S. Saigal, Surface mesh sizing control, International Journal for Numerical Methods in Engineering 47 (2000), 497-511.

[67] S. Owen, D. White, and T. Tautges, Facet-based surfaces for 3d mesh generation, 11th International Meshing Roundtable, 2002, pp. 297-312.

[68] S. Pav and N. Walkington, A robust 3d delaunay refinement algorithm, Proc. Intl. Meshing Roundtable, 2004.

[69] J. Peraire, J. Peiró, and K. Morgan, Adaptive remeshing for three-dimensional compressible flow computation, Journal of Computational Physics 103 (1992), 269-285.

[70] Jim Ruppert, A delaunay refinement algorithm for quality 2-dimensional mesh generation, J. Algorithms 18 (1995), no. 3, 548-585.

[71] Szymon Rusinkiewicz, Estimating curvatures and their derivatives on triangle meshes, 3DPVT '04: Proceedings of the 3D Data Processing, Visualization, and Transmission, 2nd International Symposium on (3DPVT'04) (Washington, DC, USA), IEEE Computer Society, 2004, pp. 486-493.

[72] R. Sadri, D. Leblond, and P. Piperni, Coupling of a wing inverse design code to an euler/navier-stokes flow solver using mesh movement capabilities, 50th AGM and Conference (Canada), 2003. 
[73] Jamshid A. Samareh, Applications of quaternions for mesh deformation, Numerical Grid Generation in Computational Field Simulations, The International Society of Grid Generation.

[74] C. Scheidegger, S. Fleishman, and C. Silva, Triangulating point-set surfaces with bounded error, Proceedings of the third Eurographics/ACM Symposium on Geometry Processing (M. Desbrun and H. Pottman, eds.), The Eurographics Association, 2005, pp. 63-72.

[75] J. Schreiner, C.E. Scheidegger, S. Fleishman, and C.T. Silva, Direct (re)meshing for efficient surface processing, (2006).

[76] _ Direct (re)meshing for efficient surface processing, SCI Institute Technical Report UUSCI-2006-013, University of Utah, 2006.

[77] Jonathan Richard Shewchuk, Delaunay refinement mesh generation, Ph.D. thesis, Scholl of Computer Science - Carnegie Mellon University, 1997.

[78] _ Tetrahedral mesh generation by delaunay refinement, Symposium on Computational Geometry, 1998, pp. 86-95.

[79] W What is a good linear element? interpolation, conditioning, and quality measures, 11th International Meshing Roundtable (Ithaca, New York), September 2002, pp. $115-126$.

[80] _ What is a good linear finite element? - interpolation, conditioning, anisotropy, and quality measures, http://citeseer.nj.nec.com/shewchuk02what.html, 2003.

[81] J.R. Shewchuk, Delaunay refinement algorithms for triangular mesh generation, Computational Geometry: Theory and Applications 22 (2002), no. 1-3, 21-74.

[82] K. Shimada, Physically-based mesh generation: Automated triangulation of surfaces and volumes via bubble packing, Ph.D. thesis, Massachusetts Institute of Technology, 1993.

[83] Kenji Shimada, Yamada Atsushi, and Itoh Takayuki, Anisotropic triangular meshing of parametric surfaces via close packing of ellipsoidal bubbles, 6th International Meshing Roundtable, 1997, pp. 375-390.

[84] Kenji Shimada and David C. Gossard, Bubble mesh: automated triangular meshing of non-manifold geometry by sphere packing, SMA '95: Proceedings of the Third Symposium on Solid Modeling and Applications, 1995, pp. 409-419. 
[85] _ Automatic triangular mesh generation of trimmed parametric surfaces for finite element analysis, Comput. Aided Geom. Des. 15 (1998), no. 3, 199-222.

[86] Kenji Shimada, Atsushi Yamada, and Takayuki Itoh, Anisotropic triangulation of parametric surfaces via close packing of ellipsoids., International Journal of Computational Geometry and Applications 10 (2000), no. 4, 417-440.

[87] Oren Sifri, Alla Sheffer, and Craig Gotsman, Geodesic-based surface remeshing., IMR, 2003, pp. 189-199.

[88] F.S. Sousa, N. Nangiavacchi, L.G. Nonato, A. Castelo, M.F. Tomé, V.G. Ferreira, J.A. Cuminato, and S. McKee, A front-tracking/front-capturing method for the simulation of 3d multi-fluid flows with free surface, Journal of computational physics 198 (2004), 469-499.

[89] N.M. Sudharsan, R. Ajaykumar, K. Murali, and K. Kumar, A comparative study of dynamic mesh updating methods used in the simulation of fluid-structure interation problems with a num-linear free surface, Proceedings of the Institution of Mechanical Engineers, Part C: Journal of Mechanical Engineering Science 218 (2004), no. 3, 283-300.

[90] Vitaly Surazhsky, Pierre Alliez, and Craig Gotsman, Isotropic remeshing of surfaces: a local parameterization approach, Proceedings of 12th International Meshing Roundtable (Santa Fe, New Mexico, USA), 2003, pp. 215-224.

[91] Vitaly Surazhsky and Craig Gotsman, High quality compatible triangulations, Proceedings of 11th International Meshing Roundtable, September 2002, pp. 183-192.

[92] __ Explicit surface remeshing, Proceedings of Eurographics Symposium on Geometry Processing (Aachen, Germany), June 2003, pp. 17-28.

[93] _ High quality compatible triangulations, Engineering with Computers 20 (2004), no. $2,147-156$.

[94] Gabriel Taubin, A signal processing approach to fair surface design, Yorktown Heights, N.Y. : IBM T.J. Watson Research Center, 1995.

[95] _ Geometric signal processing on polygonal meshes, STAR - state of the art report, Eurographics 2000, 2000, pp. 81-96.

[96] Keti Tenenblat, Introdução à geometria diferencial, UnB, 1988. 
[97] S H Teng and C W Wong, Unstructured mesh generation: Theory, practice, and perspectives, International Journal of Computer Geometry 10 (2000), no. 3, 227-266.

[98] Lloyd N. Thefethen and III David Bau, Numerical linear algebra, Siam, 1997.

[99] Holger Theisel, Christian Rössl, Rhaleb Zayer, and Hans-Peter Seidel, Normal based estimation of the curvature tensor for triangular meshes, 12th Pacific Conference on Computer Graphics and Applications, PG 2004 (Seoul, South Korea) (Daniel CohenOr, Hyeong-Seok Ko, Demetri Terzopoulos, and Joe Warren, eds.), IEEE, October 2004, pp. 288-297.

[100] R. Tilch and Rainald Löhner, Advances in discrete surface grid generation: Towards a reliable industrial tool for cfd, AIAA-02-0862, 2002.

[101] Greg Turk, Re-tiling polygonal surfaces, Computer Graphics 26 (1992), no. 2, 55-64.

[102] Alex Vlachos, Jorg Peters, Chas Boyd, and Jason L. Mitchell, Curved PN triangles, Symposium on Interactive 3D Graphics, 2001, pp. 159-166.

[103] J. Vorsatz, Ch. Rössl, and H.-P. Seidel, Dynamic remeshing and applications, SM '03: Proceedings of the eighth ACM symposium on Solid modeling and applications (New York, NY, USA), ACM Press, 2003, pp. 167-175.

[104] Jens Vorsatz, Christian Rössl, Leif Kobbelt, and Hans-Peter Seidel, Feature sensitive remeshing, Computer Graphics Forum, Proceedings of Eurographics 2001 (Alan Chalmers and Theresa-Marie Rhyne, eds.), Blackwell, 2001, pp. 393-401.

[105] Desmond J. Walton and Dereck S. Meek, A triangular g1 patch from boundary curves., Computer-Aided Design 28 (1996), no. 2, 113-123.

[106] Andrew P. Witkin and Paul S. Heckbert, Using particles to sample and control implicit surfaces, SIGGRAPH '94: Proceedings of the 21st annual conference on Computer graphics and interactive techniques (New York, NY, USA), ACM Press, 1994, pp. 269277.

[107] S. Yamakawa, Unstructured three-dimensional mesh generation with controlled anisotropy and directionality, Ph.D. thesis, Mechanical Engineering Department, Carnegie Mellon University, May 2002.

[108] S. Yamakawa and K. Shimada, High quality anisotropic tetrahedral mesh generation via ellipsoidal bubble packing, 9th International Meshing Roundtable, 2000, pp. 263-273. 
[109] Soji Yamakawa and Kenji Shimada, Anisotropic tetrahedral meshing via bubble packing and advancing front, International Journal for Numerical Methods in Engineering $\mathbf{5 7}$ (2003), 1923-1942.

[110] _ , Triangular/quadrilateral remeshing of an arbitrary polygonal surface via packing bubbles, GMP '04: Proceedings of the Geometric Modeling and Processing 2004 (Washington, DC, USA), IEEE Computer Society, 2004, p. 153.

[111] D. Zeng and C. R. Ethier, A semi-torcional spring analogy model for updating unstructured meshes, 9th Anual Conference of the CFD Sopciety of Canada, 2001, p. 113.

[112] Dehong Zeng and C. Ross Ethier, A semi-torsional spring analogy model for updating unstructured meshes in $3 d$ moving domains, Finite Elem. Anal. Des. 41 (2005), no. 11-12, 1118-1139. 